NIST Technical Note 1519

and

NTIA Report 01-387

\title{
Predicted and Measured Field Strengths \\ in the Boulder, Colorado, Area from \\ Two Proposed Terrestrial Digital \\ Television Tower Sites
}

Christopher L. Holloway, Frank H. Sanders, and Paul M. McKenna

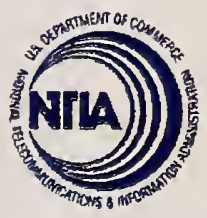

Institute for Telecommunication Sciences

National Telecommunications and Information Administration

U.S. Department of Commerce

$G C$

100

.05753

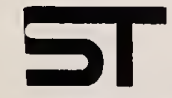

110.1519

Institute of Standards and Technology

Administration

2001

c. 2 



\section{NIST Technical Note 1519 \\ and \\ NTIA Report 01-387}

\section{Predicted and Measured Field Strengths in the Boulder, Colorado, Area from Two Proposed Terrestrial Digital Television Tower Sites}

Christopher L. Holloway

Radio-Frequency Technology Division

Electronics and Electrical Engineering Laboratory

National Institute of Standards and Technology

Boulder, CO 80305

Frank H. Sanders and Paul M. McKenna

Institute for Telecommunication Sciences

National Telecommunications and Information Administration

Boulder, CO 80305

May 2001

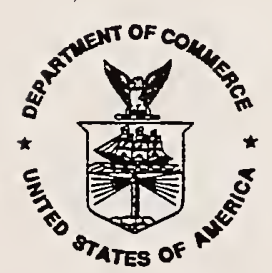

U.S. Department of Commerce

Donald L Evans, Secretary

National Institute of Standards and Technology Karen H. Brown, Acting Director
National Telecommunications and Information Administration John F. Sopko, Acting Assistant Secretary for Communications and Information 
National Institute of Standards and Technology

Technical Note 1519

Natl. Inst. Stand. Technol.

Tech. Note 1519

144 Pages (May 2001)

CODEN: NTNOEF

and

National Telecommunications and Information Administration

Report 01-387
U.S. Government Printing Office

Washington: 2001

For sale by the

Superintendent of Documents

U.S. Government Printing Office

Stop SSOP,

Washington, DC 20402-0001

Phone: (202) 512-1800

Fax: (202) 512-2250

Internet: bookstore.gpo.gov 


\section{Executive Summary}

In this report, we have analyzed the expected electric (E) field strengths in the Boulder area from two proposed terrestrial DTV transmitter locations, the Eldorado Mountain site and the Squaw Mountain site. The Eldorado Mountain and Squaw Mountain sites were selected from the set of candidate sites because these two possible sites bound the propagation environment that would occur at both the Table Mountain National Radio Quiet Zone (NRQZ) and the Department of Commerce (DOC) Laboratories in Boulder. The Eldorado Mountain site affords substantial line-of-sight coverage over the Boulder area, while the Squaw Mountain site affords only indirect (diffractive) coverage over the same area. The other possible tower sites fall between these two types of propagation conditions.

The goals of this work were to determine the expected E-field strengths at the Table Mountain NRQZ located north of Boulder, Colorado and at the DOC Laboratories located at 325 Broadway in Boulder, Colorado. This study also assessed the potential impacts of the proposed sites on a broad range of Federal Government research and metrology programs that depend upon a relatively quiet radio-frequency electromagnetic environment (see Section 8). The DOC conducted tests and analyses to assess whether Efield strengths produced by the DTV transmissions from either proposed site could meet the FCC's regulatory limits for the Table Mountain NRQZ. In addition, tests and analyses were performed to ascertain the impact of DTV transmissions from either proposed site on measurement efforts that are performed on a regular basis at the DOC Laboratories.

In this study, measured and predicted E-field strengths are used to estimate the E-field strengths in the Boulder area for the proposed transmitter antenna heights of two possible transmitter locations, Eldorado Mountain and Squaw Mountain. With these predictions, we were able to determine the E-field strengths at both the DOC Laboratories and at the Table Mountain NRQZ. The results show that at the Table Mountain NRQZ, the predicted E-field strengths are about $0.3 \mathrm{~V} / \mathrm{m}$ for a single transmitter on Eldorado Mountain at 1.0 MW EIRP. This number exceeds the FCC's regulatory (47 CFR 73.1030) limit by about an order of magnitude (approximately a factor of 10). At that level, research at the Table Mountain NRQZ will be compromised. The results also show that the E-field strengths at the DOC Laboratories for a single transmitter located on Eldorado Mountain are about $1 \mathrm{~V} / \mathrm{m}$ for 1.0 MW EIRP. These field strengths are high enough to possibly jeopardize the sensitive measurements done on a routine basis at the DOC Laboratories, as discussed in Section 8. By comparison, the results show that, at the Table Mountain NRQZ, the predicted E-field strengths are about $0.002 \mathrm{~V} / \mathrm{m}$ for a single transmitter located on Squaw Mountain with 1.0 MW EIRP. These field strengths are within the FCC's Table Mountain NRQZ regulatory (47 CFR 73.1030) limit. Thus, the results indicate that a transmitter could be located at Squaw Mountain without violating the FCC's regulatory limit or adversely impacting research at the Table Mountain NRQZ.

The data presented in this report illustrate that E-field strengths on the order of $0.5 \mathrm{~V} / \mathrm{m}$ to $1 \mathrm{~V} / \mathrm{m}$ could be present at the DOC Laboratories. The studies presented in Section 8 illustrate only a few of the potential problems that may be experienced at the DOC Laboratories. 
The measured and modeled data presented in this report are for an EIRP of $1 \mathrm{MW}$. As indicated in the report, some of the DTV channels have maximum power allocations of $1.64 \mathrm{MW}$ EIRP. The E-field strengths presented here can be transformed to a $1.64 \mathrm{MW}$ EIRP by multiplying the data shown in all the figures by a factor of 1.3 (which would increase the E-field strengths by $30 \%$ ). This would result in even higher E-field strengths in the Boulder-Denver area than those presented here, and could cause even greater interference at both the DOC facilities (see Sections 5 and 9). The FCC indicated in references cited in the report that in the future, adjustments to the allocated power levels may be granted under some situations, in order to allow power levels higher than 1.64 MW. If these higher power levels are granted, the result would be even higher E-field strengths in the Boulder-Denver area than those presented here.

For DTV reception, the FCC specifies a minimum (i.e., for noise limited DTV reception) E-field strength of $41 \mathrm{~dB} \mu \mathrm{V} / \mathrm{m}(0.11 \mathrm{mV} / \mathrm{m})$ for a receiving antenna at a height of $9.14 \mathrm{~m}$ $(30 \mathrm{ft})$. Using the ITM prediction model, we also predicted the coverage areas where the FCC's minimum field strength for acceptable reception is met or exceeded. From the results shown here, it is seen that the two proposed transmitter locations (Eldorado Mountain and Squaw Mountain) have basically the same DTV coverage areas (see Section 6). However, the data in these results show that a transmitter on Squaw Mountain will not violate the FCC's regulatory limits protecting the Table Mountain NRQZ, if these transmissions occur on the currently allotted DTV frequencies.

In a recent document (cited in this report, see Section 9), the Advanced Television Systems Committee (ATSC) Task Force on RF System Performance has suggested that in order to overcome the indoor DTV reception problem, field strengths at the $9.14 \mathrm{~m}$ (30 ft) reference height may need to be increased substantially to $97 \mathrm{~dB} \mu \mathrm{V} / \mathrm{m}$. This is an increase of $56 \mathrm{~dB}$ over the FCC minimum E-field strength, which is equivalent to an increase by a factor of approximately 631 in field strength. This $56 \mathrm{~dB}$ increase can be obtained by either substantially reducing the coverage area of DTV reception, by reducing the DTV payload data rate or by increasing the allocated transmitter power levels by an unrealistic $56 \mathrm{~dB}$. Obviously, if transmitter power levels are increased to compensate for the indoor reception problem, higher E-field strengths than those presented in this report could occur at both the Table Mountain NRQZ and at the DOC Laboratories, as well as at other areas throughout Boulder.

While the results presented in this report are for omnidirectional or omni-azimuthal directional antenna patterns, the actual antennas that will be used for the proposed tower will have some type of antenna pattern associated with them. The report discusses (Section 7) how the results presented here can be used once the antenna pattern of the proposed towers are known. 
Contents

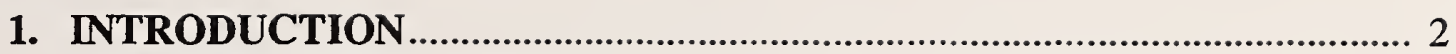

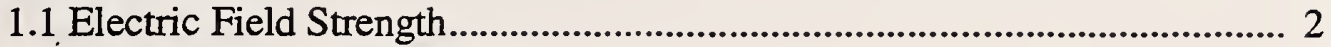

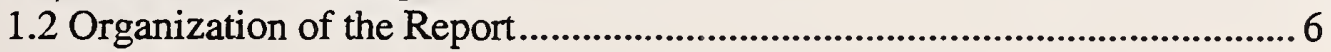

2. SPECTRUM SURVEY AT THE NRQZ AND AT THE DOC

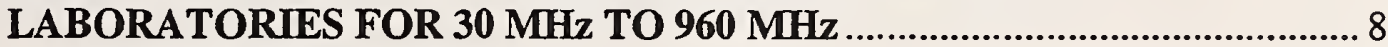

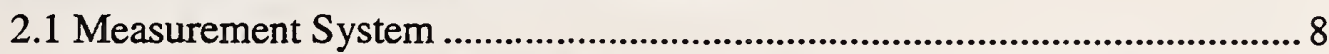

2.2 Measurement System Calibration and Correction to Incident Field

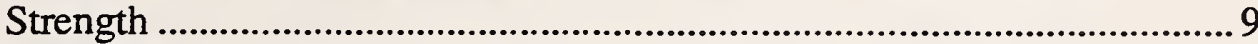

2.3 Measurement System Data Collection Algorithms and Parameters ........... 9

2.4 Data Storage and Analysis ..................................................................... 10

2.5 Table Mountain NRQZ Spectrum Survey Results: Vertically Polarized Measurements........................................................................................... 11

2.6 DOC Laboratories Spectrum Survey Results: Vertically Polarized

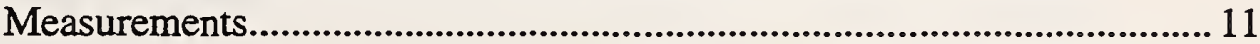

2.7 Analysis of Existing Television Signal Environment: Horizontally Polarized Measurements

3. DESCRIPTION OF THE MEASUREMENT SYSTEM FOR DTV E-FIELD

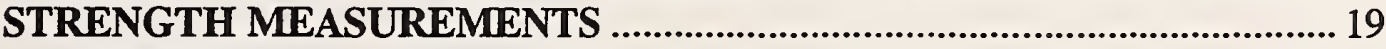

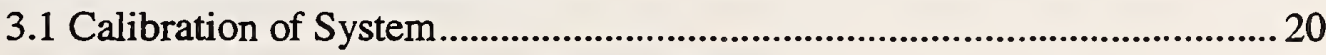

3.2 Data Analysis: Measured E-field Strengths ........................................... 20

4. COMPARISON OF MEASURED AND PREDICTED E-FIELD STRENGTHS

5. PREDICTED E-FIELD STRENGTHS FOR THE PROPOSED TOWER HEIGHTS

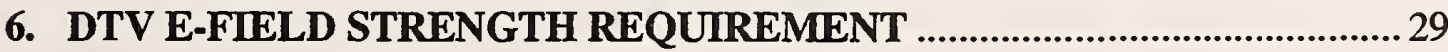

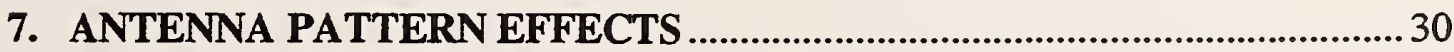

8. EFFECTS OF BROADBAND TRANSMISSION ON SENSITIVE

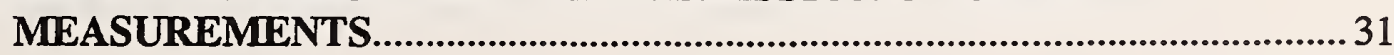

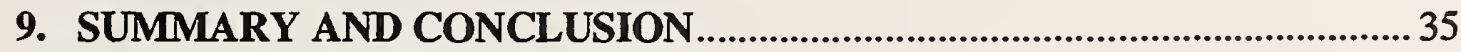

10. REFERENCES

APPENDIX A: MEASURED E-FIELD STRENGTHS OF THE 1998 AND 2001

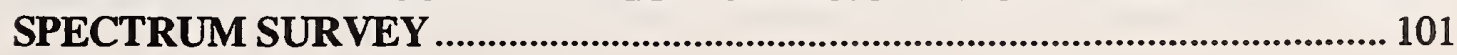

APPENDIX B: MEASURED POWER LEVELS ................................................ 125 


\section{Trade Name Disclaimer}

Certain commercial equipment, instruments, or materials are identified in this report to adequately specify conditions used in obtaining the reported information. Such identification, implied or specific, does not represent a recommendation or endorsement of the companies or the products by the National Institute of Standards and Technology or the National Telecommunications and Information Administration, nor does it imply that the materials or equipment identified are necessarily the best available for the purpose. 


\title{
Predicted and Measured Field Strengths in the Boulder, Colorado, Area from Two Proposed Terrestrial Digital Television Tower Sites
}

\author{
Christopher L. Holloway \\ National Institute of Standards and Technology \\ Boulder, Colorado 80305 \\ Frank H. Sanders and Paul M. McKenna \\ National Telecommunications and Information Administration \\ Boulder, Colorado 80305
}

A study was performed to determine the increase in ambient electromagnetic field strengths that would result from a proposal to locate a cluster of terrestrial digital television (DTV) transmission towers in proximity to the Department of Commerce (DOC) Laboratories in Boulder, Colorado. The primary objective of this study was to assess the impact on a broad range of Federal Government research and metrology programs that depend upon the relatively quiet radiofrequency electromagnetic environment. Radio-wave propagation measurements were performed for two terrestrial DTV frequencies (533 $\mathrm{MHz}$ and $772 \mathrm{MHz}$ ), and used to verify predicted DTV electric field strengths obtained from the DOC Irregular Terrain Model (TTM). The measured data were also used to determine the variation in received signal strength over small distance intervals. Radiowave propagation measurements were performed at both frequencies using two possible mountaintop transmitter locations, Eldorado Mountain and Squaw Mountain. The first (Eldorado Mountain) affords substantial line-of-sight coverage over the Boulder area, and the second (Squaw Mountain) affords only indirect (diffractive) coverage over the same area. The two propagation conditions from each site, direct and indirect, respectively, are compared to the ITM predictions. The relative variations in measured and predicted signal strengths are compared as a function of frequency and of propagation conditions. Measured and predicted data were found to be in close agreement. This provides confidence that the theoretical predictions of received signal strengths at given locations in the Boulder area are accurate. It was found that in some locations, the ambient field strengths for $1 \mathrm{MW}$ of transmitter power from a single station will exceed $1 \mathrm{~V} / \mathrm{m}$

Key words: digital television (DTV), field strength measurements, Irregular Terrain Model (ITM), National Radio Quiet Zone (NRQZ), propagation modeling, spectrum survey 


\section{INTRODUCTION}

The Federal Communications Commission (FCC) has mandated that all full-service (high-power) television broadcasters be transmitting a digital television (DTV) signal and be prepared to terminate their analog television (TV) broadcasts by 2006 [1]. In the United States, the analog television broadcast standard, or National Television System Committee (NTSC), allocates $6 \mathrm{MHz}$ of bandwidth per channel $[2,3]$. The high-power TV broadcasters have each been provided with a paired digital channel, usually in the "core" TV channels (2 through 51). If market penetration of digital television is sufficient, then the intent of the FCC directive is for analog TV broadcasts to cease and for some of the analog spectrum to be returned to the public for other communication services. In this report, the term DTV includes high-definition digital TV (HDTV). Current analog TV channels 52 through 69 will be reassigned to other uses, including the provision of additional spectrum for public-safety users (including a number of interoperability channels); some of this spectrum will also be auctioned for commercial wireless telecommunications network applications. Table 1 shows the present analog frequencies for the different TV channels along with the new DTV frequencies for some TV channels in the Denver, Colorado, Designated Market Area (DMA). Some of these TV channels have been authorized to transmit at effective radiated power (ERP) levels as high as one megawatt ( $1 \mathrm{MW}$ ), where ERP is defined as the product of the power supplied to the antenna and its gain relative to a half-wave dipole in a given direction [4]. The allocated power levels for these TV channels are also shown in table 1. Also shown in this table are the allocated power levels in units of equivalent isotropically radiated power (EIRP), defined as the product of the power supplied to the antenna and its gain relative to an isotropic antenna in a given direction [4]. Note, EIRP $=1.64$ ERP. EIRP is used throughout this report.

In Reference [1], the FCC indicates that in the future, adjustments to the allocated power levels may be granted under some situations, which would allow transmitter power levels higher than 1 MW ERP (1.64 MW EIRP). The Further Notice of Proposed Rulemaking (FNPRM) [5] indicates that maximum ERP of $5 \mathrm{MW}$ (or 8.2 MW EIRP) is possible.

\subsection{Electric Field Strength}

A minimum DTV E-field strength of $41 \mathrm{~dB} \mu \mathrm{V} / \mathrm{m}\left(1.12 \times 10^{-4} \mathrm{~V} / \mathrm{m}\right)$ at a receiving antenna height of $9.14 \mathrm{~m}(30 \mathrm{ft})$ is assumed adequate to provide satisfactory reception, as recommended by the FCC [1]. Note that $\mathrm{dB} \mu \mathrm{V} / \mathrm{m}$ refers to decibels relative to $1 \mu \mathrm{V} / \mathrm{m}$. The table of allotments was designed to essentially replicate a broadcaster's current analog Grade B coverage area with digital signal strengths greater than or equal to the minimum DTV electric field strength, while attempting to minimize analog-into-digital, digital-into-analog, and digital-into-digital co- and adjacent-channel interference with signals of other broadcasters. Transmitter power consumption is a significant operational cost, and it is therefore critical for broadcasters to have confidence that field strength prediction models are accurate, so that excessively high power levels are not transmitted. (High transmitter power can also increase deleterious interference, both into-digital and 
into-analog, for distant stations.) It is also critical for broadcasters to understand the amount by which received DTV signal strengths may vary spatially within predicted contours, so that power levels throughout the coverage area will be high enough to compensate for localities at which the actual field strength drops below the noise-limited field strength.

Reception may be possible with a $9.14 \mathrm{~m}$ outdoor antenna (this height assumes mounting $3 \mathrm{~m}$ above the rooftop of a two story residence) or indoor antenna; however, significant problems with reception with indoor antennas have been reported [6]. In this report, the Advanced Television Systems Committee (ATSC) Task Force has suggested that in order to overcome the indoor DTV reception problem, field strengths at the $9.14 \mathrm{~m} \mathrm{(30 \textrm {ft } )}$ reference height may need to be increased substantially to $97 \mathrm{~dB} \mu \mathrm{V} / \mathrm{m}$. This is an increase of $56 \mathrm{~dB}$ over the FCC $41 \mathrm{~dB} \mu \mathrm{V} / \mathrm{m}$, which is equivalent to an increase by a factor of approximately 631 in field strength. This $56 \mathrm{~dB}$ increase can be obtained by either substantially reducing the coverage area of DTV reception or by increasing the allocated transmitter power levels by an unrealistic $56 \mathrm{~dB}$.

In the Colorado Front Range (the Denver metropolitan area), several sites have been proposed as possible locations for the new DTV transmitting antenna towers. Two of these proposed sites are addressed in this report. They are on Eldorado Mountain, which is located just south of Boulder, Colorado, and on Squaw Mountain, which is located just south of Idaho Springs, Colorado. Note, the Eldorado Mountain and Squaw Mountain sites were chosen in this study because these two possible sites bound the propagation environment that would occur at both the Table Mountain NRQZ and the DOC Laboratories. The Eldorado Mountain site affords substantial line-of-sight coverage over the Boulder area, and the Squaw Mountain site affords only indirect (diffractive) coverage over the same area. The other possible tower sites fall between these two types of propagation conditions. The Department of Commerce (DOC) conducted tests and analyses to address whether DTV transmissions from these two proposed sites will produce E-field strengths that exceed the regulatory FCC limits for the Table Mountain National Radio Quiet Zone (NRQZ) north of Boulder, Colorado [8]. In addition, these tests were used to ascertain whether DTV transmissions from these proposed sites will have an adverse impact on measurement efforts that are performed on a regular basis at the DOC Laboratories located at 325 Broadway in Boulder, Colorado (hereafter referred to as the DOC Laboratories).

The DOC Laboratories in Boulder comprise three Federal research agencies: the National Institute of Standards and Technology (NIST), the National Telecommunications and Information Administration's (NTIA) Institute for Telecommunication Sciences (ITS), and the National Oceanic and Atmospheric Administration (NOAA). All three of these laboratories perform different types of measurement activities at both the Broadway location and at the Table Mountain NRQZ. The Table Mountain NRQZ is one of only two national radio quiet zones in the United States (the other being the National Radio Quiet Zone in West Virginia/Virginia [9]). The Table Mountain NRQZ provides scientists and engineers with a research environment where external radio signals (sometimes called "ambient radio noise") are kept to a minimum. The integrity of this NRQZ is mandated by both Federal regulation and state law, [8] and [10] respectively. 
These regulations and laws require that signal strengths from various transmitters must not exceed specified E-field strengths within the Table Mountain NRQZ in frequency bands above $1.6 \mathrm{MHz}$ (table 2). Other public and private institutions besides the DOC Laboratories use this NRQZ for research purposes. These include the United States Geological Survey (USGS), the National Center for Atmospheric Research (NCAR), the Deep Space Exploration Society (DSES), the Radio Amateur Satellite Corporation (AMSAT), and Coherent Technologies, to name a few.

In order to address the concerns of the DOC, propagation models were used to predict the E-field strengths at the two DOC locations (the Broadway Laboratories and the Table Mountain NRQZ). Various wave-propagation models have been developed that can be used for this task. They range from very simple free-space models to more complex irregular terrain models. Unfortunately, simple free-space models can be used only under certain conditions. A simple free-space model will give accurate results only when scatter-free line-of-sight conditions exist. However, the free-space model is a good starting point in considering broadcast field strengths and will be briefly summarized.

Consider the antenna in figure 1 , which is connected to a transmitter. Assume that this system is isolated in free space (i.e., no scattering objects are in the vicinity of the antenna). With this assumption, it can be shown [11-14] that the power density $(\mathscr{P})$, and E-field can be related as follows

$$
\mathfrak{P}=\frac{\mathrm{EIRP}}{4 \pi R^{2}} \quad\left[\mathrm{~W} / \mathrm{m}^{2}\right]
$$

and

$$
|E|=\sqrt{\eta \mathscr{P}} \quad[\mathrm{V} / \mathrm{m}]
$$

where

$$
\mathrm{EIRP}=P_{z} G_{z} .
$$

In these two expressions, EIRP is the equivalent isotropically radiated power, $P_{t}$ is the input power at the transmitter antenna terminals (in units of watts), and $G_{t}$ is the gain of the transmitter antenna, which is in general a function of directional angles $\theta$ (elevation) and $\phi$ (azimuth), relative to the antenna, in spherical coordinates. $G_{\imath}$ is the gain relative to an isotropic antenna (often expressed in units of $\mathrm{dBi}$, where $\mathrm{dBi}$ refers to antenna gain in decibels relative to an isotropic antenna). $R$ is the distance (in units of meters) from the transmitter antenna to an observation point (the location of a receiver), and $\eta$ is the free-space wave impedance given by the following

$$
\eta=120 \pi \approx 377[\Omega] .
$$


From the expressions given in equations (1) and (2), it is observed that the power density $\mathcal{P}$ decays as $\frac{1}{R^{2}}$ and the magnitude of the E-field decays as $\frac{1}{R}$. This is illustrated in figures 2 and 3, where the magnitude of the E-field and the power density are plotted as a function of $R$ for an EIRP of $1 \mathrm{MW}$. Also shown in these figures are the IEEE radio frequency (RF) population exposure limits for a typical TV frequency [15], as well as some international limits [16]. Figure 2 also shows the $30 \mathrm{mV} / \mathrm{m}$ FCC Table Mountain NRQZ limit [8], which is given in table 2 for the DTV frequencies. Notice that for a distance of $23 \mathrm{~km}$ (the distance from Eldorado Mountain to the Table Mountain NRQZ) the free-space field value is about an order of magnitude higher than the FCC NRQZ limit. By inserting the NRQZ E-field limit into the expression given in equations (1) and (2), the minimal distance at which the FCC NRQZ requirement is met for a given transmitter power level and antenna gain can be obtained as follows:

$$
R_{\min }=\left[\frac{\eta P_{t} G_{t}}{4 \pi|E|^{2}}\right]^{1 / 2} \quad[\mathrm{~m}]
$$

For $|E|=30 \mathrm{mV} / \mathrm{m}, P_{t}=1 \mathrm{MW}, G_{t}=1(\mathrm{EIRP}=1 \mathrm{MW})$, this reduces to

$$
R_{\min }=183[\mathrm{~km}](\text { or } 114 \mathrm{mi}) \text {. }
$$

Figure 1 represents an idealization of a realistic wave-propagation environment. A more realistic environment is depicted in figure 4 . The figure shows a transmitting antenna on a hillside that propagates energy toward a receiving antenna near the ground. In this scenario the radio waves that propagate toward the receiving antenna are not simply the free-space environment shown in figure 1. As the receiving antenna moves along the ground and traverses the terrain profile, the E-field strength deviates from the free-space calculations due to effects of the terrain. In a line-of-sight (LOS) path, the transmitter can be physically seen from the receiver location, e.g., points $A$ or $C$ in figure 4 . The E-field for a LOS path has contributions from a direct ray, reflected ray(s), and, to a lesser extent, from diffracted rays. The direct ray corresponds to the free-space result discussed above. The reflected rays are caused by multiple reflections due to objects in the environment (e.g., the ground, mountains, hillsides, trees, rocks, cars, buildings, people, etc.). The diffracted rays result from scattering from the edges of these objects. In a non-line-ofsight (non-LOS) path, the transmitter cannot be seen from the receiver location, e.g., point $B$ in figure 4. The E-field for a non-LOS path is the result of contributions from only reflected rays and diffracted rays. In these cases, the direct, reflected, and scattered rays may add up constructively or destructively to cause the received signal strength to be larger or smaller than that predicted using the free-space model. In order to calculate the field strength in these more complex environments, sophisticated irregular terrain models must be used.

There are various irregular terrain models available for these calculations [17-19]. In the calculations presented in this report, the ITS Irregular Terrain Model (ITM) developed at 
the DOC Laboratories is used [17-20], which is based on the work of Longley and Rice [21]. This model was developed during the 1950's and 1960's and has been continuously improved throughout the years. For the predictions reported here, this model uses USGS digital terrain elevation data to determine the actual terrain profiles for the area of interest. Once the terrain features are determined, electromagnetic models are used to calculate the E-field strengths at any desired location given a transmitter's height, antenna gain, and power level. The ITM is widely used by the broadcast and communication industries.

In this report, we use the ITM to predict the E-field strengths at the DOC Laboratories and at the Table Mountain NRQZ for transmitters located at the proposed Eldorado Mountain and Squaw Mountain sites. However, to verify that the modeled results for the two proposed locations and tower heights are accurate, comparison to measured data is required. Since measurements of E-field strengths based on proposed transmitter tower heights (approximately $116 \mathrm{~m}$ (380 ft) at Eldorado Mountain and approximately $60.96 \mathrm{~m}$ (200 ft) at Squaw Mountain), and at the maximum proposed transmitting power levels (i.e., 1 MW ERP or 1.64 EIRP) are impractical, measurements were carried out at reduced transmitter antenna heights and power levels. The proposed transmitter tower heights for the two sites were obtained from either the landowners or public documents. The measurements were performed in the geographic area of interest to the DOC Laboratories at $533 \mathrm{MHz}$ and $772 \mathrm{MHz}$, i.e., frequencies near the lower and upper ends of the UHF DTV spectrum allotment for several of the local broadcast stations. The propagation measurements were performed with fixed transmitters placed on the two mountaintops and a land-mobile receiver and data recording system. The two mountaintop locations used were the proposed Eldorado Mountain and Squaw Mountain sites. The mobile van-based receiver system was driven throughout the Boulder area, and E-field strengths were measured as a function of location across the area. Both line-ofsight and obstructed (shadowed) propagation paths were encountered during the measurements. For model validation, measured field strengths were compared to ITM calculated data as a function of location and frequency. The data also revealed the variation in received field strength as a function of location, for both line-of-sight and shadowed propagation. Once the model predictions were confirmed with the measurements, the ITM propagation model was used to calculate the E-field strengths for the proposed transmitter heights and power levels at the two proposed sites.

\subsection{Organization of the Report}

This report is organized as follows: Section 2 presents recently measured E-field strength at both the Table Mountain NRQZ and the DOC Laboratories, illustrating that the FCC E-field strength limits are currently maintained at the NRQZ and exhibiting the current field strengths at the DOC Laboratories. In Section 3, the measurement system is described and the measured data for the two different transmitter sites are shown. Also in Section 3, the measured data were scaled to the proposed transmitter power level to indicate the expected E-field strengths at both the DOC Laboratories and at the Table Mountain NRQZ north of Boulder. In Section 4, predicted E-field strengths obtained from the ITM are compared to the measured data. In Section 5, calculated E-field 
strengths are presented for the proposed antenna heights and power levels for the two different proposed transmitter sites. Section 6 discusses the FCC field strengths recommended for DTV reception. Also in this section, field strength plots for the FCC-

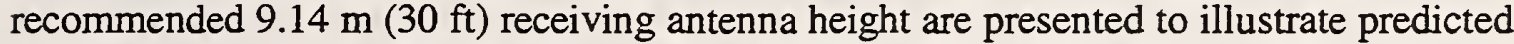
DTV reception in the Boulder-Denver area from the two proposed sites. In Section 7, antenna pattern effects are discussed. Section 8 discusses the effects of broadband transmission on sensitive measurement systems. Finally, we summarize the results and discuss the possible impact of the proposed sites on the scientific activities at both the DOC Laboratories and at the Table Mountain NRQZ facility.

In this report all measured data are scaled to a 1 MW EIRP and all the predicted E-field strengths are calculated for a $1 \mathrm{MW}$ EIRP. Use of a 1 MW EIRP facilitates rescaling both the measured and calculated field strengths to any other desired EIRP level, as the need arises.

Table 1. Frequencies and power allocations for analog frequencies for the different TV channels along with the new DTV frequencies for some TV channels in the Denver, Colorado, Designated Market Area (DMA).

\begin{tabular}{|c|c|c|c|c|c|}
\hline $\begin{array}{c}\text { Current } \\
\text { NTSC } \\
\text { channel }\end{array}$ & $\begin{array}{c}\text { Current } \\
\text { frequency } \\
\text { bands (MHz) }\end{array}$ & $\begin{array}{c}\text { New } \\
\text { DTV } \\
\text { channel }\end{array}$ & $\begin{array}{c}\text { New DTV } \\
\text { frequency bands } \\
(\mathrm{MHz})\end{array}$ & $\begin{array}{c}\text { Allocated DTV } \\
\text { ERP } \\
(\mathrm{MW})\end{array}$ & $\begin{array}{c}\text { Allocated DTV } \\
\text { EIRP } \\
\text { (MW) }\end{array}$ \\
\hline 2 & $54-60$ & 34 & $590-596$ & 1.0 & 1.64 \\
\hline 4 & $66-72$ & 35 & $596-602$ & 1.0 & 1.64 \\
\hline 6 & $82-88$ & 18 & $494-500$ & 1.0 & 1.64 \\
\hline 7 & $174-180$ & 17 & $488-494$ & 1.0 & 1.64 \\
\hline 9 & $186-192$ & 16 & $482-488$ & 1.0 & 1.64 \\
\hline 12 & $204-210$ & 38 & $614-620$ & 1.0 & 1.64 \\
\hline 14 & $470-476$ & 15 & $476-482$ & 0.099 & 0.164 \\
\hline 20 & $506-512$ & 19 & $500-506$ & 0.248 & 0.407 \\
\hline 31 & $572-578$ & 32 & $578-584$ & 0.233 & 0.383 \\
\hline 41 & $632-638$ & 40 & $626-632$ & 0.0748 & 0.129 \\
\hline 50 & $686-692$ & 51 & $692-698$ & 0.0817 & 0.134 \\
\hline 59 & $740-746$ & 43 & $644-650$ & 0.01448 & 0.024 \\
\hline
\end{tabular}

Table 2. Specified E-field strength limits for the Table Mountain NRQZ for the VHF and UHF frequency bands.

\begin{tabular}{|c|c|c|}
\hline Frequency band $(\mathrm{MHz})$ & E-field limit $(\mu \mathrm{V} / \mathrm{m})$ & E-field limit $(\mathrm{dB} \mu \mathrm{V} / \mathrm{m})$ \\
\hline $1.6-470$ & 10,000 & 80.0 \\
\hline $470-890$ & 30,000 & 89.5 \\
\hline$>890$ & 1,000 & 60.0 \\
\hline
\end{tabular}




\section{SPECTRUM SURVEY AT THE NRQZ AND AT THE DOC LABORATORIES FOR $30 \mathrm{MHz}$ TO $960 \mathrm{MHz}$}

Spectrum occupancy measurements provide data on expected E-field strengths and probabilities of occurrence that are essential for assessing the degree of utilization at a given site or in a given area. NTIA has published a set of reports [22-25] documenting spectrum occupancy between $100 \mathrm{MHz}$ and $19.7 \mathrm{GHz}$ in some of the largest metropolitan areas in the United States.

In June 1998, a spectrum survey (E-field strength measurements) was performed inside the Table Mountain NRQZ and at the DOC Laboratories to determine E-field strengths using a vertically polarized receiving antenna. In April 2001, a spectrum survey was performed inside the Table Mountain NRQZ and at the DOC Laboratories to determine E-field strengths for a horizontally polarized receiving antenna. The results of these surveys are presented in this section.

\subsection{Measurement System}

The NTIA Radio Spectrum Measurement System (RSMS) was used to perform the field strength measurements (or spectrum survey). Hardware, software, and methodology used for this survey were the same as for earlier surveys referenced above. Those reports may be consulted for detailed descriptions of broadband spectrum survey techniques used at the Table Mountain NRQZ.

The RSMS is a mobile, self-contained computer-controlled radio-receiving system capable of many measurement scenarios over a frequency range of $30 \mathrm{MHz}$ to $22 \mathrm{GHz}$. Figure 5 is a view of the RSMS with telescoping masts raised and antennas mounted for a broadband spectrum survey such as was performed at Table Mountain. The large box on the rear of the RSMS is an RF-shielded enclosure containing the measurement equipment.

The masts may be raised to as much as $9 \mathrm{~m}$ above ground level. For collection of spectrum data between $30 \mathrm{MHz}$ and $960 \mathrm{MHz}$ at Table Mountain, the forward mast was raised to full height. An omni-azimuthal directional antenna with a nominal frequency range of $30 \mathrm{MHz}$ to $1000 \mathrm{MHz}$ was used to receive signals. A $12 \mathrm{~m} \mathrm{RF}$ cable connected the antenna to the measurement system input port, located inside the van.

The RSMS measurement system is shown as a block diagram in figure 6. It consists of two independent systems, each with its own antennas, receiver and signal processing equipment, and controller/data-recording computers. The two are designated System 1 and System 2. System 1 is on the right-hand side of figure 6. For the Table Mountain NRQZ survey, this system was used to measure signals between $30 \mathrm{MHz}$ and $960 \mathrm{MHz}$. System 1 is built around a Hewlett-Packard $8566 \mathrm{~B}$ spectrum analyzer and a HewlettPackard $85685 \mathrm{~A}$ preselector. The preselector provides low-noise preamplification for a typical measurement system sensitivity of about $10 \mathrm{~dB}$ across the range of $30 \mathrm{MHz}$ to $960 \mathrm{MHz}$. The preselector also provides bandpass filtering ahead of the preamplification, to protect the measurements from the effects of strong signals in close proximity to the measurement frequencies. Bandpass filters are varactors below $500 \mathrm{MHz}$ and are yttrium- 
iron-garnet (YIG) above $500 \mathrm{MHz}$. Variable attenuation is available ahead of the bandpass filtering in the $85685 \mathrm{~A}$, but was not required for the NRQZ measurements.

The measurement system was controlled via a PC-compatible controller running customdeveloped ITS measurement software. The computer program set all measurement parameters to operator specifications. Parameters are varied on a band-by-band basis (see measurement system data collection algorithms, below). The computer performed measurements on a band-by-band basis, in accordance with a preconfigured sequence for the bands between $30 \mathrm{MHz}$ and $960 \mathrm{MHz}$. The computer recorded all measurement data to an internal hard drive for subsequent retrieval and analysis at the NTIA/TTS laboratory.

\subsection{Measurement System Calibration and Correction to Incident Field Strength}

The measurement system was calibrated at least once every 24 hours during the spectrum survey. RSMS calibrations make use of a NIST-traceable standard noise diode at the antenna connection point. The procedure is standard Y-factor, in which measured power with the noise diode turned on is compared to measured power with the noise diode turned off. System noise figure and gain are computed across the entire frequency range to be surveyed. Reports [22] through [25] contain detailed descriptions of this technique as implemented for the RSMS.

As data are collected, all measured amplitudes are corrected for the system gain. Corrected amplitudes are stored for later retrieval and analysis. These data are in units of decibels relative to $1 \mathrm{~mW}(\mathrm{dBm})$ for a measurement system with $50 \Omega$ impedance.

Measured data are converted to other units, if necessary, during post-measurement data analysis. The conversion to incident field strength is accomplished by implementing the following equation (see References [11] and [26] for details):

$$
|E|=P_{\text {meas }}+77.2+20 \log (f)-G_{r} \text {, }
$$

where $|E|$ is the magnitude of the E-field strength at the antenna in units of $\mathrm{dB} \mu \mathrm{V} / \mathrm{m}$, $P_{\text {meas }}$ is the measured power in units of $\mathrm{dBm}, f$ is the frequency in units of megahertz (MHz), and $G_{\mathrm{r}}$ is the gain of the measurement antenna (the receiver antenna) at frequency $f$ in units of $\mathrm{dBi}$. Note, $\mathrm{dBm}$ refers to decibels relative to $1 \mathrm{~mW}$, and $\mathrm{dBi}$ refers to antenna gain in decibels relative to an isotropic antenna.

\subsection{Measurement System Data Collection Algorithms and Parameters}

RSMS data collection algorithms and parameters are tailored to the characteristics of the signals that typically occupy each spectrum band. The two fundamental algorithms that are used are swept-frequency and stepped-frequency. Swept-frequency measurements require that data be collected as the measurement system is continuously tuned across a frequency range of interest. Swept-frequency measurements are used in non-radar bands. Stepped-frequency measurements require that data be collected at fixed-tuned frequencies, with detectors (usually peak) operated at each frequency for specified 
intervals of time. Stepped-frequency measurements are used in radar bands. For the purposes of this survey, stepped-frequency measurements were performed between $420 \mathrm{MHZ}$ and $450 \mathrm{MHz}$ and between $900 \mathrm{MHz}$ and $930 \mathrm{MHz}$. All other bands utilized swept-frequency measurements.

Measurement parameters within each band are specified for maximum probability of intercept (POI). POI is maximized through careful selection of intermediate frequency (IF) bandwidth, video (post-detector) bandwidth, and detector type (e.g., peak versus average). The IF bandwidth is selected to match or slightly exceed the typical signal bandwidth within each band. Video bandwidth equals or slightly exceeds IF bandwidth. Detection may be either peak or sample, depending upon signal characteristics. Details are provided in References [22] through [25].

During the one-week period of this survey, the bands were visited in accordance with a preconfigured measurement sequence. The sequence was designed to ensure that each band was measured at least once during each hour of the diurnal cycle, and usually bands were measured several times during each hour. Bands that normally show highly dynamic changes in activity (e.g., land mobile radio bands) were visited much more frequently than low-dynamic bands (e.g., broadcasting). Details are described in References [22] through [25].

\subsection{Data Storage and Analysis}

All data for the Table Mountain NRQZ survey were recorded to the controller PC's internal hard drive. The data were later archived. Data initially recorded within each band showed maximum, minimum, and average signal strengths for periods of about a minute each, as described more fully in Reference [22] through [25]. Typically, each of these raw recordings was produced from dozens or even hundreds of individual spectrum analyzer sweeps.

When data were retrieved for analysis, all raw recordings for each band were combined to show the overall maximum, minimum, and average signal strengths within each band during the entire measurement period of one week. The cumulative data for all bands between $30 \mathrm{MHz}$ and $960 \mathrm{MHz}$ for the 1998 spectrum survey for a vertically polarized antenna are presented in Appendix A of this report (figures A.1 through A.34), and discussed in Sections 2.5 and 2.6. The cumulative data for all bands between existing TV channels from the 2001 spectrum survey for a horizontally polarized antenna are presented in Appendix A of this report (figures A.35 through A.43), and discussed in Section 2.7. 


\subsection{Table Mountain NRQZ Spectrum Survey Results: Vertically Polarized Measurements}

Table 3 summarizes the measured occupancy and strengths on a band-by-band basis for the Table Mountain NRQZ. All signals that are required to meet the 47 CFR 73.1030 limits within the Table Mountain NRQZ were observed to be in compliance. Moreover, virtually all other measured signals within the NRQZ also meet the limits. This may be partly due to the relatively rural location of the NRQZ. Of the handful of signals that do not meet the limits (and which are not required to meet them, because they are mobile systems), the measurement data indicate that field strengths are typically exceeded only briefly.

The results of this spectrum survey allow us to conclude with certainty that for vertically polarized measurements the NRQZ is, in fact, quiet. It therefore remains a useful and necessary location for radio experiments that cannot be performed in the presence of high-level background signals.

\subsection{DOC Laboratories Spectrum Survey Results: Vertically Polarized Measurements}

As a comparative data set, a spectrum survey identical to the one at the Table Mountain NRQZ was performed at the DOC Laboratories in June 1998. The same measurement hardware and software were used as that for the Table Mountain survey. The RSMS was located next to the NIST groundscreen, an outdoor antenna range located on the west side of the DOC site. The location afforded a limited line-of-sight view of the city of Boulder, but was well within a propagation shadow for most Denver-area broadcast transmitters (on Lookout Mountain, near Golden, Colorado).

The groundscreen measurements were run for a week. Plots of the measured E-field strengths are shown in Appendix A, figures A.18 through A.34. Table 4 summarizes the measured occupancy and strengths on a band-by-band basis for the NIST groundscreen.

In most bands between $30 \mathrm{MHz}$ and $960 \mathrm{MHz}$, the NIST groundscreen shows significantly higher signal strengths, and often more ambient noise, than the same bands within the Table Mountain NRQZ. Therefore, the Table Mountain NRQZ is an important resource for carrying out high-sensitivity, low-noise radio-wave measurements in these bands.

\subsection{Analysis of Existing Television Signal Environment: Horizontally Polarized Measurements}

The 1998 spectrum surveys at the Table Mountain NRQZ and the NIST groundscreen at the DOC Laboratories were performed with vertically polarized measurement antennas. This polarization, although useful for measuring most incident signals (land mobile radio, and radar, for example), was cross-polarized to most (horizontally polarized) television signals. To provide maximum coupling to television signals, the 1998 measurements were repeated between April 12-20, 2001, at the Table Mountain NRQZ and at the NIST groundscreen at the DOC Laboratories, this time using a horizontally polarized log 
periodic antenna (LPA). Measurements were also performed with the LPA at a second location at the DOC Laboratories, at the end of Wing 4 of Building 1 (the Radio Building). Other than the antenna used, all measurement conditions and parameters at these locations matched those of the 1998 spectrum survey.

The LPA was pointed in azimuth to maximize received signal strength from ambient television signals at these locations (that is, approximately toward Lookout Mountain). The gain of the LPA was factored into resulting measurements of incident field strength at these locations.

Because several television stations were already transmitting in the Denver area when the Table Mountain NRQZ was created, transmissions from those stations were grandfathered at preexisting levels exceeding the Table Mountain NRQZ limits. Those stations, and the strengths at which they are permitted to exceed the NRQZ thresholds, are shown in table 5 .

The measurement results are shown in figures A.35 through A.43 and are summarized in tables 6 through 8 . In these figures, maximum, minimum, and mean levels during the measurement period are shown. Additionally, note that the relatively high level of television carriers at the Table Mountain NRQZ required the insertion of $10 \mathrm{~dB}$ of attenuation in the bands with grandfathered signal strengths when the polarizations were matched. This attenuation was also used in the measurements in the other television bands, and at the other measurement locations, for the sake of consistency. This need for insertion of such attenuation is, in general, undesirable for DOC research programs conducted at the Table Mountain NRQZ and at the DOC Laboratories (see Section 8).

Table 6 summarizes the measured occupancy and strengths at the different locations for the $54 \mathrm{MHz}$ through $88 \mathrm{MHz}$ frequency range. Television signal strengths at the Table Mountain NRQZ are currently at the prescribed limits, including grandfathered signal strengths for Channels 4 and 6. Background noise levels on Channel 3 (unoccupied) are somewhat higher with horizontal polarization than with vertical polarization. Comparison of the Table Mountain NRQZ measurements with those performed on the NIST groundscreen facility and the end of Wing 4 of the NIST/TTS Radio Building on Broadway in Boulder, shows that the received television carrier field-strengths are higher within the NRQZ than at the DOC Laboratories on Broadway. But, apart from the TV signals, the spectrum is typically quieter at the Table Mountain NRQZ than at the Broadway locations. The noisier environment at the DOC Laboratories is due presumably to extensive development in the Boulder area. The characteristics of the ambient noise on the DOC Laboratories vary somewhat as a function of antenna polarization and precise location, but in no case is the ambient noise on the campus totally abated by polarization or location.

Table 7 summarizes the measured occupancy and strengths at the different locations for the $174 \mathrm{MHz}$ through $216 \mathrm{MHz}$ frequency range. Television signal strengths at the Table Mountain NRQZ are currently at the prescribed limits, including grandfathered signal strengths for Channels 7 and 9. Background noise strengths are comparable with horizontal and vertical polarizations. Comparing the Table Mountain NRQZ 
measurements with those performed on the NIST groundscreen and at the end of Wing 4 of the NIST/ITS Radio Building at the DOC Laboratories, the received television carrier field strengths are higher within the Table Mountain NRQZ than at the DOC Laboratories. But apart from the TV signals, the spectrum is typically quieter at the Table Mountain NRQZ than at the DOC Laboratories. The noisier environment at the DOC Laboratories is due presumably to extensive development in the Boulder area. The characteristics of the ambient noise at the DOC Laboratories vary somewhat as a function of antenna polarization and precise location, but in no case is the ambient noise on the campus totally abated by polarization or location. The overall higher level of maximum noise in the 1998 groundscreen measurements, relative to the 2001 groundscreen data, may be due to the longer period over which the 1998 measurements were conducted.

Table 8 summarizes the measured occupancy and strengths at the different locations for the $512 \mathrm{MHz}$ through $806 \mathrm{MHz}$ frequency range. Television signal strengths at the Table Mountain NRQZ are currently at the prescribed limits. Channel 41 appears to exceed the limit by $1 \mathrm{~dB}$ in the graph, but this is within the uncertainty of the measurement (a conservative estimate of the measurement uncertainty is $\pm 2 \mathrm{~dB}$ ). Comparison of measurements at Table Mountain with those performed on the NIST groundscreen and at the end of Wing 4 of the NIST/ITS Radio Building at the DOC Laboratories, shows that the received television carrier field strengths are typically higher within the Table Mountain NRQZ than at the DOC Laboratories. But apart from the TV signals, the spectrum is typically quieter at the Table Mountain NRQZ than at the DOC Laboratories. The noisier environment at the DOC Laboratories is due presumably to extensive development in the Boulder area. The characteristics of the ambient noise at the DOC Laboratories are noted to vary somewhat as a function of antenna polarization and precise location, but in no case is the ambient noise on the campus totally abated by polarization or location.

Although existing television signals are somewhat higher in amplitude at the Table Mountain NRQZ than at the DOC Laboratories (due to direct LOS propagation to the Table Mountain NRQZ versus indirect propagation to the DOC Laboratories), the ambient noise level at the Table Mountain NRQZ is typically less than at the DOC Laboratories. The ambient carrier strengths within the Table Mountain NRQZ are within the limits described in 47 CFR 73.1030, with the exceptions of the grandfathered limits for Channels $4,6,7$, and 9 .

Due to terrain shadowing of transmissions from Lookout Mountain to the DOC Laboratories location, NTSC television signals typically have lower field strengths at the NIST groundscreen facility than within the NRQZ (which has line-of-sight coverage from most Denver-area NTSC broadcast station locations). This situation will change, and the Boulder DOC Laboratories will be subjected to significantly higher television signal strengths, if DTV transmitters are located in line-of-sight proximity to the DOC Laboratories. If that occurs, it will make the $\mathrm{NRQZ}$ environment even more important as an asset for measurements in the bands occupied by broadcast television. If new DTV transmitter locations do not have line-of-sight coverage of the DOC Laboratories, then a situation somewhat similar to the current propagation conditions may continue. 

measurements.

\begin{tabular}{|c|c|}
\hline $\begin{array}{l}\text { Frequency } \\
\text { range } \\
(\mathrm{MHz})\end{array}$ & $\begin{array}{l}\text { Description of activity measured at the Table Mountain } \\
\text { NRQZ during one week in June } 1998\end{array}$ \\
\hline $30-54$ & $\begin{array}{l}\text { This band shows little activity. Only one signal is present full-time. Even the highest } \\
\text { signal measured was more than } 20 \mathrm{~dB} \text { below the NRQZ limit. }\end{array}$ \\
\hline $54-88$ & $\begin{array}{l}\text { Television channels } 2,4 \text {, and } 6 \text { (measured with a vertically polarized antenna) are the } \\
\text { significant occupants. All these signals are at or below the NRQZ limit. }\end{array}$ \\
\hline $88-108$ & This is the FM broadcast band. All signals are below the NRQZ limit. \\
\hline $108-136$ & $\begin{array}{l}\text { Air-traffic-control voice communications and aeronautical navigation aids are observed } \\
\text { in this band. Although not subject to the NRQZ limits, none of these signals exceeded } \\
\text { the limit. }\end{array}$ \\
\hline $136-174$ & $\begin{array}{l}\text { Land mobile radio signals are observed in this band. Most of these are intermittently } \\
\text { transmitted. Some approached the NRQZ limit, but none exceeded it. Mobile signals are } \\
\text { not required to meet the NRQZ limits. }\end{array}$ \\
\hline $174-216$ & $\begin{array}{l}\text { Television channels } 7,9 \text {, and } 12 \text { (measured with a vertically polarized antenna) are the } \\
\text { significant occupants. All these signals are at or below the NRQZ limit. }\end{array}$ \\
\hline $216-225$ & Little traffic is observed in this band, and all signals are well below the NRQZ limits. \\
\hline $225-400$ & $\begin{array}{l}\text { Little traffic is observed in this band, which is used primarily for military } \\
\text { communications, military air traffic control, and some aeronautical radio navigation } \\
\text { aids. Although these signals do not need to meet the NRQZ limit, all were measured at } \\
\text { strengths below the limit. }\end{array}$ \\
\hline $400-406$ & $\begin{array}{l}\text { A few signals are observed in this band, which is used primarily for meteorological } \\
\text { transmitters. None approached the NRQZ limit. }\end{array}$ \\
\hline $406-420$ & $\begin{array}{l}\text { One signal in this land mobile radio band approached, but did not exceed, the NRQZ } \\
\text { limit. These signals are not required to meet the limit. }\end{array}$ \\
\hline $420-450$ & $\begin{array}{l}\text { No activity is observed in this band, which is used for long-range military radars. No } \\
\text { such radars are operated in the Table Mountain area. }\end{array}$ \\
\hline $450-470$ & $\begin{array}{l}\text { Heavy traffic is observed in this land mobile radio band. Although these transmitters do } \\
\text { not need to meet NRQZ limits, only three exceeded the NRQZ limit, and then only } \\
\text { momentarily. }\end{array}$ \\
\hline $470-512$ & $\begin{array}{l}\text { Only television channels } 14,17 \text {, and } 20 \text { (measured with a vertically polarized antenna) } \\
\text { are observed in this part of the spectrum. Their measured signals are below the NRQZ } \\
\text { limit. }\end{array}$ \\
\hline $512-812$ & $\begin{array}{l}\text { UHF television signals (measured with a vertically polarized antenna) are the only } \\
\text { occupants observed in this part of the spectrum. Their measured signal strengths are } \\
\text { well below the NRQZ limit. }\end{array}$ \\
\hline $806-902$ & $\begin{array}{l}\text { Despite heavy observed traffic in the cellular telephone and trunked radio bands in this } \\
\text { part of the spectrum, only a single, mobile signal (not subject to the NRQZ limits) } \\
\text { momentarily exceeded the NRQZ threshold during the survey. }\end{array}$ \\
\hline $902-928$ & $\begin{array}{l}\text { Although signals in this industrial, scientific, and medical (ISM) band are not subject to } \\
\text { NRQZ restrictions, all observed signals were below the NRQZ limit, with a single, } \\
\text { momentary exception for a single signal. Stepped measurements, performed to observe } \\
\text { radar signals, show no activity. No such radars operate near Table Mountain. }\end{array}$ \\
\hline $928-932$ & $\begin{array}{l}\text { Pager signals are observed in large numbers and densities, and do exceed the NRQZ } \\
\text { limit. They are not, however, required to meet the limit. }\end{array}$ \\
\hline $928-960$ & $\begin{array}{l}\text { Special mobile radio (SMR) traffic in this band is observed, and the signal densities } \\
\text { were moderate compared to major metropolitan areas [22-25]. Many of these signals } \\
\text { exceed the NRQZ limit, although typically for short intervals. These signals are not } \\
\text { required to meet the NRQZ limits. }\end{array}$ \\
\hline
\end{tabular}


Table 4. Summary of NIST groundscreen spectrum survey at the DOC Laboratories: vertically polarized measurements.

\begin{tabular}{|c|c|}
\hline $\begin{array}{l}\text { Frequency } \\
\text { range } \\
\text { (MHz) }\end{array}$ & $\begin{array}{c}\text { Description of activity measured at the DOC Laboratories, } \\
\text { during one week in June } 1998\end{array}$ \\
\hline $30-54$ & $\begin{array}{l}\text { This band shows substantial ambient noise. The same spectrum within the Table } \\
\text { Mountain NRQZ is quieter. }\end{array}$ \\
\hline $54-88$ & $\begin{array}{l}\text { Carriers for television channels } 2,4 \text {, and } 6 \text { are } 20 \mathrm{~dB} \text { to } 30 \mathrm{~dB} \text { (measured with a } \\
\text { vertically polarized antenna) lower at the groundscreen than within the NRQZ. This is } \\
\text { due to terrain shadowing of the DOC Laboratories from the transmitter locations. } \\
\text { Table Mountain obtained line-of-sight propagation to these transmitters. }\end{array}$ \\
\hline $88-108$ & $\begin{array}{l}\text { This is the FM broadcast band. Signals at the DOC Laboratories are } 10 \mathrm{~dB} \text { to } 15 \mathrm{~dB} \\
\text { higher than within the NRQZ. }\end{array}$ \\
\hline $108-136$ & $\begin{array}{l}\text { Air-traffic-control voice communications and aeronautical navigation aids are } \\
\text { observed in this band. Power levels are comparable to those measured within the } \\
\text { NRQZ, as would be expected for predominantly airborne signals. }\end{array}$ \\
\hline $136-174$ & $\begin{array}{l}\text { Land mobile radio signals are observed in this band at strengths about } 8 \mathrm{~dB} \text { higher } \\
\text { than within the NRQZ. }\end{array}$ \\
\hline $174-216$ & $\begin{array}{l}\text { The highest-level carriers in this band at the NIST groundscreen are in the range of } \\
60 \mathrm{~dB} \mu \mathrm{V} / \mathrm{m} \text { to } 70 \mathrm{~dB} \mu \mathrm{V} / \mathrm{m} \text { field strength, comparable to the highest carriers in this } \\
\text { band at the NRQZ (one of which is as high as } 78 \mathrm{~dB} \mu \mathrm{V} / \mathrm{m} \text { ). But the groundscreen } \\
\text { environment is noisier, with peak noise envelope amplitudes of between } 35 \mathrm{~dB} \mu \mathrm{V} / \mathrm{m} \\
\text { and } 40 \mathrm{~dB} \mu \mathrm{V} / \mathrm{m} \text {. At the NRQZ, by comparison, the peak noise envelope is between } \\
28 \mathrm{~dB} \mu \mathrm{V} / \mathrm{m} \text { and } 30 \mathrm{~dB} \mu \mathrm{V} / \mathrm{m} \text {. }\end{array}$ \\
\hline $216-225$ & $\begin{array}{l}\text { The groundscreen shows more signal activity, and significantly more noise, than } \\
\text { within the NRQZ. }\end{array}$ \\
\hline $225-400$ & $\begin{array}{l}\text { This spectrum is significantly noisier, and is occupied by more signals for a higher } \\
\text { percentage of time, than within the NRQZ. }\end{array}$ \\
\hline $400-406$ & $\begin{array}{l}\text { This spectrum is noisier, is occupied by more signals, and shows as much as } 40 \mathrm{~dB} \\
\text { higher signal amplitude, than within the NRQZ. }\end{array}$ \\
\hline $406-420$ & $\begin{array}{l}\text { Occupancy of this band is comparable in amplitude and number of signals to the } \\
\text { NRQZ. The Boulder campus shows more noise (up to about } 30 \mathrm{~dB} \mu \mathrm{V} / \mathrm{m} \text { ) than the } \\
\text { NRQZ (at about } 20 \mathrm{~dB} \mu \mathrm{V} / \mathrm{m} \text { ). }\end{array}$ \\
\hline $420-450$ & $\begin{array}{l}\text { Noise at the groundscreen location occurs between } 70 \text { and } 90 \mathrm{~dB} \mu \mathrm{V} / \mathrm{m} \text {, as compared } \\
\text { to peak strengths of only } 60 \text { to } 70 \mathrm{~dB} \mu \mathrm{V} / \mathrm{m} \text { within the } \mathrm{NRQZ} \text {. }\end{array}$ \\
\hline $450-470$ & Signals at the groundscreen are $5 \mathrm{~dB}$ to $10 \mathrm{~dB}$ higher than within the NRQZ. \\
\hline $470-512$ & $\begin{array}{l}\text { Due to terrain shadowing from television broadcast locations to the DOC } \\
\text { Laboratories, television signals (measured with a vertically polarized antenna) in this } \\
\text { band are equal to or lower in power at the groundscreen than within the NRQZ. }\end{array}$ \\
\hline $512-812$ & $\begin{array}{l}\text { Terrain shadowing of the groundscreen location provides UHF television signal } \\
\text { strengths (measured with a vertically polarized antenna) that are comparable to those } \\
\text { within the NRQZ. }\end{array}$ \\
\hline $806-902$ & $\begin{array}{l}\text { Cellular base station signals are about } 8 \mathrm{~dB} \text { higher at the groundscreen location than } \\
\text { within the NRQZ. }\end{array}$ \\
\hline $902-928$ & $\begin{array}{l}\text { At the groundscreen, peak envelopes of signals in this industrial, scientific, and } \\
\text { medical (ISM) band are typically at field strengths of } 50 \mathrm{~dB} \mu \mathrm{V} / \mathrm{m} \text { to } 65 \mathrm{~dB} \mu \mathrm{V} / \mathrm{m} \text {. } \\
\text { This is significantly higher than the typical peak envelope strengths of } 40 \mathrm{~dB} \mu \mathrm{V} / \mathrm{m} \text { to } \\
45 \mathrm{~dB} \mu \mathrm{V} / \mathrm{m} \text { within the NRQZ. }\end{array}$ \\
\hline $928-932$ & Pager signals at the groundscreen are comparable to those within the NRQZ. \\
\hline $928-960$ & $\begin{array}{l}\text { Special mobile radio (SMR) traffic in this band occurs at about } 10 \mathrm{~dB} \text { higher } \\
\text { strengths than within the NRQZ. Pager signals at the two locations are comparable. } \\
\text { Above } 940 \mathrm{MHz} \text {, signals at the groundscreen are typically about } 20 \mathrm{~dB} \text { to } 30 \mathrm{~dB} \\
\text { higher than within the NRQZ. }\end{array}$ \\
\hline
\end{tabular}


Table 5. Grandfathered television signal strengths at the Table Mountain NRQZ.

\begin{tabular}{|c|c|c|}
\hline $\begin{array}{c}\text { Current } \\
\text { NTSC } \\
\text { channel }\end{array}$ & $\begin{array}{c}\text { Grandfathered signal strength within the } \\
\text { Table Mountain NRQZ }(\mathrm{dB} \mu \mathrm{V} / \mathrm{m})\end{array}$ & $\begin{array}{c}\text { Decibels exceeding the Table Mountain } \\
\text { NRQZ limit of }+80 \mathrm{~dB} \mu \mathrm{V} / \mathrm{m}\end{array}$ \\
\hline 4 & 84.1 & 4.1 \\
\hline 6 & 81.8 & 1.8 \\
\hline 7 & 94.4 & 14.4 \\
\hline 9 & 94.3 & 14.3 \\
\hline
\end{tabular}

Table 6. Television signals between $54 \mathrm{MHz}$ and $88 \mathrm{MHz}$ at the different measurement locations.

\begin{tabular}{|c|l|l|l|}
\hline $\begin{array}{c}\text { NTSC } \\
\text { channel }\end{array}$ & \multicolumn{1}{|c|}{ Table Mountain } & \multicolumn{1}{|c|}{ NIST groundscreen } & End of Wing 4, Bldg. 1 \\
\hline 2 & $\begin{array}{l}\text { With matched polarization on } \\
\text { the measurement antenna, } \\
\text { signal power is just below the } \\
\text { limit (at }+79 \mathrm{~dB} \mu \mathrm{V} / \mathrm{m}) .\end{array}$ & $\begin{array}{l}\text { With matched polarization } \\
\text { on the measurement } \\
\text { antenna, Channel } 2 \\
\text { maximum signal is } \\
+70 \mathrm{~dB} \mu \mathrm{V} / \mathrm{m} .\end{array}$ & $\begin{array}{l}\text { Maximum measured signal } \\
\text { strength is }+65 \mathrm{~dB} \mu \mathrm{V} / \mathrm{m}, \\
5 \mathrm{~dB} \text { less than on the } \\
\text { groundscreen. }\end{array}$ \\
\hline 4 & $\begin{array}{l}\text { With matched polarization on } \\
\text { the measurement antenna, } \\
\text { grandfathered signal strength } \\
\text { is just below the limit (at } \\
+83 \mathrm{~dB} \mu \mathrm{V} / \mathrm{m}) .\end{array}$ & $\begin{array}{l}\text { With matched polarization } \\
\text { on the measurement } \\
\text { antenna, Channel } 4 \\
\text { maximum signal is } \\
+78 \mathrm{~dB} \mu \mathrm{V} / \mathrm{m} . \mathrm{A} \text { transient } \\
\text { noise spike at } 69 \mathrm{MHz} \\
\text { occurred. }\end{array}$ & $\begin{array}{l}\text { Maximum measured signal } \\
\text { strength is }+72 \mathrm{~dB} \mu \mathrm{V} / \mathrm{m}, \\
6 \mathrm{~dB} \text { less than on the } \\
\text { groundscreen. }\end{array}$ \\
\hline 5 & $\begin{array}{l}\text { With matched polarization on } \\
\text { the measurement antenna, } \\
\text { weak signal from a distant } \\
\text { Channel } 5 \mathrm{dransmitter} \text { is } \\
\text { observed at a maximum of } \\
\text { about }+55 \mathrm{~dB} \mu \mathrm{V} / \mathrm{m} .\end{array}$ & $\begin{array}{l}\text { With matching } \\
\text { measurement antenna } \\
\text { polarization, a significant } \\
\text { signal }(+60 \mathrm{~dB} \mu \mathrm{V} / \mathrm{m}) \text { from } \\
\text { a distant Channel } 5 \\
\text { transmitter is noted. }\end{array}$ & $\begin{array}{l}\text { Maximum measured signal } \\
\text { strength is }+57 \mathrm{~dB} \mu \mathrm{V} / \mathrm{m}, \\
\text { groundscreen. }\end{array}$ \\
\hline $\begin{array}{l}\text { With matched polarization on } \\
\text { the measurement antenna, } \\
\text { grandfathered signal strength } \\
\text { is just below the limit (at } \\
\text { about }+81 \mathrm{~dB} \mu \mathrm{V} / \mathrm{m}) .\end{array}$ & $\begin{array}{l}\text { With matched polarization } \\
\text { on the measurement } \\
\text { antenna, Channel } 2 \\
\text { maximum signal is } \\
+73 \mathrm{~dB} \mu \mathrm{V} / \mathrm{m} .\end{array}$ & $\begin{array}{l}\text { Maximum measured signal } \\
\text { strength is }+78 \mathrm{~dB} \mu \mathrm{V} / \mathrm{m}, \\
5 \mathrm{~dB} \text { more than on the } \\
\text { groundscreen. }\end{array}$ \\
\hline
\end{tabular}


Table 7. Television signals between $174 \mathrm{MHz}$ and $216 \mathrm{MHz}$ at the different measurement locations.

\begin{tabular}{|c|c|c|c|}
\hline $\begin{array}{l}\text { NTSC } \\
\text { channel }\end{array}$ & Table Mountain & NIST groundscreen & End of Wing 4, Bldg. 1 \\
\hline 7 & $\begin{array}{l}\text { With matched } \\
\text { polarization on the } \\
\text { measurement antenna, } \\
\text { signal power is just below } \\
\text { the grandfathered limit (at } \\
+93 \mathrm{~dB} \mu \mathrm{V} / \mathrm{m}) \text {. }\end{array}$ & $\begin{array}{l}\text { With matched polarization on } \\
\text { the measurement antenna, } \\
\text { maximum signal is } \\
+61 \mathrm{~dB} \mu \mathrm{V} / \mathrm{m} \text {. }\end{array}$ & $\begin{array}{l}\text { Same comments as for the } \\
\text { groundscreen } \\
\text { measurements. }\end{array}$ \\
\hline 9 & $\begin{array}{l}\text { With matched } \\
\text { polarization on the } \\
\text { measurement antenna, } \\
\text { grandfathered signal } \\
\text { strength is below the limit } \\
\text { (at }+91 \mathrm{~dB} \mu \mathrm{V} / \mathrm{m} \text { ). }\end{array}$ & $\begin{array}{l}\text { With matched polarization on } \\
\text { the measurement antenna, } \\
\text { maximum signal is } \\
+61 \mathrm{~dB} \mu \mathrm{V} / \mathrm{m} \text {. }\end{array}$ & $\begin{array}{l}\text { Same comments as for the } \\
\text { groundscreen } \\
\text { measurements. }\end{array}$ \\
\hline 10 & $\begin{array}{l}\text { With matched } \\
\text { polarization on the } \\
\text { measurement antenna, a } \\
\text { weak signal from a } \\
\text { distant Channel } 10 \\
\text { transmitter is observed at } \\
\text { a maximum of about } \\
+35 \mathrm{~dB} \mu \mathrm{V} / \mathrm{m} \text {. }\end{array}$ & $\begin{array}{l}\text { On vertical polarization, a } \\
\text { signal ( }+25 \mathrm{~dB} \mu \mathrm{V} / \mathrm{m}) \text { from a } \\
\text { distant Channel } 10 \text { transmitter } \\
\text { is noted. This is not seen in } \\
\text { the horizontally polarized } \\
\text { measurement, likely because } \\
\text { of temporal variation in the } \\
\text { indirect propagation of this } \\
\text { signal. }\end{array}$ & $\begin{array}{l}\text { Not observed in this } \\
\text { measurement. This may be } \\
\text { due to temporal variation } \\
\text { in the indirect propagation } \\
\text { of this signal. }\end{array}$ \\
\hline 11 & $\begin{array}{l}\text { With matched } \\
\text { polarization on the } \\
\text { measurement antenna, } \\
\text { signal strength is well } \\
\text { below the limit (at about } \\
+68 \mathrm{~dB} \mu \mathrm{V} / \mathrm{m}) \text {. }\end{array}$ & $\begin{array}{l}\text { With matched polarization on } \\
\text { the measurement antenna, } \\
\text { maximum signal is } \\
+79 \mathrm{~dB} \mu \mathrm{V} / \mathrm{m} \text {. This transmitter } \\
\text { is located on a high rooftop a } \\
\text { few blocks from the DOC } \\
\text { Laboratories. }\end{array}$ & $\begin{array}{l}\text { Same comments as for the } \\
\text { groundscreen } \\
\text { measurements. }\end{array}$ \\
\hline 12 & $\begin{array}{l}\text { With matched } \\
\text { polarization on the } \\
\text { measurement antenna, } \\
\text { signal strength is below } \\
\text { the limit (at about } \\
+75 \mathrm{~dB} \mu \mathrm{V} / \mathrm{m}) \text {. }\end{array}$ & $\begin{array}{l}\text { With matched polarization, a } \\
\text { weak signal ( }+35 \mathrm{~dB} \mu \mathrm{V} / \mathrm{m}) \text { is } \\
\text { noted. This Channel's service } \\
\text { is carried on Channel } 11 \text { in the } \\
\text { Boulder area. }\end{array}$ & $\begin{array}{l}\text { Same comments as for the } \\
\text { groundscreen } \\
\text { measurements }\end{array}$ \\
\hline
\end{tabular}


Table 8. Television signals between $512 \mathrm{MHz}$ and $806 \mathrm{MHz}$ at the different measurement locations.

\begin{tabular}{|c|c|c|c|}
\hline $\begin{array}{l}\text { NTSC } \\
\text { channel }\end{array}$ & Table Mountain & NIST groundscreen & End of Wing 4, Bldg. 1 \\
\hline $\begin{array}{l}31 \\
\text { and } \\
32\end{array}$ & $\begin{array}{l}\text { Channel } 31 \text { is notable for } \\
\text { having a paired digital } \\
\text { transmission at Channel } 32 \text {. } \\
\text { Maximum measured carrier } \\
\text { strength of }+75 \mathrm{~dB} \mu \mathrm{V} / \mathrm{m} \text { is } \\
\text { typical for UHF television } \\
\text { signals measured at Table } \\
\text { Mtn. NRQZ }\end{array}$ & $\begin{array}{l}\text { With matched polarization on } \\
\text { the measurement antenna, } \\
\text { maximum signal is } \\
+62 \mathrm{~dB} \mu \mathrm{V} / \mathrm{m} \text {. }\end{array}$ & $\begin{array}{l}\text { Similar results as for the } \\
\text { groundscreen } \\
\text { measurements. }\end{array}$ \\
\hline 41 & $\begin{array}{l}\text { With matched polarization } \\
\text { on the measurement } \\
\text { antenna, maximum signal } \\
\text { strength is }+91 \mathrm{~dB} \mu \mathrm{V} / \mathrm{m} \text {. } \\
\text { This matches the maximum } \\
\text { allowed at the quiet zone, to } \\
\text { within the measurement } \\
\text { uncertainty of the RSMS. }\end{array}$ & $\begin{array}{l}\text { With matched polarization on } \\
\text { the measurement antenna, } \\
\text { Channel } 41 \text { maximum signal } \\
\text { is }+96 \mathrm{~dB} \mu \mathrm{V} / \mathrm{m} \text {. This is the } \\
\text { highest television signal } \\
\text { strength measured at any site } \\
\text { during any measurement. }\end{array}$ & $\begin{array}{l}\text { Similar results as for the } \\
\text { groundscreen } \\
\text { measurements. }\end{array}$ \\
\hline Others & $\begin{array}{l}\text { With matched polarization } \\
\text { on the measurement } \\
\text { antenna, typical maximum } \\
\text { signal strengths are between } \\
+70 \text { and }+85 \mathrm{~dB} \mu \mathrm{V} / \mathrm{m} \text {. A } \\
\text { total of about } 14 \text { television } \\
\text { signals are measured within } \\
\text { the band. }\end{array}$ & $\begin{array}{l}\text { With matched polarization on } \\
\text { the measurement antenna, } \\
\text { typical maximum signal } \\
\text { strengths are between }+60 \text { and } \\
+80 \mathrm{~dB} \mu \mathrm{V} / \mathrm{m} \text {. Two signals are } \\
\text { observed at strengths of }+86 \\
\text { and }+92 \mathrm{~dB} \mu \mathrm{V} / \mathrm{m} \text {. A total of } \\
\text { about } 15 \text { television signals are } \\
\text { measured within the band. }\end{array}$ & $\begin{array}{l}\text { Similar results as for the } \\
\text { groundscreen } \\
\text { measurements. Note } \\
\text { higher overall noise } \\
\text { strengths than at the } \\
\text { groundscreen. }\end{array}$ \\
\hline
\end{tabular}




\section{DESCRIPTION OF THE MEASUREMENT SYSTEM FOR DTV E-FIELD STRENGTH MEASUREMENTS}

In this section, the measurement system is explained, and measured results are presented and discussed. The transmitter systems on each mountaintop and the receiver measurement system in the van were configured as shown in the block diagram of figure 7. The transmitter consisted of two signal generators coupled into a single power amplifier via a combiner. The amplifier output incorporated a low-pass filter to reduce harmonic emissions. Figure 8 is an annotated photograph of the transmitter system used on both mountaintops. The signal was radiated from the first mountaintop (Eldorado Mountain) near Boulder (see the map in figure 9) via an omni-azimuthal directional antenna (with $1.9 \mathrm{dBi}$ gain), mounted $3.66 \mathrm{~m}$ (12.0 ft) high at the edge of a cliff that overlooks the Boulder-Denver metro area. The second mountaintop (Squaw Mountain) is located significantly farther from Boulder (also shown in the map in figure 9), giving little line-of-sight coverage over the measurement area. The transmitter at this site was similar to that at Eldorado, but a different transmitter antenna was used. The transmitter antenna was a log periodic array with $6.5 \mathrm{dBi}$ gain and was mounted $8.2 \mathrm{~m}(26.91 \mathrm{ft})$ above the ground. This array had a $3 \mathrm{~dB}$ beamwidth of $90 \mathrm{deg}$, and the beam was centered on the measurement area.

The transmitted signals were continuous, sinusoidal waves. This allowed the measurement bandwidths in the receivers to be set at sufficiently narrow values to observe the transmitted signals with nominal signal-to-noise ratios of $10 \mathrm{~dB}$ or more. The EIRP levels transmitted from the Eldorado Mountain site were $22.5 \mathrm{dBm}$ and $30.5 \mathrm{dBm}$ for the $533 \mathrm{MHz}$ and $772 \mathrm{MHz}$ systems, respectively. The EIRP levels transmitted from the Squaw Mountain site were $35.1 \mathrm{dBm}$ and $43.5 \mathrm{dBm}$ for the $533 \mathrm{MHz}$ and $772 \mathrm{MHz}$ systems, respectively.

The mobile measurement system, shown in figure 5 , used a $1.9 \mathrm{dBi}$ gain omni-azimuthal directional antenna mounted on a vehicle rooftop at $2.95 \mathrm{~m}(9.68 \mathrm{ft})$ above the ground. As shown in figure 7 , the antenna line was routed to a splitter, and from there the received signal was coupled to a pair of receivers. Each receiver was dedicated to a single frequency (533 $\mathrm{MHz}$ or $772 \mathrm{MHz}$ ). Each receiver included a pre-selector (a varactor bandpass filter to reject strong adjacent-frequency signals) and a low-noise preamplifier (affording a noise figure of approximately $10 \mathrm{~dB}$ for the measurement system).

The preselector outputs were routed to spectrum analyzers. Each spectrum analyzer was tuned to the applicable frequency, with a zero Hertz frequency span. The IF bandwidth was set to $10 \mathrm{kHz}$, and the lowpass video bandwidth was set slightly wider. Positive peak detection was used. The sweep time was set to $60 \mathrm{~s}$, so that each spectrum analyzer would record the received signal strength at the applicable frequency for $1 \mathrm{~min}$ at a time.

Each spectrum analyzer was controlled via a laptop PC-compatible computer. The computer downloaded each minute's-worth of data to data files, and then automatically reconfigured the spectrum analyzers and preselectors for the next minute of data. These systems were set to run continuously. Thus, received signal strength was continuously 
measured at each frequency. Seventeen peak amplitude strengths were measured and recorded per second at each frequency during data acquisition runs.

As the mobile measurement system was driven throughout the Boulder area, a global positioning system (GPS) receiver was used to track the vehicle's position. Notes were also kept on the vehicle's location as a function of local landmarks (e.g., road intersections). The routes driven for this study are shown in figures $10 \mathrm{a}, 10 \mathrm{~b}$, and $10 \mathrm{c}$. The measurements for each mountaintop were performed on separate days during the week of January 22, 2001.

\subsection{Calibration of System}

The transmitter signal strengths coupled to the antennas were verified directly using calibrated spectrum analyzers. Antenna gain characteristics were taken from manufacturers' data sheets for the individual antennas used in the study.

The receiver system was calibrated at the antenna output using a noise diode and a standard Y-factor excess noise ratio calibration technique in which power is measured in the receiver system with the diode alternately turned on and then off. The complete system path of RF line, splitter, preselectors, and spectrum analyzers was calibrated with this technique. System noise figure was typically about $10 \mathrm{~dB}$, and the correction factor between spectrum analyzer output and true power level was typically about $20 \mathrm{~dB}$. These numbers were obtained from a noise diode calibration. The noise diode output levels are traceable to NIST.

Noise diode calibration data were stored in computer look-up tables, and were added automatically to all measured power levels. All stored data were corrected at the tir 2 of collection. Antenna factor data were not incorporated into these stored data; iield strengths were computed after the measurements were completed, by adding antenna factor data to the measured power levels in the measurement system circuitry. A conservative estimate of the measurement uncertainty is $\pm 2 \mathrm{~dB}$.

\subsection{Data Analysis: Measured E-field Strengths}

Recorded data were reduced from noise-diode-corrected measurement units in the receiver system circuitry $(\mathrm{dBm})$ to peak received field strength in free space. This was accomplished by adding the appropriate antenna correction factors. Four different sets of data were collected for the two measured frequencies ( $533 \mathrm{MHz}$ and $772 \mathrm{MHz}$ ) at the two different transmitting sites (Eldorado Mountain and Squaw Mountain). For each frequency and transmitter location, data were collected at various locations around the Boulder area. Appendix B presents the actual measured power levels for all the various locations, frequencies, and transmitter sites. From the Eldorado Mountain location the input power to the antenna was $0.115 \mathrm{~W}(20.6 \mathrm{dBm})$ and $0.724 \mathrm{~W}(28.6 \mathrm{dBm})$ for the $533 \mathrm{MHz}$ and $772 \mathrm{MHz}$ systems, respectively. The gain of the transmitting antenna at the Eldorado Mountain site was $1.9 \mathrm{dBi}$. From the Squaw Mountain location the input power to the antenna was $0.724 \mathrm{~W}(28.6 \mathrm{dBm})$ and $5.0 \mathrm{~W}(37 \mathrm{dBm})$ for the $533 \mathrm{MHz}$ and 
$772 \mathrm{MHz}$ systems, respectively. The gain of the transmitting antenna at the Squaw Mountain site was $6.5 \mathrm{dBi}$.

In this analysis, we are interested in the field strengths for $1 \mathrm{MW}$ power radiating out of the transmitter (i.e., $1 \mathrm{MW}$ EIRP). In lieu of transmitting $1 \mathrm{MW}$ in this experiment, the measured power level in Appendix B can easily be transformed to any desired transmitter power level. Since Maxwell's equations are linear, it can be shown that by using the measured power level presented in Appendix B, received power levels for any given transmitter power in $\mathrm{dBm}$ can be obtained. For a given frequency, gain, and distance, received power is proportional to transmitted power (hence logarithms add) and the results for an arbitrary transmitter power can be obtained by scaling the measurements

$$
P=P_{\text {mes }}-P_{t}+P_{\text {eff }}[\mathrm{dBm}] .
$$

Here, $P_{\text {mes }}$ is the measured power level given in Appendix B, $P_{t}$ is the power level at the input to the antenna for the different systems (defined below), and $P_{\text {eff }}$ is the input power level to the antenna that would correspond to $1 \mathrm{MW}(90 \mathrm{dBm}) \mathrm{EIRP}$, and is given by the following

$$
P_{e f f}=\mathrm{EIRP}-G_{t}=90-G_{t} \quad[\mathrm{dBm}]
$$

where $G_{t}$ is the transmitter antenna gain. Recall that for the Eldorado Mountain site the transmitting antenna gain was $1.9 \mathrm{dBi}$, and for the Squaw Mountain site the transmitting antenna gain was $6.5 \mathrm{dBi}$. Therefore, for the Eldorado Mountain site

$$
P_{\text {eff }}=88.1[\mathrm{dBm}]
$$

and for the Squaw Mountain site

$$
P_{\text {eff }}=83.5[\mathrm{dBm}]
$$

$P_{t}$ is different for the different sites and the different frequencies used. For the Eldorado Mountain site

$$
\begin{aligned}
& P_{t}=20.6[\mathrm{dBm}] \text { for } 533 \mathrm{MHz} \\
& P_{t}=28.6[\mathrm{dBm}] \text { for } 772 \mathrm{MHz}
\end{aligned}
$$

and for the Squaw Mountain site

$$
\begin{aligned}
& P_{t}=28.6[\mathrm{dBm}] \text { for } 533 \mathrm{MHz} \\
& P_{t}=37.0[\mathrm{dBm}] \text { for } 772 \mathrm{MHz} .
\end{aligned}
$$


With these various values of $P_{t}$ and $P_{\text {eff }}$, the following expressions can be used to transform the measured power levels to the power level that would be received assuming 1 MW EIRP. For the Eldorado Mountain site

$$
\begin{aligned}
& P=P_{\text {mes }}-20.6+88.1[\mathrm{dBm}] \text { for } 533 \mathrm{MHz} \\
& P=P_{\text {mes }}-28.6+88.1[\mathrm{dBm}] \text { for } 772 \mathrm{MHz},
\end{aligned}
$$

and for the Squaw Mountain site

$$
\begin{aligned}
& P=P_{\text {mes }}-28.6+83.5[\mathrm{dBm}] \text { for } 533 \mathrm{MHz} \\
& P=P_{\text {mes }}-37.0+83.5[\mathrm{dBm}] \text { for } 772 \mathrm{MHz}
\end{aligned}
$$

In order to obtain the E-field strengths, the transformed power levels given in equations (16) through (19) need to be converted to power densities. Given the power in $\mathrm{dBm}$, the power density is given by the following:

$$
\mathscr{P}=\frac{1}{A_{\text {eff }}} \frac{10^{(P / 10)}}{1000} \quad\left[\mathrm{~W} / \mathrm{m}^{2}\right],
$$

where $A_{\text {eff }}$ is the effective area of the receiving antenna, which is a function of wavelength and the receiving antenna's gain [11]:

$$
A_{e f f}=\frac{\lambda^{2} 10^{(G, / 10)}}{4 \pi}\left[\mathrm{m}^{2}\right]
$$

where $G_{r}$ is the receiving antenna gain and is $1.9 \mathrm{dBi}(1.55)$ for all the measurements. $\lambda$ is the wavelength, which is equal to $0.563 \mathrm{~m}(1.85 \mathrm{ft})$ and $0.389 \mathrm{~m}(1.27 \mathrm{ft})$ for a frequency of $533 \mathrm{MHz}$ and $772 \mathrm{MHz}$, respectively. Thus, the effective areas for the two different frequencies are:

$$
\begin{array}{ll}
A_{e f f}=0.0391\left[\mathrm{~m}^{2}\right], & \text { for } 533 \mathrm{MHz} \text {, and } \\
A_{e f f}=0.0186\left[\mathrm{~m}^{2}\right], & \text { for } 772 \mathrm{MHz} .
\end{array}
$$

Once the power density is obtained, the E-field can be calculated from equation (2) given in Section 1.

Figures 11 through 48 show the measured E-field scaled to $1 \mathrm{MW}$ EIRP for the two proposed sites and the two different frequencies. Figures 11 through 20 are the measured E-field strengths for a transmitter on Eldorado Mountain operating at $533 \mathrm{MHz}$. Figures 11 and 12 are the measured data for the DOC Laboratories and the Table Mountain NRQZ, respectively, while figures 13 through 20 show the measured E-field strengths for various other locations throughout the Boulder area. It was necessary to perform measurements over a broader geographic area than just the DOC properties to validate the area-specific propagation models that formed the basis of this assessment. 
Figures 21 through 30 are the measured E-field strengths for a transmitter on Eldorado Mountain operating at $772 \mathrm{MHz}$. Figures 21 and 22 are the measured data for the DOC Laboratories and the Table Mountain NRQZ, respectively, while figures 23 through 30 show the measured E-field strengths for various other locations throughout the Boulder area.

Figures 31 through 38 are the measured E-field strengths for a transmitter on Squaw Mountain operating at $533 \mathrm{MHz}$. Figures 31 and 32 illustrate the measured data for the DOC Laboratories and the Table Mountain NRQZ, respectively, while figures 33 through 38 illustrate measured data for an area outside of Boulder and an area outside of Golden, Colorado.

Figures 39 through 46 are the measured E-field strengths for a transmitter on Squaw Mountain operating at $772 \mathrm{MHz}$. Figures 39 and 40 illustrate the measured data for the DOC Laboratories and for the Table Mountain NRQZ, respectively, while figures 41 through 46 illustrate measured data for an area outside of Boulder and an area outside of Golden, Colorado.

The rapid variation in the measured data is due to the multiple signal (multipath) reflections that arrive at the receiving antenna as the measurement vehicle is in motion. Some other interesting features present themselves in these data. For example, for the case when the transmitter is located on Eldorado Mountain, the results for the Table Mountain NRQZ location exhibit much less variability than the other measured locations. This is explained by the fact that the Table Mountain NRQZ site has, virtually, a LOS path from the Eldorado Mountain transmitter and, hence, there are very few objects (excluding the ground reflection) at the Table Mountain NRQZ that would cause multipath effects.

Figures 17 and 27 show results for the Eldorado Canyon route for a transmitter on Eldorado Mountain. Notice how the E-field strengths increase dramatically as the measurement vehicle emerged out of the canyon onto Highway 93. It should be noted that the field strengths in the canyon will most likely be higher than the measured results, if the Eldorado transmitter is raised to its proposed height of $115.5 \mathrm{~m}$ (380 ft), see Section 5. This is because shadowing in the canyon would be less. Figures 19 and 29 show results for the Greenbriar loop for a transmitter on Eldorado Mountain. These figures show measured data for both LOS and non-LOS paths. For the LOS path (on top of Shanahan Hill at Shanahan Ridge Park, around Fairview High School, and Southern Hills Junior High), field strengths of $1 \mathrm{~V} / \mathrm{m}$ and higher are observed. For the non-LOS portion of the loop, the field strengths drop to about $0.3 \mathrm{~V} / \mathrm{m}$.

The effects of moving automobiles are seen in figures 47 and 48 . These figures show measured data obtained at the intersection of Highway 93 and Highway 72, south of Boulder, for frequencies of $533 \mathrm{MHz}$ and $772 \mathrm{MHz}$, respectively. Notice the change in the variation of the measured E-field when the measurement vehicle and/or other vehicles on the road were either in motion or were stopped. In particular, note that when the measurement vehicle was parked or stopped at the light, the higher frequency data (figure 
48) exhibit more variation in the E-field strengths than do the lower frequency data. This is expected since scattering from automobiles would be more pronounced for shorter wavelengths (i.e., higher frequencies). These differences in the field variation are also due to the fact that higher frequency signals experience more rapid phase variation, which can alter how the multipath reflections add.

Propagation effects due to terrain features (LOS and non-LOS or shadowing) for a transmitter on Eldorado Mountain can readily be seen for the data collected for the $28^{\text {th }}$ Street route, the Broadway route, and the McCaslin loop (see figures 13 through 16 and figures 23 through 26). For example, on the $28^{\text {th }}$ Street route (figures 13 and 23) notice the very strong signal strength until the intersection of $28^{\text {th }}$ (Highway 36 ) and Broadway is reached. At that point the road dips into a valley and no LOS path is present (i.e., the road dips into a terrain shadowed region). Similar results for the Broadway route are observed (see figures 14 and 24). For this route we see strong signal strengths at the top of the Table Mountain NRQZ, but the signal decreases as the measurement vehicle drove off the top of Table Mountain. The field strengths stay low throughout the northern part of Boulder on Broadway (this part of the route is shadowed from Eldorado Mountain), and as the measurement vehicle approached Arapahoe Avenue, the field strengths increase. The trend of increasing field strengths continues as the vehicle emerged into a LOS situation on south Broadway. Finally, the McCaslin loop results are shown in figures $15,16,25$, and 26 . The variation in the E-field due to the terrain features was observed for this route as well. In particular, notice how the field strengths increase to about $1 \mathrm{~V} / \mathrm{m}$ when the measurement vehicle drove through NCAR's parking lot on the top of Table Mesa.

The measured E-field strengths at both the DOC Laboratories and at the Table Mountain NRQZ facility are examined next. Figures 12 and 22 show the measured E-field strengths at the Table Mountain NRQZ for a transmitter located on Eldorado Mountain for frequencies of $533 \mathrm{MHz}$ and $772 \mathrm{MHz}$, respectively. From these figures it is seen that the measured E-field strengths exceed the FCC's regulatory requirements, which is unacceptable for research applications at the Table Mountain NRQZ. Figures 11 and 21 show the E-field strengths measured at the DOC Laboratories for frequencies of $533 \mathrm{MHz}$ and $772 \mathrm{MHz}$, respectively. From these two figures, it is seen that the measured E-field strengths range from $0.1 \mathrm{~V} / \mathrm{m}$ to as high as $1 \mathrm{~V} / \mathrm{m}$. These high field strengths at the Broadway site could possibly have an adverse effect on the sensitive measurements that are performed on a routine basis at the DOC Laboratories, as discussed in Section 8.

Figures 32 and 40 show the measured E-field strengths at the Table Mountain NRQZ for a transmitter located on Squaw Mountain for frequencies of $533 \mathrm{MHz}$ and $772 \mathrm{MHz}$, respectively. From these figures it is seen that the measured E-field strengths do not exceed the FCC limits for the Table Mountain NRQZ.

The measured E-field strengths at the DOC Laboratories for a transmitter on Squaw Mountain are shown in figures 31 and 39. It is interesting to observe that data in these figures resemble a Rayleigh type of fading propagation channel, which is indicative of a non-LOS, multipath mobile environment $[27,28]$. 
The data presented in this section are for an EIRP of $1 \mathrm{MW}$. Some of the DTV channels have maximum power allocations of 1.64 MW EIRP. The E-fields presented here can be transformed to a $1.64 \mathrm{MW}$ EIRP by multiplying the results in all the figures by a factor of 1.3 , resulting in even higher E-field strengths than those presented here.

\section{COMPARISON OF MEASURED AND PREDICTED E-FIELD STRENGTHS}

The data in the last section show measured E-field strengths for the two proposed DTV tower sites at $1 \mathrm{MW}$ EIRP. The data were collected for a transmitter height of $3.66 \mathrm{~m}$ $(12.0 \mathrm{ft})$ on the cliff edge of Eldorado Mountain (not the proposed $116 \mathrm{~m}$ ( $380 \mathrm{ft}$ ) height), and for a transmitter height of $8.2 \mathrm{~m}(27 \mathrm{ft}$ ) at Squaw Mountain (not the proposed $60.96 \mathrm{~m}(200 \mathrm{ft})$ height). In order to verify any calculated E-field strengths at the proposed tower locations and heights, comparisons to measured data for the lower antenna heights are needed. In this section, calculated E-fields obtained from the ITM (Longley-Rice model) are compared to the measured data in the above section.

Using a $1 \mathrm{MW}$ EIRP and the same transmitter and receiver antenna heights as were used in the measurements, the E-field strengths for a transmitter located on Eldorado Mountain were calculated using the ITM. Contour plots of E-field strengths for the BoulderDenver area at $533 \mathrm{MHz}$, for both a horizontally and vertically polarized transmitting antenna, are shown in figures 49 and 50, respectively. Figures 51 and 52 show the contour plots of E-field strengths for the Boulder-Denver area at $772 \mathrm{MHz}$ for both a horizontally and vertically polarized transmitting antenna, respectively. The different colors on these contour plots indicate different E-field strengths.

Using the results shown in figures 49 through 52, specific locations can be directly compared to the routes that the measurement vehicle drove to collect the data in the previous section. Figure 53 shows the calculated E-field strengths for the $28^{\text {th }}$ Street route in Boulder for $533 \mathrm{MHz}$. These results were calculated using receiver latitudes/longitudes obtained from the GPS data set collected during the measurements. Upon comparing the measured (see figure 13) and predicted (or modeled) E-field strengths, excellent agreement is demonstrated. Both the measured and predicted field strengths are about $0.7 \mathrm{~V} / \mathrm{m}$ on the LOS portion of the route (before the Highway 36 intersection). It is also seen that both the measured and the predicted field strengths are about $0.02 \mathrm{~V} / \mathrm{m}$ on the non-LOS path portion of the route (Highway 36 to the Table Mountain NRQZ).

Notice, however, that the measured data have much more variability than the predicted field strengths. As mentioned above, the variability in the measured data is due to the vehicle's motion and the motion of the local objects relative to the measurement vehicle, as well as the fact that the measured data contain three-dimensional multipath effects. Reflections reaching the receiver from all directions are indicative of a true threedimensional multipath environment. Keep in mind that the predicted E-field strengths do not have local scatterers (i.e., buildings, cars, people, etc.) in the model. Only the terrain profile is taken into account. Also, the ITM uses only profile data on the bearing from 
the transmitter to the receiver location, referred to as the great circle path. Thus, multipath due to terrain features that are not in the path from the transmitter and the receiver will not be modeled (i.e., three-dimensional multipath effects are not modeled). With this noted, this comparison shows that the ITM predictions correlate very well to the measured data for both the LOS and non-LOS portions of this route.

Figure 54 shows the calculated E-field strengths for the Broadway route in Boulder. Upon comparing the measured E-field strengths (see figure 14) and modeled results, excellent agreement is again demonstrated. Both the measured and predicted field strengths are about $0.2 \mathrm{~V} / \mathrm{m}$ near the Table Mountain NRQZ. In the north Boulder part of the route, both the measured and predicted field strengths are about $0.02 \mathrm{~V} / \mathrm{m}$. Both results show that field strengths increase as the measurement vehicle climbed out of the shadowed region south of Arapahoe Avenue. Both results also show field strengths of $1 \mathrm{~V} / \mathrm{m}$ and higher on Highway 93.

Figure 55 shows the calculated E-field strengths for the McCaslin loop in the Boulder area. Upon comparing the measured (see figures 15 and 16) and modeled results, excellent agreement is again demonstrated. Both the measured and predicted field strengths are about $1 \mathrm{~V} / \mathrm{m}$ and higher for the Highway 93 portion of the route. Also notice that both the measured and predicted results show dips in the field strengths ranging from $0.01 \mathrm{~V} / \mathrm{m}$ to $0.1 \mathrm{~V} / \mathrm{m}$ for some of the non-LOS locations. Notice that both the measured and predicted results show the same behavior in the field strengths as the measurement vehicle drove to and from the top of the NCAR site, with the field strengths at the top of NCAR reaching values of $1 \mathrm{~V} / \mathrm{m}$. The observed dips in the field strengths seen going to and coming from the top of NCAR are caused by shadowing (non-LOS path) of Eldorado Mountain by Shanahan Hill (also called Shanahan Ridge) on this. portion of the route.

Figure 56 shows the calculated E-field strengths for the Table Mountain NRQZ. Upon comparing the measured (see figure 12) and modeled results, excellent agreement is demonstrated. Both the measured and predicted results show field strengths of about $0.2 \mathrm{~V} / \mathrm{m}$. Most of the locations at the Table Mountain NRQZ have a LOS path to the Eldorado transmitter, which results in the relatively small variations in the measured field strengths and in the almost constant value of the modeled data. The dips seen in both results correspond to one location at the Table Mountain NRQZ where a non-LOS path is present. Both the measured and modeled field strengths for a transmitter on Eldorado Mountain show that all locations on the Table Mountain NRQZ exceed the FCC regulatory limits given in table 2 .

Figure 57 shows the calculated E-field strengths for the DOC Laboratories. Upon comparing the measured (see figure 11) and modeled results, excellent agreement is demonstrated. E-field strengths between $0.5 \mathrm{~V} / \mathrm{m}$ and $1 \mathrm{~V} / \mathrm{m}$ are observed. The roads on this site are surrounded by buildings. This is reflected in the measured data and is highlighted in figure 11. The decrease in field strengths seen in the measured data due to building blockage of the signal is not apparent in the modeled data since the ITM prediction model does not take buildings into account in the calculations. There are a few locations on the site where non-LOS paths are present due to shadowing caused by 
Shanahan Hill and Table Mesa. At the shadowed location (or non-LOS location) both the measured and modeled results give the same field strength of about $0.05 \mathrm{~V} / \mathrm{m}$. Both these results show that the outside field strengths at the DOC Laboratories will be close to $0.5 \mathrm{~V} / \mathrm{m}$ to $1 \mathrm{~V} / \mathrm{m}$, which can possibly jeopardize the sensitive measurements that are performed on the site, see Section 8.

The Squaw Mountain transmitter location was analyzed next. Using a 1 MW EIRP with the same transmitter and receiver antenna heights used in the measurements, the E-field strengths for a transmitter located on Squaw Mountain were calculated. Contour plots of E-field strengths for the Boulder-Denver area for $533 \mathrm{MHz}$ for both a horizontally and vertically polarized transmitting antenna are shown in figures 58 and 59 , respectively. Figures 60 and 61 show the contour plots of E-field strengths for the Boulder-Denver area for $772 \mathrm{MHz}$ for both a horizontally and vertically polarized transmitting antenna, respectively. Once again the different colors correspond to different E-field strengths.

Figure 62 shows the calculated E-field strengths for the Table Mountain NRQZ for the transmitter located at Squaw Mountain. Upon comparing the measured E-field strengths (see figure 32) and modeled results, good agreement is demonstrated. Both the measured and predicted results show field strengths of about $1 \mathrm{mV} / \mathrm{m}$ to $3 \mathrm{mV} / \mathrm{m}$. Both the measured and modeled results show that field strengths for all locations on the Table Mountain NRQZ are below the FCC regulatory limits, given in table 2. Thus, the measured and modeled data show that for Squaw Mountain, a transmitter antenna height of $8.2 \mathrm{~m}(26.91 \mathrm{ft})$ does not violate the Table Mountain NRQZ. Predicted field strengths for the actual proposed antenna heights are discussed in the next section.

There are a few situations where the measured and modeled results do not agree very well. This occurs in deep shadow regions. The reason why the ITM fails to correctly predict the field in deep shadow regions is explained as follows. The ITM (or any irregular terrain model for that matter) is considered a quasi-two-dimensional model. This means that irregular terrain models use only the terrain profile for the bearing between the transmitter and receiver. Terrain features and objects that would scatter and/or reflect radio waves that are not on the bearing are not used in the calculation of the field strengths. It is possible that in a deeply shadowed location, the majority of the energy reaching the receiver is from scattering and reflections from objects off of the bearing direction (i.e., mountains, hills, buildings, cars, etc.). In such a deep fade region, the ITM field strength calculations are based only on a diffracted path. Thus, accounting for only the diffracted path and neglecting the other paths results in errors in field strength predictions.

This point is illustrated in figures 63 and 64 . These figures show the predicted field strengths for a transmitter location on Squaw Mountain for the McCaslin route and the Boulder-to-Golden route. By comparing these figures to the experimental results presented in figures 36 and 35 , respectively, it is seen that for the moderate shadow regions the measured and modeled E-field strengths are similar. For the deep shadow region the two results differ. The modeled results predict lower field strengths than those from the measured data. 
For the McCaslin route, strong signal strengths are observed in the middle part of the route, and as the route turns back towards the Flatirons, deep shadowing regions are observed. For the Boulder-to-Golden route, strong signal strengths are observed on Indiana Avenue. However, once the route turns back to Highway 93, deep shadowing is observed in both results. This difference is due to the fact that the ITM does not take into account the full three-dimensional terrain features, and as a result, it underestimates the field strengths.

Once again, this situation only occurs in deep shadow regions. Figures 53, 54, and 62 show that for moderate shadow regions (the Table Mountain NRQZ and the Broadway route), the ITM predictions compare very well to the measured values, illustrating the accuracy of the ITM for moderate shadow regions. In any event, ITM predictions are conservative, since in deep shadow locations the predicted field strengths are less than those that were measured.

\section{PREDICTED E-FIELD STRENGTHS FOR THE PROPOSED TOWER HEIGHTS}

The previous section demonstrated that the ITM model can accurately (except in deep shadow regions, as explained above) predict field strengths for both LOS and non-LOS locations for a given antenna height. Therefore, this model was used with confidence to calculate and predict field strengths for the actual proposed antenna heights for both the Eldorado Mountain and Squaw Mountain sites.

Figures 65 and 66 show contour plots of the E-field strengths for the Boulder-Denver area for a transmitter located at Eldorado Mountain for $533 \mathrm{MHz}$ and $772 \mathrm{MHz}$, respectively. The results in these figures are for horizontal polarization with a transmitter

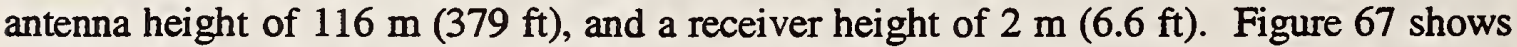
the E-field strengths at the Table Mountain NRQZ for $533 \mathrm{MHz}$ and $772 \mathrm{MHz}$. From this figure it is seen that for the Table Mountain NRQZ, the predicted field strengths are about $0.2 \mathrm{~V} / \mathrm{m}$. This value, based upon transmission from Eldorado Mountain, exceeds the FCC regulatory limit by about an order of magnitude (or by about a factor of ten in E-field strength). This level of excess would thus jeopardize the research at the Table Mountain NRQZ.

Figure 68 shows the E-field strengths at the DOC Laboratories for $533 \mathrm{MHz}$ and $772 \mathrm{MHz}$. From this figure it is seen that for the DOC Laboratories, the predicted field strengths approach $0.5 \mathrm{~V} / \mathrm{m}$ to $1 \mathrm{~V} / \mathrm{m}$ at various locations. These field strengths are high enough to affect some of the sensitive measurements performed on a routine basis at the DOC Laboratories, see Section 8.

The Squaw Mountain site is analyzed next. Figures 69 and 70 show contour plots of the E-field strengths for the Boulder-Denver area for a transmitter located at Squaw Mountain for $533 \mathrm{MHz}$ and $772 \mathrm{MHz}$, respectively. The results in these figures are for horizontal polarizations with a transmitter antenna height of $60.96 \mathrm{~m}(200 \mathrm{ft})$, and a receiver height of $2 \mathrm{~m}(6.56 \mathrm{ft})$. Figure 71 shows the field strengths at the Table 
Mountain NRQZ for $533 \mathrm{MHz}$ and $772 \mathrm{MHz}$. The difference in field strengths for the two frequencies is due to the fact that the amplitude of the diffracted wave decreases with increasing frequency. From this figure it is seen that for the Table Mountain NRQZ, the predicted field strengths are about $0.1 \mathrm{mV} / \mathrm{m}$ to $0.2 \mathrm{mV} / \mathrm{m}$. These field strengths are well within the FCC Table Mountain NRQZ regulatory limits. Thus, a transmitter can be located at Squaw Mountain without violating the FCC regulatory limits or jeopardizing the research efforts at the Table Mountain NRQZ.

Even though the DTV frequency allocation is in the $400 \mathrm{MHz}$ to $700 \mathrm{MHz}$ band, there is the possibility that broadcasters could decide to broadcast DTV signals at their currently assigned NTSC frequencies [29]. This means that some DTV transmissions could be below $400 \mathrm{MHz}$. Since propagation loss can decrease with frequency, it is important to calculate field strengths that would result from broadcasting at the lower NTSC frequencies. Field strengths were calculated at $54 \mathrm{MHz}$ (the lowest NTSC frequency) at the Table Mountain NRQZ and at the DOC Laboratories with the transmitter on Eldorado Mountain and Squaw Mountain. These results are shown in figures 67,68, and 71. In figure 67 , it is seen that the $54 \mathrm{MHz}$ results are very similar to the $533 \mathrm{MHz}$ and 772 $\mathrm{MHz}$ results for a transmitter on Eldorado Mountain. The similarity in the results for all three frequencies is due to the fact that the Table Mountain NRQZ is LOS from Eldorado Mountain. For a transmitter on Eldorado Mountain, the E-field strengths for all three frequencies exceed the FCC limit. In figure 71 (transmitter on Squaw Mountain), it is seen that the $54 \mathrm{MHz}$ field strengths are somewhat larger than those at the other two frequencies (due to diffraction effects). As seen in table 2, the FCC NRQZ limit is smaller for $54 \mathrm{MHz}$. The predicted E-field strengths for a transmitter on Squaw Mountain at $54 \mathrm{MHz}$ do exceed this FCC limit.

Here again, the data presented in this section are for an EIRP of $1 \mathrm{MW}$. Since some DTV broadcasters have received allocations to transmit at $1.64 \mathrm{MW}$ (see table 1), predicted field strengths for 1.64 MW are needed. The E-field presented here can be converted to a $1.64 \mathrm{MW}$ EIRP level by multiplying the results in all the figures by a factor of 1.3 , resulting in even higher E-field strengths than those presented here. This would result in even greater E-field strengths in the Boulder-Denver area, and would cause even greater interference at both of the DOC facilities due to a transmitter located on the Eldorado Mountain site.

\section{DTV E-FIELD STRENGTH REQUIREMENT}

Measured and modeled results to this point have assumed either a $2 \mathrm{~m}(6.6 \mathrm{ft})$ or $2.95 \mathrm{~m}$ $(9.68 \mathrm{ft})$ receiving antenna height. Designs of tower locations and power requirements are based on the FCC's $9.14 \mathrm{~m}$ (30 ft) receiver antenna height assumption. For acceptable DTV reception, the FCC has recommended a minimum E-field strength of $41 \mathrm{~dB} \mu \mathrm{V} / \mathrm{m}$ $(0.11 \mathrm{mV} / \mathrm{m})$ at a $9.14 \mathrm{~m}(30 \mathrm{ft})$ receiver antenna height [1]. The ITM prediction model can be used to determine at what locations in the Boulder-Denver area the $41 \mathrm{~dB} \mu \mathrm{V} / \mathrm{m}$

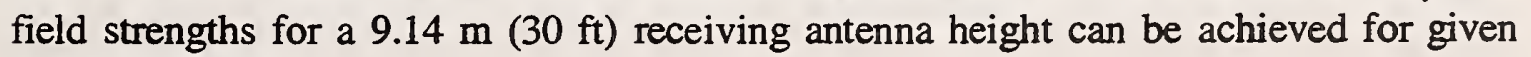
tower locations. 
Figures 72 and 73 show the contour plot of the predicted field strengths for the BoulderDenver area for a transmitter located at Eldorado Mountain for frequencies of $533 \mathrm{MHz}$ and $772 \mathrm{MHz}$, respectively. These results were calculated for a transmitter antenna

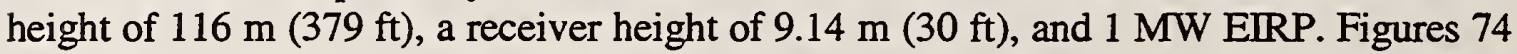
and 75 show the contour plots of the predicted field strengths for the Boulder-Denver area for a transmitter located on Squaw Mountain for $533 \mathrm{MHz}$ and $772 \mathrm{MHz}$, respectively. These results were calculated for a transmitter antenna height of $60.96 \mathrm{~m}$

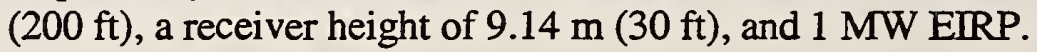

One might ask how transmitter locations would affect DTV reception. Of interest here are the locations where the $41 \mathrm{~dB} \mu \mathrm{V} / \mathrm{m}(0.11 \mathrm{mV} / \mathrm{m}) \mathrm{FCC}$ field strength is exceeded. If 41 $\mathrm{dB} \mu \mathrm{V} / \mathrm{m}$ is exceeded, DTV reception is possible according to the FCC's assumptions. The data shown in figures 72 through 75 are re-plotted to illustrate where the FCC's minimum field strength is met or exceeded. These new results are shown in figures 76 through 79. In figures 76 through 79 , the white areas in the plot correspond to where the FCC's minimum field strength is exceeded. The blue shaded areas indicate areas with field strengths that are below the FCC's minimum field strength recommendation for DTV reception. These blue areas indicate that DTV may not be received in these areas, as indicated by the FCC's recommendation. Note that as far as the FCC's $41 \mathrm{~dB} \mu \mathrm{V} / \mathrm{m}$ $(0.11 \mathrm{mV} / \mathrm{m})$ recommendation is concerned, it is seen in figures 76 through 79 that Squaw Mountain covers basically the same area as a transmitter on Eldorado Mountain, for the purposes of DTV reception with a $9.14 \mathrm{~m}(30 \mathrm{ft})$ height fixed receiving antenna. Based on the results in the previous section, while the Squaw Mountain site covers the same area as the Eldorado Mountain site, the Squaw Mountain site does not violate the regulatory field strength limits protecting the Table Mountain NRQZ. The Squaw Mountain site would also provide additional protection to the DOC Laboratories. Note that if a $1.64 \mathrm{MW}$ EIRP is used, the $41 \mathrm{~dB} \mu \mathrm{V} / \mathrm{m}$ recommendation limits would extend the DTV coverage area.

\section{ANTENNA PATTERN EFFECTS}

All the predicted E-field strengths presented in this report were obtained with the assumption that the transmitting antenna was an omnidirectional antenna. The measurement data presented here were collected with antennas with moderate antenna patterns, i.e., a $1.9 \mathrm{dBi}$ omni-azimuthal directional antenna on the Eldorado Mountain site and a $6.5 \mathrm{dBi}$ log-periodic antenna on the Squaw Mountain site. The actual antennas that will be used for the proposed tower will have some type of antenna pattern associated with them. The ITM propagation model presented here has a capability of using any transmitter antenna pattern in the prediction. Unfortunately, at this time we do not have information on the antenna patterns. At a later date, when and if such antenna patterns are available, new predicted $E$-field strengths will be calculated.

With this noted, the results in this report can still be used once the actual antenna patterns are known, as explained in the following. When LOS propagation conditions are present, the simple free-space calculation given in equation (2) can be used to determine the Efield strengths without the need to resort to the ITM prediction model. LOS situations 
occur for the Eldorado Mountain site for the Boulder area. For a transmitter location on Eldorado Mountain, many locations throughout the Boulder area (including the DOC Laboratories and the Table Mountain NRQZ) exhibit LOS paths. The ability of the simple free-space calculation given in equation (2) to predict E-field strengths in a LOS situation is illustrated in figures 11 and 12. These figures show the measured E-field strengths for a transmitter located on Eldorado Mountain for the DOC Laboratories and the Table Mountain NRQZ. Notice that the free-space calculation correlates very well with the measured data. There is some variability in the measured data, due to multipath effects that the free-space model cannot account for, but typical E-field strengths at both sites are very well accounted for with the free-space model.

Thus, once the actual antenna patterns are known, the EIRP in any direction can be obtained, and equation (2) can be used to estimate the E-field strengths in the LOS situation. An alternative approach is to simply scale the results in this report by the appropriate EIRP for an antenna at a given location and a given direction. From the results in figure 12, it is seen that, for a transmitter on Eldorado Mountain, a reduction of $23 \mathrm{~dB}$ in either the transmitter power level or in the antenna gain is needed to achieve the FCC NRQZ limit.

\section{EFFECTS OF BROADBAND TRANSMISSION ON SENSITIVE MEASUREMENTS}

Historically, the radio science programs in the former National Bureau of Standards (those programs are now in NIST and ITS) drove the need to establish a field site remote from their Washington, DC, laboratories. Boulder was chosen over several contenders because of the relatively quiet. radio-frequency electromagnetic environment, which would allow for more accurate measurements and experiments; the varied geographic terrain, which would facilitate the study of radio propagation; and the presence of a major university (the University of Colorado) as well as the proximity of a large city (Denver). The technical mission of the Boulder labs was to develop the most accurate possible reference standards and calibration services to insure compatibility of the emerging radio, microwave, and radar technologies that the nation was then developing. Radio propagation research was fundamental to this work, and as higher frequencies were explored, the interactions between electromagnetic waves and atmospheric layers led to new directions of research. This work was, and continues to be, fundamental to all of the advances made in radio-frequency technology. NIST's research on accurate measurement systems, and its development of standards and calibration services for the Nation, play an essential role in making possible the technologies that we use daily such as wireless communication, high-speed digital technology, time-and-frequency synchronization, satellite communications, radar, and optical fiber communications links, to name only a few.

Radio research projects performed outdoors often require that receivers be constructed to receive wideband signals. Furthermore, those receivers must often be constructed with high performance, low noise amplifiers (LNAs) in the so-called front-end, just after the receive antenna. The requirement for wide bandwidth means that such receivers integrate 
the total energy across a wide part of the spectrum. The LNAs used in those front ends are susceptible to nonlinear effects due to the integration of large amounts of energy across wide portions of spectrum. This effect has been documented in Reference [30]. Simply put, a wideband radio receiver with a sensitive amplifier in the front end will experience a condition known as overload in the presence of strong signals that are not only present at the desired frequency, but that are also substantially off-tuned from the center frequency. Overload of LNAs can occur in the presence of strong signals even if those signals are as much as a few hundred megahertz off the receiver's center frequency [30]. When an LNA goes into an overload condition, its gain is greatly reduced. The result is loss of the desired signal or signals.

Because of the Government's need to be able to perform radio research in outdoor locations with wideband, sensitive receivers, the only practical and general technical solution is to limit the total power originating from local signal sources. The limitation must be adequate to ensure that the cumulative (integrated) amount of energy that is coupled into the sensitive front end amplifiers from all local signals is low enough not to overload the receiver front ends. This is one requirement that has caused the Federal Government to create and maintain the Table Mountain NRQZ.

The grandfathered signal levels of television channels $4,6,7$, and 9 provide an example of the difficulties that high signal strengths within the NRQZ produce for sensitive radio measurement systems. These grandfathered signal levels within the NRQZ range from about $3 \mathrm{~dB}$ above the limit to as much as $13 \mathrm{~dB}$ above the limit. When the spectrum survey in this report was performed, it was necessary to insert $10 \mathrm{~dB}$ of attenuation into the measurement system's front end to prevent overload by these television signals. That is, the sensitivity of the entire measurement system had to be degraded by $10 \mathrm{~dB}$ to prevent saturation due to these signals. This attenuation had to be inserted for all measurements in the television bands between $50 \mathrm{MHz}$ and $88 \mathrm{MHz}$ (due to strong $\mathrm{E}$ fields from channels 4 and 6), and also between $170 \mathrm{MHz}$ and $220 \mathrm{MHz}$ (due to E-fields from channels 7 and 9). Signal strengths below the NRQZ limits usually require no attenuation in the receiver system front end, and enable more sensitive and more accurate measurements.

Similar measurement degradation will impair the usefulness of measurements and experiments in other bands, to the extent that signals in those bands exceed the NRQZ limits. Mobile signals that exceed the NRQZ limits may provide some technical opportunities for ameliorative work-arounds, but broadcast signals that are effectively present on a continuous basis do not allow such work-arounds. Receivers in those bands are permanently impaired by the incident signals, as happened for the horizontally polarized spectrum survey measurements described above. This integrating effect of several frequencies transmitting simultaneously has adverse effects on several types of research measurement efforts that occur at both the Table Mountain NRQZ and at the DOC Lajoratories.

There are no Federal, state, or local laws or regulations, corresponding to the NRQZ restrictions, that protect the DOC Laboratories. However, the level of EM-field emissions from the proposed towers may be high enough on-site to compromise some experimental 
and metrological programs. The E-field strengths from a single station transmitting at 1 MW EIRP from Eldorado Mountain will result in $0.5 \mathrm{~V} / \mathrm{m}$ to $1 \mathrm{~V} / \mathrm{m}$ over the entire site. To date, six stations have been given permission to operate at 1.6 MW EIRP, which, upon scaling the results above to the 1.6 MW EIRP level, results in an E-field-strength on-site of $0.6 \mathrm{~V} / \mathrm{m}$ to $1.3 \mathrm{~V} / \mathrm{m}$. Furthermore, the potential tower operators are soliciting existing TV and FM stations to move their transmitters to the Eldorado Mountain site. Such a concentration of transmitters will have a more adverse effect because of the even broader spectral coverage. Cutting-edge physics, metrology, and radio research conducted at the DOC Laboratories for the benefit of industry and the Nation could be compromised. Some examples of programs sensitive to electromagnetic fields are given below.

The research and antenna calibrations conducted at the NIST Open Area Test Site (OATS) groundscreen facility is critical for support of a very broad cross section of industry. Literally the entire U.S. electronics industry, including all manufacturers of computer and information technology, communications equipment, medical electronic equipment, electronic test equipment, television and other electronic entertainment equipment, certain appliances, industrial equipment, and many other categories, must test their product's conformity to national and international standards. To be recognized, these tests must be traceable to NIST, and the standards themselves are developed in an international forum with NIST providing the technical expertise and experimental validation to advance the cause of U.S. industry. All tests and calibrations, and experimental research performed on the groundscreen are performed from $30 \mathrm{MHz}$ to $1 \mathrm{GHz}$, and the DTV bands will cover a significant portion of this band $(476 \mathrm{MHz}$ to $698 \mathrm{MHz}$ ). The comparatively strong field strengths from the DTV towers (on Eldorado Mountain) will literally override the signals that NIST generates and uses in its calibrations and experiments. Furthermore, the broad nature of the signals is such that it will not be possible to shift to an adjacent null in the spectrum and obtain an approximate measurement. NIST research that supports ANSI, ITI, IEC/CISPR, as well as a broad cross section of industry, will be compromised.

Interference problems with DTV signals are currently being experienced by commercial electromagnetic compatibility (EMC) laboratories where EMC measurements and calibrations are performed routinely at other OATS facilities, as indicated by Roland Gubisch [31], the vice-chair of the United States Council of EMC Laboratories (USCEL). USCEL was developed to aid U.S. industry with EMC standards and testing procedures. Gubisch indicated [31] that DTV signals have had adverse effects on an OATS in the Boston, Massachusetts, area. At this OATS and other sites, field strengths as low as $0.0002 \mathrm{~V} / \mathrm{m}(46 \mathrm{~dB} \mu \mathrm{V} / \mathrm{m})$ have interfered with tests. The $0.0002 \mathrm{~V} / \mathrm{m}$ is the FCC radiated emission limit for unintentional radiators [32]. The DTV signals act as $6 \mathrm{MHz}$ wideband noise in the $500 \mathrm{MHz}$ to $700 \mathrm{MHz}$ frequency range, hindering the ability to test and certify electronic products on these outdoor sites. The broadband noise nature of the $6 \mathrm{MHz}$ DTV signals can be seen in the 2001 spectrum survey for the DTV Channel 32 (578 MHz to $584 \mathrm{MHz}$ ) transmission, see figure A.41. In fact, Gubisch has informed NIST that USCEL members have experienced problems on outdoor facilities when DTV E-field levels are even lower than $0.0002 \mathrm{~V} / \mathrm{m}$. The broad $6 \mathrm{MHz}$ signals from each station and the even broader spectrum saturation from strings of adjacent channels are 
preventing EMC test laboratories from making measurements in outdoor facilities that are prescribed by international standards. This is forcing commercial labs to use much more costly and potentially less accurate special indoor facilities such as semi-anechoic chambers. However, NIST as the national standards laboratory that provides the basis for and harmonization of all national measurements, must maintain the smallest uncertainties possible in its measurements.

Other examples of the types of interference that would be experienced at the DOC Laboratories are as follows. In order to simulate potential effects of instrumentation of the proposed DTV towers on Eldorado Mountain, experiments were performed in two different laboratories at NIST. In these experiments E-field strengths of $0.1 \mathrm{~V} / \mathrm{m}$, $0.5 \mathrm{~V} / \mathrm{m}$, and $1.0 \mathrm{~V} / \mathrm{m}$ (the values that would be present at the DOC Laboratories as discussed above) were generated in two different research laboratories. The first laboratory was in the Optoelectronics Division, the Sources and Detectors Group. This group is developing standards and measurement systems for optical intensity noise of laser transmitters and optical fiber amplifiers used in optical communications systems. These consist of both laboratory and transfer standards. In the study, E-field strengths of $0.1 \mathrm{~V} / \mathrm{m}, 0.5 \mathrm{~V} / \mathrm{m}$, and $1.0 \mathrm{~V} / \mathrm{m}$ were radiated onto optical noise instrumentation at frequencies of $400 \mathrm{MHz}$ to $700 \mathrm{MHz}$. This frequency range falls within the broad frequency range of interest for noise studies, which presently is $100 \mathrm{MHz}$ to $4.1 \mathrm{GHz}$ and higher. For field strengths of $0.1 \mathrm{~V} / \mathrm{m}$, the noise floor of the instrumentation rose between $7 \mathrm{dBm} / \mathrm{Hz}$ and $10 \mathrm{dBm} / \mathrm{Hz}$ within this frequency range, a significant amount. At field strengths of $0.5 \mathrm{~V} / \mathrm{m}$ the noise floor rose by $15 \mathrm{dBm} / \mathrm{Hz}$ to $33 \mathrm{dBm} / \mathrm{Hz}$, a large and disturbing amount. At field strengths of $1 \mathrm{~V} / \mathrm{m}$ the noise floor rose by $22 \mathrm{dBm} / \mathrm{Hz}$ to $43 \mathrm{dBm} / \mathrm{Hz}$, a significant amount. Without additional shielding of the affected equipment, the resultant increase in the noise floor would prevent NIST from performing low intensity noise measurements, in this frequency range, that are important in noise studies. Presently, it is not known how well additional shielding would diminish this problem. Such a result can only be determined experimentally.

The second experiment was performed in the Time and Frequency Division of NIST. In this division, the Atomic Standards Group, Network Synchronization Group, and Time and Frequency Service Group use GPS signals for the following: (1) to contribute the NIST clock (frequency standards) data to the computation of TAI (International Atomic Time) and UTC (Coordinated Universal Time), (2) to compare UTC as realized at NST, to the frequency standards of other remote laboratories (such as the U.S. Naval Observatory, the National Physical Laboratory of the United Kingdom, the PhysikalischTechnische Bundesanstalt in Braunschweig, Germany, etc.), and (3) to provide time and frequency dissemination/calibration service to industry and research institutions. In the study, E-field strengths of $0.1 \mathrm{~V} / \mathrm{m}$ and $0.5 \mathrm{~V} / \mathrm{m}$ at $613.8 \mathrm{MHz}$ and $787.7 \mathrm{MHz}$ were incident onto the antennas for three different types of GPS receivers. The antennas were located on the roof of the main building at the DOC Laboratories, see figure 80 . This figure also illustrates the LOS path that would be present from the Eldorado Mountain tower site. These two frequencies correspond to the first subharmonic of the GPS L2 $(1227.6 \mathrm{MHz})$ and GPS LI (1575.42 MHz) frequencies. Due to nonlinearity effects of the GPS receiver's LNA (low noise amplifier), the $613.8 \mathrm{MHz}$ and $787.5 \mathrm{MHz}$ signals at 0.5 $\mathrm{V} / \mathrm{m}$ saturated the front end of the GPS receiver, resulting in loss of GPS signal lock by 
the receiver. When the second harmonics of these frequencies were greater than $-136 \mathrm{dBm}$ as received by the GPS antennas, the receiver could not lock on the GPS signal. Once the E-field strength was reduced to $0.1 \mathrm{~V} / \mathrm{m}$ the receiver was able to lock on the GPS signal.

The above examples represent only a sample of possible and likely negative effects of higher levels of ambient electromagnetic fields in this frequency range on DOC Laboratory programs in the Boulder, Colorado, area. Other technical programs at NIST, as well as NOAA and ITS programs, may also be impacted.

\section{SUMMARY AND CONCLUSION}

In this report, we have analyzed the expected E-field strengths in the Boulder area from two proposed terrestrial DTV transmitter locations, the Eldorado Mountain site and the Squaw Mountain site. The Eldorado Mountain and Squaw Mountain sites were chosen in this study because these two possible sites bound the propagation environment that would occur at both the Table Mountain NRQZ and the DOC Laboratories. The Eldorado Mountain site affords substantial line-of-sight coverage over the Boulder area, and the Squaw Mountain site affords only indirect (diffractive) coverage over the same area. The other possible tower sites fall between these two types of propagation conditions. The proposed transmitter tower heights for the two sites were obtained from either the landowners or public documents.

In this analysis, measurements of the E-field strengths for a transmitter located at each of these sites were performed. These measured data were then compared to predicted Efield strengths obtained from the ITS ITM propagation model. The predicted field strengths from the two transmitter locations matched well with measured strengths from those locations at frequencies near both ends of the existing UHF television band. This indicates that the ITM predictions are reliable, and can be used with confidence in predicting the strengths that might be received at any given location in the area (with the exception of very deep shadowed regions) for any given transmitter and receiver heights.

The ITS ITM propagation model was then used to predict the E-field strengths in the Boulder area for the actual proposed transmitter antenna heights of two possible transmitter locations, Eldorado Mountain and Squaw Mountain. The E-field strengths were calculated based on 1.0 MW EIRP. Once the E-field strengths are obtained for 1.0 MW EIRP, the E-field strengths can be scaled to any desired transmitter power level. With these predictions, we were able to determine the E-field strengths at both the DOC Laboratories and at the Table Mountain NRQZ. The results presented here show that at the Table Mountain NRQZ, the predicted E-field strengths are about $0.3 \mathrm{~V} / \mathrm{m}$ for a transmitter on Eldorado Mountain at 1.0 MW EIRP. This number exceeds the FCC's regulatory (47 CFR 73.1030) limit by about an order of magnitude. At that level, the research at the Table Mountain NRQZ will be compromised. The results also show that the E-field strengths at the DOC Laboratories for a transmitter located on Eldorado Mountain are about $1 \mathrm{~V} / \mathrm{m}$ for 1.0 MW EIRP. These field strengths are high enough to possibly jeopardize the sensitive measurements done on a routine basis at the DOC Laboratories, as discussed in Section 8. On the other hand, the results presented here 
show that at the Table Mountain NRQZ, the predicted E-field strengths are about $0.002 \mathrm{~V} / \mathrm{m}$ for a transmitter located on Squaw Mountain for 1.0 MW EIRP. These field strengths are well within the FCC's Table Mountain NRQZ regulatory (47 CFR 73.1030) limit. Thus, the results presented here indicate that a transmitter could be located at Squaw Mountain without violating the FCC's regulatory limit or jeopardizing the research efforts at the Table Mountain NRQZ.

As discussed above, the measured and modeled data presented in this report are for an EIRP of $1 \mathrm{MW}$. As indicated in table 1, some of the DTV channels have maximum power allocations of 1.64 MW EIRP. The E-field strengths presented here can be transformed to a $1.64 \mathrm{MW}$ EIRP by multiplying the data shown in all the figures by a factor of 1.3 (which would increase the E-field strengths by $30 \%$ ). This would result in even higher E-field strengths in the Boulder-Denver area than those presented here, and would cause even greater interference at both the DOC facilities due to a transmitter located on the Eldorado Mountain site. After scaling the results in this report to the current maximum EIRP levels (1.64 MW EIRP), the E-field strengths at both the Table Mountain NRQZ and DOC Laboratories can be determined for this maximum transmitter power level. The E-field strengths at the Table Mountain NRQZ would be about $0.4 \mathrm{~V} / \mathrm{m}$ for a transmitter on Eldorado Mountain with $1.64 \mathrm{MW}$ EIRP, and the E-field strengths at the DOC Laboratories would be about $1.3 \mathrm{~V} / \mathrm{m}$ for 1.64 MW EIRP. In Reference [1], the FCC indicates that in the future, adjustments to the allocated power levels may be granted under some situations, in order to allow power levels higher than $1.64 \mathrm{MW}$. The FNPRM [5] indicated maximum ERP of $5 \mathrm{MW}$ (or $8.2 \mathrm{MW}$ EIRP). If these high power levels are granted, the result would be even higher E-field strengths in the BoulderDenver area than those presented here.

In this report we also present data from a recent spectrum survey of the Table Mountain NRQZ. The results of this spectrum survey indicate that at the time of the survey (late 1998 and April 2001) the requirements of 47 CFR 73.1030 were being met by applicable signals at the Table Mountain NRQZ. The site therefore continues to be a useful and necessary location for present and future radio experiments. We also present results of a spectrum survey performed at the DOC Laboratories, illustrating a generally low level of ambient electromagnetic fields.

For DTV reception, the FCC specifies a minimum E-field strength of $41 \mathrm{~dB} \mu \mathrm{V} / \mathrm{m}$ $(0.11 \mathrm{mV} / \mathrm{m})$ for a receiver antenna at a height of $9.14 \mathrm{~m}(30 \mathrm{ft})$. Using the ITM prediction model, we also predicted the coverase areas where the FCC's minimum field strength for acceptable reception is met or exceeded. From the results shown here, it is seen that the two proposed transmitter locations (Eldorado Mountain and Squaw Mountain) have basically the same DTV coverage areas. However, the data in these results show that a transmitter on Squaw Mountain will not violate the FCC regulatory limits protecting the Table Mountain NRQZ.

The models and measurements discussed in this report can aid in determining whether the minimum field strength requirement of $41 \mathrm{~dB} \mu \mathrm{V} / \mathrm{m}$ can be achieved at various locations. However, another very important consideration for DTV (and any digital communication system, for that matter) is multipath effects. Multipath effects result in bit error rates 
(BER), or data error, in digital systems [33-39]. These effects can and do occur with DTV. The multipath issue is not isolated to the outdoor propagation environment. The multipath effects for an indoor propagation environment (i.e., a signal propagating to a TV antenna inside a house) can be equal or more critical [6, 40-44]. The indoor multipath issue is confronted in the following manner. In laying out the recommendations for DTV system designs (i.e., the Advanced Television Systems Committee (ATSC) standardization process), receiving antennas were assumed to be located on the outside of homes at an antenna height of $9.14 \mathrm{~m}(30 \mathrm{ft})$. However, this may not be possible for one reason or another (e.g., some communities have ordinances or covenants against external TV antennas). As a result, receiving antennas may be placed inside homes, either on top of TV sets or in attics. DTV signals propagating into homes will reflect off of surfaces and objects in the home, resulting in substantial multipath. This indoor multipath issue can have an adverse effect on the quality of service for DTV systems. More detailed studies are needed in order to determine whether the multipath environment from the two proposed sites is substantially different in order to assess the ultimate location of the antenna towers. Such a study can help in the assessments of the DTV receiver standards, in order to determine whether the indoor and outdoor multipath problem will affect the quality of service of terrestrial DTV systems and affect terrestrial DTV proliferation in the marketplace. This is important because of the issue of the encumbrances on the analog spectrum (i.e., channels 52 through 69), which are scheduled to be returned for other uses at the end of the DTV transition.

Furthermore, in a recent report [6], the ATSC Task Force has discussed the indoor DTV reception problem. This report includes reviews of the results of recent field tests of DTV reception in and around several major metropolitan areas in North and South America. For example, in the Washington, DC-Baltimore, Maryland, metroplex, it notes that DTV reception success fell from $75 \%$ (on average) of all outdoor antenna sites with $9.14 \mathrm{~m}$ (30 ft) antennas to $32 \%$ of all indoor antenna sites. (The indoor sites were preferentially chosen for adequate DTV electric field strengths outdoors, at the $9.14 \mathrm{~m}$ antenna height.) A considerable portion of the report is devoted to a discussion of potential improvements in DTV receiver and antenna technologies that would be likely to enhance DTV reception with indoor (and outdoor) antennas. Short of these improvements, the report lays out two possible options to improve indoor reception. The first option would be to lower the maximum data rate. The second option would be to increase the E-field strengths to make indoor reception more robust, by increasing DTV transmitters' ERPs. The ATSC report suggests that in order to overcome the indoor antenna problem, field strengths at the 9.14 $\mathrm{m}(30 \mathrm{ft}$ ) reference height may need to be increased substantially to $97 \mathrm{~dB} \mu \mathrm{V} / \mathrm{m}$. This is an increase of $56 \mathrm{~dB}$ over the FCC's $41 \mathrm{~dB} \mu \mathrm{V} / \mathrm{m}$, which is a factor of approximately 631 in field strength. This $56 \mathrm{~dB}$ increase can be obtained by either substantially reducing the coverage area of DTV reception or by increasing the power by $56 \mathrm{~dB}$, clearly an unrealistic scenario. Obviously, if transmitter power levels are increased to compensate for the indoor problem, higher E-field strengths than those presented in this report could occur at both the DOC Laboratories and at the Table Mountain NRQZ, as well as at other areas throughout Boulder.

The studies in this report were carried out for two individual frequencies. In reality the DTV transmitter tower will have systems transmitting simultaneously over the entire 
band of frequencies shown in table 1. As discussed in this report, because of the way systems respond to a broad band of frequencies, a cumulative (integrated effect) amount of energy can couple into a system and adversely affect the sensitivity of a measurement, thereby potentially jeopardizing the quality of research performed at the DOC Laboratories. The data presented in this report illustrate that E-field strengths on the order of $1 \mathrm{~V} / \mathrm{m}$ could be present at the DOC Laboratories. The studies presented in Section 8 illustrate only a few of the potential problems that may be experienced at the DOC laboratories.

While the results presented in this report are for omnidirectional or omni-azimuthal directional antenna patterns, they will remain relevant once the actual antenna patterns are known. For LOS propagation, the simple free-space calculation given in equation (2) can be used to determine the E-field strengths without the need to resort to the ITM prediction model. LOS propagation conditions occur for the Eldorado Mountain site for the Boulder area (including the DOC Laboratories and the Table Mountain NRQZ). Therefore, once the actual antenna patterns are known, the EIRP in any direction can be obtained, and equation (2) can be used to estimate the E-field strengths in LOS situations. An alternative approach is to simply scale the results in this report by the appropriate EIRP for an antenna at a given location. With this noted, the results in this report are valid for estimating the E-field strengths in the Boulder-Denver area. If additional results are needed for a given transmitting antenna pattern at a specific location, the ITM could be used for such analysis at a future date. 


\section{REFERENCES}

[1] Advanced television systems and their impact upon the existing television broadcast service. Sixth Report and Order, Federal Communications Commission, FCC 97-115, MM Docket No. 87-268; April 1997.

[2] Report of National Television System Committee. National Television System Committee; 1953.

[3] Fink, D.C. Color television standards: Selected papers and records. New York: McGraw-Hill; 1971.

[4] Code of Federal Regulations, Title 47: Telecommunication, Part 2: Frequency allocations and radio treaty matters; General rules and regulations, Subpart A: Terminology. Part 2.1 Terms and Definitions. Office of the Federal Register, National Archives and Records Administration, p. 330; October 1, 2000.

[5] Advanced television systems and their impact upon the existing television broadcast services. Sixth Further Notice of Proposed Rule Making, Federal Communications Commission, MM Docket No. 87-268; August 14, 1996.

[6] Performance assessment of the ATSC transmission system, equipment and future directions. Report of the ATSC Task Force on RF System Performance; April 12, 2001. http://www.atsc.org (April 20, 2001).

[7] Annual assessment of the status of competition in the market for the delivery of video programming. Seventh Annual Report, Federal Communications Commission, CS Docket No. 00-132; January 8, 2001.

[8] Code of Federal Regulations, Title 47, Chapter I: Federal Communications Commission: Telecommunication. Section 73.1030: Notifications concerning interference to radio astronomy, research and receiving installations. Office of the Federal Register, National Archives and Records Administration, pp. 279-280, October 1, 2000.

[9] Manual of regulations and procedures for federal radio frequency management, National Telecommunications and Information Administration, January 2000 edition with May/September 2000 revisions, pp. 8-43 to 8-45; 2000.

[10] Telecommunication Research Facilities of the United States, Colorado Revised Statutes, vol. 11, chap. 97. Permanent Cumulative Supplement, Article 26, Sections $36-26-1$ to $36-26-5$; 106-2-35 and $139-60-11 ; 1969$.

[11] Balanis, C.A. Antenna theory: Analysis and design. New York: John Wiley \& Sons, Inc.; 1997. 
[12] Friss, H.T. A note on a simple transmission formula, Proc. IRE, 34: 254-256; 1946.

[13] Maclean, T.S.M.; Wu, Z. Radiowave propagation over ground. London: Chapman \& Hall; 1993.

[14] Shibuya, S. A basic atlas of radio-wave propagation. New York: John Wiley \& Sons, Inc.; 1987.

[15] IEEE standard for safety levels with respect to human exposure to radio frequency electromagnetic fields, $3 \mathrm{kHz}$ to $300 \mathrm{GHz}$. IEEE C95.1-1991; April 27, 1992.

[16] Polk C.; Postow, E. CRC handbook of biological effects of electromagnetic fields. Boca Raton, FL: CRC Press, Inc.; 1986.

[17] Janaswamy, R. Radiowave propagation and smart antennas for wireless communication. Boston, MA: Kluwer Academic Publishers; 2001.

[18] Adawi, N.S.; Bertoni, H.L.; Child, J.R.; Danial, W.A.; Detra, J.E.; Eckert, R.P.; Flath, E.H.; Forrest, R.T.; Lee, W.C.Y.; McConoughery, S.R.; Murray, P.J.; Sachs, H.; Schrenk, G.L.; Shepherd, N.H.; Shipley, F.D. Coverage prediction for mobile radio systems operating in the $800 / 900 \mathrm{MHz}$ frequency range. IEEE Trans. Vehicular Technol., 37(1): 3-75; 1988.

[19] Blaunstein, N. Radio propagation in cellular networks. Boston, MA: Artech House; 2000.

[20] Hufford, G.A.; Longley, A.G.; Kissick, W.A. A guide to the use of the ITS irregular terrain model in the area prediction mode. NTIA Report 82-100: April 1982.

[21] Longley A.G.; Rice, P.L. Prediction of tropospheric radio transmission loss over irregular terrain: A computer method-1968. ESSA Technical Report ERL 79-ITS67; July 1968.

[22] Sanders F.H.; Lawrence, V.S. Broadband spectrum survey at Denver, Colorado. NTIA Report 95-321; September 1995.

[23] Sanders, F.H.; Ramsey, B.J.; Lawrence, V.S. Broadband spectrum survey at San Diego, California. NTIA Report 97-334; December 1996.

[24] Sanders, F.H.; Ramsey, B.J.; Lawrence, V.S. Broadband spectrum survey at Los Angeles, California. NTIA Report 97-336; May 1997.

[25] Sanders, F.H.; Ramsey, B.J.; Lawrence, V.S. Broadband spectrum survey at San Francisco, California May-June 1995. NTIA Report 99-367; July 1999. 
[26] The temporal and spectral characteristics of ultrawideband signals, Kissick, W.A., ed. NTIA Report 01-383; January 2001, Appendix C.

[27] Jakes, W.C. Microwave mobile communications. New York: IEEE Press; 1974.

[28] Steele, R. Mobile radio communications. New York: IEEE Press; 1992.

[29] Review of the Commission's rules and policies affecting the conversion to digital television. Report and Order, Federal Communications Commission, FCC 01-24, MM Docket No. 00-39; January 2001.

[30] Sanders, F.H.; Hinkle, R.L.; Ramsey, B.J.; Analysis of compatibility between radar stations and $4 \mathrm{GHz}$ fixed-satellite earth stations. NTIA Report 94-313; July 1999.

[31] Gubisch, R. Phone call and E-mail communication, weeks of April 23-27, 2001, and May 7-11, 2001.

[32] Code of Federal Regulations, Title 47: Telecommunication, Section 15.109: Radiated emission limits. Office of the Federal Register, National Archives and Records Administration, pp. 697-698; October 1, 2000.

[33] Chuang, J.C.-I. The effects of time delay spread on portable radio communications channels with digital modulation. IEEE J. Selected Areas in Commun., 5(5): 879-889; 1987.

[34] Macario, R.C.V. Modern personal radio systems. London: IEE; 1996.

[35] Cox, D.C. Correlation bandwidth and delay spread multipath propagation statistics for $910 \mathrm{MHz}$ urban mobile radio channels. IEEE Trans. Commun., 23(11): 1271-1280; 1975.

[36] Jakes, W.C. An approximate method to estimate an upper bound on the effect of multipath delay distortion on digital transmission. IEEE Trans. Commun., 27(1): 76-81; 1979.

[37] Aprille, T.J. Filtering and equalization for digital transmission. IEEE Commun. Magazine, pp. 17-24; March 1983.

[38] Webb, W.T. Equaliser techniques for QAM transmissions over dispersive mobile channels. IEE Proc., 138(6): 566-576; 1991.

[39] Pahlavan, K.; Levesque, A.H. Wireless information networks. New York: Johin Wiley \& Sons, Inc.; 1998.

[40] Hufford, G. A characterization of the multipath in the HDTV channel. IEEE Trans. Broadcasting, 38: 252-255; December 1992. 
[41] Sari, H.; Karam, G.; Jeanclaude, I. Transmission techniques for digital terrestrial TV broadcasting. IEEE Commun. Magazine: pp. 100-109; February 1995.

[42] Mignone, V.; Morello, A. CD3-OFDM: A novel demodulation scheme for fixed and mobile receivers. IEEE Trans. Commun., 44: 1144-1151: September 1996.

[43] Ghosh, M. Blind decision feedback equalization for terrestrial television receivers. Proc. IEEE: pp. 2070-2081; October 1998.

[44] Fox, B. Digital TV rollout: Has the United States got it wrong with digital terrestrial TV. IEEE Spectrum, 38(2): 65-67; February 2001. 


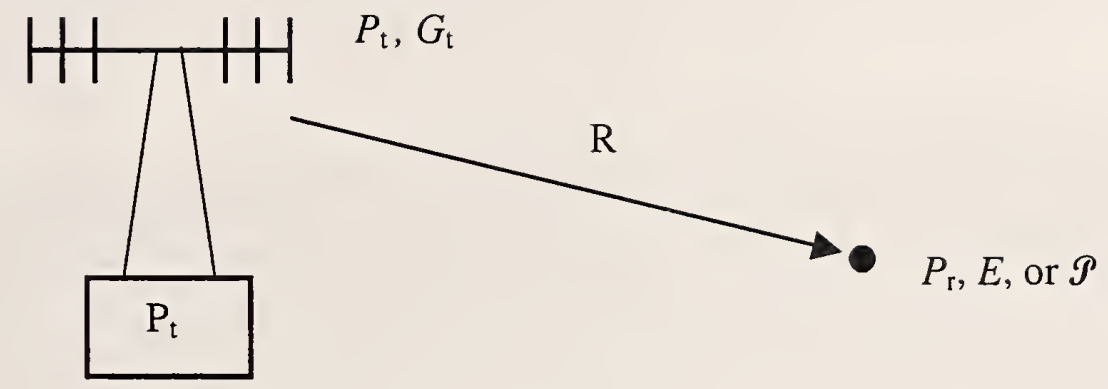

Figure 1. Illustration of an antenna in free space.

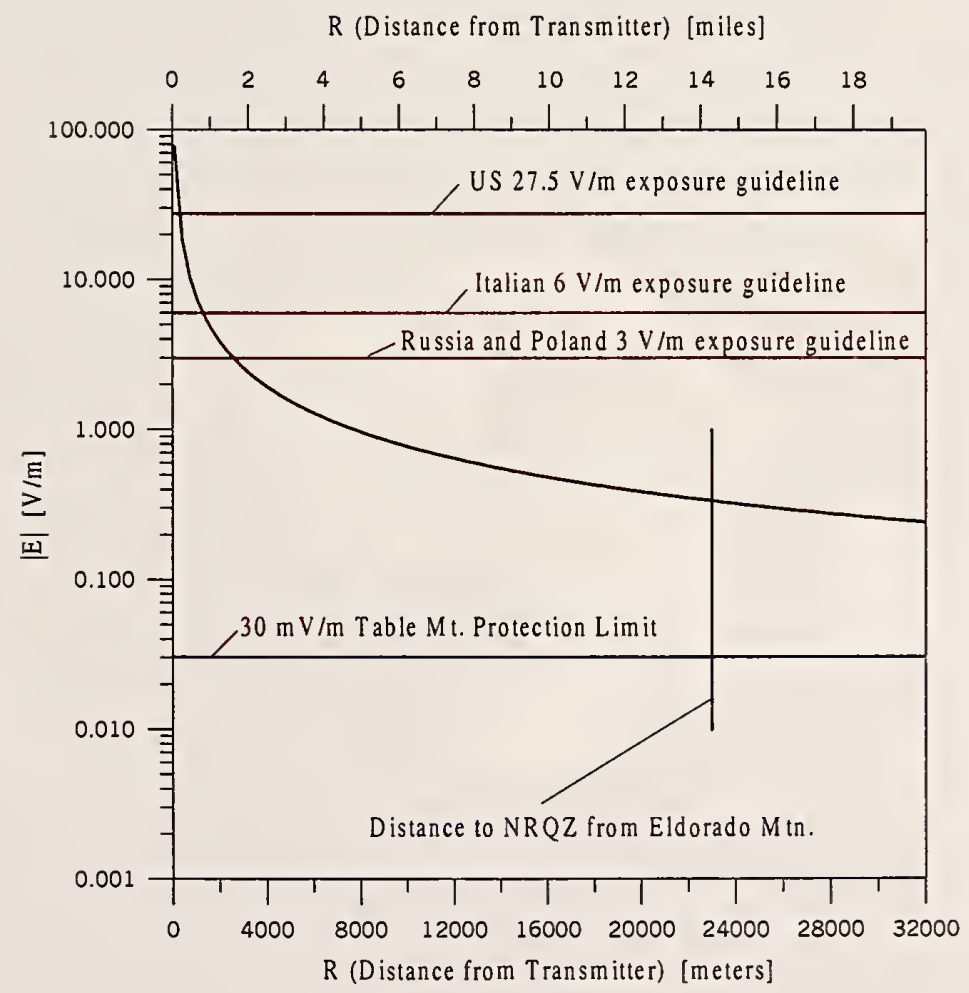

Figure 2. Magnitude of the E-field calculated for a free-space environment as a function of $R$ for an EIRP of $1 \mathrm{MW}$. 
$R$ (Distance from Transmitter) [miles]

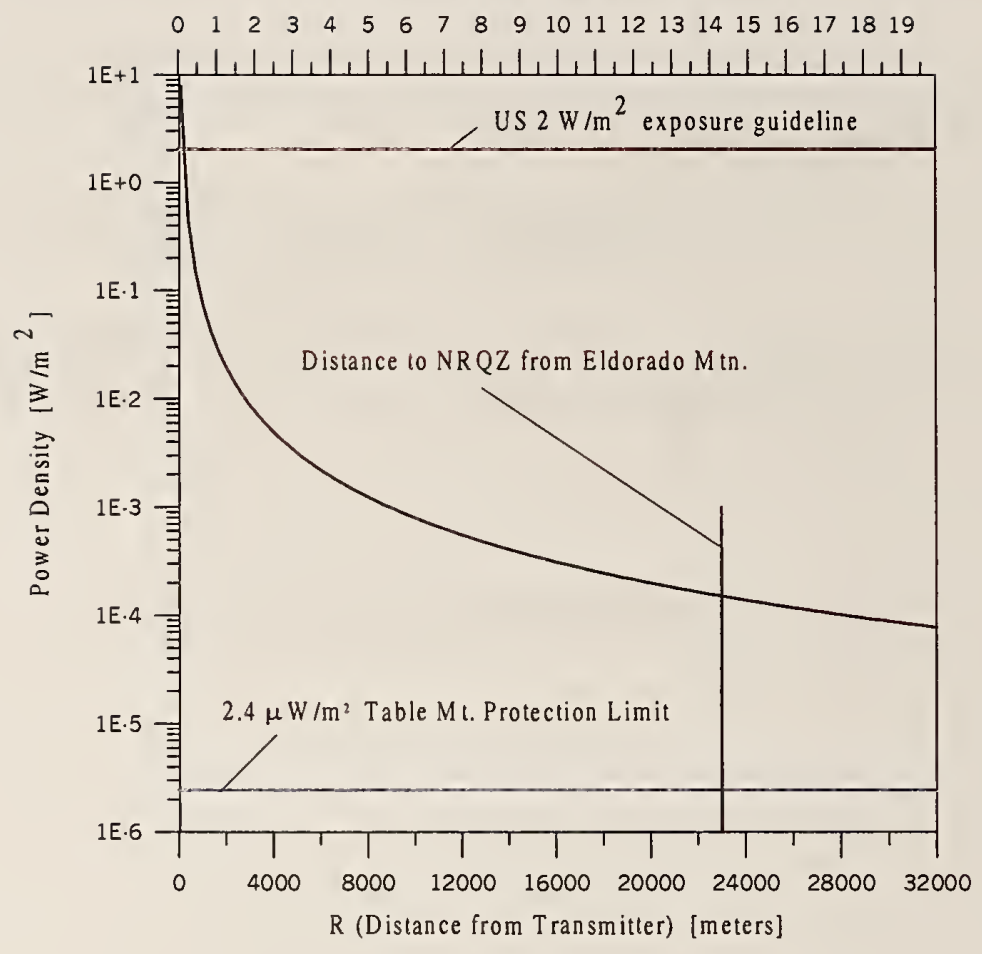

Figure 3. The power density $\mathcal{P}$ calculated for a free-space environment as a function of $R$ for an EIRP of $1 \mathrm{MW}$.

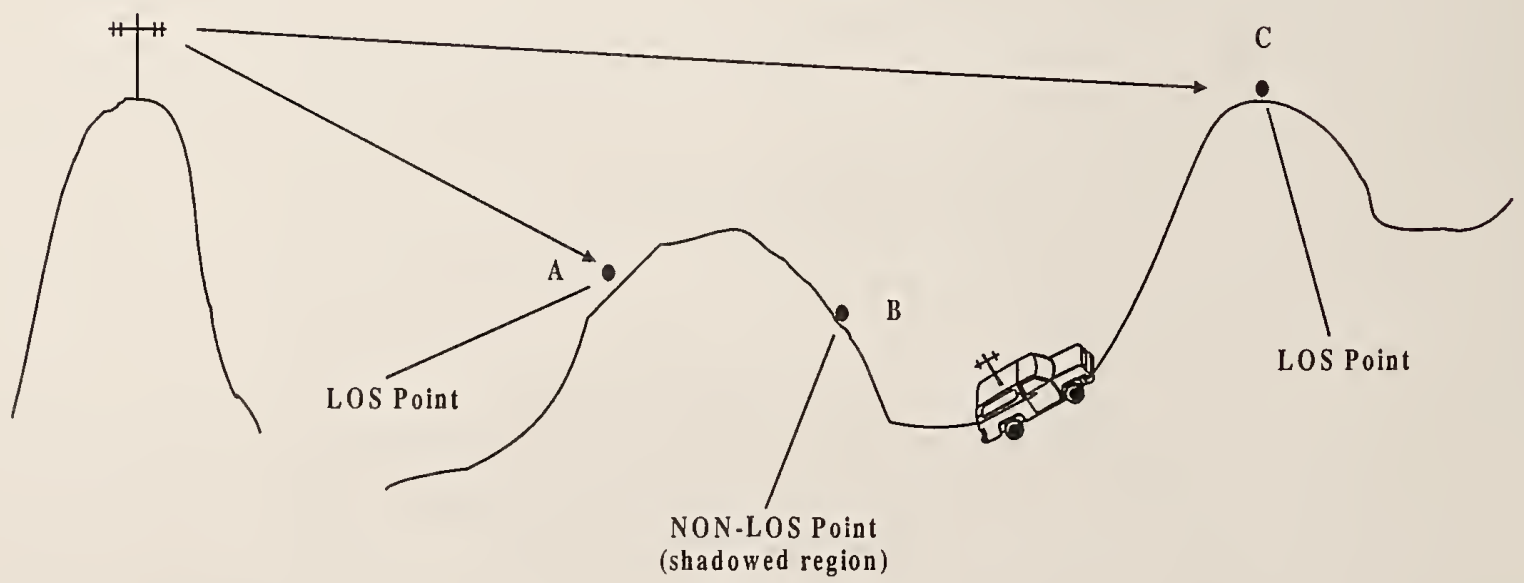

Figure 4. Illustration of a realistic propagation environment where irregular terrain features (or profiles) are present. Both a line-of-sight (LOS) path and a non-line-of-sight (non-LOS) path are shown. 


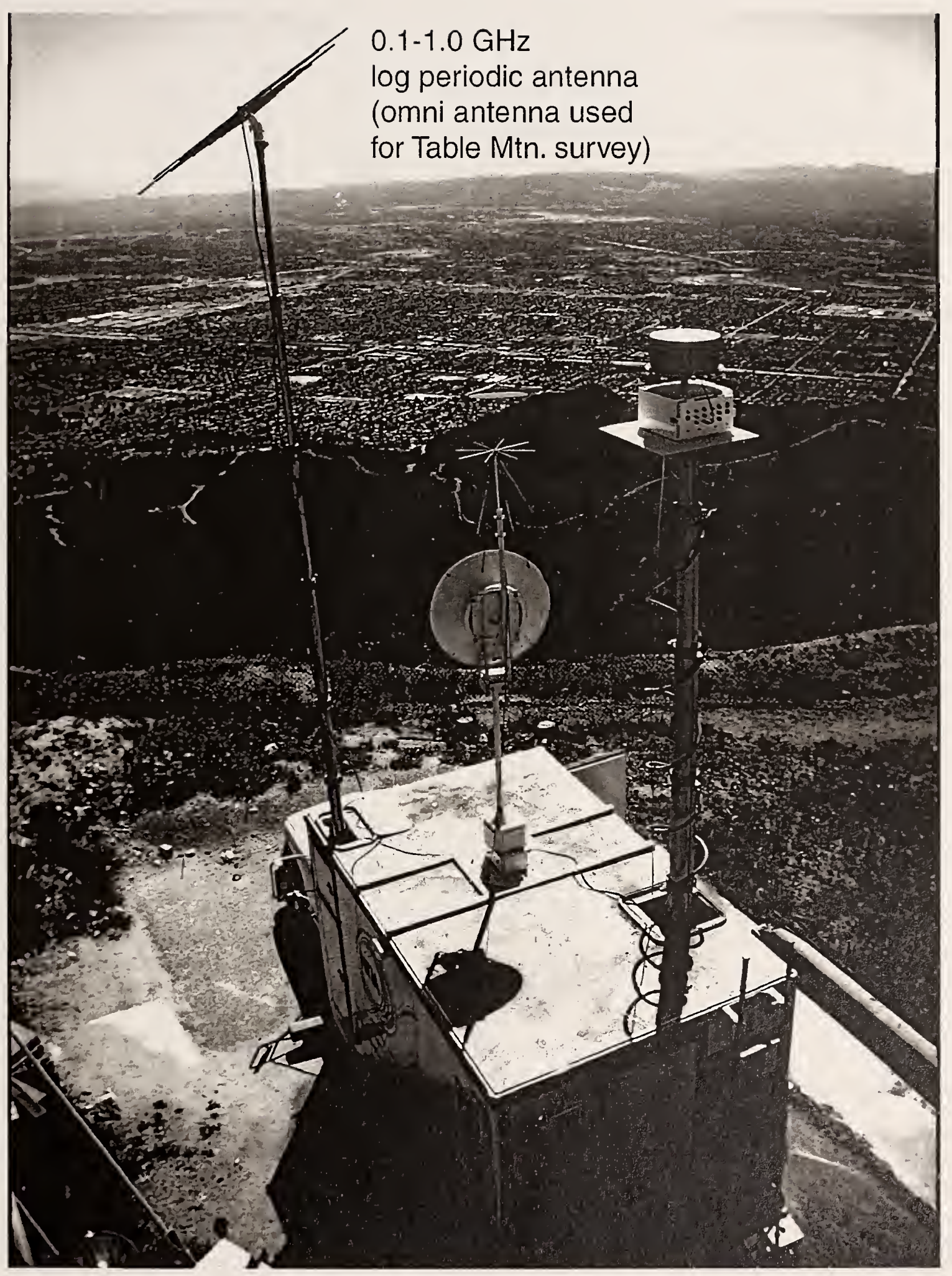

Figure 5. Illustration of the RSMS with telescoping masts raised and antennas mounted for a broadband spectrum survey such as was performed at the Table Mountain NRQZ. 


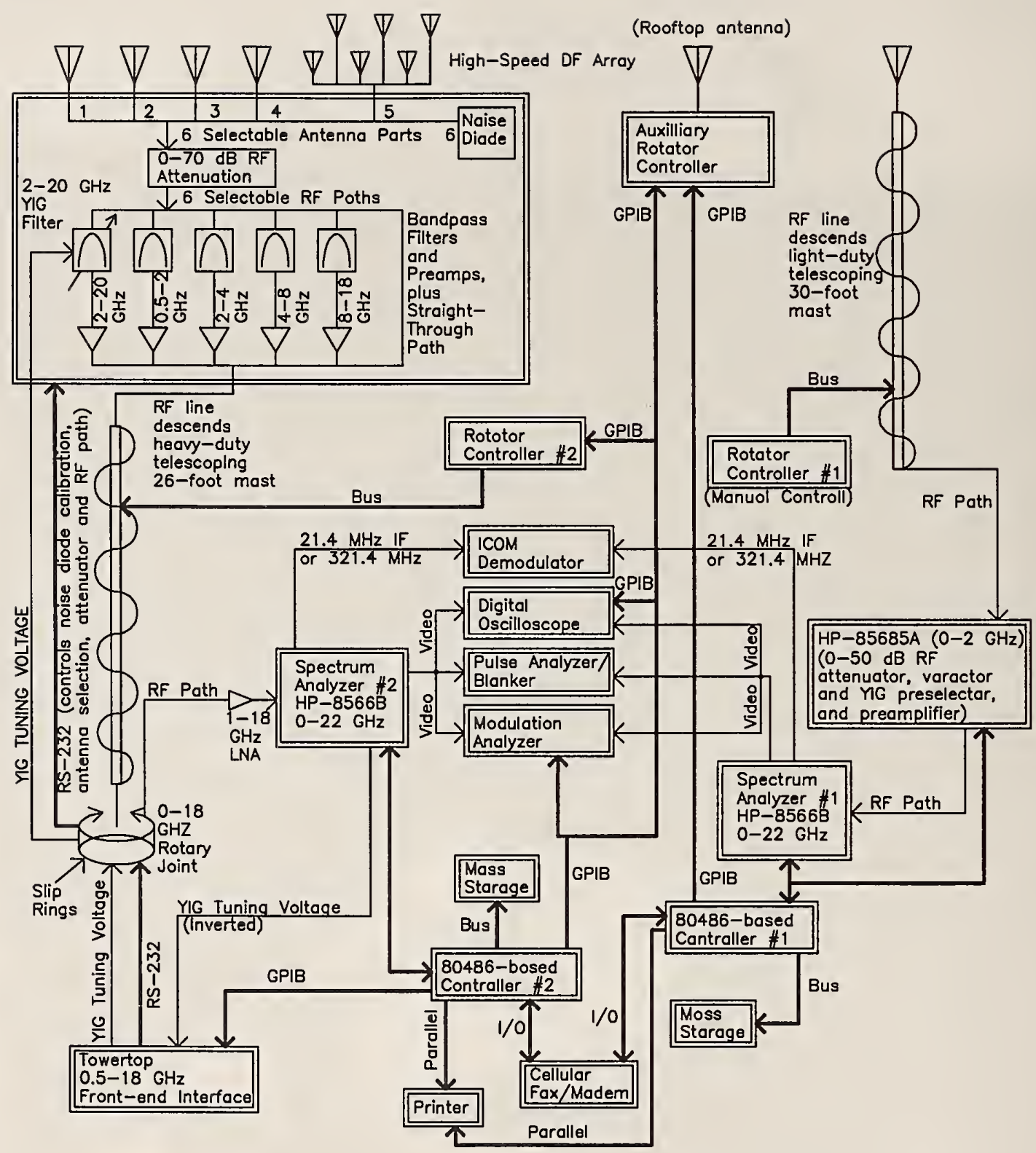

Figure 6. Block diagram of the RSMS measurement system. 


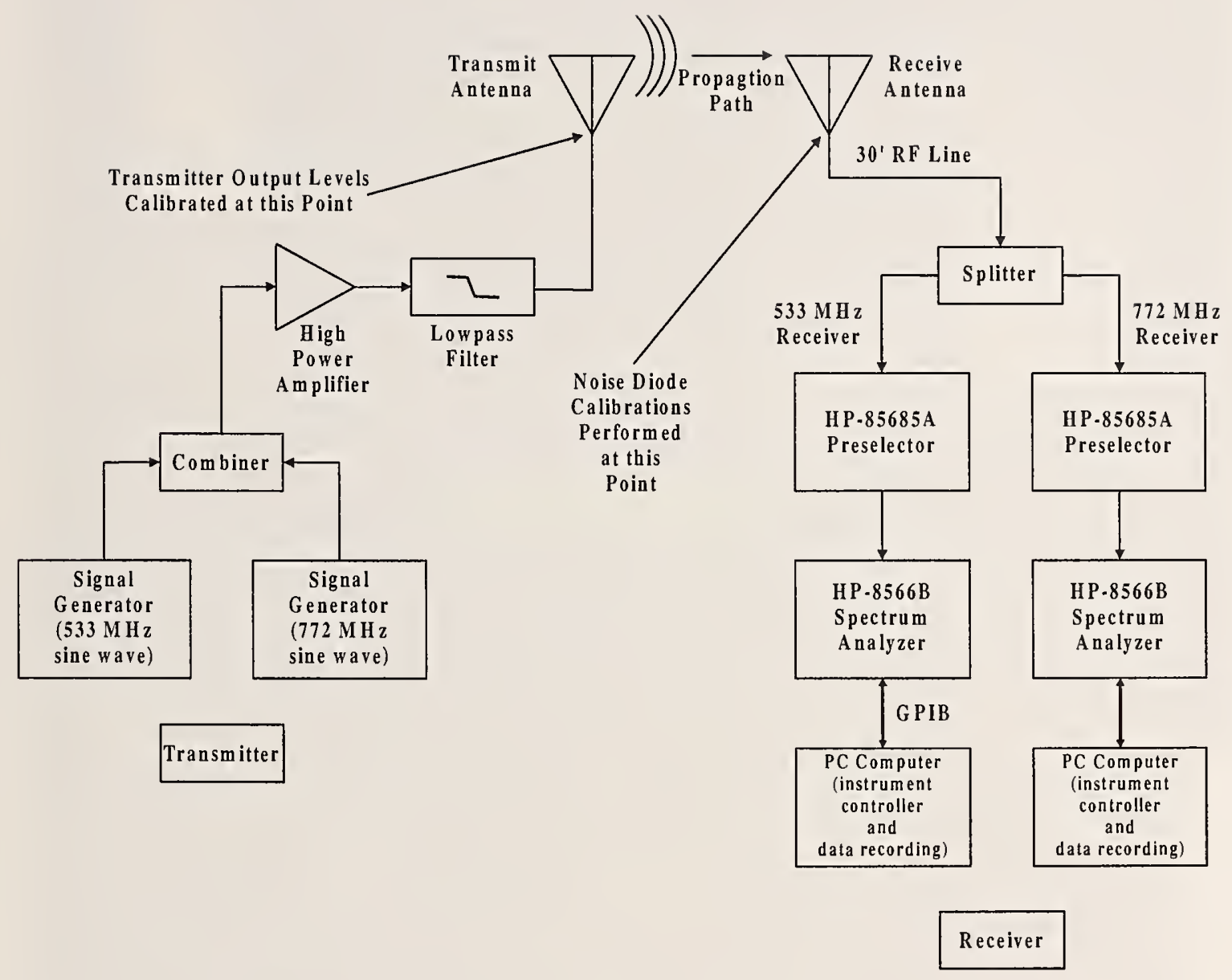

Figure 7. Block diagram of the transmitter systems on each mountaintop and the receiver measurement system. 


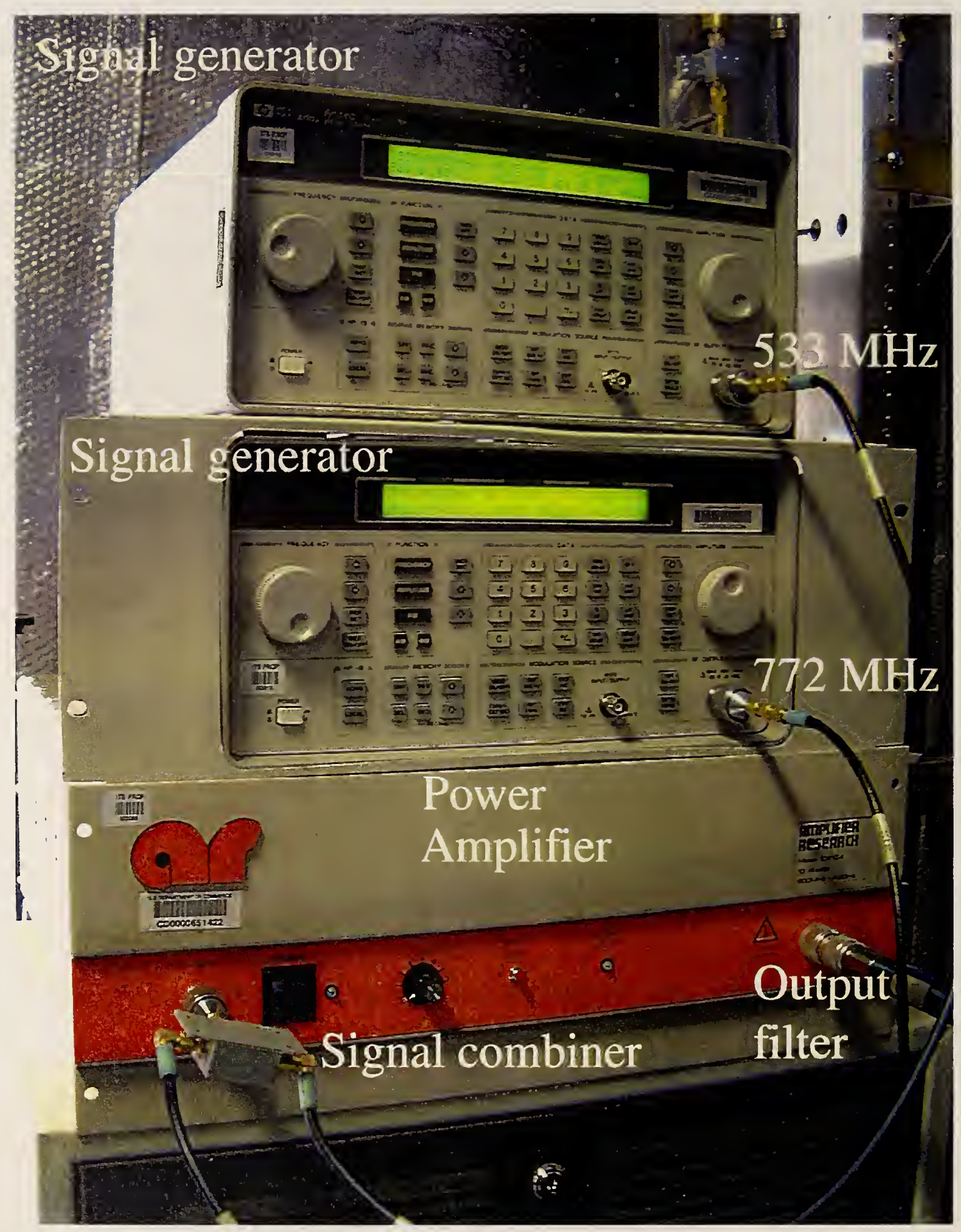

Figure 8. An annotated photograph of the transmitter system used on both mountaintops. 


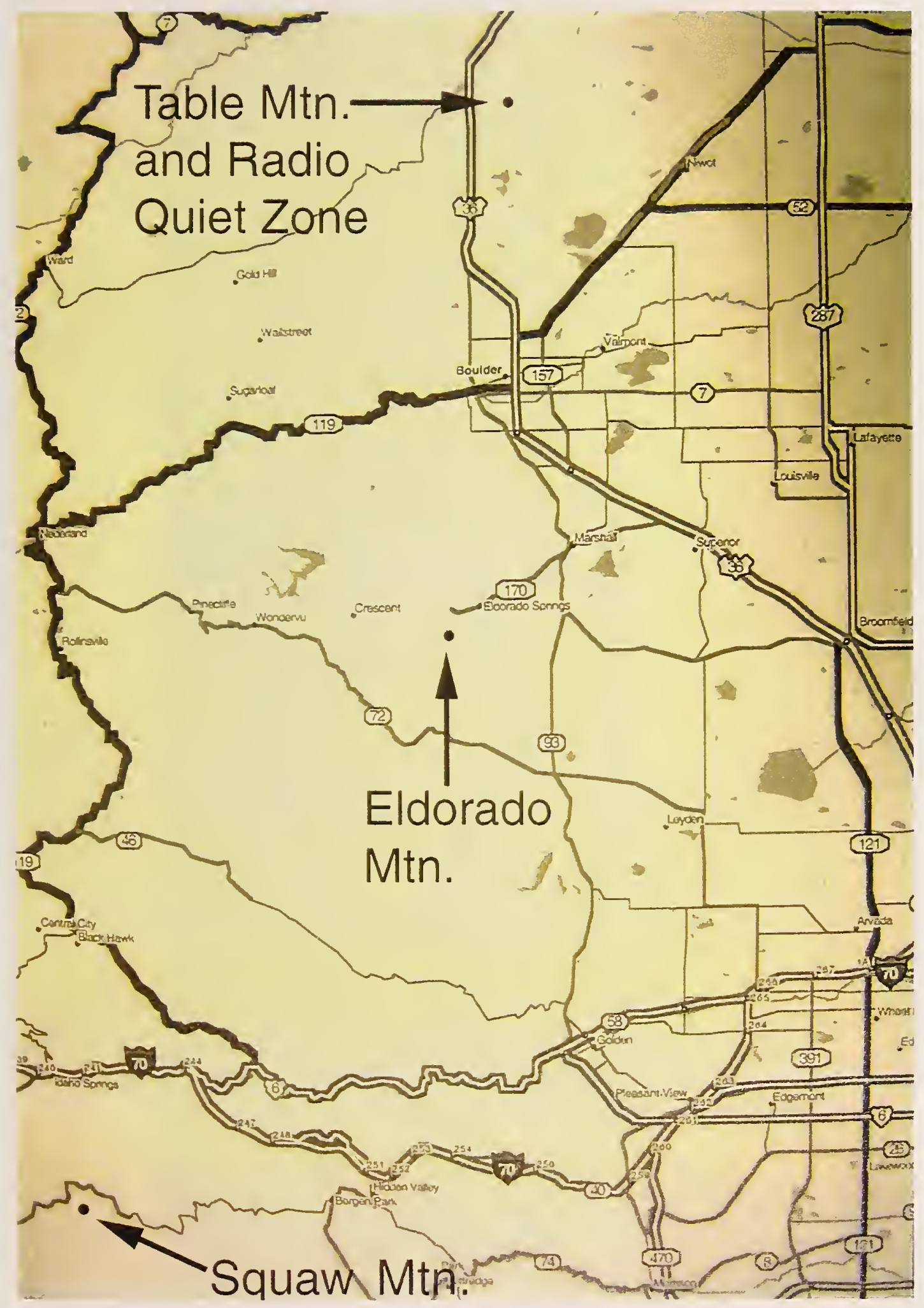

Figure 9. Map of the Denver-Boulder area showing the locations of the two proposed sites (Eldorado Mountain and Squaw Mountain) and the Table Mountain NRQZ. 


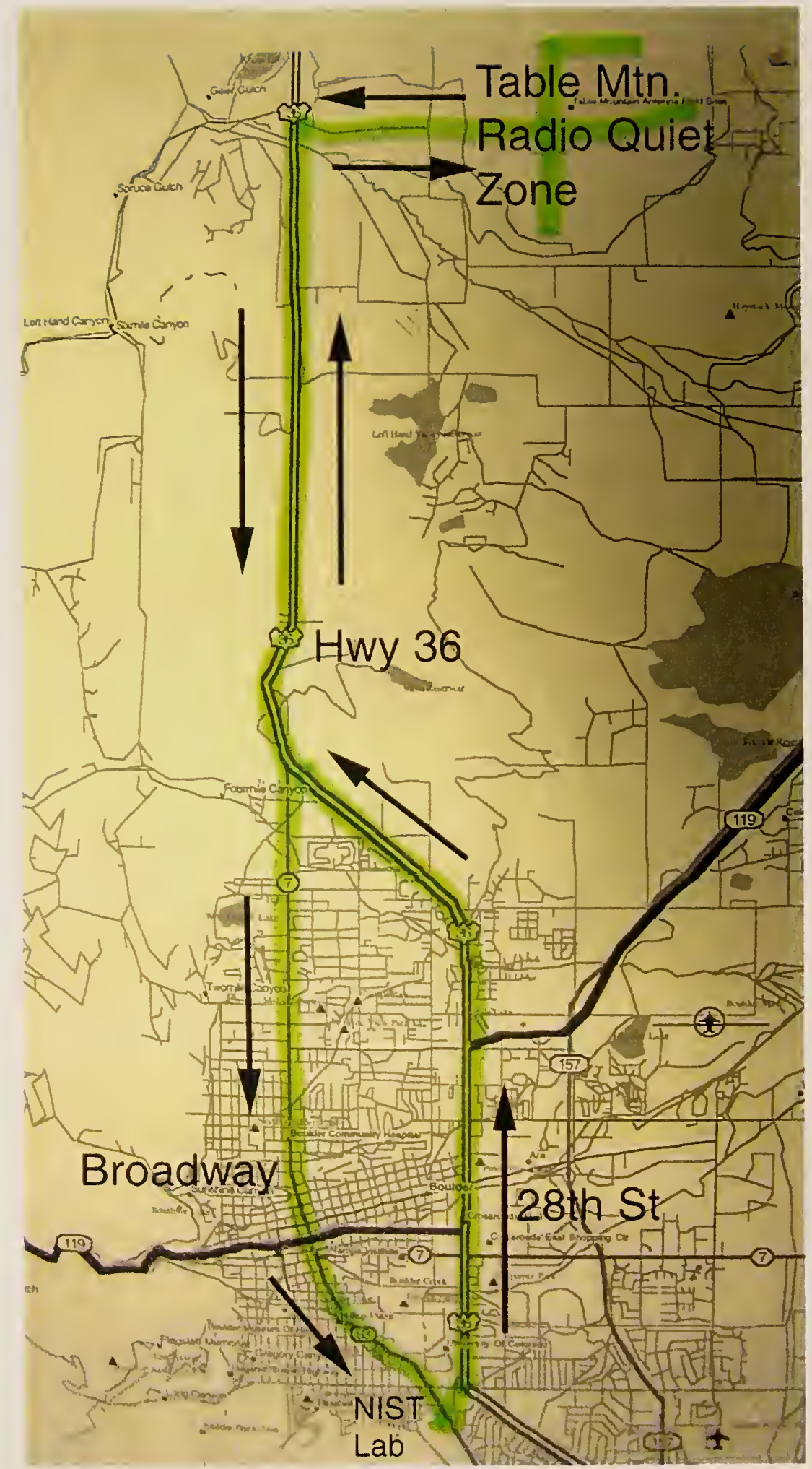

Figure 10a. Map of the $28^{\text {th }}$ Street Route and the Broadway/Highway 93 Route. 


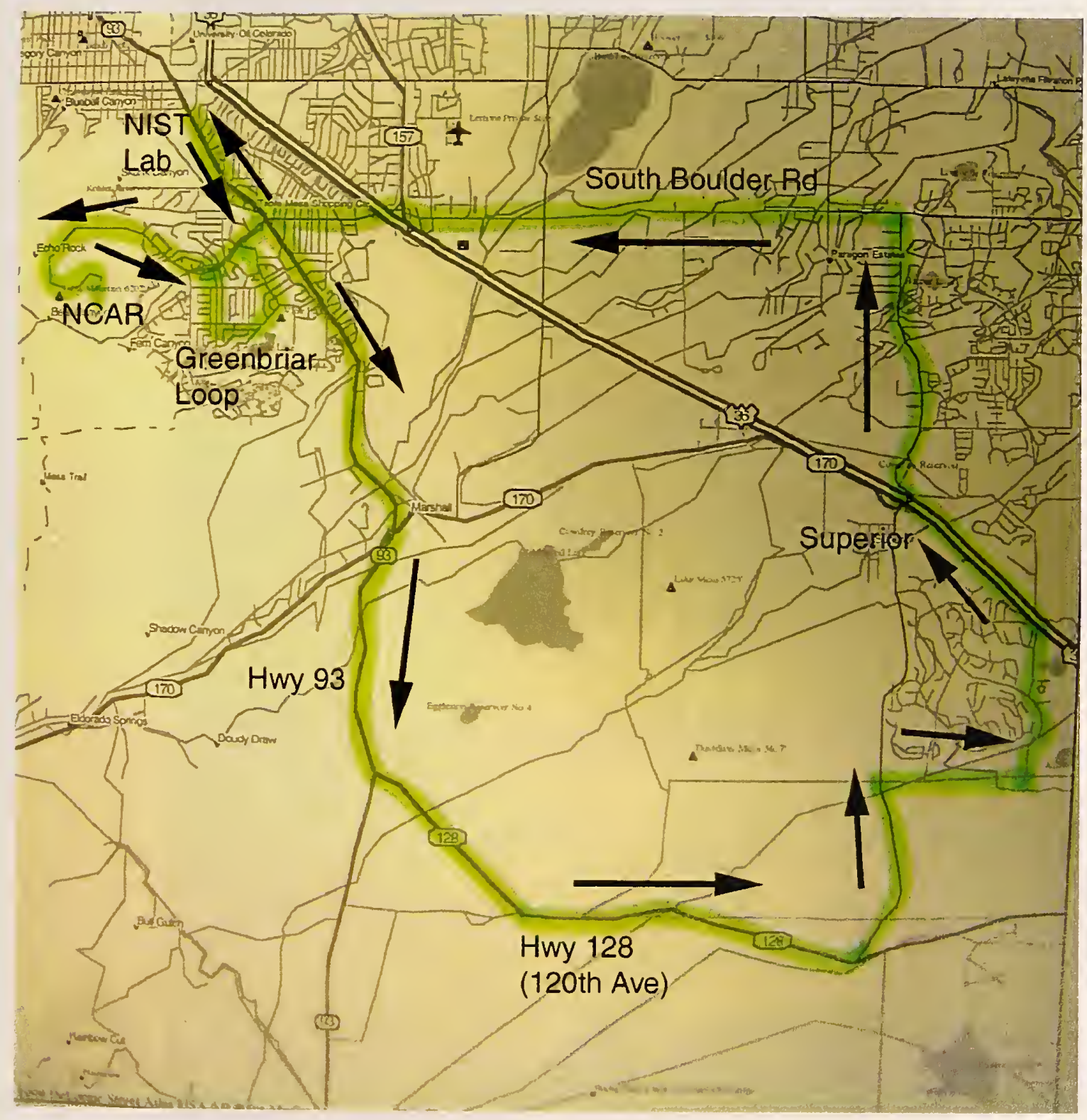

Figure 10b. Map of the McCaslin Loop, also showing the Greenbriar loop and NCAR. 


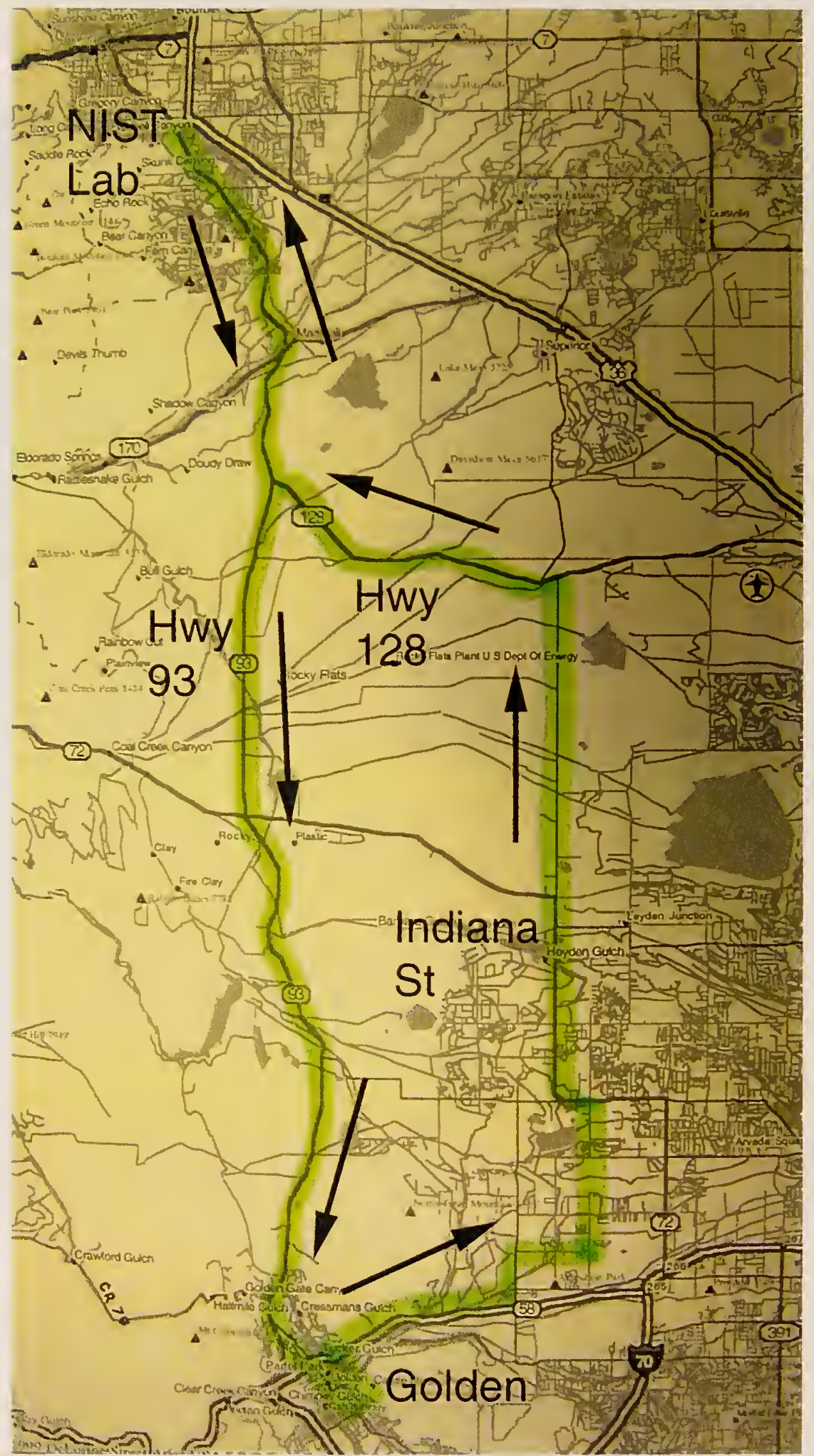

Figure 10c. Map of the Boulder-to-Golden route. 


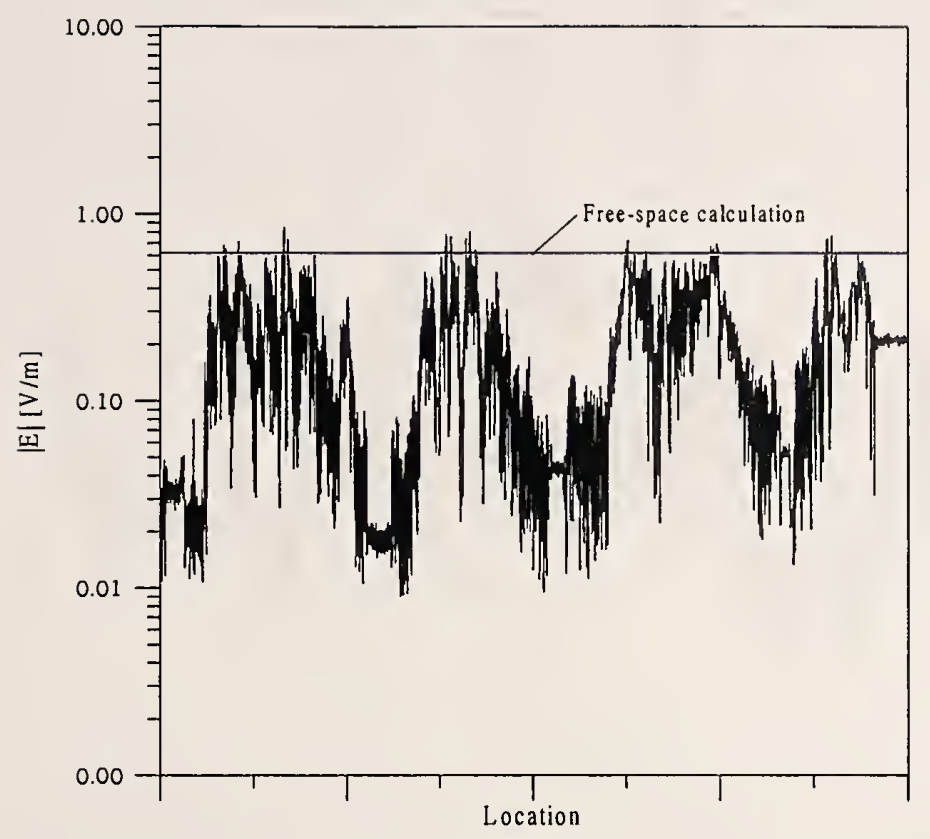

Figure 11. Measured E-field levels scaled to $1 \mathrm{MW}$ EIRP at the DOC Laboratories. These results are for a transmitter on Eldorado Mountain for a frequency of $533 \mathrm{MHz}$, a transmitter height of $3.66 \mathrm{~m}(12.0 \mathrm{ft})$, and a receiver height of $2.95 \mathrm{~m}(9.68 \mathrm{ft})$.

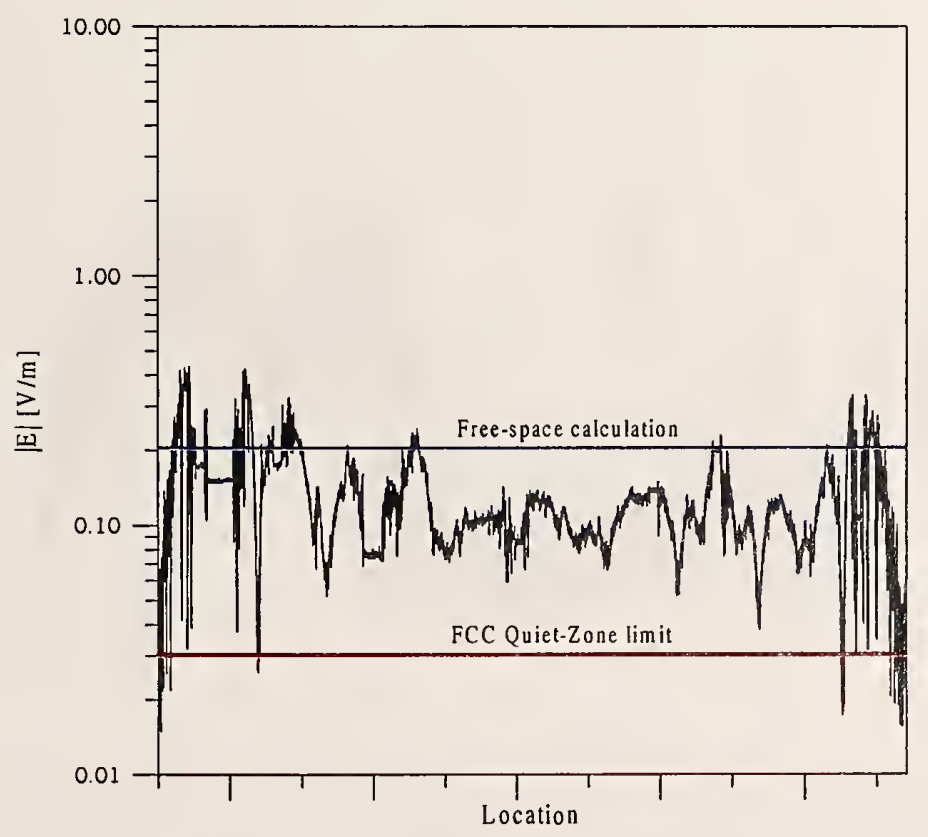

Figure 12. Measured E-field levels scaled to $1 \mathrm{MW}$ EIRP at the Table Mountain NRQZ. These results are for a transmitter on Eldorado Mountain for a frequency of $533 \mathrm{MHz}$, a transmitter height of $3.66 \mathrm{~m}(12.0 \mathrm{ft})$, and a receiver height of $2.95 \mathrm{~m}(9.68 \mathrm{ft})$. 


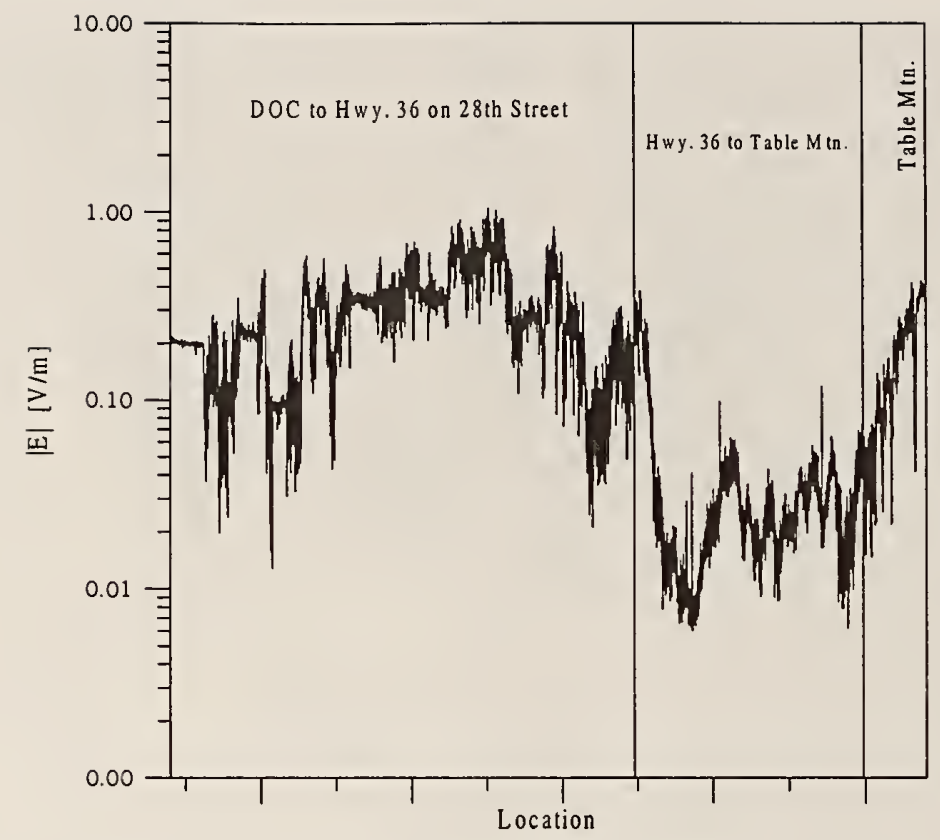

Figure 13. Measured E-field levels scaled to $1 \mathrm{MW}$ EIRP from the DOC Laboratories down $28^{\text {th }}$ Street to the Table Mountain NRQZ. These results are for a transmitter on Eldorado Mountain for a frequency of $533 \mathrm{MHz}$, a transmitter height of $3.66 \mathrm{~m}(12.0 \mathrm{ft})$, and a receiver height of $2.95 \mathrm{~m}(9.68 \mathrm{ft})$.

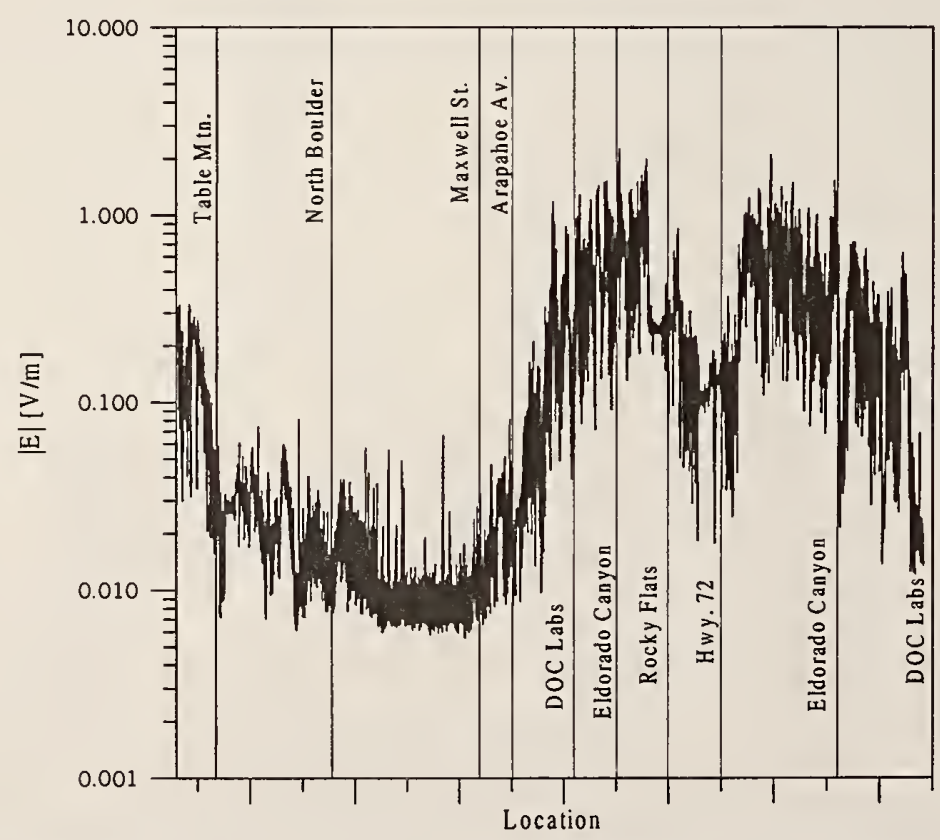

Figure 14. Measured E-field levels scaled to 1 MW EIRP from Table Mountain NRQZ to Highway 72 via Highway 36, Broadway, and Highway 93. These results are for a transmitter on Eldorado Mountain for a frequency of $533 \mathrm{MHz}$, a transmitter height of $3.66 \mathrm{~m}(12.0 \mathrm{ft})$, and a receiver height of $2.95 \mathrm{~m}(9.68 \mathrm{ft})$. 


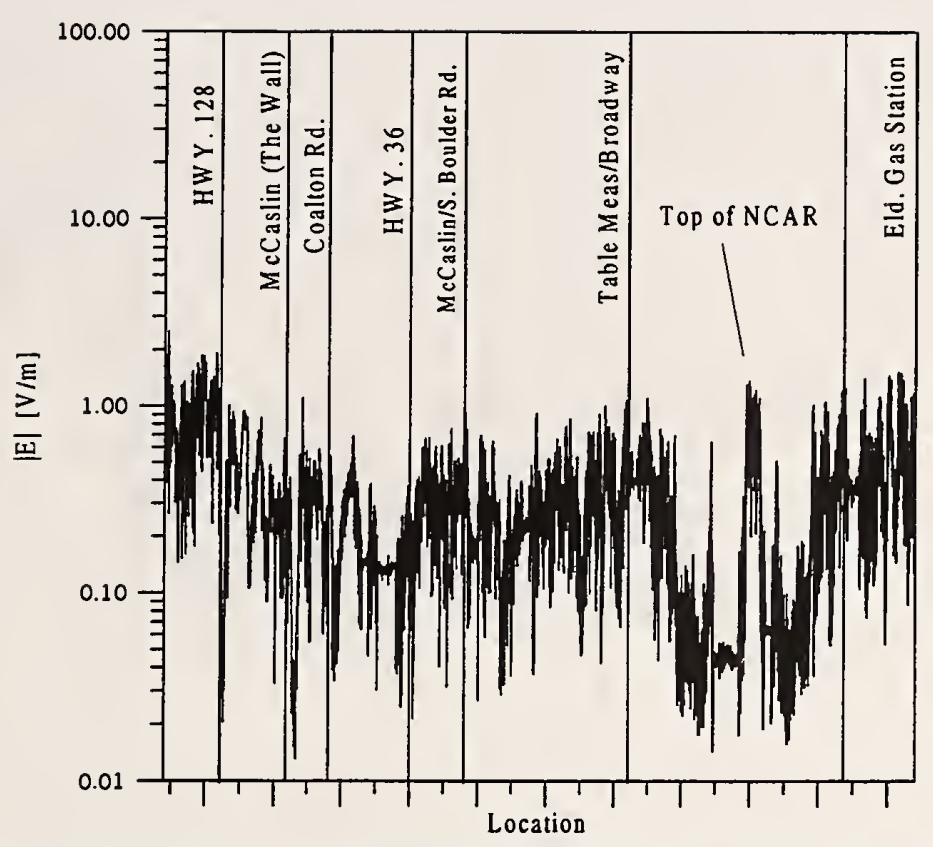

Figure 15. Measured E-field levels scaled to $1 \mathrm{MW}$ EIRP on the McCaslin loop. These results are for a transmitter on Eldorado Mountain for a frequency of $533 \mathrm{MHz}$, a transmitter height of $3.66 \mathrm{~m}(12.0 \mathrm{ft})$, and a receiver height of $2.95 \mathrm{~m}(9.68 \mathrm{ft})$.

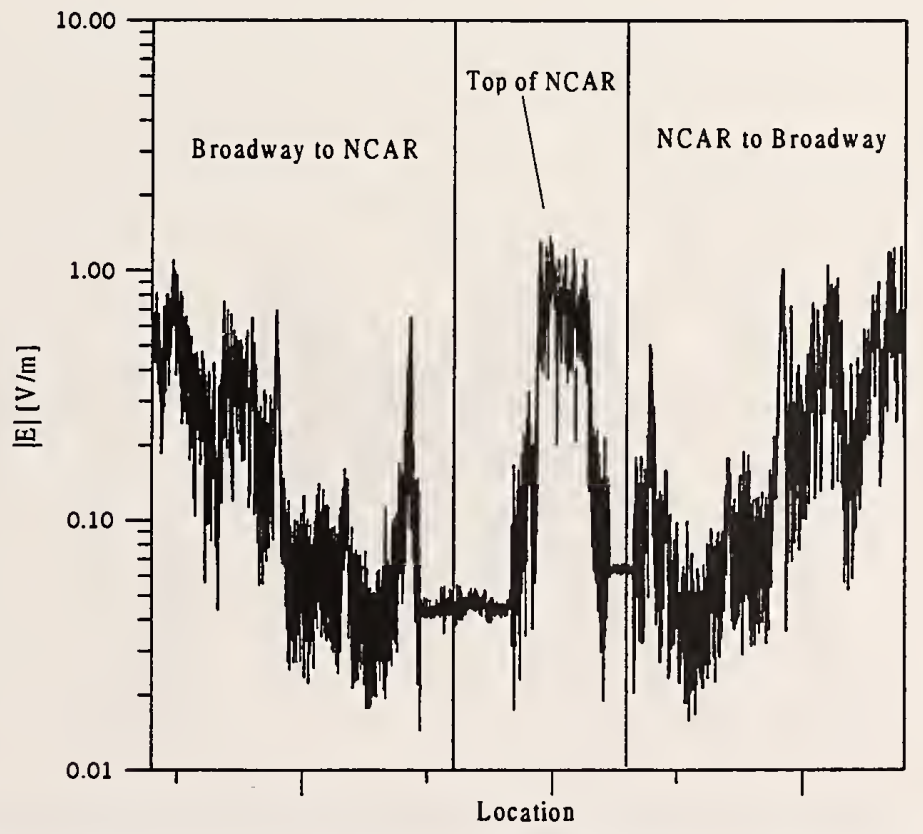

Figure 16. Measured E-field levels scaled to $1 \mathrm{MW}$ EIRP at the NCAR facility at the top of Table Mesa. These results are for a transmitter on Eldorado Mountain for a frequency of $533 \mathrm{MHz}$, a transmitter height of $3.66 \mathrm{~m}(12.0 \mathrm{ft})$, and a receiver height of $2.95 \mathrm{~m}$ $(9.68 \mathrm{ft})$. 


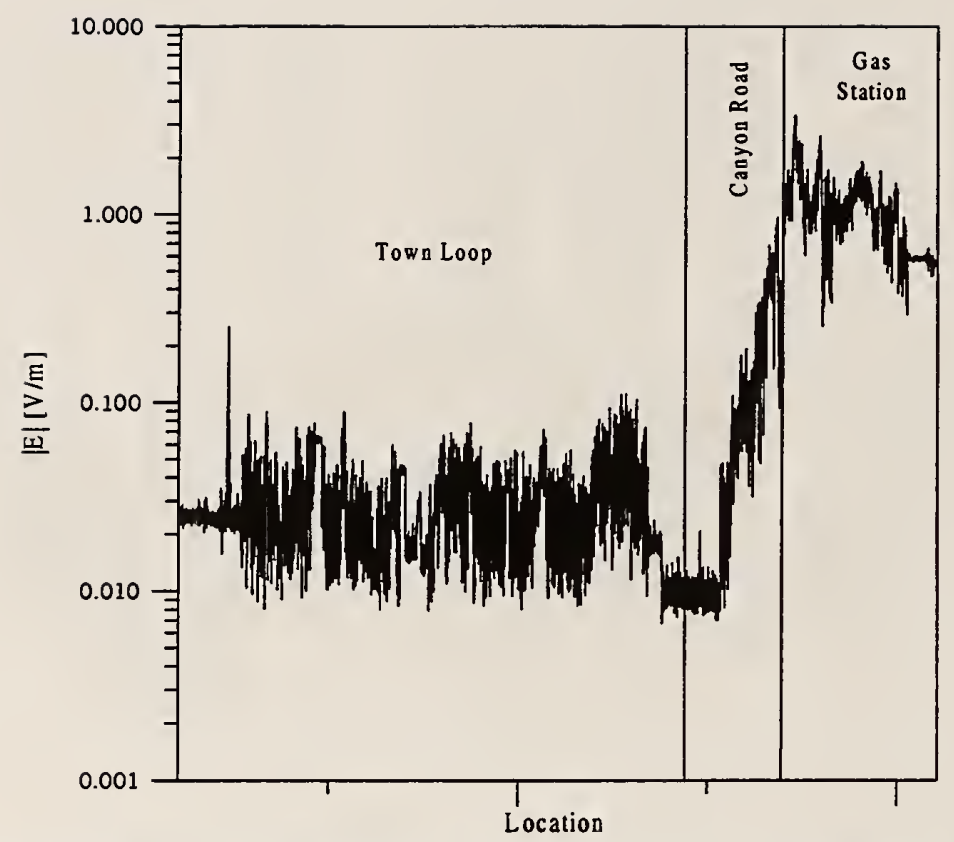

Figure 17. Measured E-field levels scaled to $1 \mathrm{MW}$ EIRP in Eldorado Canyon. These results are for a transmitter on Eldorado Mountain for a frequency of $533 \mathrm{MHz}$, a transmitter height of $3.66 \mathrm{~m}(12.0 \mathrm{ft})$, and a receiver height of $2.95 \mathrm{~m}(9.68 \mathrm{ft})$.

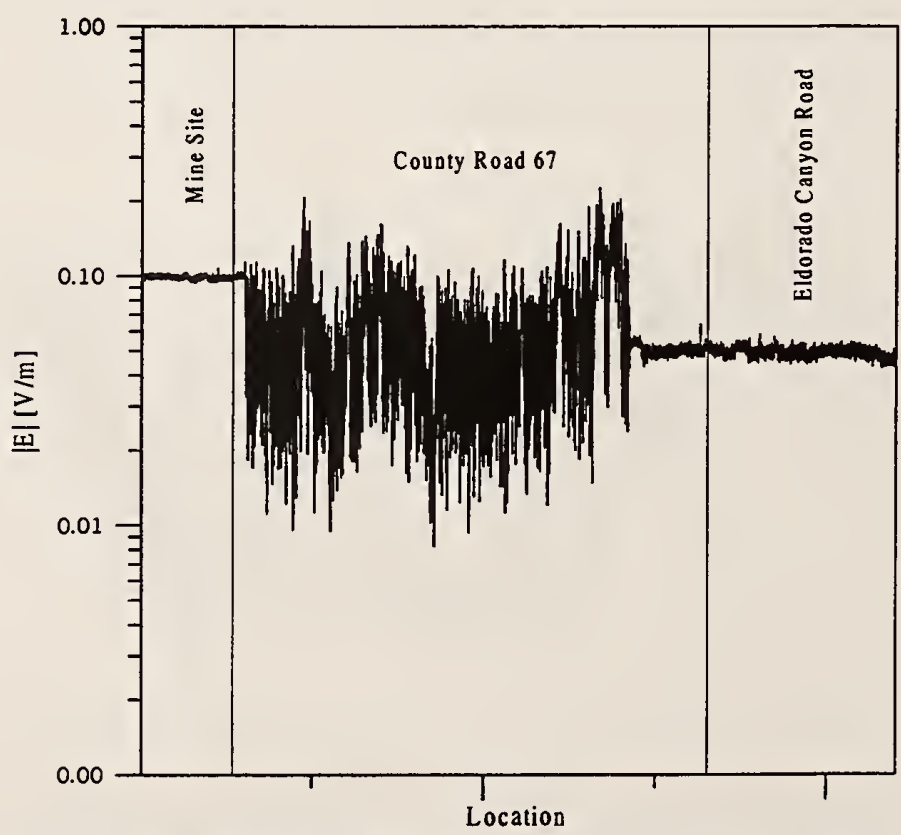

Fig:sre 18. Measured E-field levels scaled to 1 MW EIRP on County Road 67. These resuits are for a transmitter on Eldorado Mountain for a frequency of $533 \mathrm{MHz}$, a transmitter height of $3.66 \mathrm{~m}(12.0 \mathrm{ft})$, and a receiver height of $2.95 \mathrm{~m}(9.68 \mathrm{ft})$. 


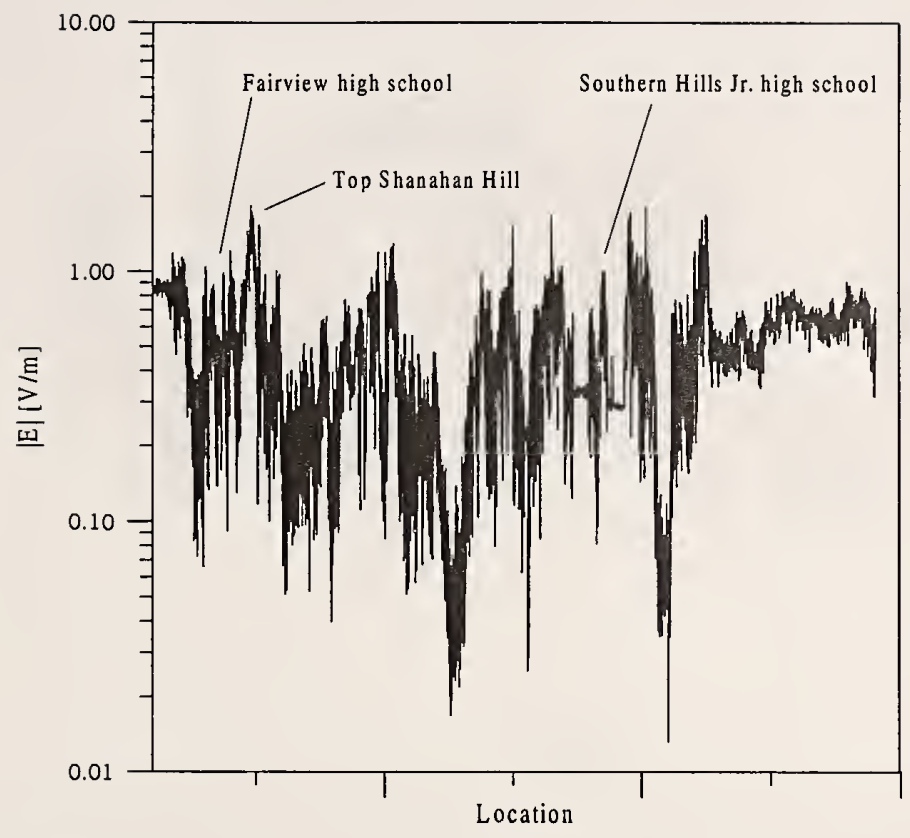

Figure 19. Measured E-field levels scaled to $1 \mathrm{MW}$ EIRP on Greenbriar loop. These results are for a transmitter on Eldorado Mountain for a frequency of $533 \mathrm{MHz}$, a transmitter height of $3.66 \mathrm{~m}(12.0 \mathrm{ft})$, and a receiver height of $2.95 \mathrm{~m}(9.68 \mathrm{ft})$.

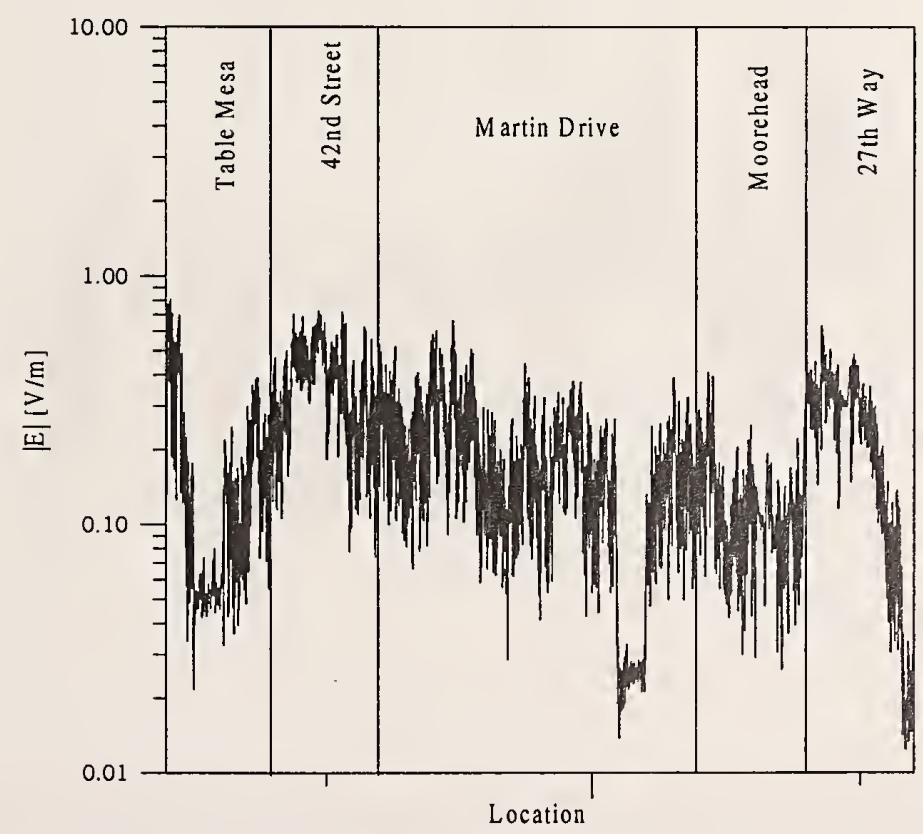

Figure 20. Measured E-field levels scaled to $1 \mathrm{MW}$ EIRP in the Martin Acres neighborhood. These results are for a transmitter on Eldorado Mountain for a frequency of $533 \mathrm{MHz}$, a transmitter height of $3.66 \mathrm{~m}(12.0 \mathrm{ft})$, and a receiver height of $2.95 \mathrm{~m}$ $(9.68 \mathrm{ft})$. 


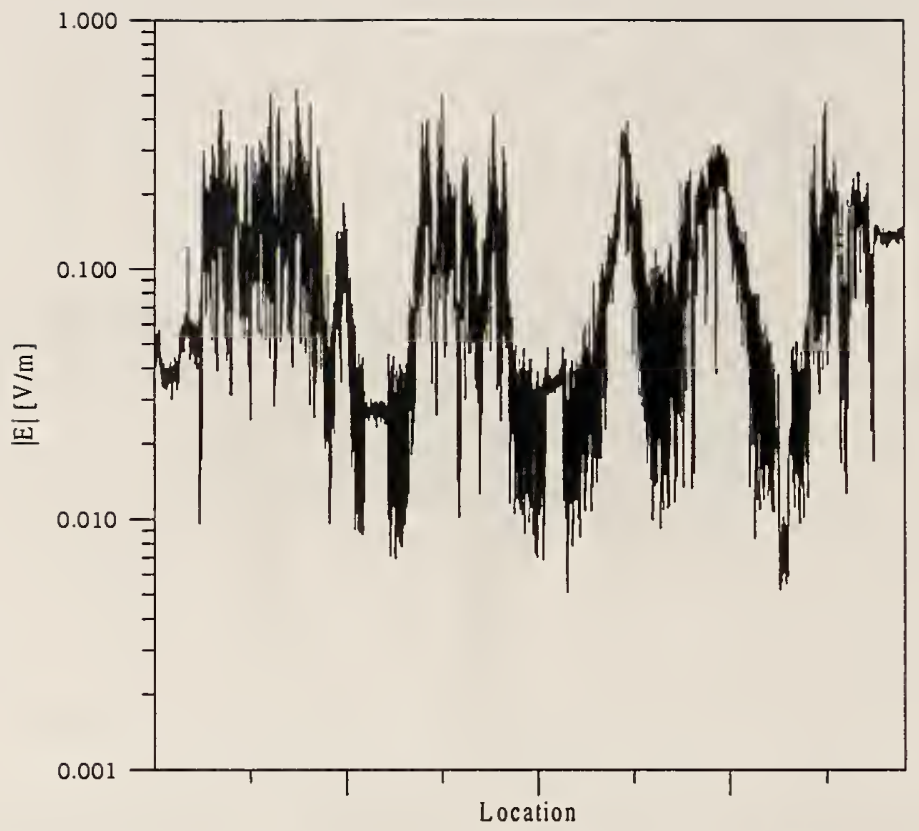

Figure 21. Measured E-field levels scaled to 1 MW EIRP at the DOC Laboratories. These results are for a transmitter on Eldorado Mountain for a frequency of $772 \mathrm{MHz}$, a transmitter height of $3.66 \mathrm{~m}(12.0 \mathrm{ft})$, and a receiver height of $2.95 \mathrm{~m}(9.68 \mathrm{ft})$.

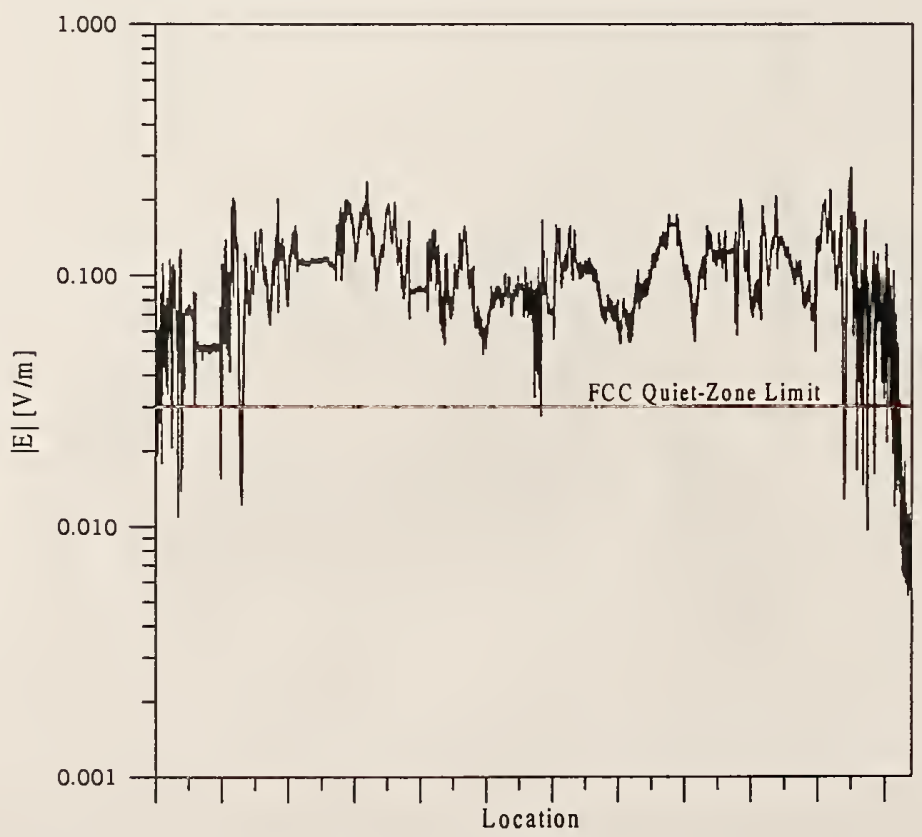

Figure 22. Measured E-field levels scaled to 1 MW EIRP at the Table Mountain NRQZ. These results are for a transmitter on Eldorado Mountain for a frequency of $772 \mathrm{MHz}$, a transmitter height of $3.66 \mathrm{~m}(12.0 \mathrm{ft})$, and a receiver height of $2.95 \mathrm{~m}(9.68 \mathrm{ft})$. 


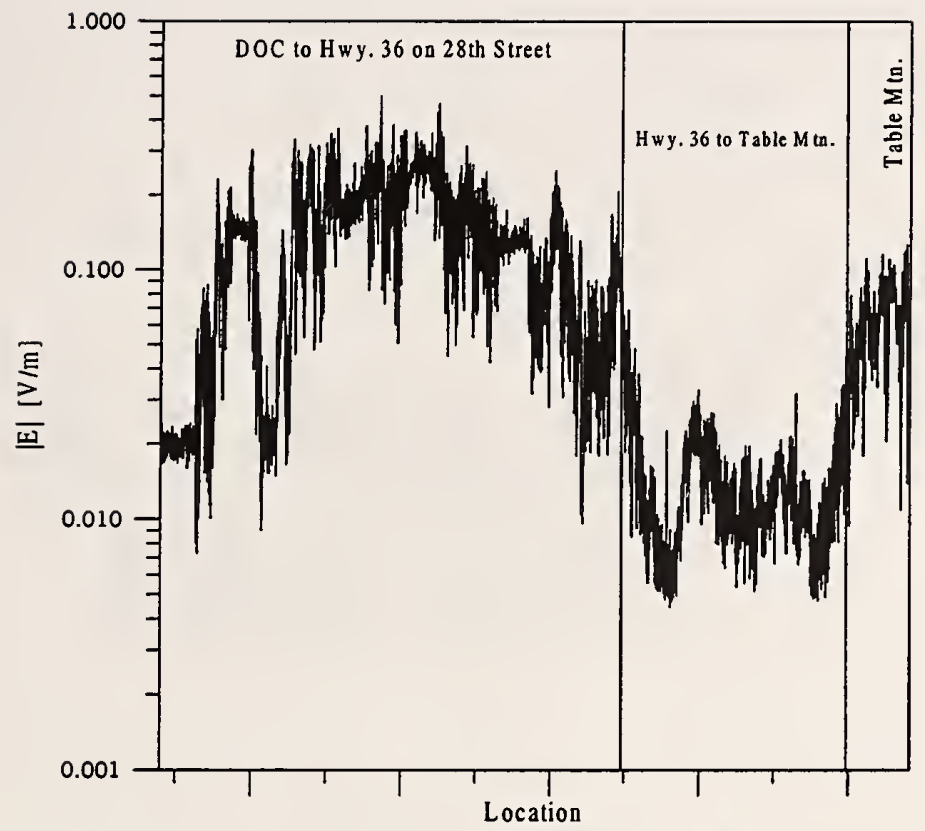

Figure 23. Measured E-field levels scaled to $1 \mathrm{MW}$ EIRP from the DOC Laboratories down $28^{\text {th }}$ Street to the Table Mountain NRQZ. These results are for a transmitter on Eldorado Mountain for a frequency of $772 \mathrm{MHz}$, a transmitter height of $3.66 \mathrm{~m}(12.0 \mathrm{ft})$, and a receiver height of $2.95 \mathrm{~m}(9.68 \mathrm{ft})$.

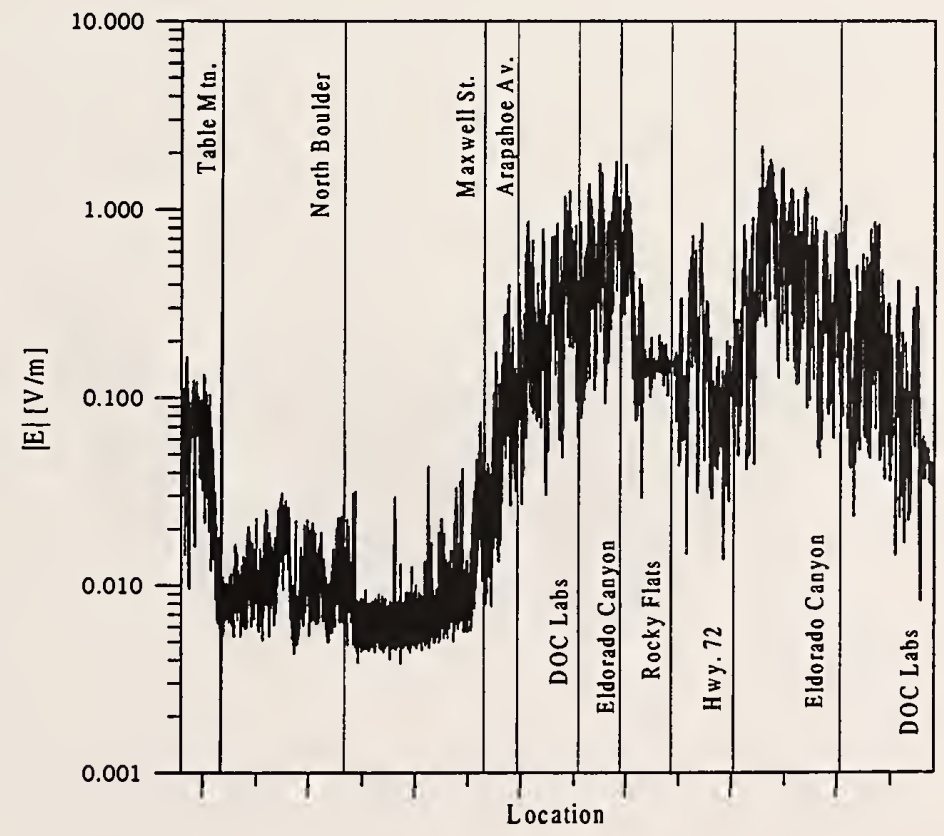

Figure 24. Measured E-field levels scaled to $1 \mathrm{MW}$ EIRP from Table Mountain NRQZ to Highway 72 via Highway 36, Broadway, and Highway 93. These results are for a transmitter on Eldorado Mountain for a frequency of $772 \mathrm{MHz}$, a transmitter height of $3.66 \mathrm{~m}(12.0 \mathrm{ft})$, and a receiver height of $2.95 \mathrm{~m}(9.68 \mathrm{ft})$. 


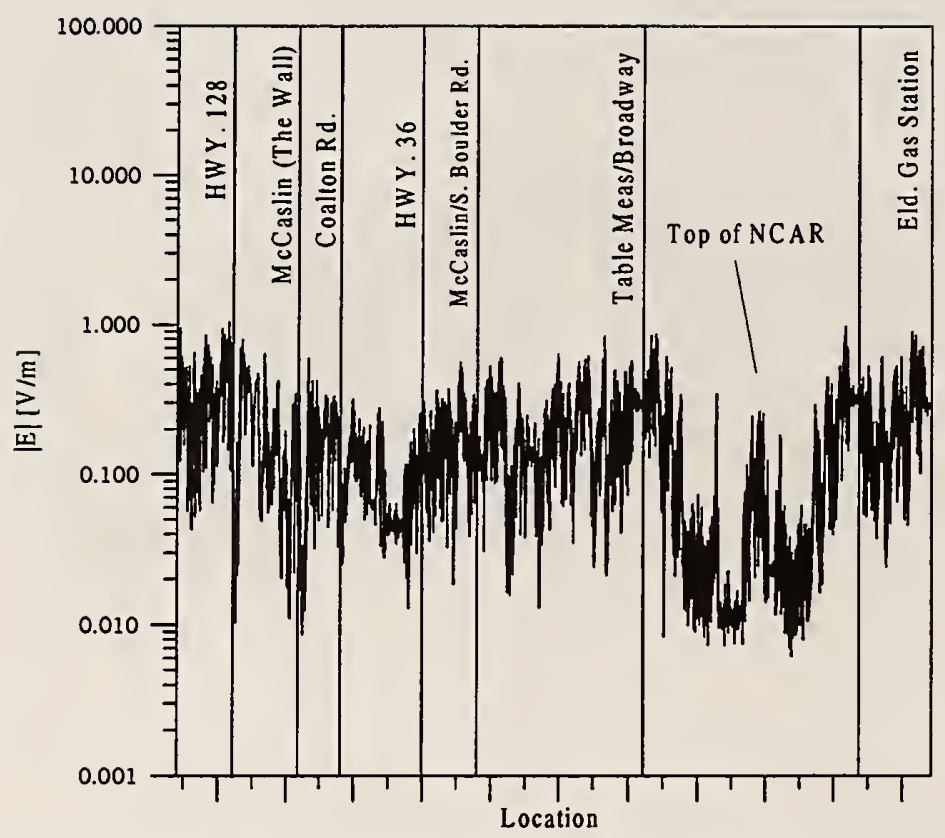

Figure 25. Measured E-field levels scaled to $1 \mathrm{MW}$ EIRP on the McCaslin loop. These results are for a transmitter on Eldorado Mountain for a frequency of $772 \mathrm{MHz}$, a transmitter height of $3.66 \mathrm{~m}(12.0 \mathrm{ft})$, and a receiver height of $2.95 \mathrm{~m}(9.68 \mathrm{ft})$.

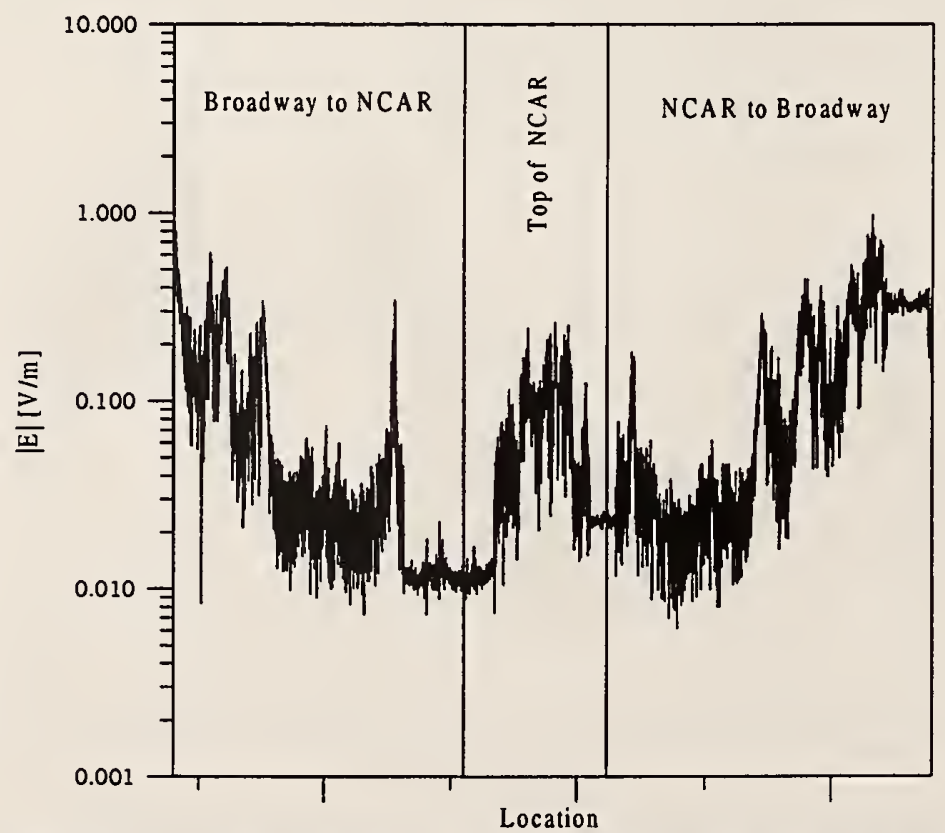

Figure 26. Measured E-field levels scaled to $1 \mathrm{MW}$ EIRP at the NCAR facility at the top of Table Mesa. These results are for a transmitter on Eldorado Mountain for a frequency of $772 \mathrm{MHz}$, a transmitter height of $3.66 \mathrm{~m}(12.0 \mathrm{ft})$, and a receiver height of $2.95 \mathrm{~m}$ $(9.68 \mathrm{ft})$. 


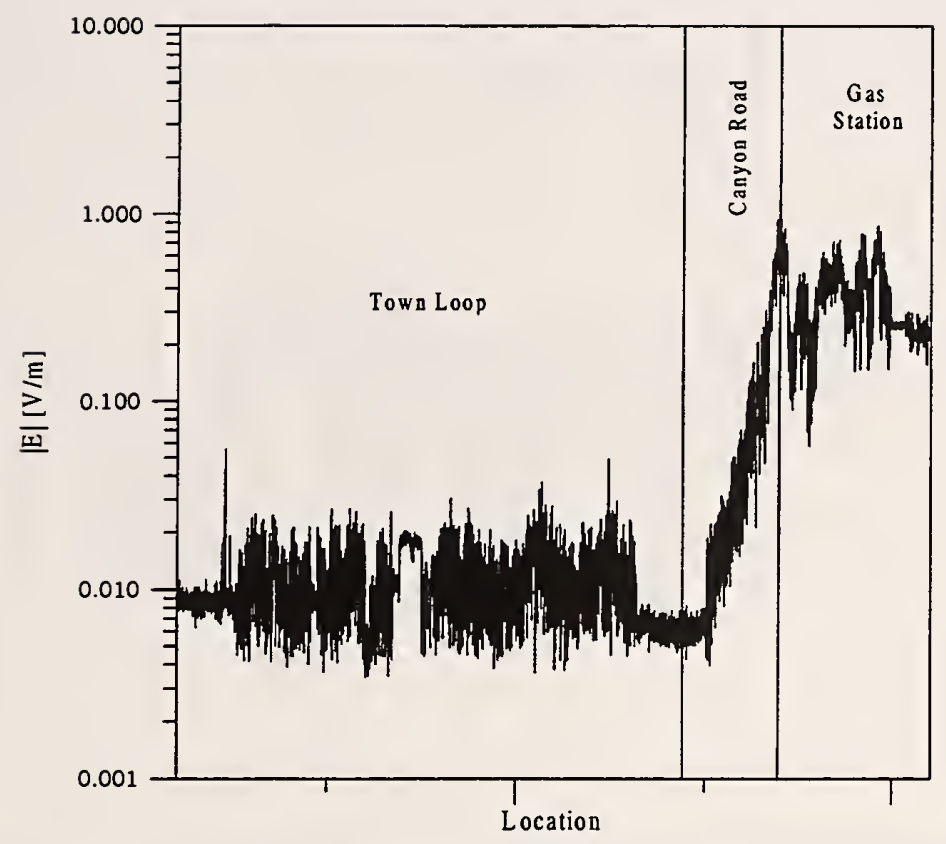

Figure 27. Measured E-field levels scaled to $1 \mathrm{MW}$ EIRP in Eldorado Canyon. These results are for a transmitter on Eldorado Mountain for a frequency of $772 \mathrm{MHz}$, a transmitter height of $3.66 \mathrm{~m}(12.0 \mathrm{ft})$, and a receiver height of $2.95 \mathrm{~m}(9.68 \mathrm{ft})$.

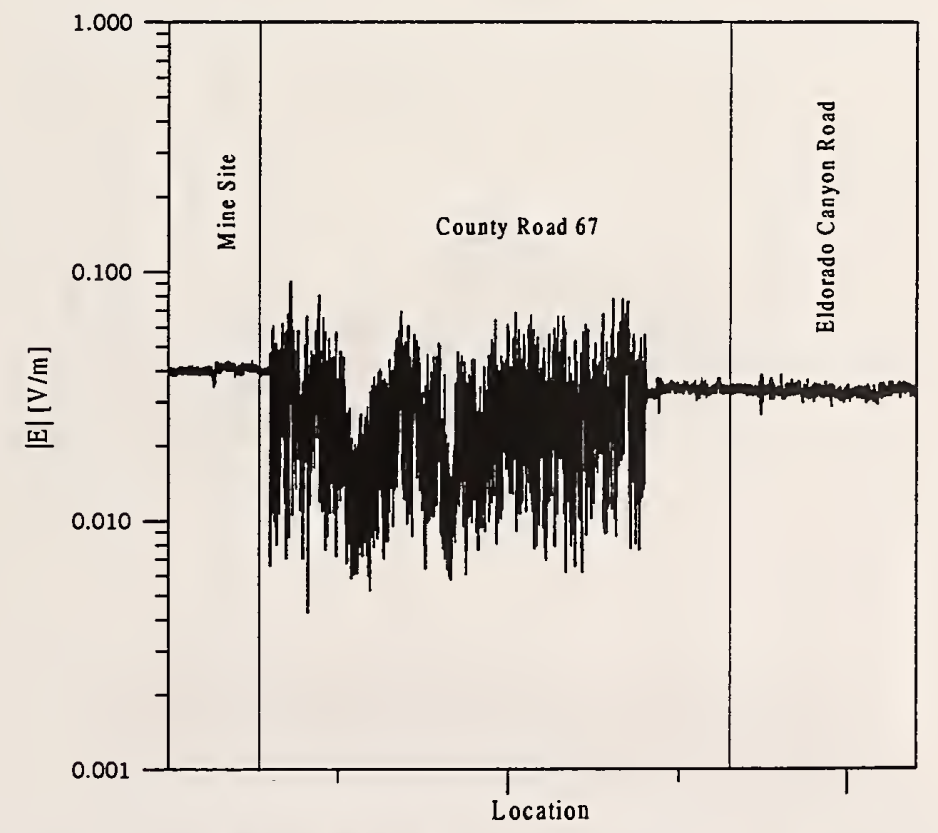

Figure 28. Measured E-field levels scaled to $1 \mathrm{MW}$ EIRP on County Road 67. These results are for a transmitter on Eldorado Mountain for a frequency of $772 \mathrm{MHz}$, a transmitter height of $3.66 \mathrm{~m}(12.0 \mathrm{ft})$, and a receiver height of $2.95 \mathrm{~m}(9.68 \mathrm{ft})$. 


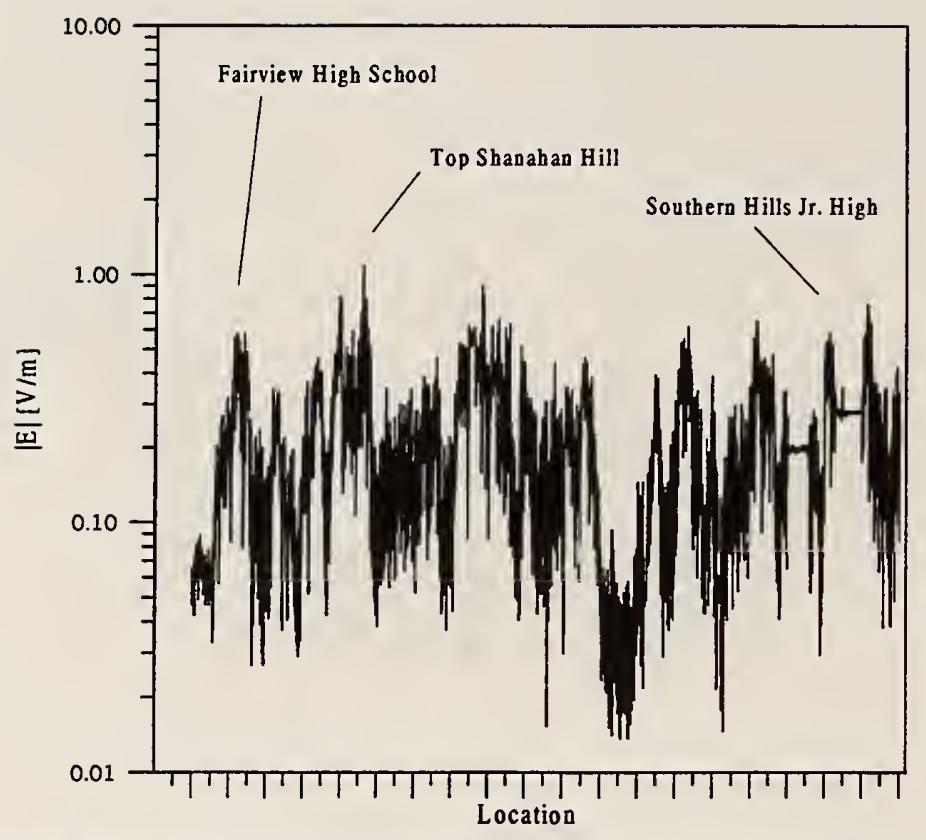

Figure 29. Measured E-field levels scaled to $1 \mathrm{MW}$ EIRP on Greenbriar loop. These results are for a transmitter on Eldorado Mountain for a frequency of $772 \mathrm{MHz}$, a transmitter height of $3.66 \mathrm{~m}(12.0 \mathrm{ft})$, and a receiver height of $2.95 \mathrm{~m}(9.68 \mathrm{ft})$.

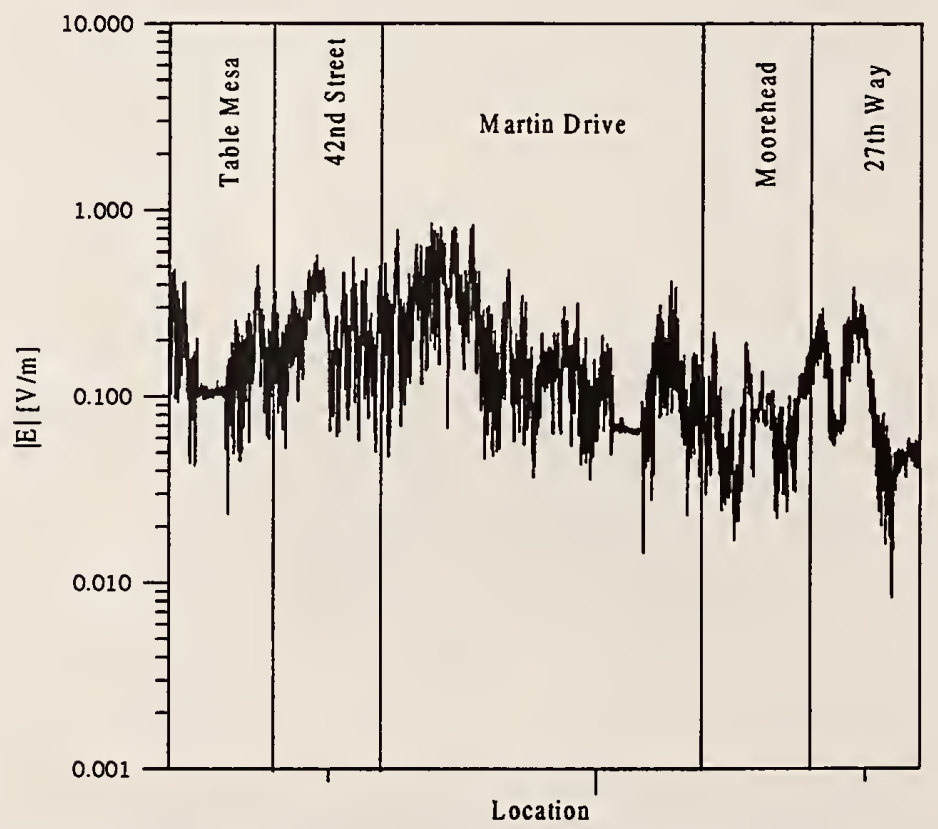

Figure 30. Measured E-field levels scaled to $1 \mathrm{MW}$ EIRP in the Martin Acres neighborhood. These results are for a transmitter on Eldorado Mountain for a frequency of $772 \mathrm{MHz}$, a transmitter height of $3.66 \mathrm{~m}(12.0 \mathrm{ft})$, and a receiver height of $2.95 \mathrm{~m}$ $(9.68 \mathrm{ft})$. 


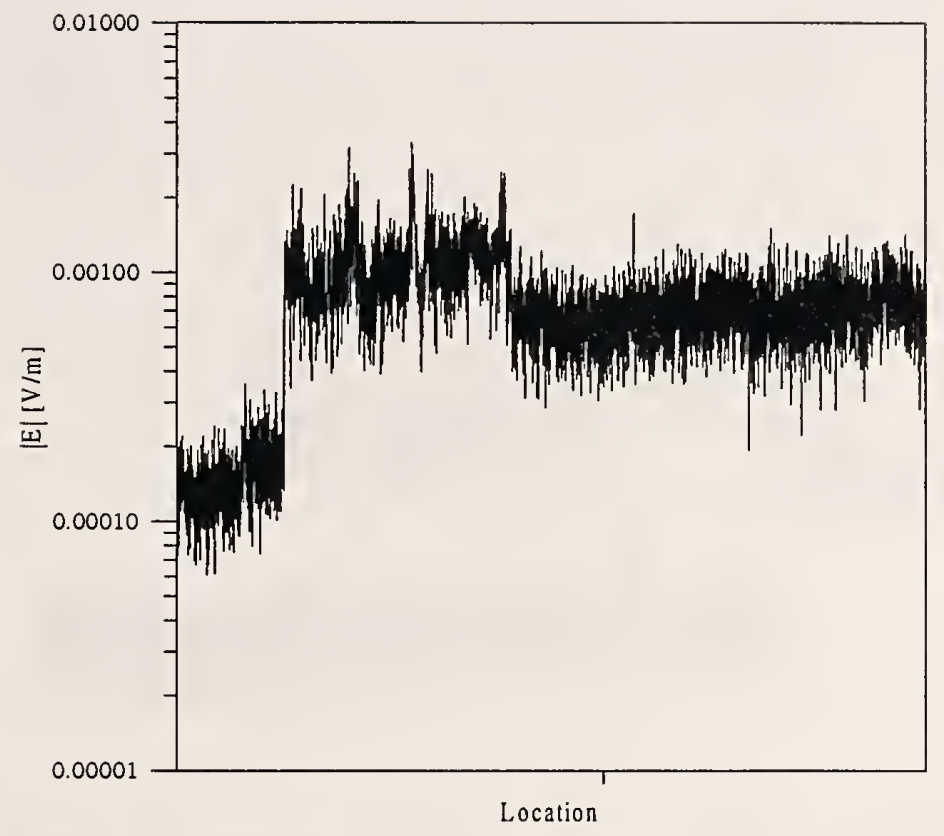

Figure 31. Measured E-field levels scaled to $1 \mathrm{MW}$ EIRP at the DOC Laboratories. These results are for a transmitter on Squaw Mountain for a frequency of $533 \mathrm{MHz}$, a transmitter height of $8.2 \mathrm{~m}(26.9 \mathrm{ft})$, and a receiver height of $2.95 \mathrm{~m}(9.68 \mathrm{ft})$.

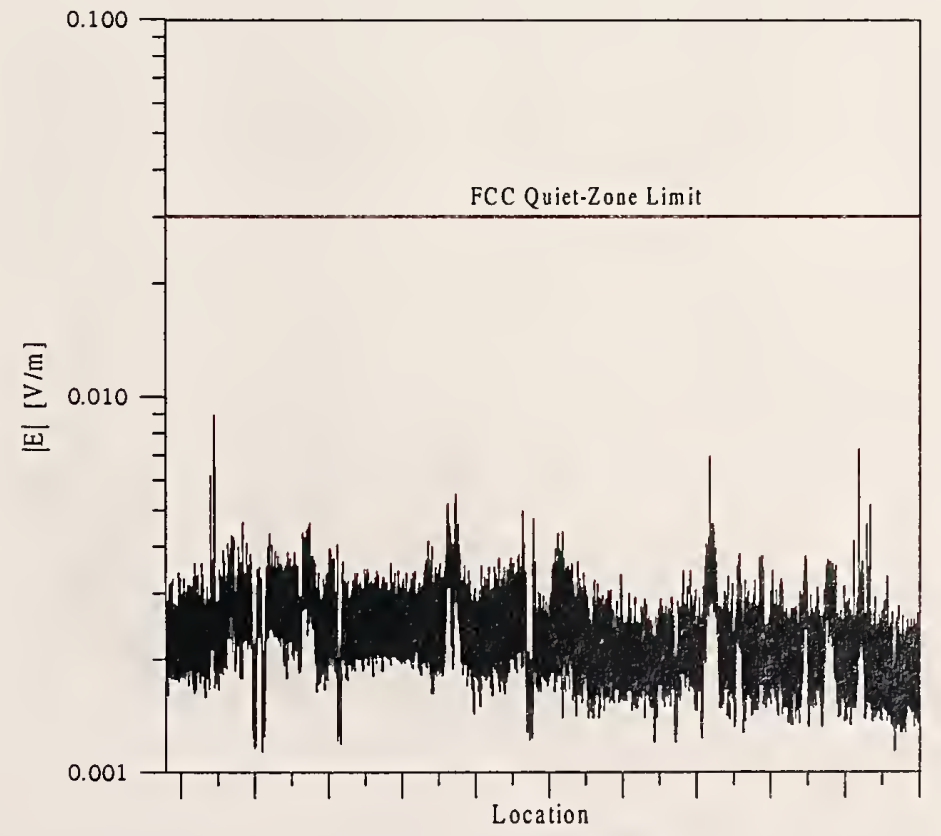

Figure 32. Measured E-field levels scaled to $1 \mathrm{MW}$ EIRP at the Table Mountain NRQZ. These results are for a transmitter on Squaw Mountain for a frequency of $533 \mathrm{MHz}$, a transmitter height of $8.2 \mathrm{~m}(26.9 \mathrm{ft})$, and a receiver height of $2.95 \mathrm{~m}(9.68 \mathrm{ft})$. 


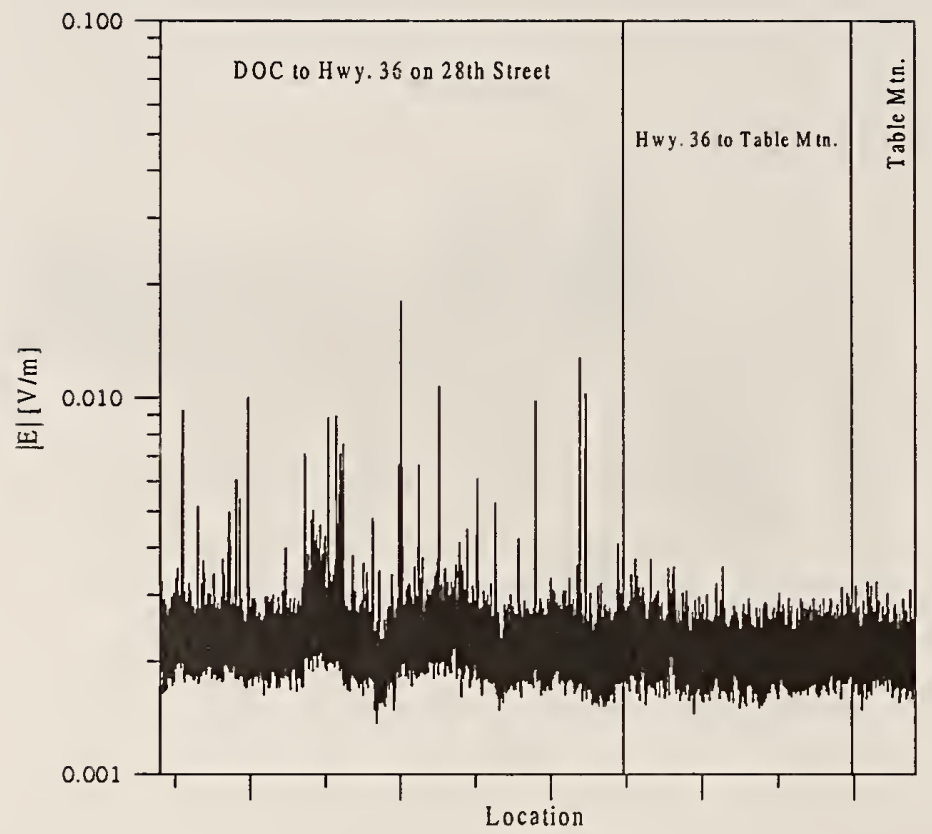

Figure 33. Measured E-field levels scaled to $1 \mathrm{MW}$ EIRP from the DOC Laboratories down $28^{\text {th }}$ Street to the Table Mountain NRQZ. These results are for a transmitter on Squaw Mountain for a frequency of $533 \mathrm{MHz}$, a transmitter height of $8.2 \mathrm{~m}(26.9 \mathrm{ft})$, and a receiver height of $2.95 \mathrm{~m}(9.68 \mathrm{ft})$.

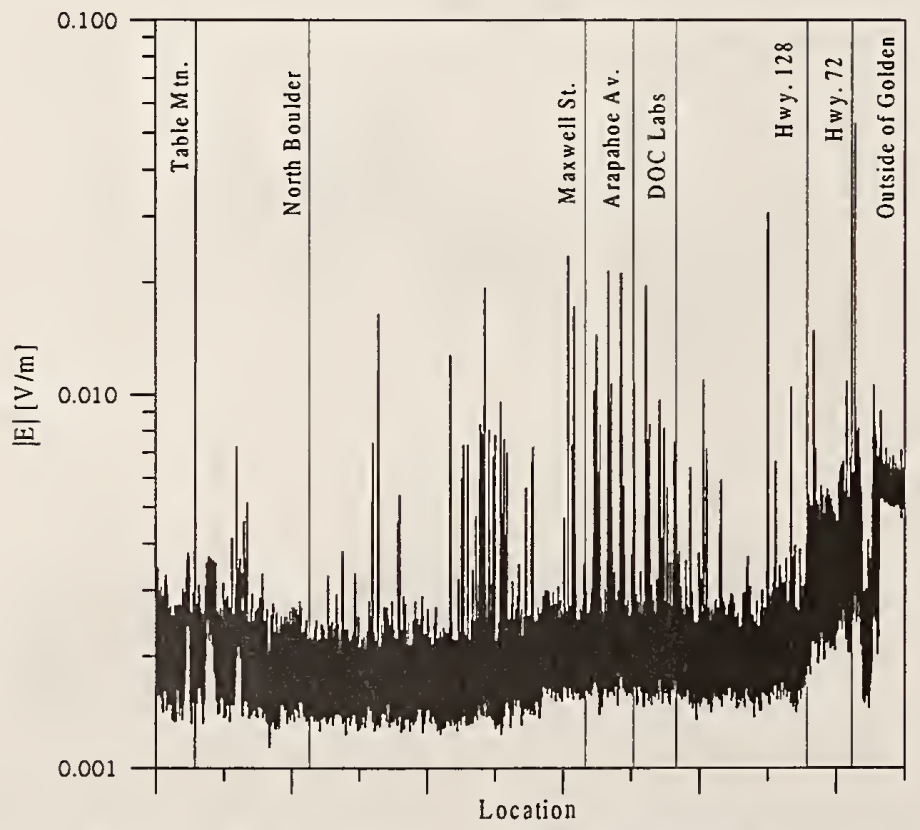

Figure 34. Measured E-field levels scaled to 1 MW EIRP from the Table Mountain NRQZ to Highway 72 via Highway 36, Broadway, and Highway 93. These results are for a transmitter on Squaw Mountain for a frequency of $533 \mathrm{MHz}$, a transmitter height of $8.2 \mathrm{~m}(26.9 \mathrm{ft})$, and a receiver height of $2.95 \mathrm{~m}(9.68 \mathrm{ft})$. 


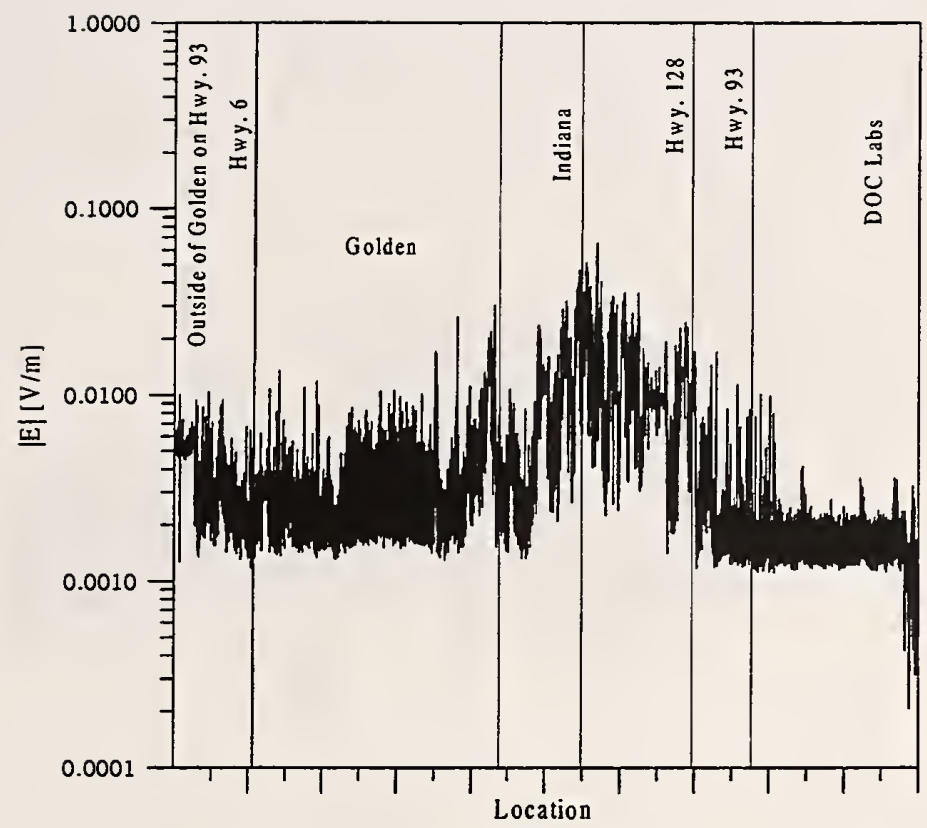

Figure 35. Measured E-field levels scaled to $1 \mathrm{MW}$ EIRP on the Boulder/Golden loop. These results are for a transmitter on Squaw Mountain for a frequency of $533 \mathrm{MHz}$, a transmitter height of $8.2 \mathrm{~m}$ ( $26.9 \mathrm{ft})$, and a receiver height of $2.95 \mathrm{~m}(9.68 \mathrm{ft})$.

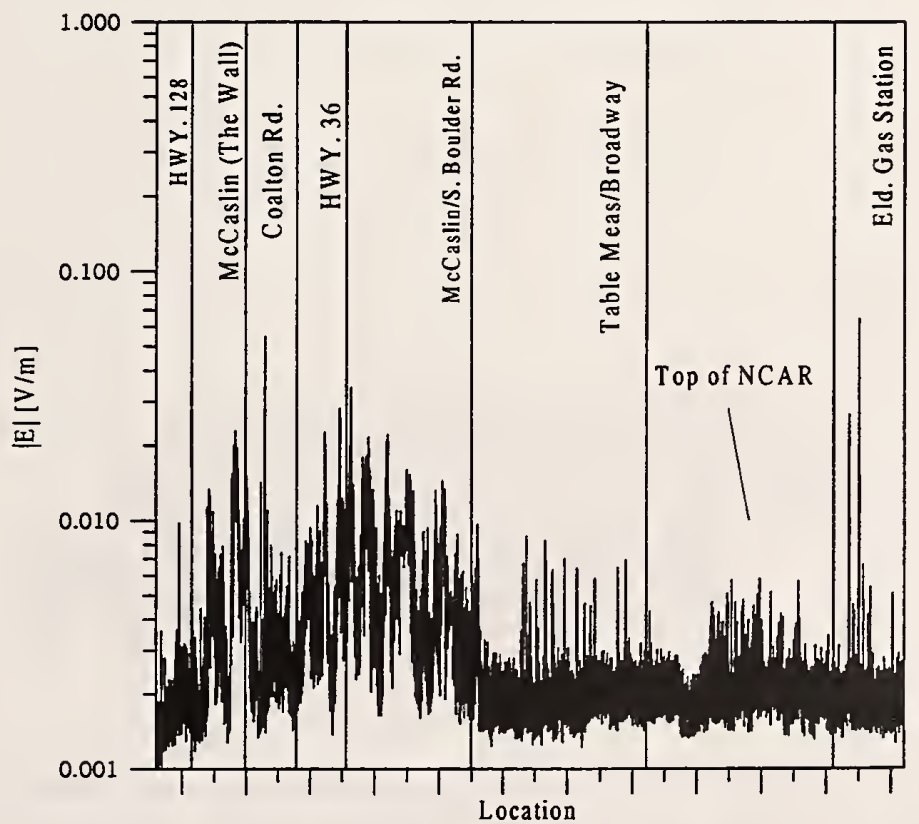

Figure 36. Measured E-field levels scaled to $1 \mathrm{MW}$ EIRP on the McCaslin loop. These results are for a transmitter on Squaw Mountain for a frequency of $533 \mathrm{MHz}$, a transmitter height of $8.2 \mathrm{~m}(26.9 \mathrm{ft})$, and a receiver height of $2.95 \mathrm{~m}(9.68 \mathrm{ft})$. 


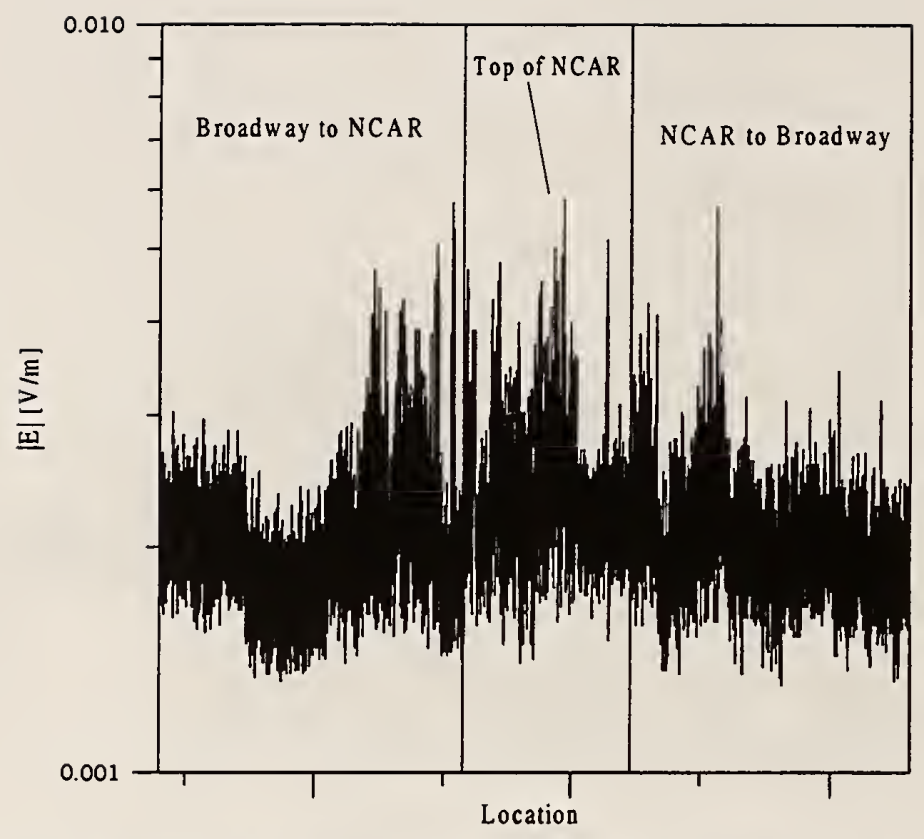

Figure 37. Measured E-field levels scaled to $1 \mathrm{MW}$ EIRP at the NCAR facility at the top of Table Mesa. These results are for a transmitter on Squaw Mountain for a frequency of $533 \mathrm{MHz}$, a transmitter height of $8.2 \mathrm{~m}(26.9 \mathrm{ft})$, and a receiver height of $2.95 \mathrm{~m}(9.68 \mathrm{ft})$.

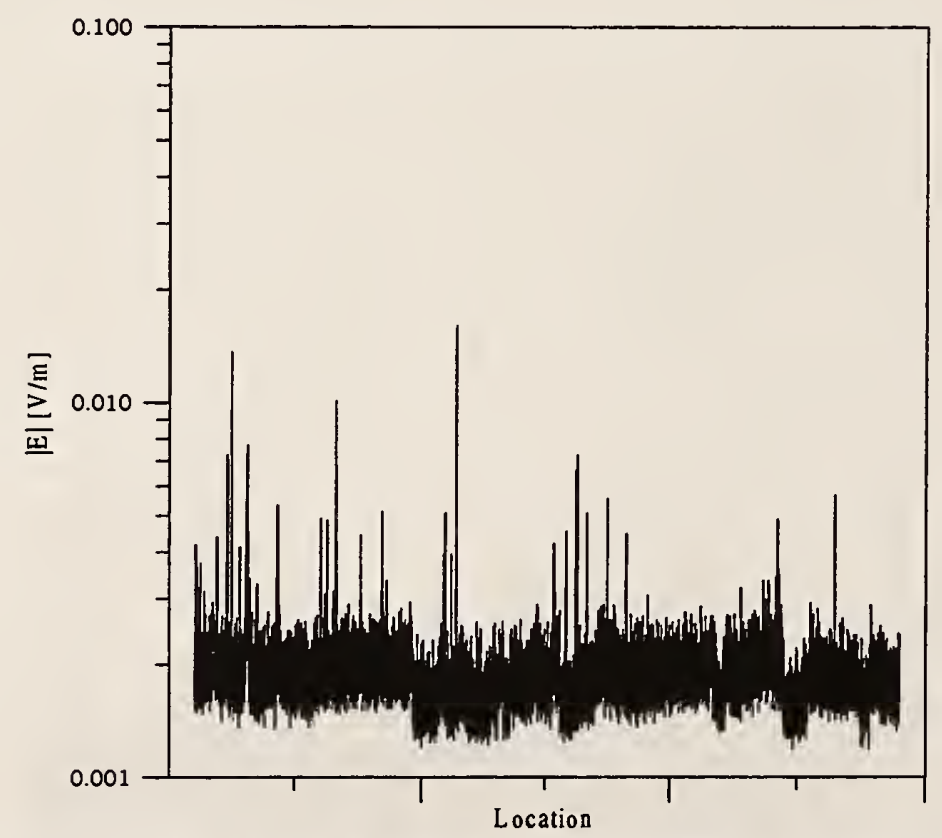

Figure 38. Measured E-field levels scaled to $1 \mathrm{MW}$ EIRP on Greenbriar loop. These results are for a transmitter on Squaw Mountain for a frequency of $533 \mathrm{MHz}$, a transmitter height of $8.2 \mathrm{~m}(26.9 \mathrm{ft})$, and a receiver height of $2.95 \mathrm{~m}(9.68 \mathrm{ft})$. 


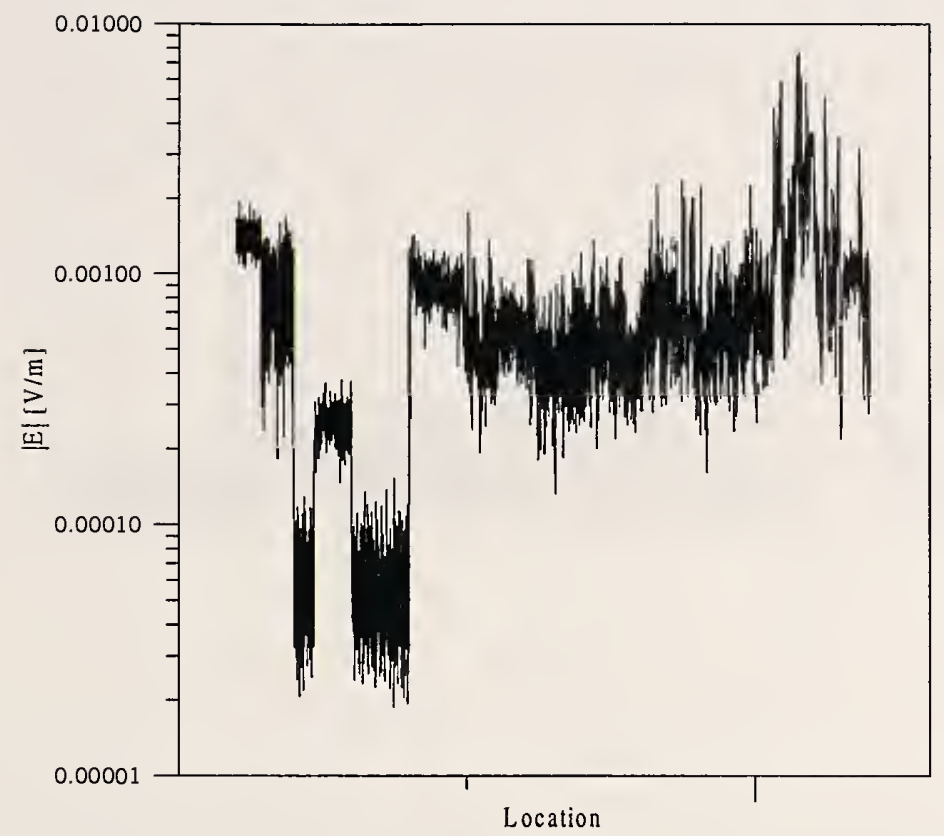

Figure 39. Measured E-field levels scaled to 1 MW EIRP at the DOC Laboratories. These results are for a transmitter on Squaw Mountain for a frequency of $772 \mathrm{MHz}$, a transmitter height of $8.2 \mathrm{~m}(26.9 \mathrm{ft})$, and a receiver height of $2.95 \mathrm{~m}(9.68 \mathrm{ft})$.

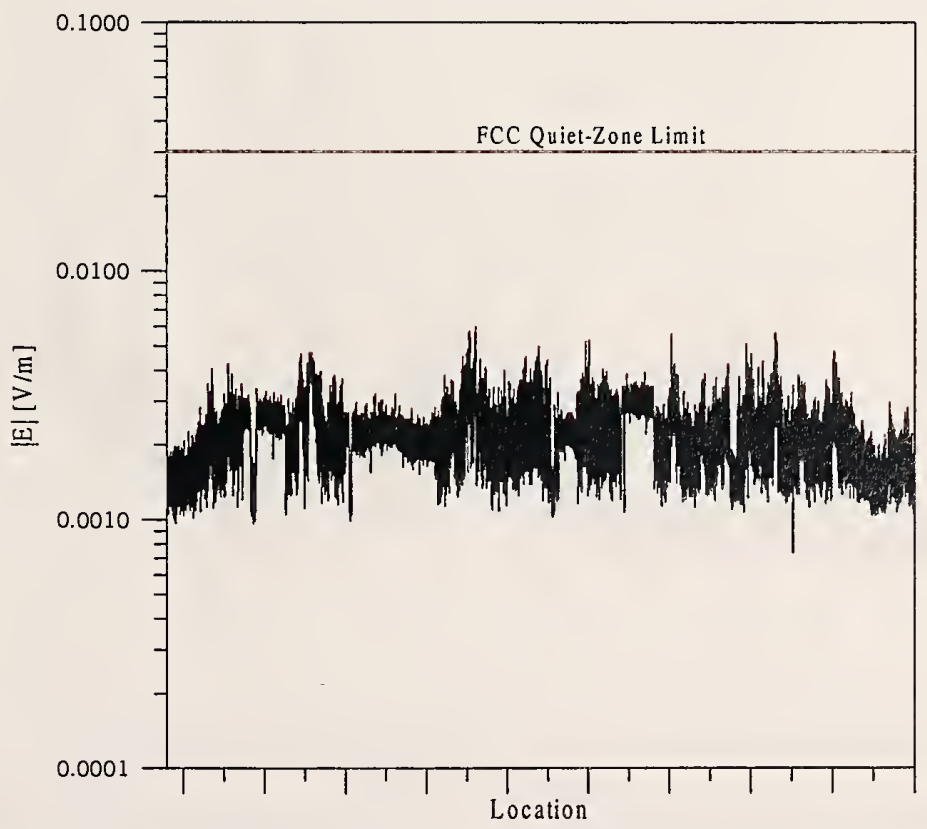

Figure 40. Measured E-field levels scaled to $1 \mathrm{MW}$ EIRP at the Table Mountain NRQZ. These results are for a transmitter on Squaw Mountain for a frequency of $772 \mathrm{MHz}$, a transmitter height of $8.2 \mathrm{~m}(26.9 \mathrm{ft})$, and a receiver height of $2.95 \mathrm{~m}(9.68 \mathrm{ft})$. 


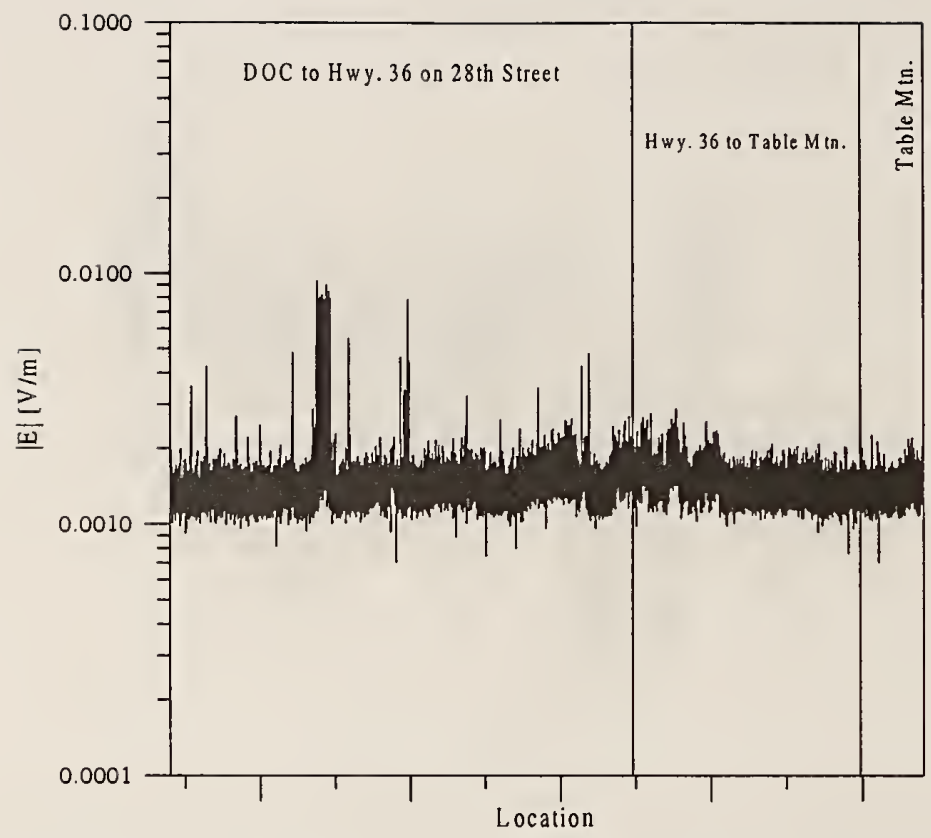

Figure 41. Measured E-field levels scaled to $1 \mathrm{MW}$ EIRP from the DOC Laboratories down $28^{\text {th }}$ Street to the Table Mountain NRQZ. These results are for a transmitter on Squaw Mountain for a frequency of $772 \mathrm{MHz}$, a transmitter height of $8.2 \mathrm{~m}(26.9 \mathrm{ft})$, and a receiver height of $2.95 \mathrm{~m}(9.68 \mathrm{ft})$.

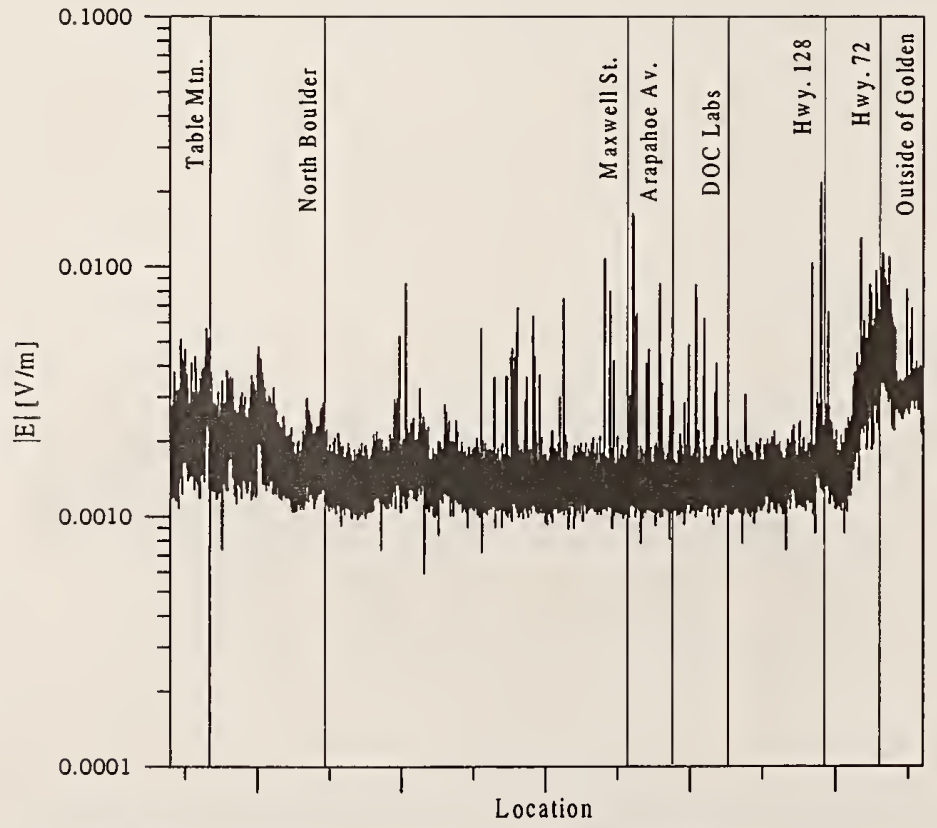

Figure 42. Measured E-field levels scaled to 1 MW EIRP from the Table Mountain NRQZ to Highway 72 via Highway 36, Broadway, and Highway 93. These results are for a transmitter on Squaw Mountain for a frequency of $772 \mathrm{MHz}$, a transmitter height of $8.2 \mathrm{~m}(26.9 \mathrm{ft})$, and a receiver height of $2.95 \mathrm{~m}(9.68 \mathrm{ft})$. 


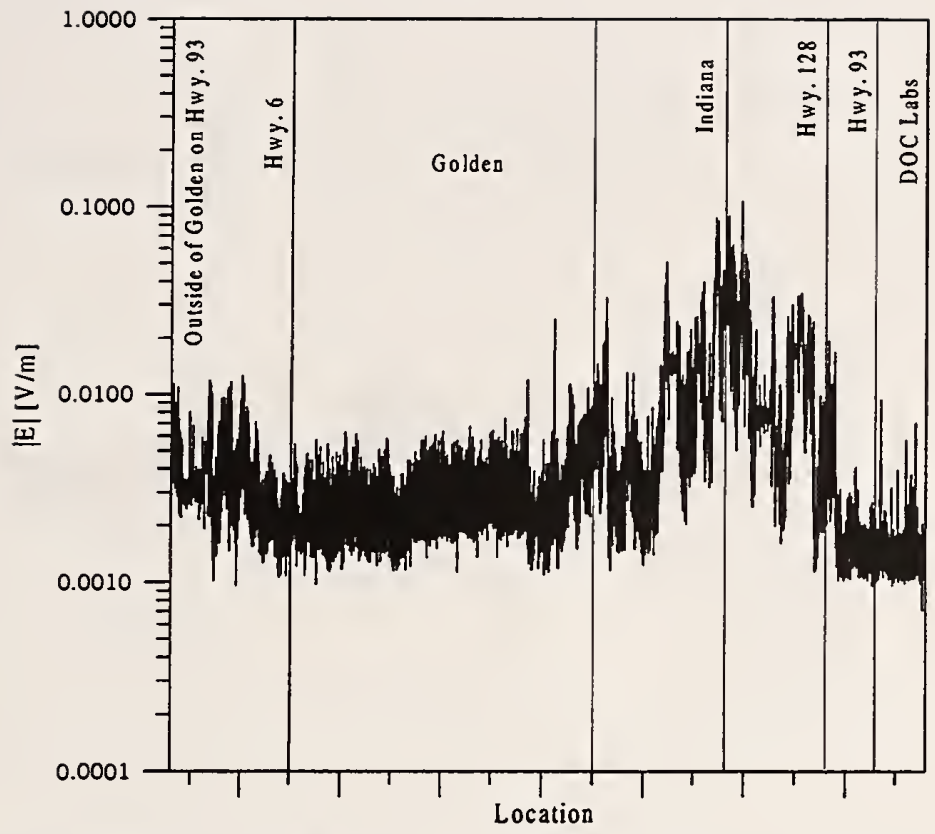

Figure 43. Measured E-field levels scaled to $1 \mathrm{MW}$ EIRP on the Boulder/Golden loop. These results are for a transmitter on Squaw Mountain for a frequency of $772 \mathrm{MHz}$, a transmitter height of $8.2 \mathrm{~m}(26.9 \mathrm{ft})$, and a receiver height of $2.95 \mathrm{~m}(9.68 \mathrm{ft})$.

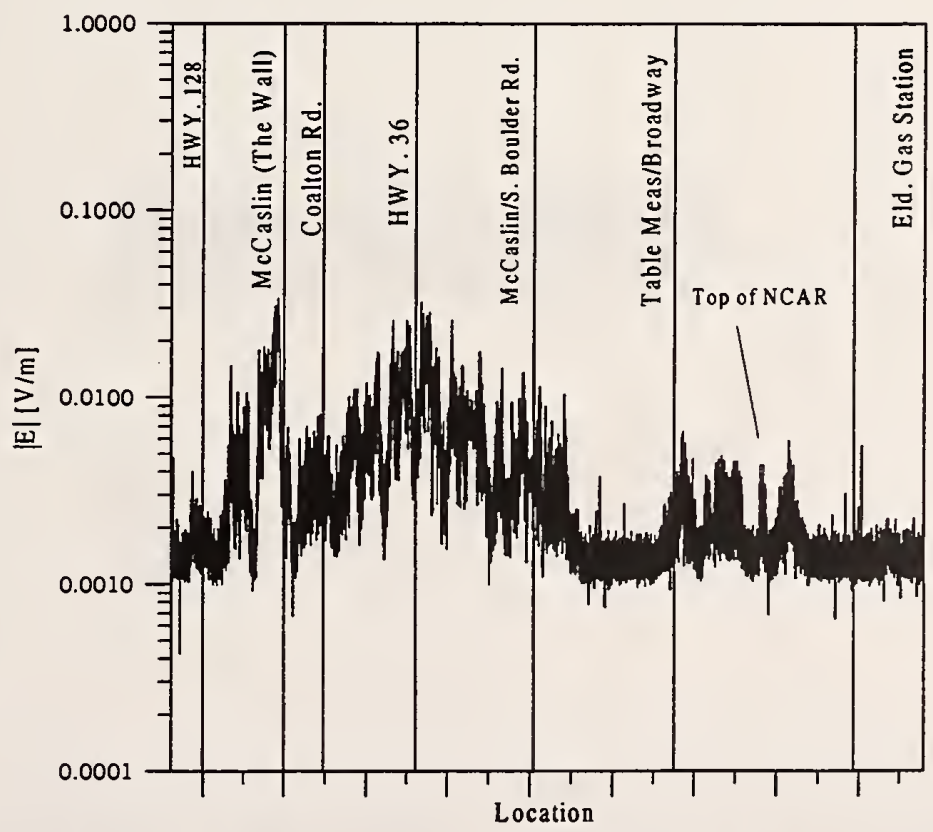

Figure 44. Measured E-field levels scaled to $1 \mathrm{MW}$ EIRP on the McCaslin loop. These results are for a transmitter on Squaw Mountain for a frequency of $772 \mathrm{MHz}$, a transmitter height of $8.2 \mathrm{~m}(26.9 \mathrm{ft})$, and a receiver height of $2.95 \mathrm{~m}(9.68 \mathrm{ft})$. 


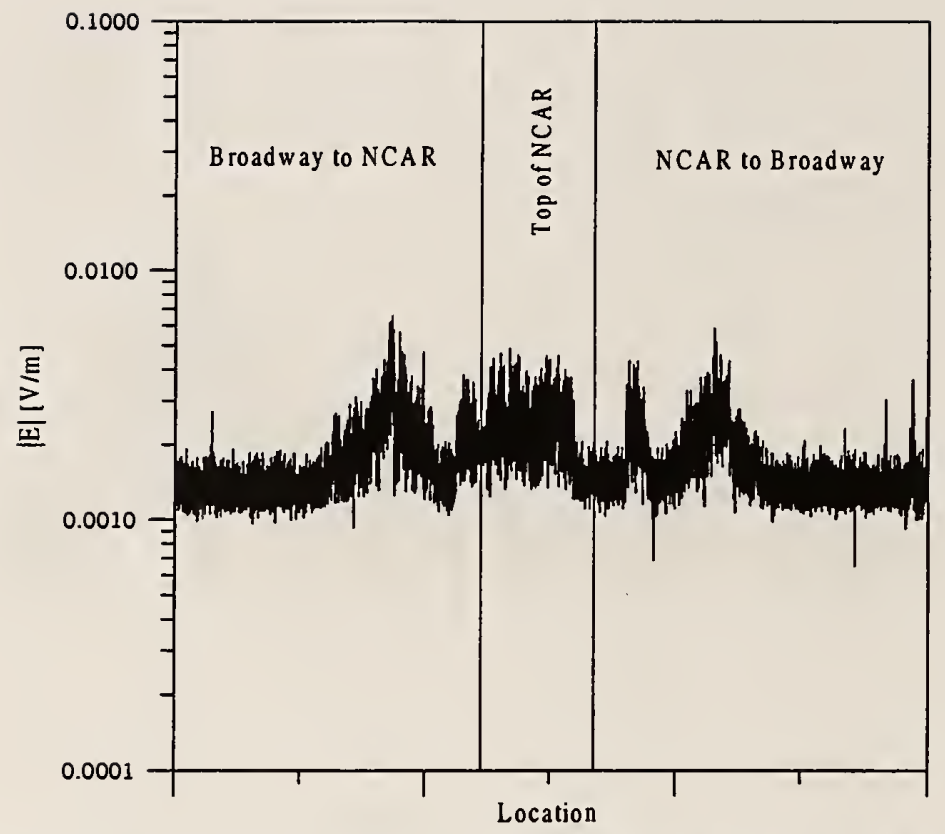

Figure 45. Measured E-field levels scaled to $1 \mathrm{MW}$ EIRP at the NCAR facility at the top of Table Mesa. These results are for a transmitter on Squaw Mountain for a frequency of $772 \mathrm{MHz}$, a transmitter height of $8.2 \mathrm{~m}(26.9 \mathrm{ft})$, and a receiver height of $2.95 \mathrm{~m}(9.68 \mathrm{ft})$.

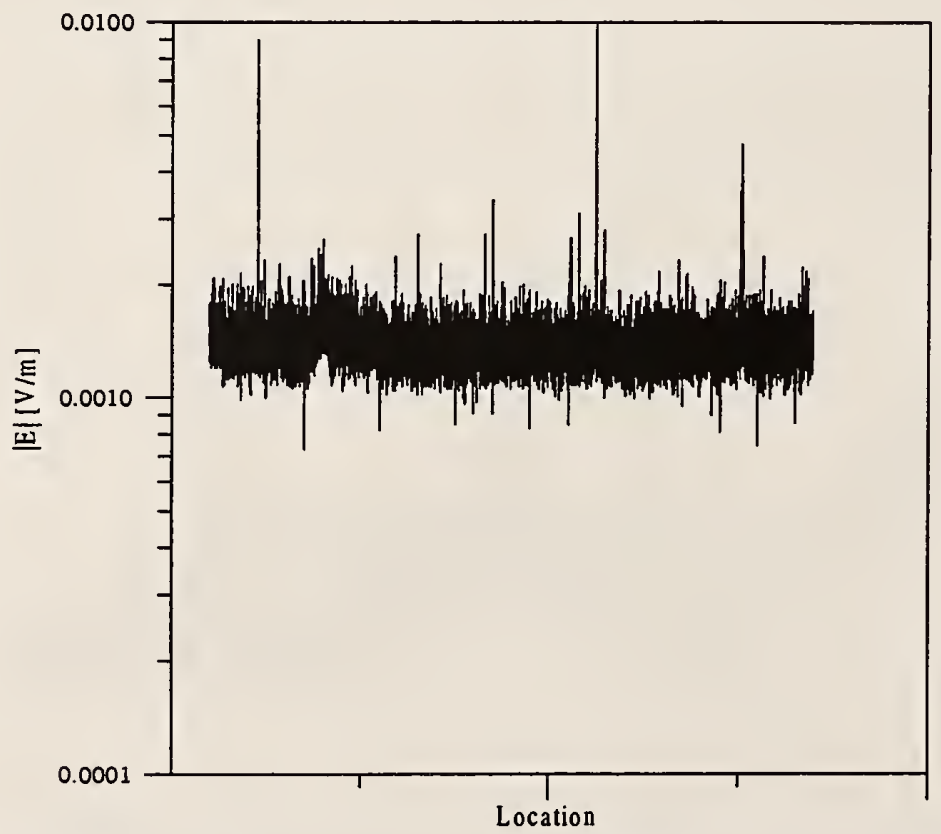

Figure 46. Measured E-field levels scaled to $1 \mathrm{MW}$ EIRP on the Greenbriar loop. These results are for a transmitter on Squaw Mountain for a frequency of $772 \mathrm{MHz}$, a

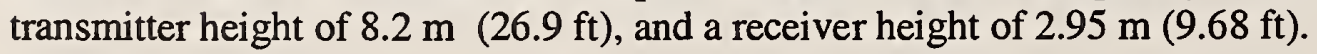




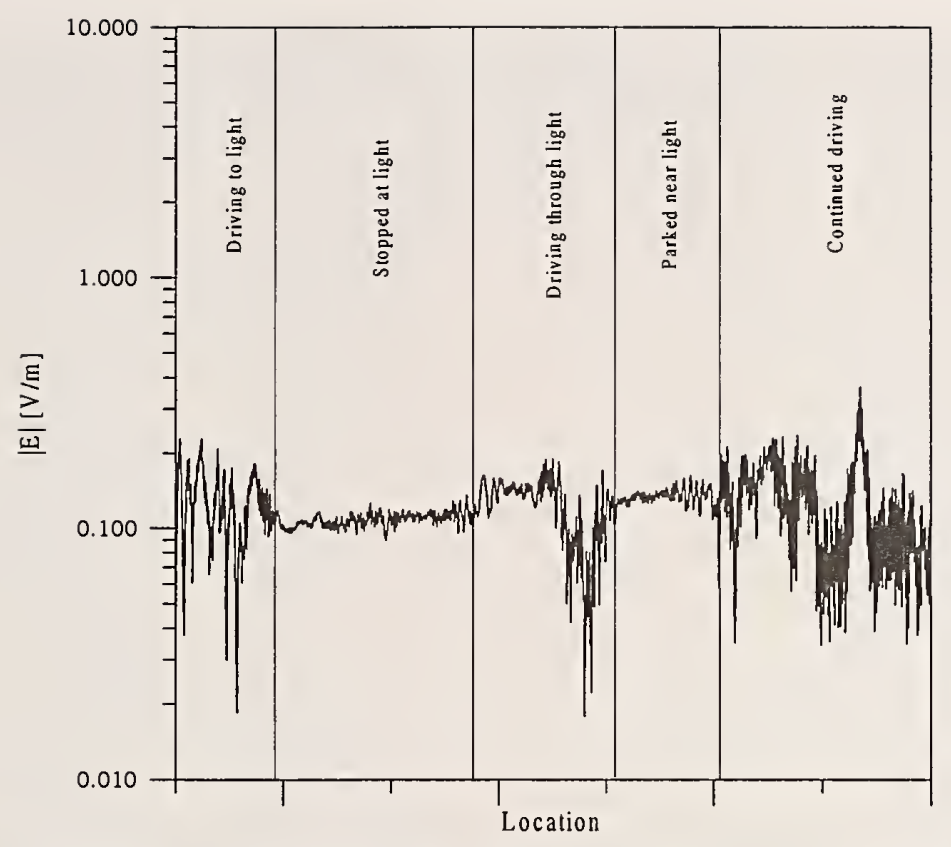

Figure 47. Measured E-field scaled to 1 MW EIRP at the intersection of Highway 93 and Highway 72. These results are for a transmitter on Eldorado Mountain for a frequency of

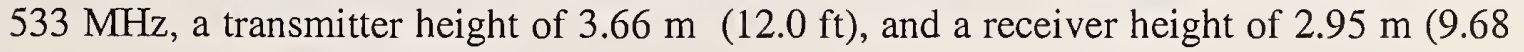
$\mathrm{ft})$.

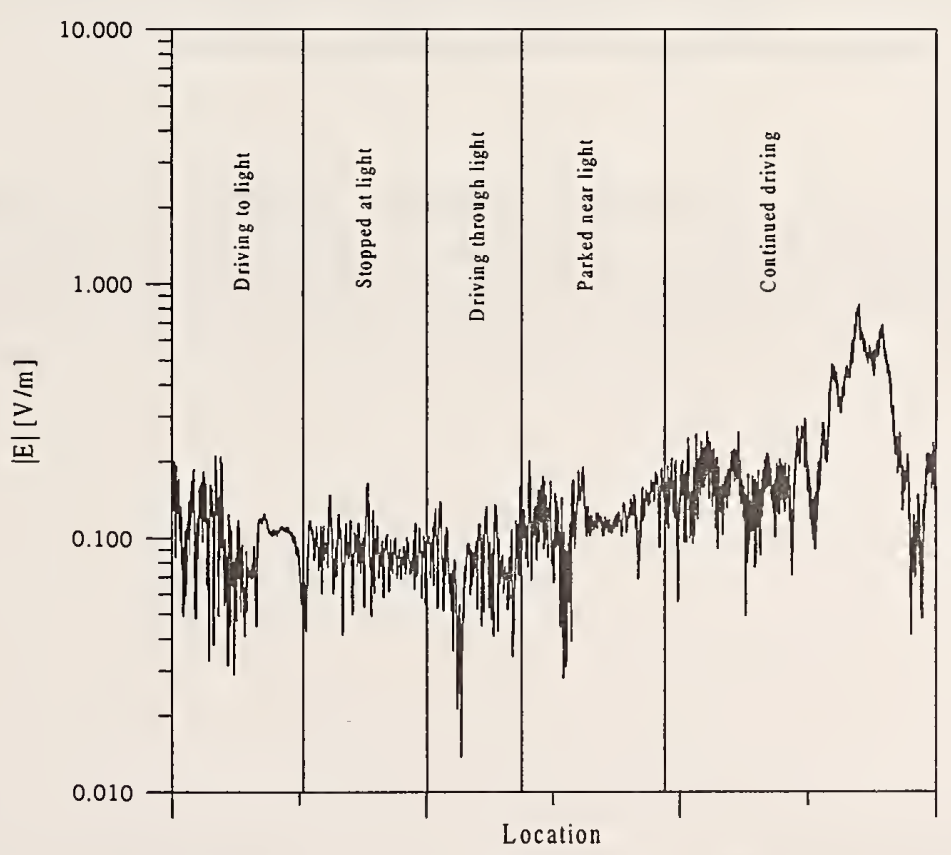

Figure 48. Measured E-field scaled to $1 \mathrm{MW}$ EIRP at the intersection of Highway 93 and Highway 72. These results are for a transmitter on Eldorado Mountain for a frequency of $772 \mathrm{MHz}$, a transmitter height of $3.66 \mathrm{~m}(12.0 \mathrm{ft})$, and a receiver height of $2.95 \mathrm{~m}(9.68$ $\mathrm{ft})$. 


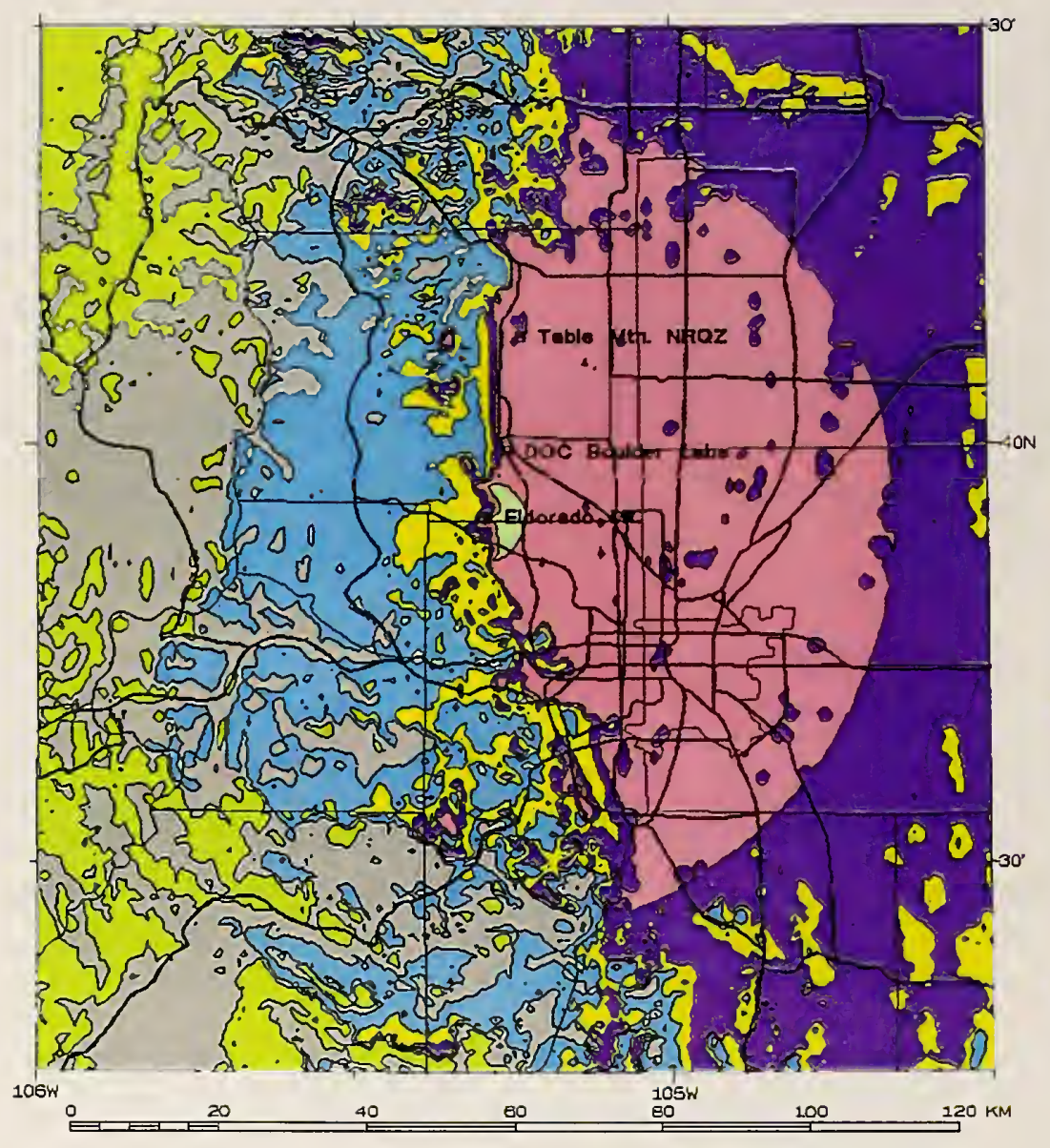
Eldorado Mt.
ITS
Proposed site (533 MHz, $1 \mathrm{Mw}$ EIRP,HP) $19-\mathrm{MBr}^{-01} 13: 44: 58$ CS065Mar1901B.ques 1997 Census

Fiela Intensity(dBuv/mi $\square$ Greater than $10 \mathrm{~V} / \mathrm{m}$
Area:
Population:
Housenolds:

1 to $10 \mathrm{v} / \mathrm{m}$

Area: Population: 30. $\mathrm{sa} \mathrm{km}$

ani 1 to $1 \mathrm{~V} / \mathrm{m}$ Area: $\quad 3800 \mathrm{sq} \mathrm{km}$ $\begin{array}{ll} & \\ \text { Population: } & 1838000 . \\ \text { HDUEeholds: } & 547000 .\end{array}$

- 01 to $.1 \mathrm{~V} / \mathrm{m}$ Area: 3980 . sq $\mathrm{km}$ $\begin{array}{ll}\text { Population: } & 364000 . \\ \text { Households: } & 103000 .\end{array}$

.001 to $.01 \mathrm{~V} / \mathrm{m}$ Area: $\quad 01580.59 \mathrm{~km}$ Population: 133000 . .0001 to $.001 \mathrm{~V} / \mathrm{m}$ Ares: $2740.30 \mathrm{~km}$ $\begin{array}{ll}\text { Population: } & 48000 . \\ \text { Households: } & 14000 .\end{array}$ . 00001 to $.0001 \mathrm{~V} / \mathrm{m}$ Area: $30.0001 \mathrm{v} / \mathrm{m} / \mathrm{km}$ Households: $\quad 28000$.

less than $.00001 \mathrm{~V} / \mathrm{m}$ Area: 1990. sa $\mathrm{km}$ Population: $\quad 8000$.

Figure 49. Contour plot of the modeled (or predicted) E-field levels around the DenverBoulder area for a horizontally polarized antenna. These results are for a transmitter on Eldorado Mountain for a frequency of $533 \mathrm{MHz}, \mathrm{EIRP}=1 \mathrm{MW}$, a transmitter height of $3.66 \mathrm{~m}(12 \mathrm{ft})$, and a receiver height of $2.95 \mathrm{~m}(9.68 \mathrm{ft})$. 

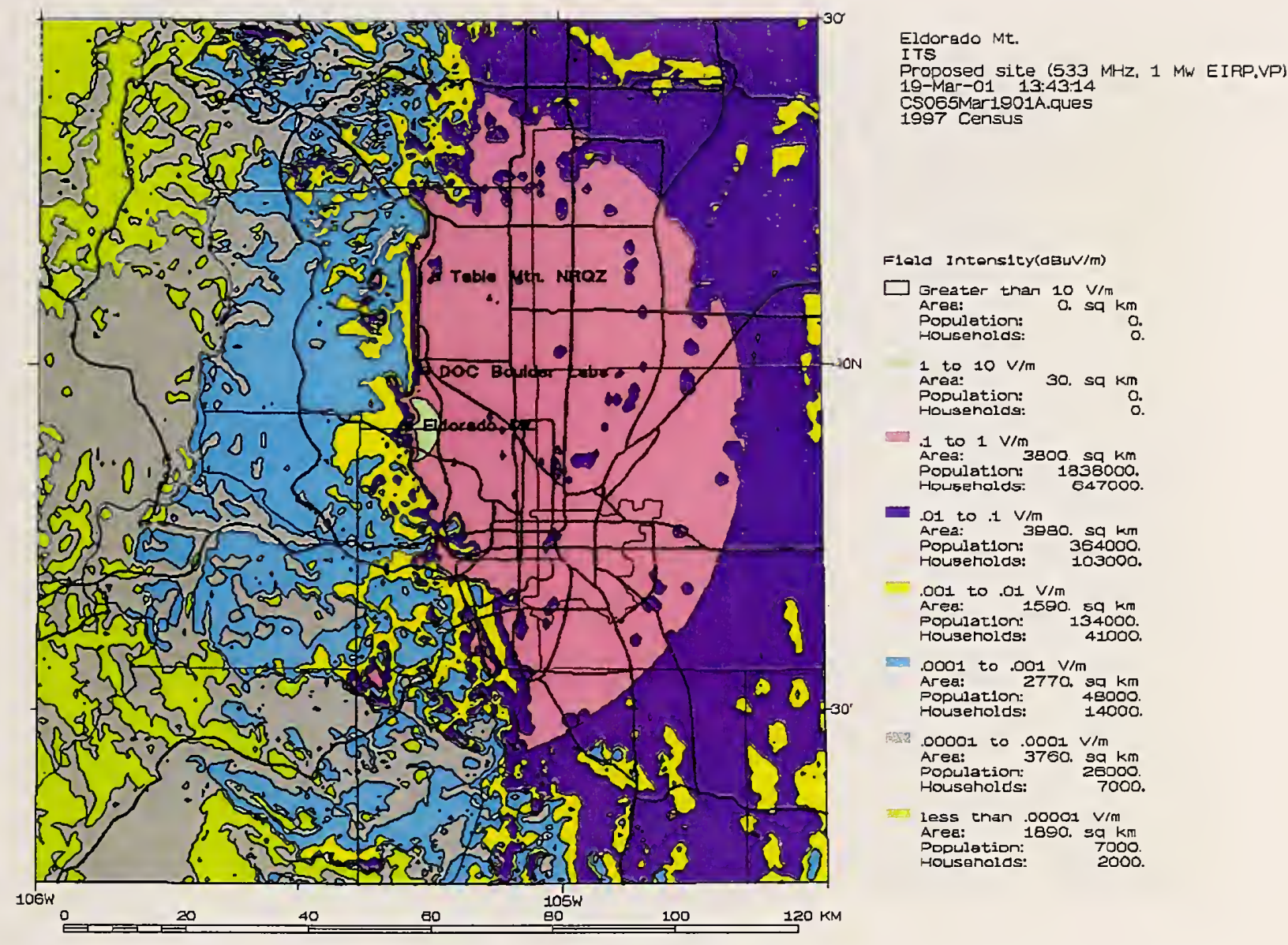

Figure 50. Contour plot of the modeled (or predicted) E-field levels around the DenverBoulder area for a vertically polarized antenna. These results are for a transmitter on Eldorado Mountain for a frequency of $533 \mathrm{MHz}, \mathrm{EIRP}=1 \mathrm{MW}$, a transmitter height of $3.66 \mathrm{~m}(12 \mathrm{ft})$, and a receiver height of $2.95 \mathrm{~m}(9.68 \mathrm{ft})$. 

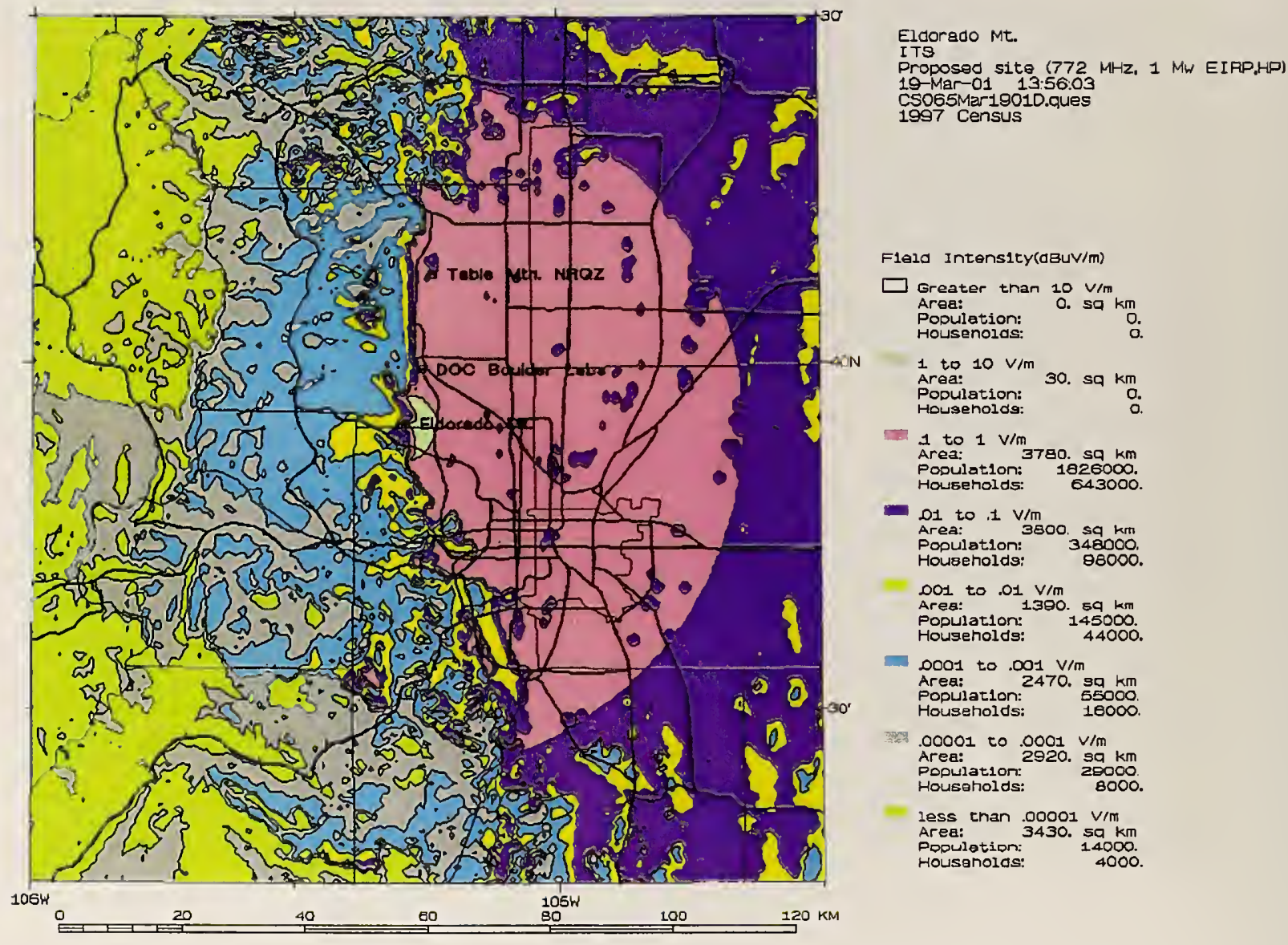

Figure 51. Contour plot of the modeled (or predicted) E-field levels around the DenverBoulder area for a horizontally polarized antenna. These results are for a transmitter on Eldorado Mountain for a frequency of $772 \mathrm{MHz}, \mathrm{EIRP}=1 \mathrm{MW}$, a transmitter height of $3.66 \mathrm{~m}(12 \mathrm{ft})$, and a receiver height of $2.95 \mathrm{~m}(9.68 \mathrm{ft})$. 

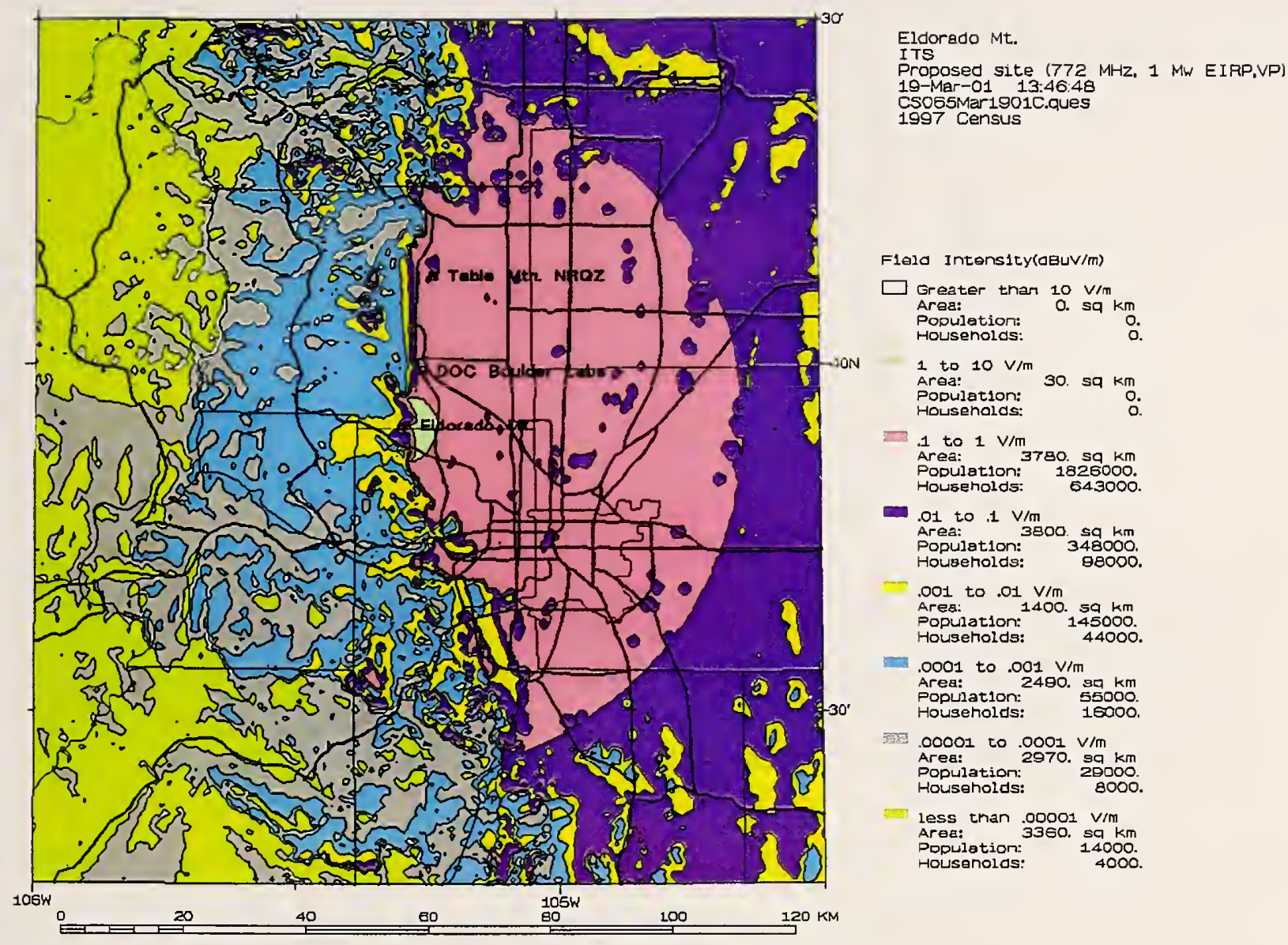

Fleld Intensity(abuV/m)

$\square$ Greater than $10 \mathrm{~V} / \mathrm{m}$ Araa: $\quad$ o. sq km Housenolds: 1 to $10 \mathrm{~V} / \mathrm{m}$ Population: Housenolds:

ए 1 to $1 \mathrm{~V} / \mathrm{m}$ Area: $3780 . \mathrm{sq} \mathrm{km}$ Households: 643000 .

01 to $1 \mathrm{~V} / \mathrm{m}$ Area: $3800 . \mathrm{sq} \mathrm{km}$ $\begin{array}{rr}\text { Population: } & \mathbf{3 4 8 0 0 0 .} \\ \text { Howreholds: } & \mathbf{8 8 0 0 0} \text {. }\end{array}$

- .001 to $.01 \mathrm{~V} / \mathrm{m}$ Area: .001 to $1400.59 \mathrm{~km}$ Households: $\quad 44000$.

ind 0001 to $.001 \mathrm{~V} / \mathrm{m}$ Area: 2490. $39 \mathrm{~km}$ Households: $\quad 1 \Subset 000$.

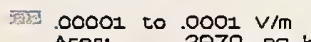
Area: $2970.59 \mathrm{~km}$
Population: Households: $\quad 8000$.

Intur less than .00001 V/m Area: 3360 . $59 \mathrm{~km}$ Housenolas: 4000

Figure 52. Contour plot of the modeled (or predicted) E-field levels around the DenverBoulder area for a vertically polarized antenna. These results are for a transmitter on Eldorado Mountain for a frequency of $772 \mathrm{MHz}, \mathrm{EIRP}=1 \mathrm{MW}$, a transmitter height of

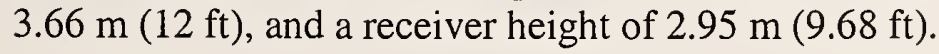




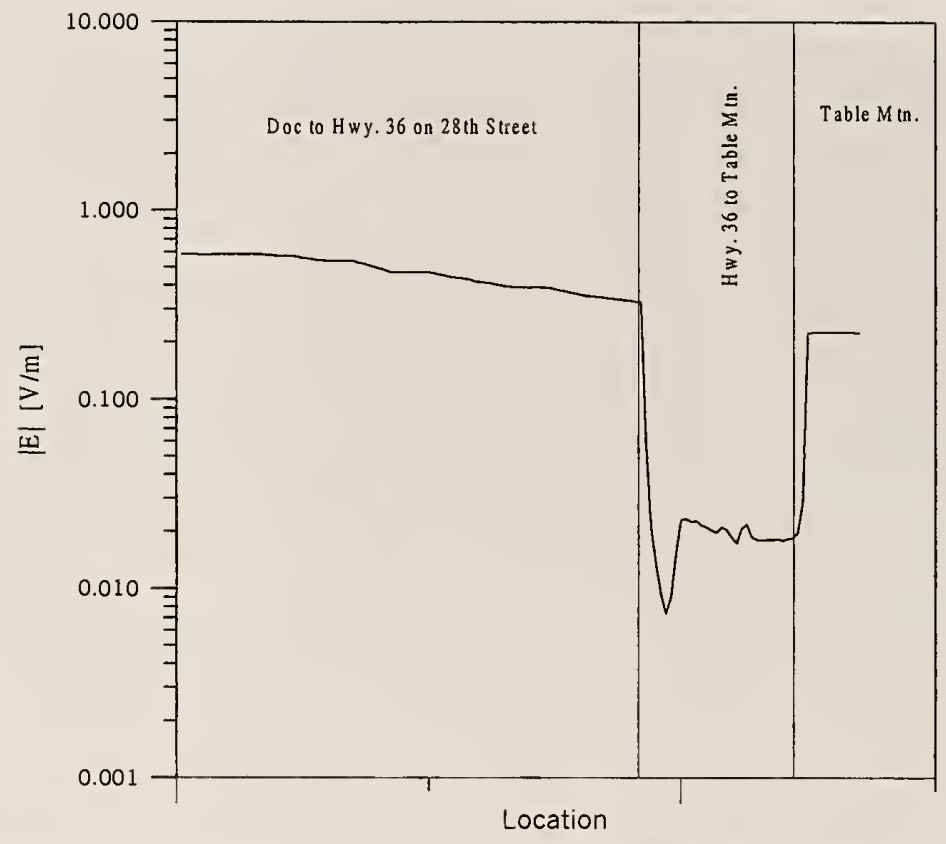

Figure 53. Modeled (or predicted) E-field levels on the $28^{\text {th }}$ Street Route. These results are for a transmitter on Eldorado Mountain for a frequency of $533 \mathrm{MHz}, \mathrm{EIRP}=1 \mathrm{MW}$, a transmitter height of $3.66 \mathrm{~m}(12 \mathrm{ft})$, and a receiver height of $2.95 \mathrm{~m}(9.68 \mathrm{ft})$.

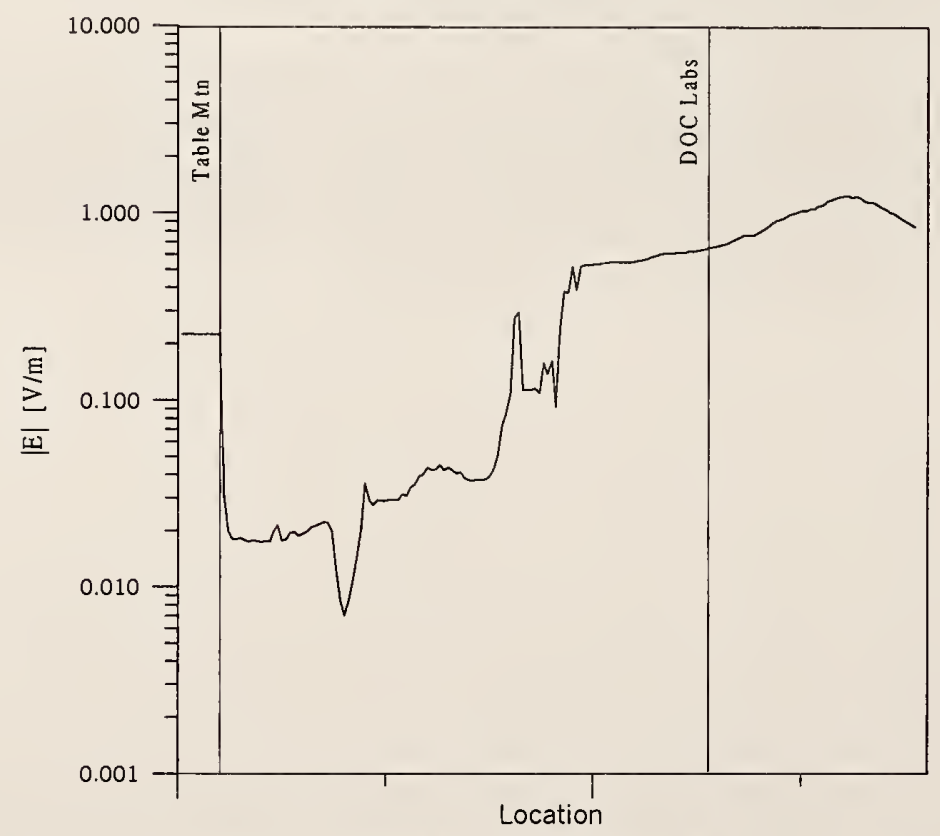

Figure 54. Modeled (or predicted) E-field levels on the Broadway Route. These results are for a transmitter on Eldorado Mountain for a frequency of $533 \mathrm{MHz}, \mathrm{EIRP}=1 \mathrm{MW}$, a transmitter height of $3.66 \mathrm{~m}(12 \mathrm{ft})$, and a receiver height of $2.95 \mathrm{~m}(9.68 \mathrm{ft})$. 


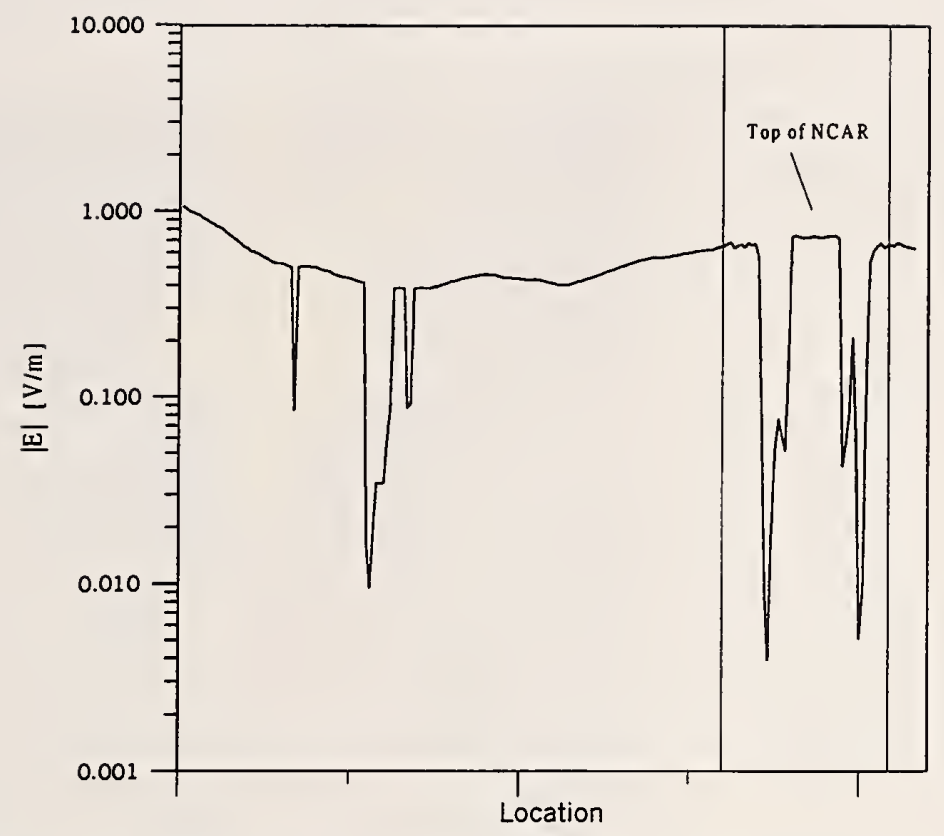

Figure 55. Modeled (or predicted) E-field levels on the McCaslin Loop. These results are for a transmitter on Eldorado Mountain for a frequency of $533 \mathrm{MHz}, \mathrm{EIRP}=1 \mathrm{MW}$, a transmitter height of $3.66 \mathrm{~m}(12 \mathrm{ft})$, and a receiver height of $2.95 \mathrm{~m}(9.68 \mathrm{ft})$.

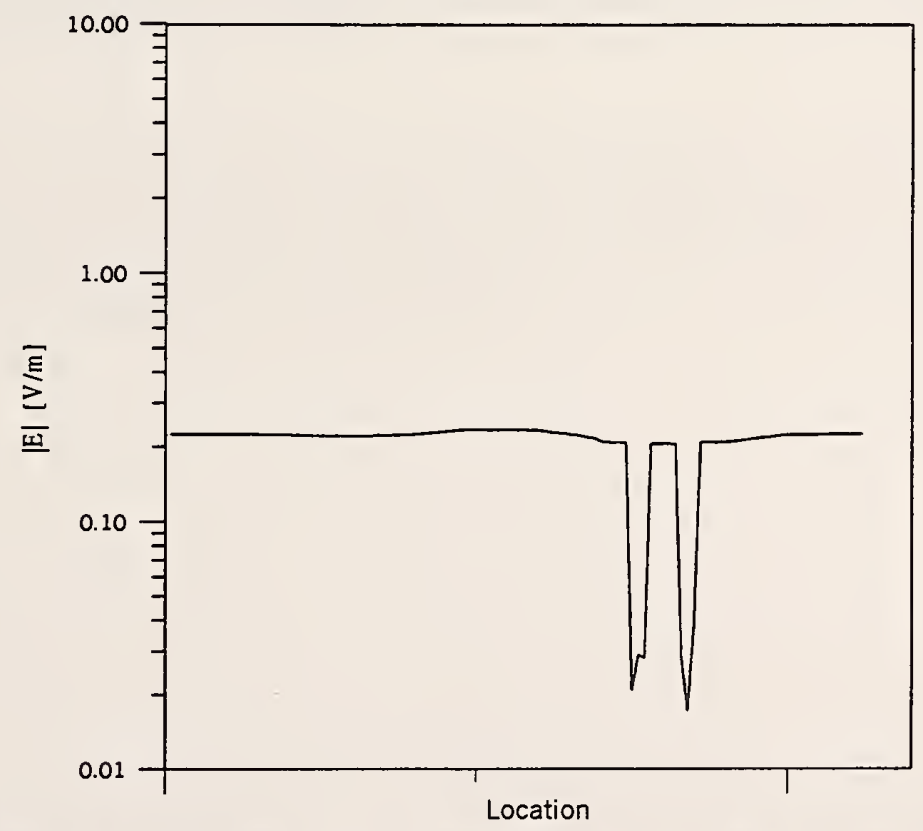

Figure 56. Modeled (or predicted) E-field levels at the Table Mountain NRQZ. These results are for a transmitter on Eldorado Mountain for a frequency of $533 \mathrm{MHz}, \mathrm{EIRP}=1$ MW, a transmitter height of $3.66 \mathrm{~m}(12 \mathrm{ft})$, and a receiver height of $2.95 \mathrm{~m}(9.68 \mathrm{ft})$. 


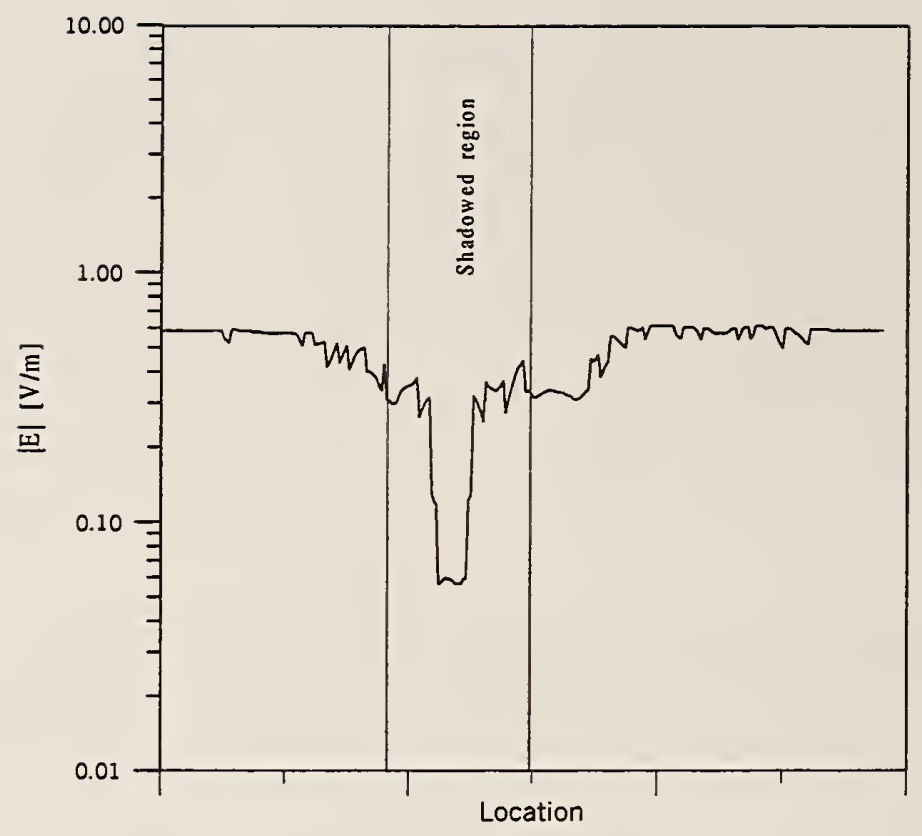

Figure 57. Modeled (or predicted) E-field levels at the DOC Laboratories. These results are for a transmitter on Eldorado Mountain for a frequency of $533 \mathrm{MHz}, \mathrm{EIRP}=1 \mathrm{MW}$, a transmitter height of $3.66 \mathrm{~m}(12 \mathrm{ft})$, and a receiver height of $2.95 \mathrm{~m}(9.68 \mathrm{ft})$. 


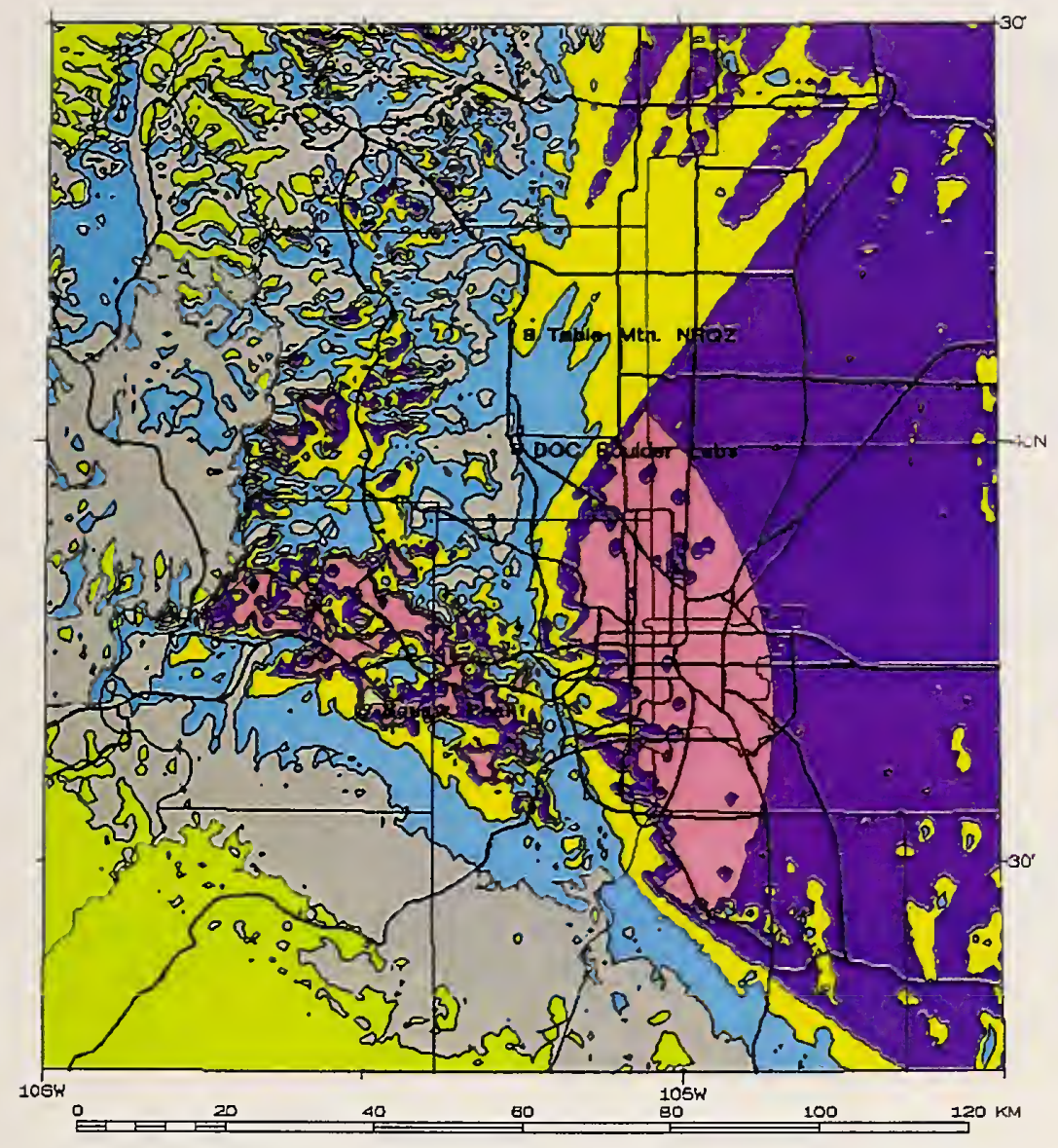

Squaw Peak

ITS

Proposed site (533 MHz, $224 \mathrm{kw}$. VP)

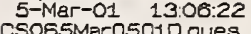

1997 Census
Flald Intansicy(oBUV/m)
$\square$ Greater than $10 \mathrm{~V} / \mathrm{m}$ Population: Households:
1 to $10 \mathrm{~V} / \mathrm{m}$ Area: Podulation:

1 to 1 VI Pooulation: $1380.59 \mathrm{~km}$ Housenolds: 139000

III to $11 \mathrm{~V} / \mathrm{m}$ Area: 4950 . $\mathrm{sq} \mathrm{km}$ How8eholds: 188000

D01 to $01 \mathrm{~V} / \mathrm{m}$ Area: $2580.59 \mathrm{~km}$ $\begin{array}{ll}\text { Population: } & 322000 \\ \text { Households: } & 101000 .\end{array}$

= .001 to $.001 \mathrm{~V} / \mathrm{m}$ .001 to $.001 \mathrm{~V} / \mathrm{m}$
Area: Population: 137000 .

500001 to $0001 \mathrm{v} / \mathrm{m}$ Area: $3930.89 \mathrm{~km}$ $\begin{array}{ll}\text { Pooulation: } & 80000 . \\ \text { Households: } & \mathbf{3 0 0 0 0}\end{array}$ less than .00001 V/m Area: 2000. $50 \mathrm{~km}$ Housanolos: 1000 .

Figure 58. Contour plot of the modeled (or predicted) E-field levels around the DenverBoulder area for a horizontally polarized antenna. These results are for a transmitter on Squaw Mountain for a frequency of $533 \mathrm{MHz}, E I R P=1 \mathrm{MW}$, a transmitter height of 8.20 $\mathrm{m}(26.91 \mathrm{ft})$, and a receiver height of $2.95 \mathrm{~m}(9.68 \mathrm{ft})$. 


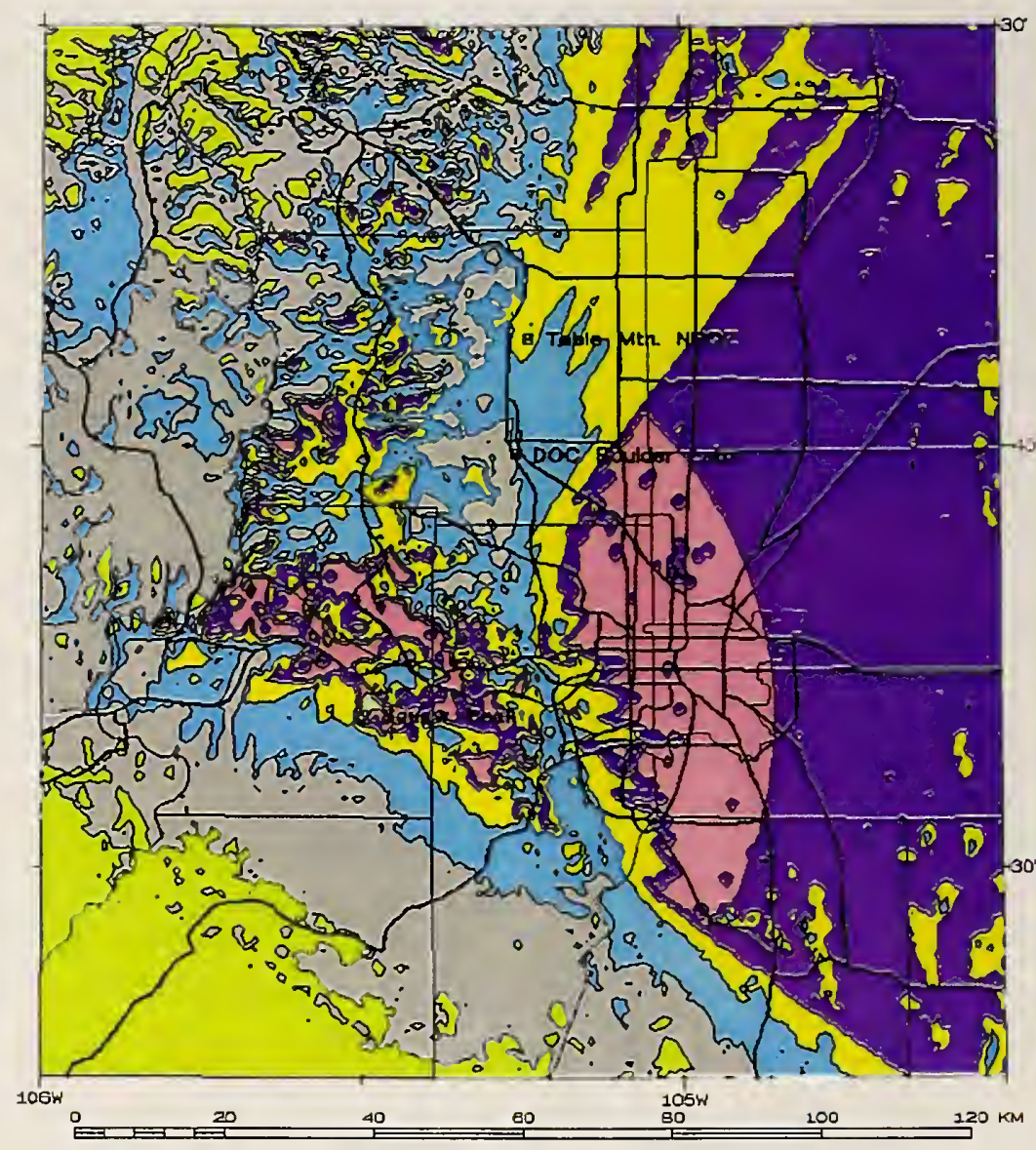
Squaw Peak
Proposed site (533 MHz, $224 \mathrm{~kW}$, VP) 5-Mar-O1 13:04:40 c5065Mar0501C.ques

1997 Census

Flela Intensity(aBuV/m)

$\square$ Greater than $10 \mathrm{~V} / \mathrm{m}$ Area: $\quad 0.5 q \mathrm{~km}$ Population:

1 to $10 \mathrm{~V} / \mathrm{m}$ Area: Population 10. $5 q \mathrm{~km}$ 1 to $1 \mathrm{~V} / \mathrm{m}$ Podulation: 1205000 439000

- 01 to $1 \mathrm{~V} / \mathrm{m}$ Area: 4880 . $\mathrm{sa} \mathrm{km}$ $\begin{array}{ll}\text { Population: } & 659000 . \\ \text { Households: } & 199000 .\end{array}$ .oo1 to $.01 \mathrm{~V} / \mathrm{m}$ Area: $2590.59 \mathrm{~km}$ Population: 323000 . Householdsi 102000.

and 0001 to $.01 \mathrm{~V} / \mathrm{m}$ Area: $3000.89 \mathrm{~km}$ $\begin{array}{ll}\text { Population: } & 136000 . \\ \text { Households: } & 43000 .\end{array}$

एक 00001 to $.0001 \mathrm{v} / \mathrm{m}$ Area: 3960. $\mathrm{Bq} \mathrm{km}$ $\begin{array}{ll}\text { Population: } & 90000 . \\ \text { Housaholds: } & 30000 .\end{array}$

less than .00001 V/m Area: 1940. sa km Housenolas: 1000.

Figure 59. Contour plot of the modeled (or predicted) E-field levels around the DenverBoulder area for a vertically polarized antenna. These results are for a transmitter on Squaw Mountain for a frequency of $533 \mathrm{MHz}, \mathrm{EIRP}=1 \mathrm{MW}$, a transmitter height of 8.20 $\mathrm{m}(26.91 \mathrm{ft})$, and a receiver height of $2.95 \mathrm{~m}(9.68 \mathrm{ft})$. 


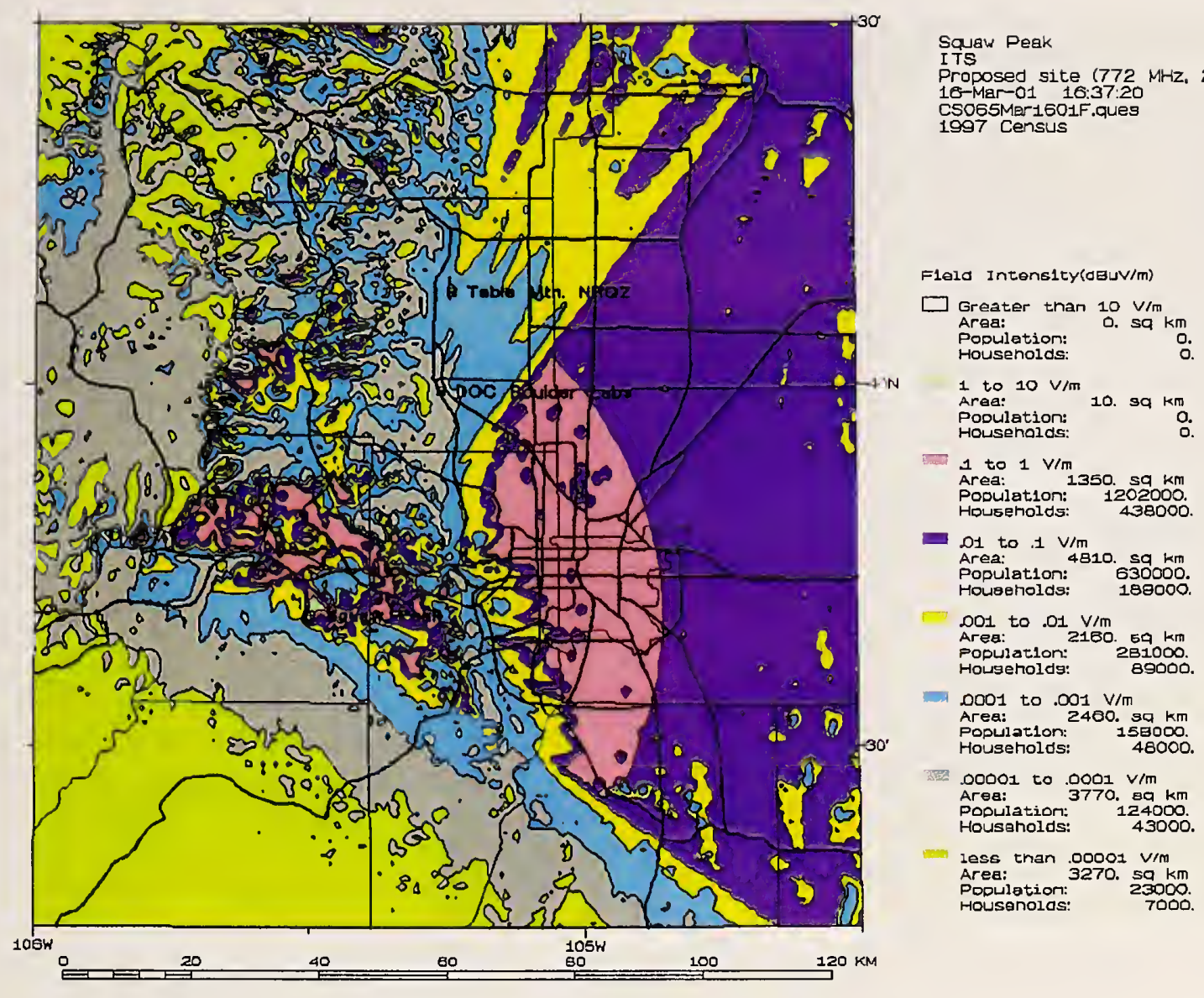

Figure 60. Contour plot of the modeled (or predicted) E-field levels around the DenverBoulder area for a horizontally polarized antenna. These results are for a transmitter on Squaw Mountain for a frequency of $772 \mathrm{MHz}, E I R P=1 \mathrm{MW}$, a transmitter height of 8.20 $\mathrm{m}(26.91 \mathrm{ft})$, and a receiver height of $2.95 \mathrm{~m}(9.68 \mathrm{ft})$. 


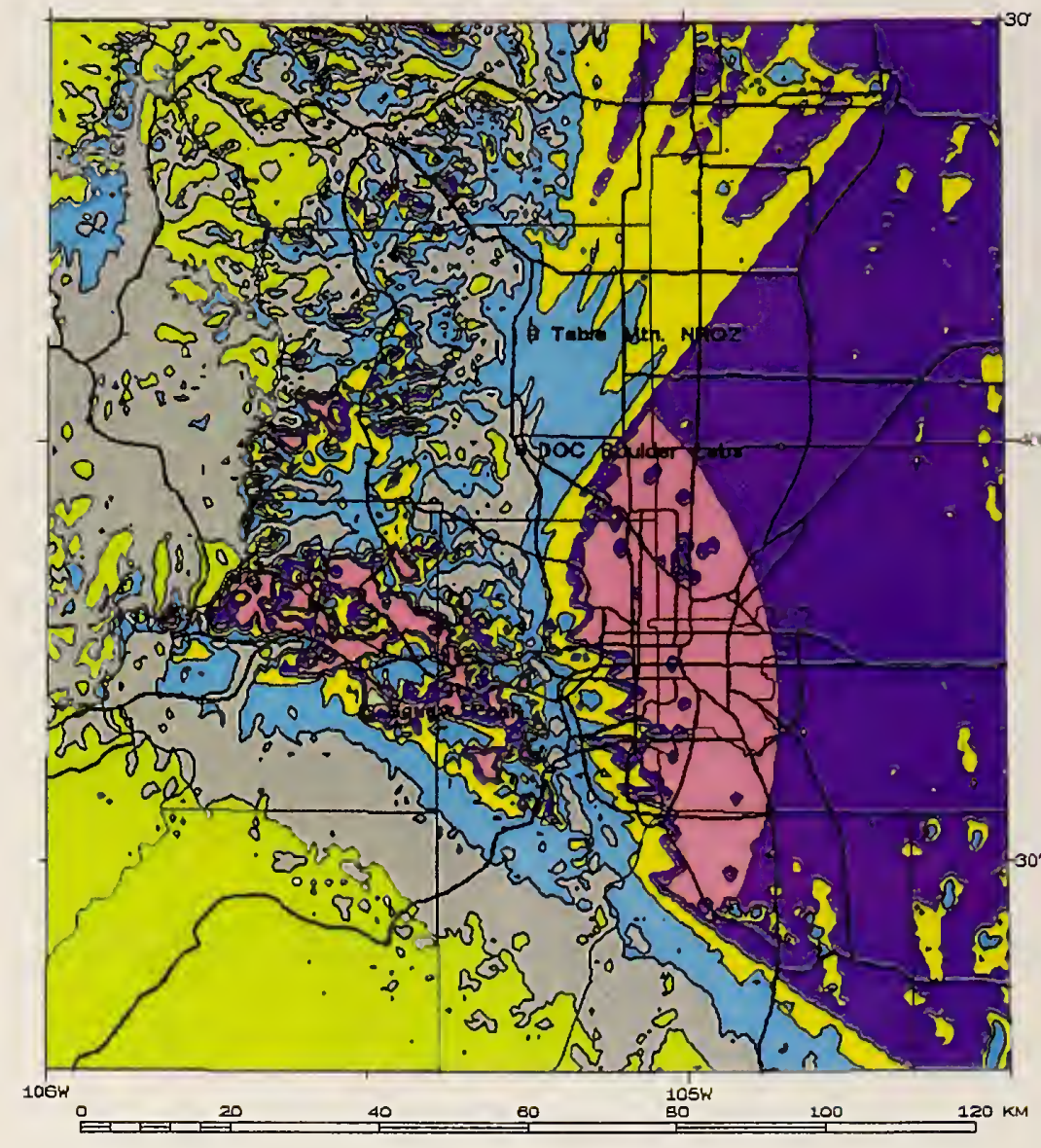

Squaw Peak

ITS

Proposed site (772 MHZ, 224 kw, VP) 16-Mar-01 16:35:29 CSO65Mer1601E.ques 1997 Census

Field Intonsity(aBuV/m)

$\square$ Greater than $10 \mathrm{~V} / \mathrm{m}$ Araa: Pooulation: o. sq $\mathrm{km}$. 1 to $10 \mathrm{~V} / \mathrm{m}$ Area: Pooulation: 10. $\mathrm{sq} \mathrm{km}$

in 1 to $1 \mathrm{~V} / \mathrm{m}$ Area: $1350 \mathrm{sg} \mathrm{km}$ $\begin{array}{ll}\text { Area: } & \text { Population: } 1202000 \text {. } \\ \text { Household5: } & 438000 .\end{array}$

- 01 to $.1 \mathrm{~V} / \mathrm{m}$ Area: $4810 . \mathrm{sq} \mathrm{km}$ $\begin{array}{ll}\text { Population: } & 630000 . \\ \text { Houbeholds: } & 188000 .\end{array}$ . Area: to $01 \mathrm{~V} / \mathrm{m}$ $\begin{array}{ll}\text { Population: } & 881000 . \\ \text { Households: } & 89000 .\end{array}$

Do D01 to . $001 \mathrm{~V} / \mathrm{m}$ Area: 2480 . sa $\mathrm{km}$ $\begin{array}{ll}\text { Population: } & 150000 . \\ \text { Households: } & 49000 .\end{array}$

000001 to $0001 \mathrm{~V} / \mathrm{m}$ Area: $3790 . \mathrm{ka} \mathrm{km}$ $\begin{array}{ll}\text { Pooulation: } & 124000 . \\ \text { Housaholds: } & 44000 .\end{array}$

less than ocoor $\mathrm{V} / \mathrm{m}$ $\begin{array}{ll}\text { Area: } & 3210 . \\ \text { Population: } & \text { sam } \\ \text { Housenolas: } & 7000 .\end{array}$

Figure 61. Contour plot of the modeled (or predicted) E-field levels around the DenverBoulder area for a vertically polarized antenna. These results are for a transmitter on Squaw Mountain for a frequency of $772 \mathrm{MHz}, E I R P=1 \mathrm{MW}$, a transmitter height of 8.20 $\mathrm{m}(26.91 \mathrm{ft})$, and a receiver height of $2.95 \mathrm{~m}(9.68 \mathrm{ft})$. 


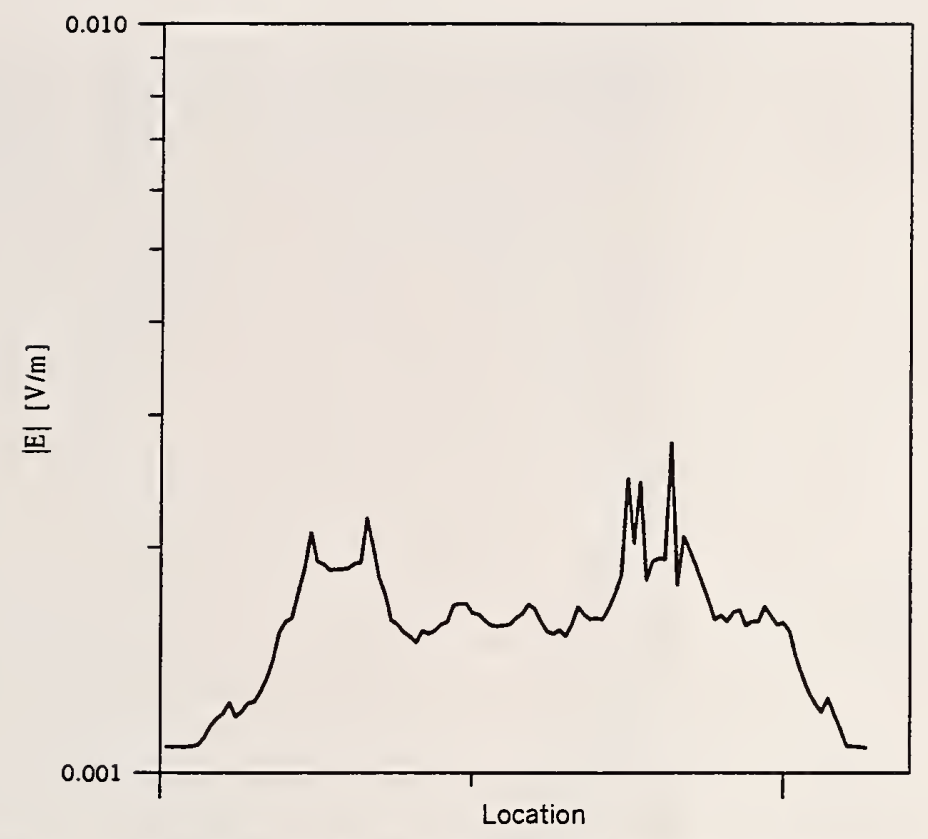

Figure 62. Modeled (or predicted) E-field levels at the Table Mountain NRQZ. These results are for a transmitter on Squaw Mountain for a frequency of $533 \mathrm{MHz}, \mathrm{EIRP}=1$ $\mathrm{MW}$, a transmitter height of $8.20 \mathrm{~m}(26.91 \mathrm{ft})$, and a receiver height of $2.95 \mathrm{~m}(9.68 \mathrm{ft})$.

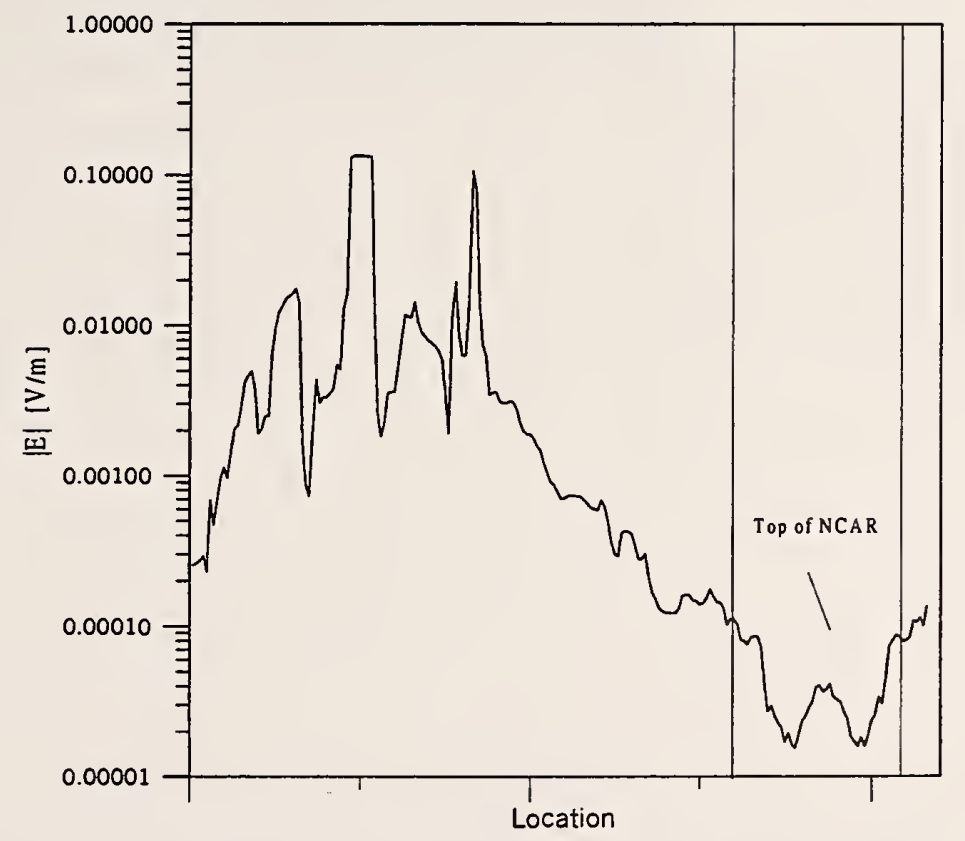

Figure 63. Modeled (or predicted) E-field levels on the McCaslin Loop. These results are for a transmitter on Squaw Mountain for a frequency of $533 \mathrm{MHz}$, EIRP=1 MW, a transmitter height of $8.20 \mathrm{~m}(26.91 \mathrm{ft})$, and a receiver height of $2.95 \mathrm{~m}(9.68 \mathrm{ft})$. 


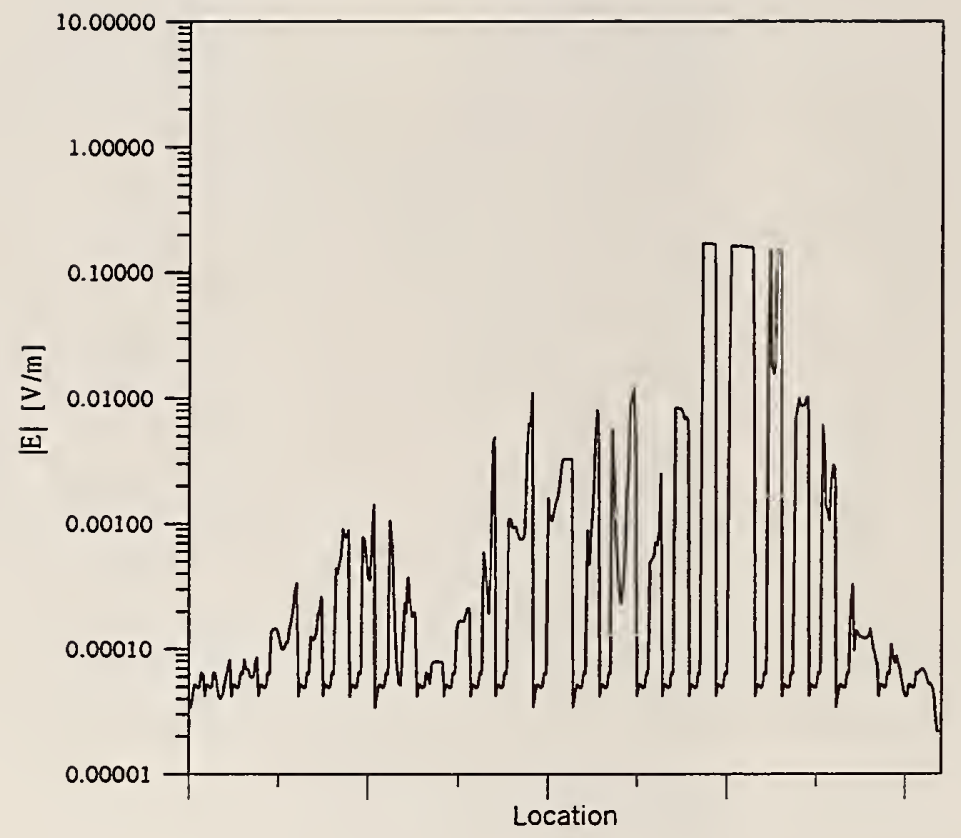

Figure 64. Modeled (or predicted) E-field levels on the Golden/Boulder Route. These results are for a transmitter on Squaw Mountain for a frequency of $533 \mathrm{MHz}, \mathrm{EIRP}=1$ MW, a transmitter height of $8.20 \mathrm{~m}(26.91 \mathrm{ft})$, and a receiver height of $2.95 \mathrm{~m}(9.68 \mathrm{ft})$. 


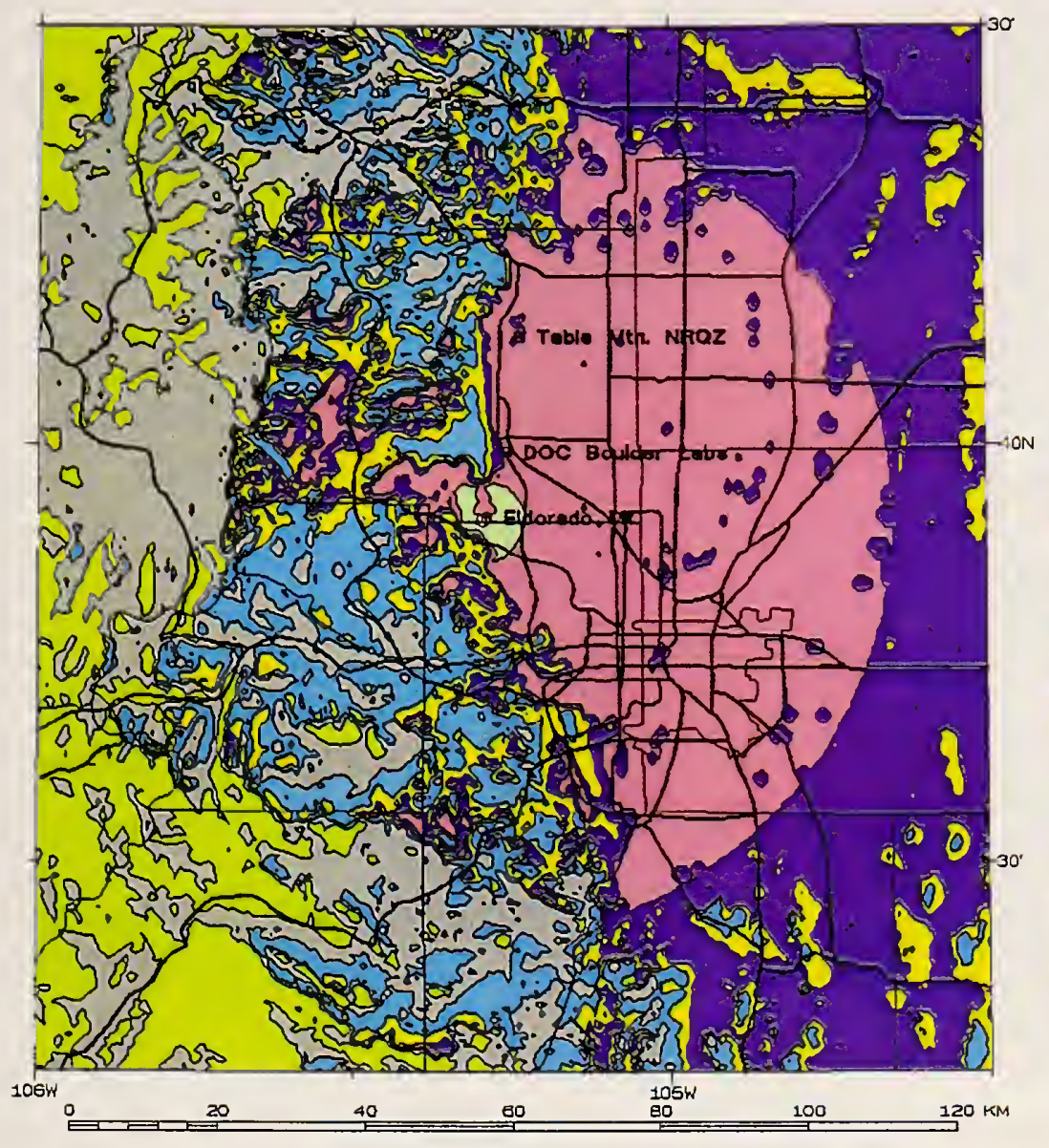

Eldorado Mountain

ITS

Proposed site (533 MHz, $1 \mathrm{MW}$ EIRP)

19-Mar-01 16:39:15

C5o65Mar1901U.ques

Field Intonsity(dBuv/m)

$\begin{array}{ll}\square & \text { Greater than } 10 \mathrm{v} / \mathrm{m} \\ \text { Area: } & 0 . \mathrm{sq} \mathrm{km} \\ \text { Popwlation: } & 0 . \\ \text { Housenolds: } & 0 .\end{array}$

1 to $10 \mathrm{~V} / \mathrm{m}$

Area:

Population:

50. $\mathrm{sa} \mathrm{km}$

II 1 to $1 \mathrm{~V} / \mathrm{m}$

Area: $4030 \mathrm{sq} \mathrm{km}$ Population: 1855000.
HDUSeholds:

al .01 to $1 \mathrm{~V} / \mathrm{m}$ Area: $4160 . \mathrm{sa} \mathrm{km}$ $\begin{array}{ll}\text { Population: } & 358000 . \\ \text { Housenolds: } & 100000 .\end{array}$

.001 to $.01 \mathrm{~V} / \mathrm{m}$

Area: $1730.59 \mathrm{~km}$ $\begin{array}{ll}\text { Population: } & 128000 . \\ \text { Housenolds: } & 38000 .\end{array}$

all .0001 to .001 V/m Area: $2170.89 \mathrm{~km}$ $\begin{array}{ll}\text { Population: } & 39000 . \\ \text { Households: } & 11000 .\end{array}$

s. 00001 to $.0001 \mathrm{v} / \mathrm{m}$ Area: 3440 . sa km Population: $\quad 30000$.
Households:

less than .00001 V/m Area: $2220.59 \mathrm{~km}$ $\begin{array}{ll}\text { Population: } & 8000 . \\ \text { Housenolas: } & 2000 .\end{array}$

Figure 65. Contour plot of the modeled (or predicted) E-field levels around the DenverBoulder area for a horizontally polarized antenna. These results are for a transmitter on Eldorado Mountain for a frequency of $533 \mathrm{MHz}, \mathrm{EIRP}=1 \mathrm{MW}$, a transmitter height of $116 \mathrm{~m}(379 \mathrm{ft})$, and a receiver height of $2 \mathrm{~m}(6.56 \mathrm{ft})$. 

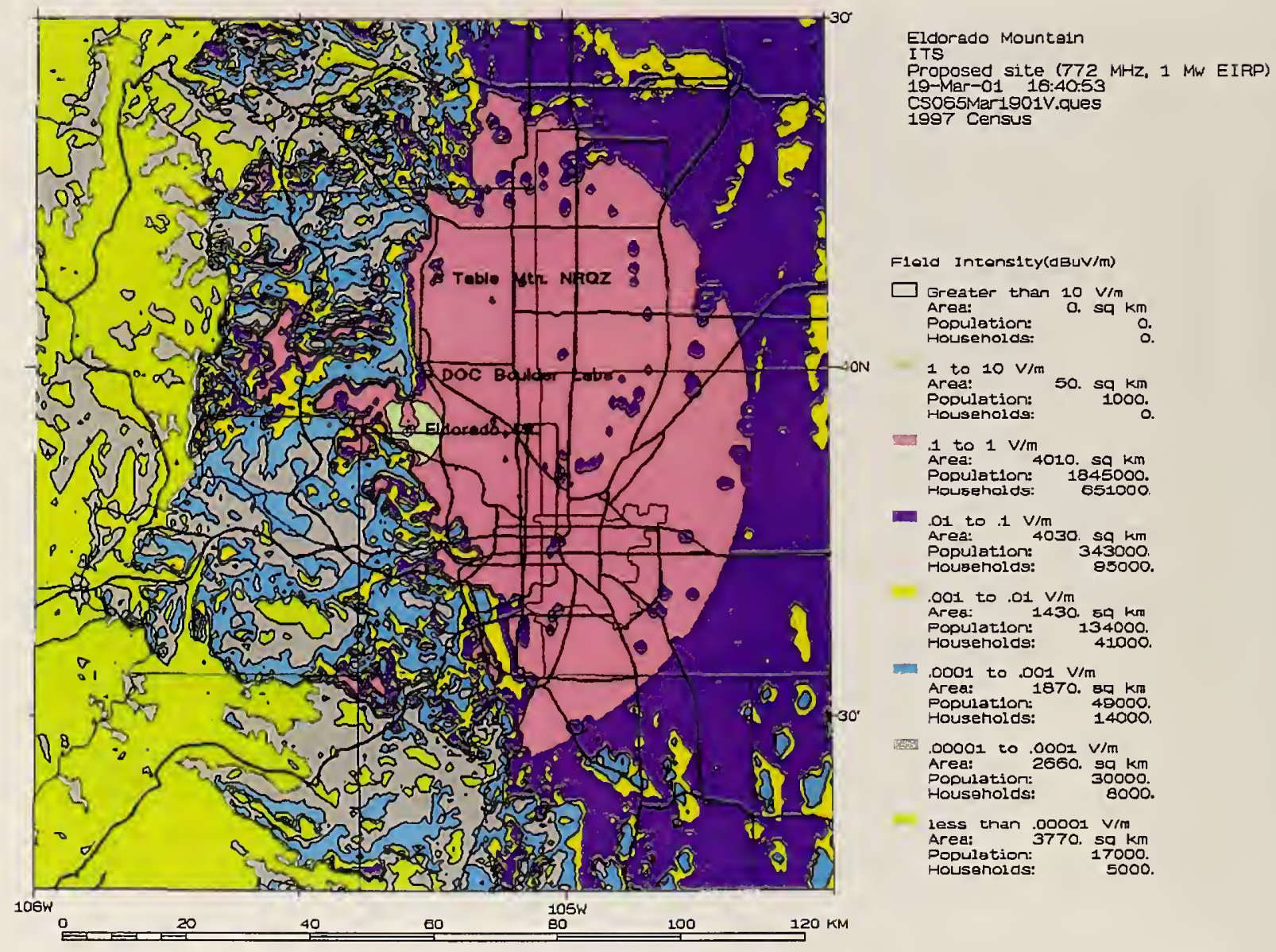

Flold Intensity(dBuv/m)

$\square$ Greater than $10 \mathrm{~V} / \mathrm{m}$ Araa:
Populetion:
Housenolos:

1 to $10 \mathrm{~V} / \mathrm{m}$ Area: $10 \mathrm{~V} / \mathrm{m}$ 50. $\mathrm{sq} \mathrm{km}$ Population:
Housenolds:

aㅣ 1 to $1 \mathrm{~V} / \mathrm{m}$ $4010 \mathrm{sq} \mathrm{km}$ Population: 1845000 .

Area: $4030 . \mathrm{sq} \mathrm{km}$ Population: $\quad 343000$.
Households: .001 to $.01 \mathrm{~V} / \mathrm{m}$ Area: $1430.50 \mathrm{~km}$ $\begin{array}{lr}\text { Population: } & 134000 . \\ \text { Housenolds: } & 41000 .\end{array}$ .0001 to $.001 \mathrm{~V} / \mathrm{m}$

Area: to 1870 . 8 म $\mathrm{km}$

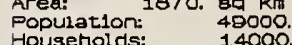

.00001 to $.0001 \mathrm{~V} / \mathrm{m}$ Area: 2560 . $39 \mathrm{~km}$ $\begin{array}{ll}\text { Population: } & 30000 . \\ \text { Households: } & 8000 .\end{array}$

less than .00001 V/m less than .00001
Area:
Potm Population: $\quad 17000$.
Housenolas:

Figure 66. Contour plot of the modeled (or predicted) E-field levels around the DenverBoulder area for a horizontally polarized antenna. These results are for a transmitter on Eldorado Mountain for a frequency of $772 \mathrm{MHz}, \mathrm{EIRP}=1 \mathrm{MW}$, a transmitter height of $116 \mathrm{~m}(379 \mathrm{ft})$, and a receiver height of $2 \mathrm{~m}(6.56 \mathrm{ft})$. 


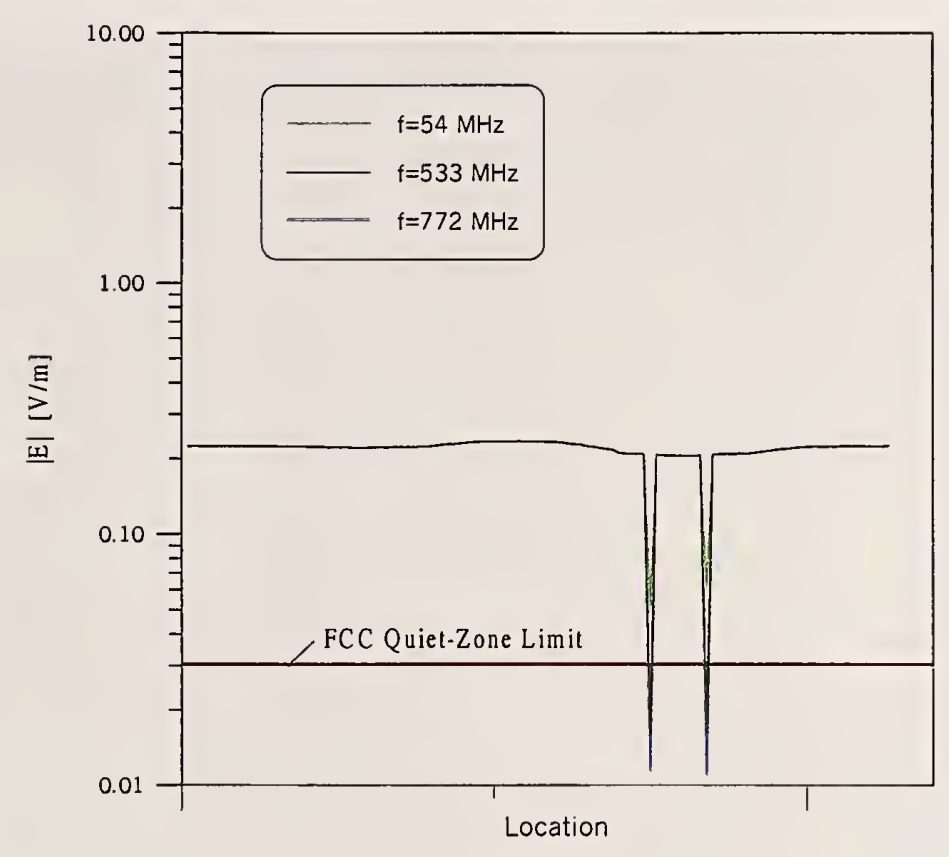

Figure 67. Modeled (or predicted) E-field levels at the Table Mountain NRQZ. These results are for a transmitter on Eldorado Mountain, EIRP $=1 \mathrm{MW}$, a transmitter height of $116 \mathrm{~m}(397 \mathrm{ft})$, and a receiver height of $2 \mathrm{~m}(6.56 \mathrm{ft})$.

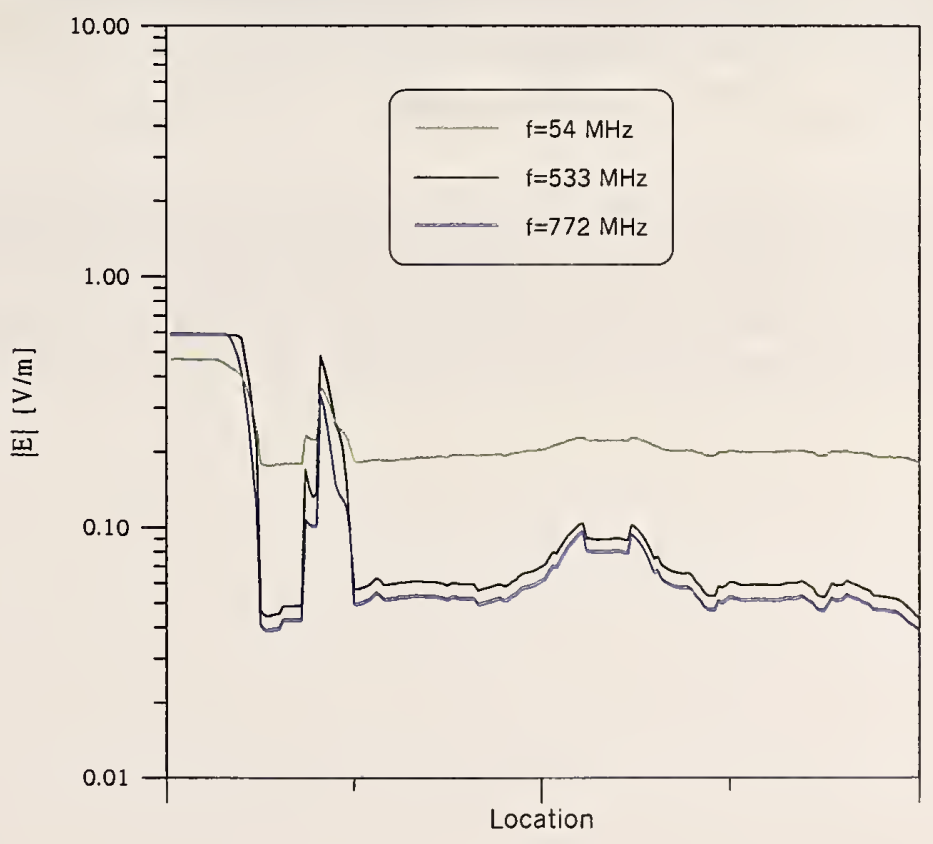

Figure 68. Modeled (or predicted) E-field levels at the DOC Laboratories. These results are for a transmitter on Eldorado Mountain, EIRP=1 MW, a transmitter height of $116 \mathrm{~m}$ $(397 \mathrm{ft})$, and a receiver height of $2 \mathrm{~m}(6.56 \mathrm{ft})$. 

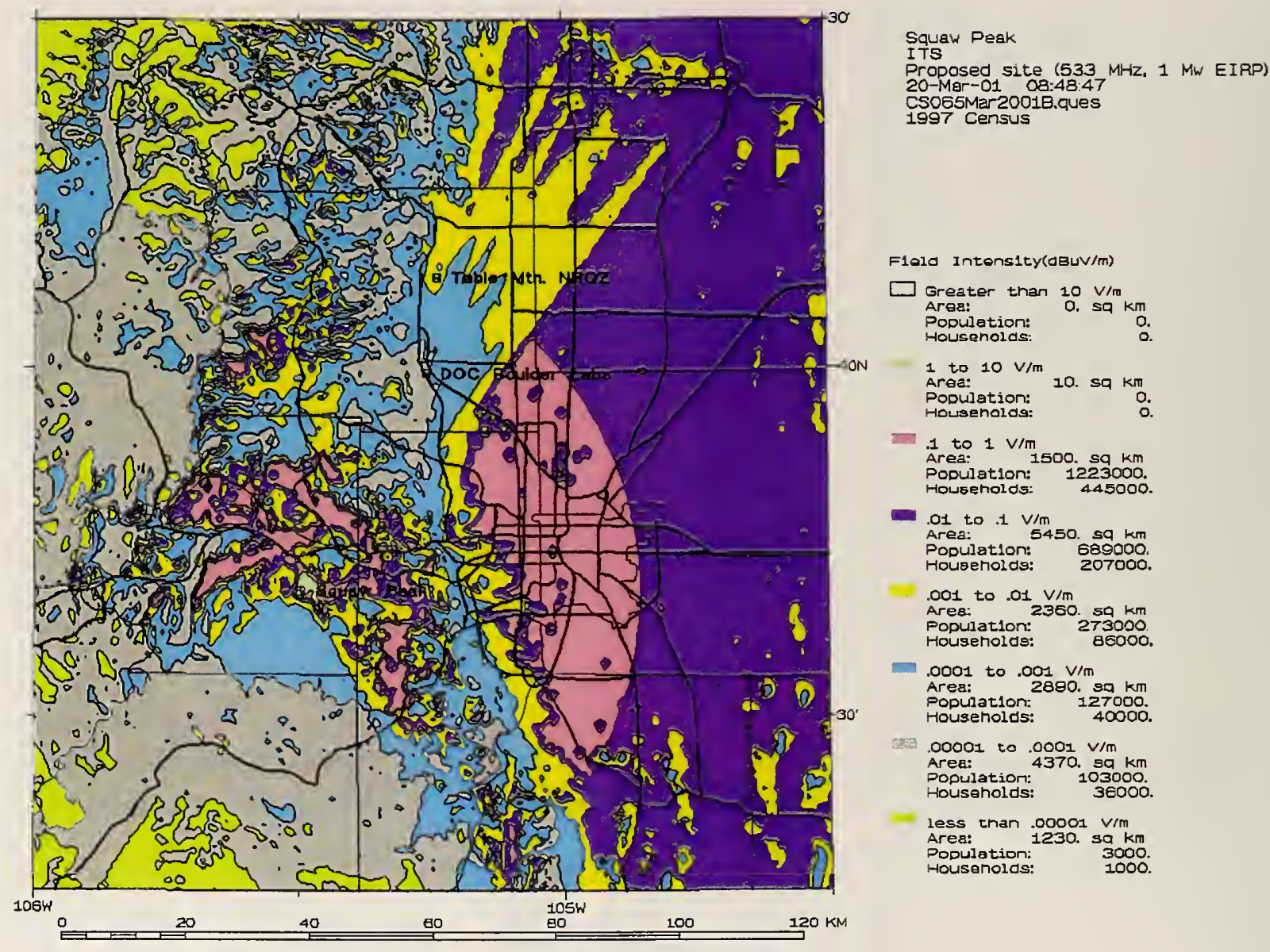

Figure 69. Contour plot of the modeled (or predicted) E-field levels around the DenverBoulder area for a horizontally polarized antenna. These results are for a transmitter on Squaw Mountain for a frequency of $533 \mathrm{MHz}, \mathrm{EIRP}=1 \mathrm{MW}$, a transmitter height of $60.96 \mathrm{~m}(200 \mathrm{ft})$, and a receiver height of $2 \mathrm{~m}(6.56 \mathrm{ft})$. 


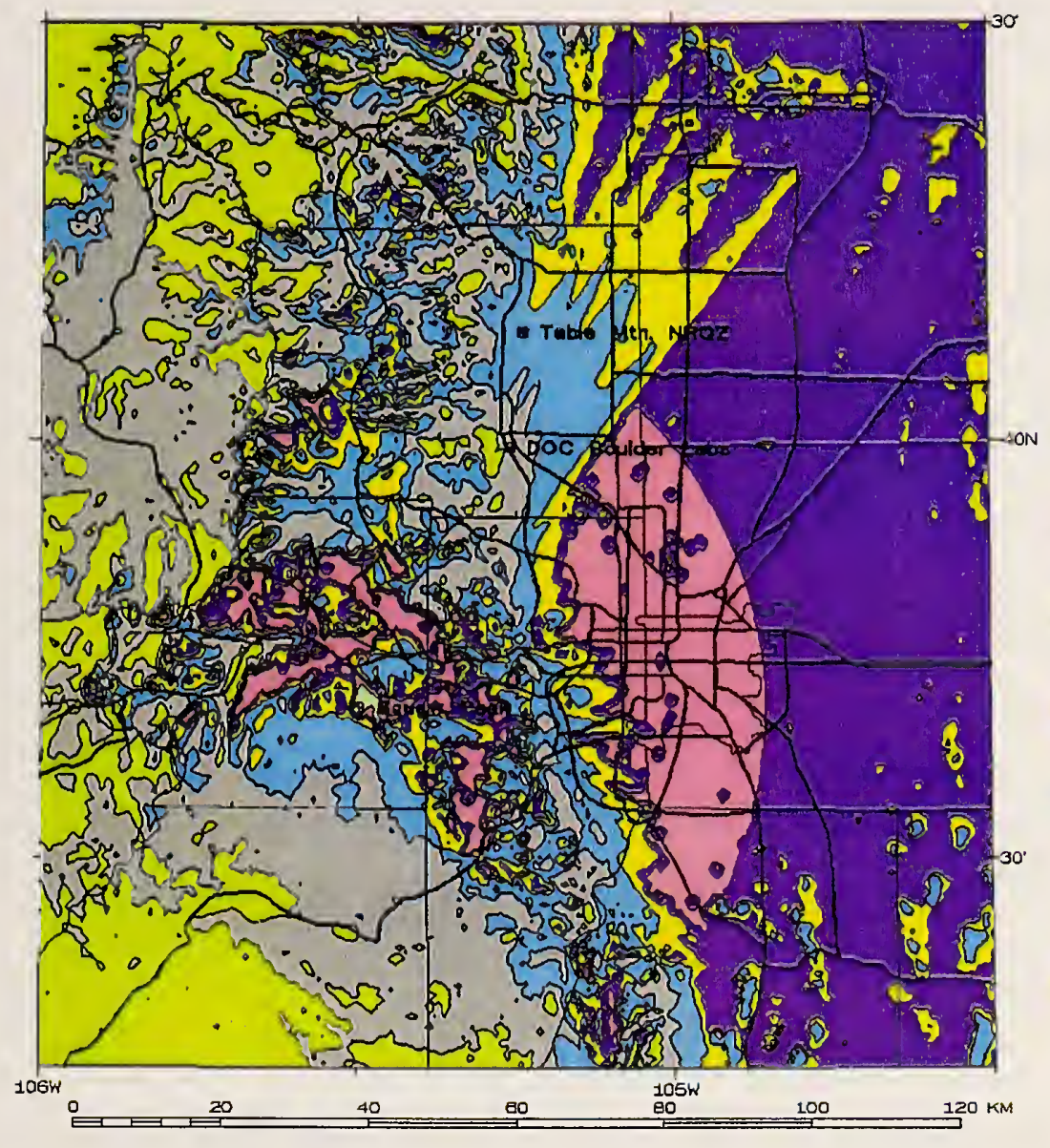
Squaw Peak
ITS
Proposed site (772 MHz, $1 \mathrm{MW}$ EIRP)
19-Mar-01 16:23:57
CSO65Mar19010.ques
1997 Census

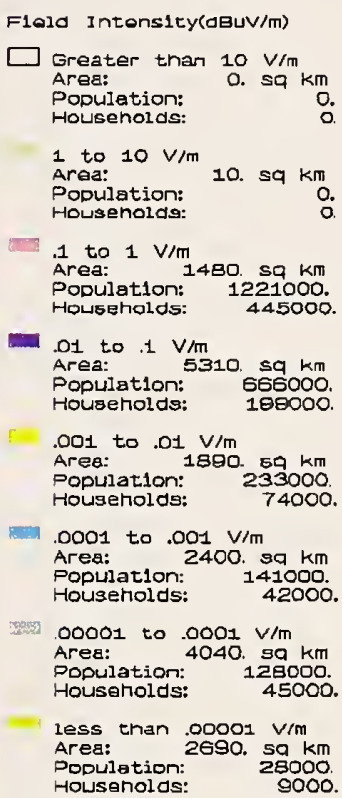

Figure 70. Contour plot of the modeled (or predicted) E-field levels around the DenverBoulder area for a horizontally polarized antenna. These results are for a transmitter on Squaw Mountain for a frequency of $772 \mathrm{MHz}, \mathrm{EIRP}=1 \mathrm{MW}$, a transmitter height of

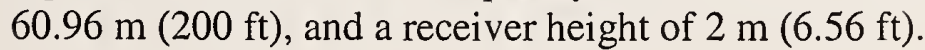




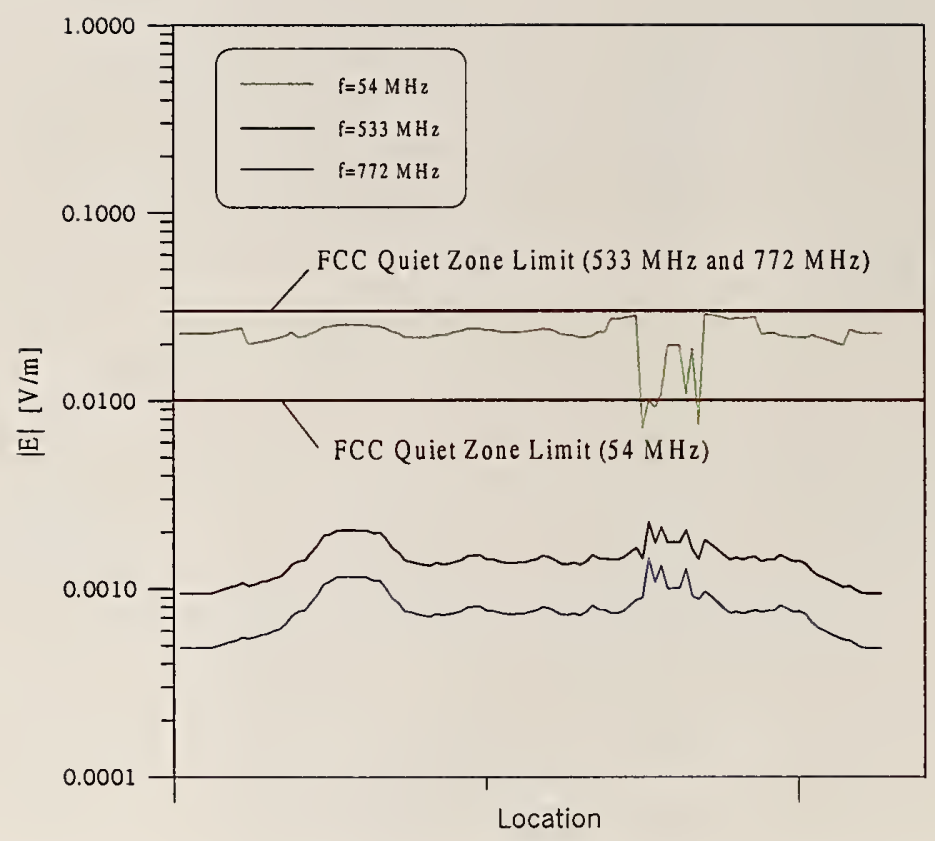

Figure 71. Modeled (or predicted) E-field levels at the Table Mountain NRQZ. These results are for a transmitter on Squaw Mountain, EIRP=1 MW, a transmitter height of

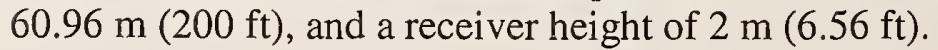



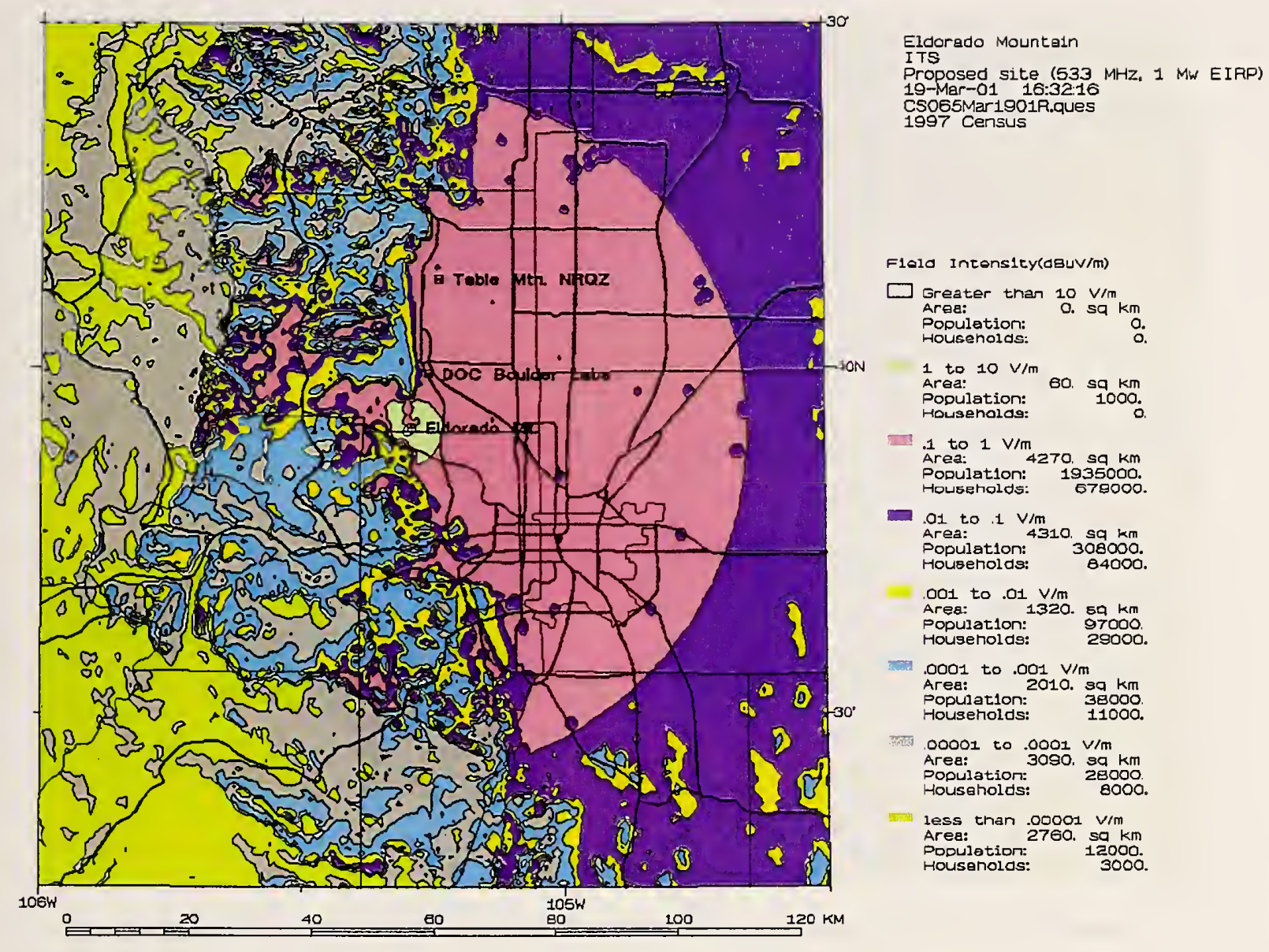

Figure 72. Contour plot of the modeled (or predicted) E-field levels around the DenverBoulder area for a horizontally polarized antenna. These results are for a transmitter on Eldorado Mountain for a frequency of $533 \mathrm{MHz}, \mathrm{EIRP}=1 \mathrm{MW}$, a transmitter height of $116 \mathrm{~m}(379 \mathrm{ft})$, and a receiver height of $9.14 \mathrm{~m}(30 \mathrm{ft})$. 

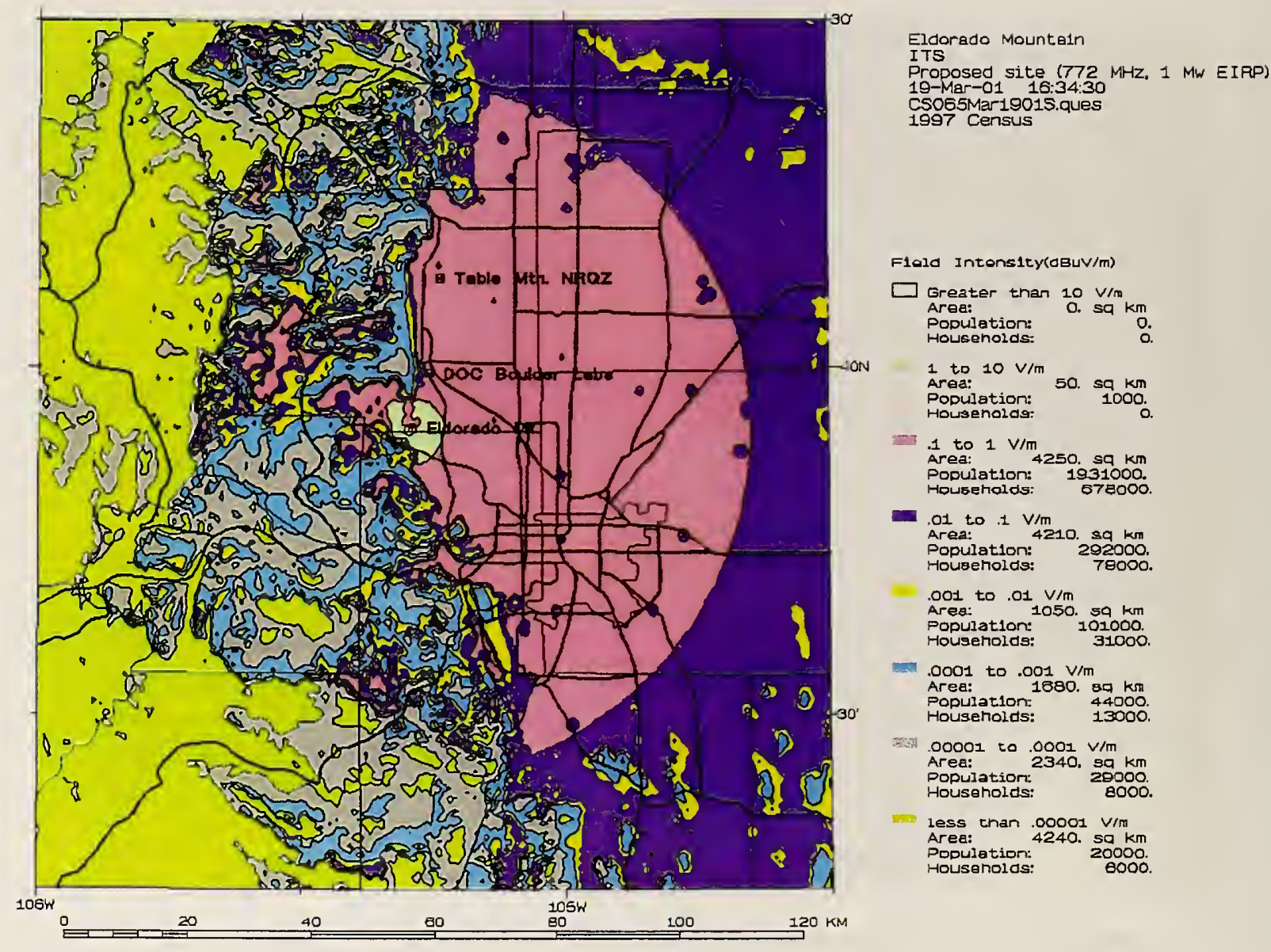

8000.

Figure 73. Contour plot of the modeled (or predicted) E-field levels around the DenverBoulder area for a horizontally polarized antenna. These results are for a transmitter on Eldorado Mountain for a frequency of $772 \mathrm{MHz}, \mathrm{EIRP}=1 \mathrm{MW}$, a transmitter height of $116 \mathrm{~m}(379 \mathrm{ft})$, and a receiver height of $9.14 \mathrm{~m}(30 \mathrm{ft})$. 


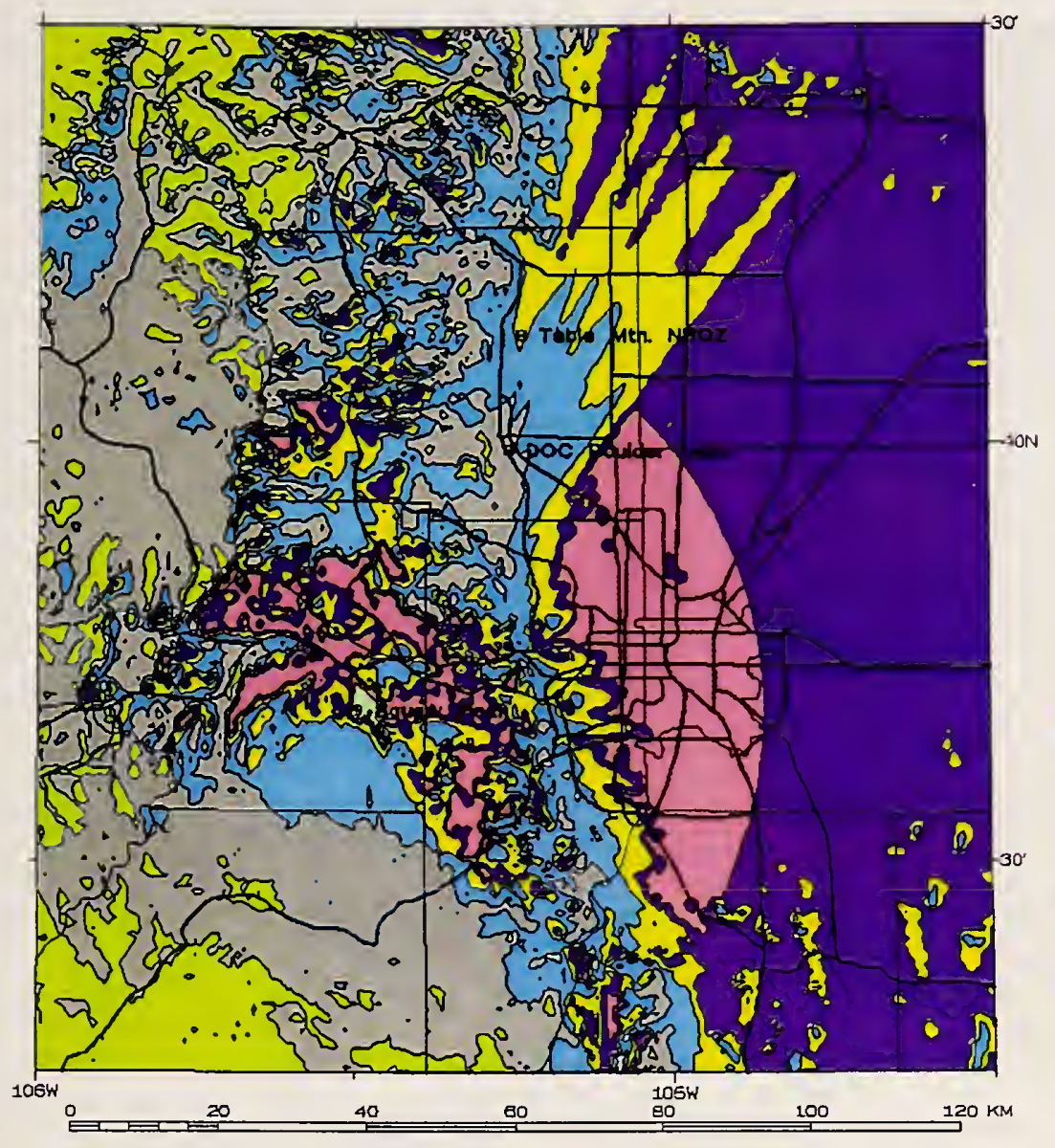

Squaw Peak

ITS

Proposed site (533 MiHz، 1 MW EIRP)

20-Mar-01 08:47:14

CS065Mar2001A.ques

Flola intans 1 ty(aBuv/m)

$\square$ Greater than $10 \mathrm{~V} / \mathrm{m}$
Areas
Populetion: $0 . \mathrm{sq} \mathrm{km}$

population:

1 to $10 \mathrm{~V} / \mathrm{m}$

10. sq $\mathrm{km}$ Households:

피 1 to $1 \mathrm{~V} / \mathrm{m}$

Area: $1800.99 \mathrm{~km}$ Population: 1275000 .

$=01$ to $1 \mathrm{~V} / \mathrm{m}$

Area: $5670 . \mathrm{sa} \mathrm{km}$ $\begin{array}{ll}\text { Populat1on: } & 668000 . \\ \text { Howbenolds: } & 200000 .\end{array}$

.001 to $.01 \mathrm{~V} / \mathrm{m}$ Aree: $1950.59 \mathrm{~km}$ 220000.
Population:
Households:

Ina .0001 to $.001 \mathrm{~V} / \mathrm{m}$ Area: 2610. $89 \mathrm{~km}$ $\begin{array}{ll}\text { Population: } & 122000 . \\ \text { Households: } & 37000 .\end{array}$ .00001 to $.0001 \mathrm{~V} / \mathrm{m}$ Area: 4240. sa km $\begin{array}{lr}\text { Pooulation: } & 120000 \\ \text { Households: } & 42000 .\end{array}$

less than $.00001 \mathrm{~V} / \mathrm{m}$ Area: $1730 . \mathrm{sa} \mathrm{km}$ Housenolds: $\quad 4000$

Figure 74. Contour plot of the modeled (or predicted) E-field levels around the DenverBoulder area for a horizontally polarized antenna. These results are for a transmitter on Squaw Mountain for a frequency of $533 \mathrm{MHz}, \mathrm{EIRP}=1 \mathrm{MW}$, a transmitter height of $60.96 \mathrm{~m}(200 \mathrm{ft})$, and a receiver height of $9.14 \mathrm{~m}(30 \mathrm{ft})$. 

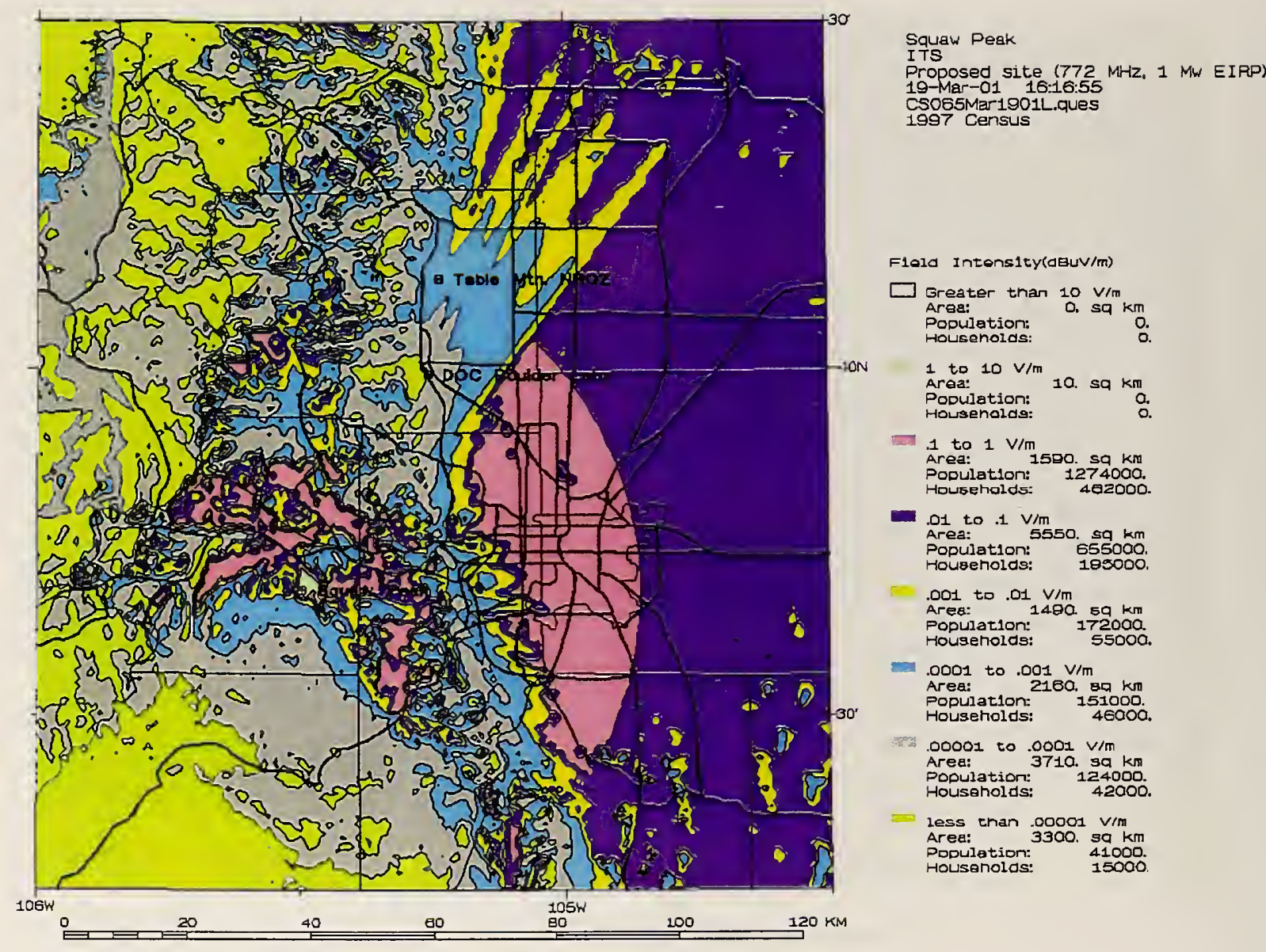

$$
\text { Housenolds: } 195000 .
$$$$
.001 \text { to } .01 \mathrm{~V} / \mathrm{m}
$$$$
\text { Area: } 1400.59 \mathrm{~km}
$$

- less than .00001 V/m Area: $\quad 3300$. $59 \mathrm{~km}$ $\begin{array}{ll}\text { Population: } & 41000 . \\ \text { Housanolas: } & \end{array}$

Figure 75. Contour plot of the modeled (or predicted) E-field levels around the DenverBoulder area for a horizontally polarized antenna. These results are for a transmitter on Squaw Mountain for a frequency of $772 \mathrm{MHz}, \mathrm{EIRP}=1 \mathrm{MW}$, a transmitter height of $60.96 \mathrm{~m}(200 \mathrm{ft})$, and a receiver height of $9.14 \mathrm{~m}(30 \mathrm{ft})$. 


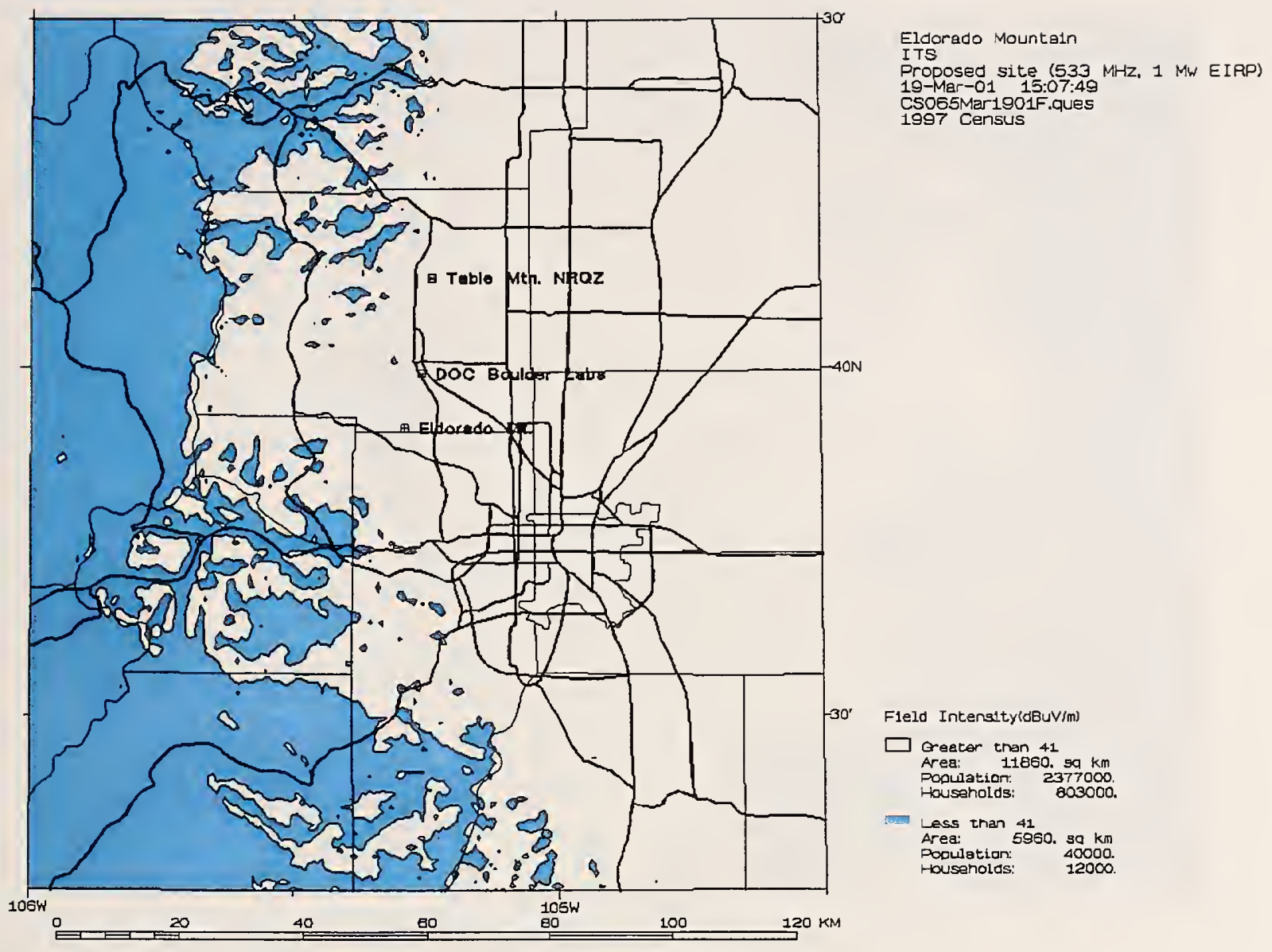

Figure 76. Area coverage plot of the $41 \mathrm{~dB} \mu \mathrm{V} / \mathrm{m}$ FCC recommendation around the Denver-Boulder area for a horizontally polarized antenna. These results are for a transmitter on Eldorado Mountain for a frequency of $533 \mathrm{MHz}$, EIRP=1 MW, a

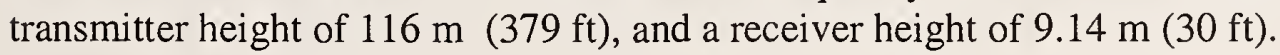




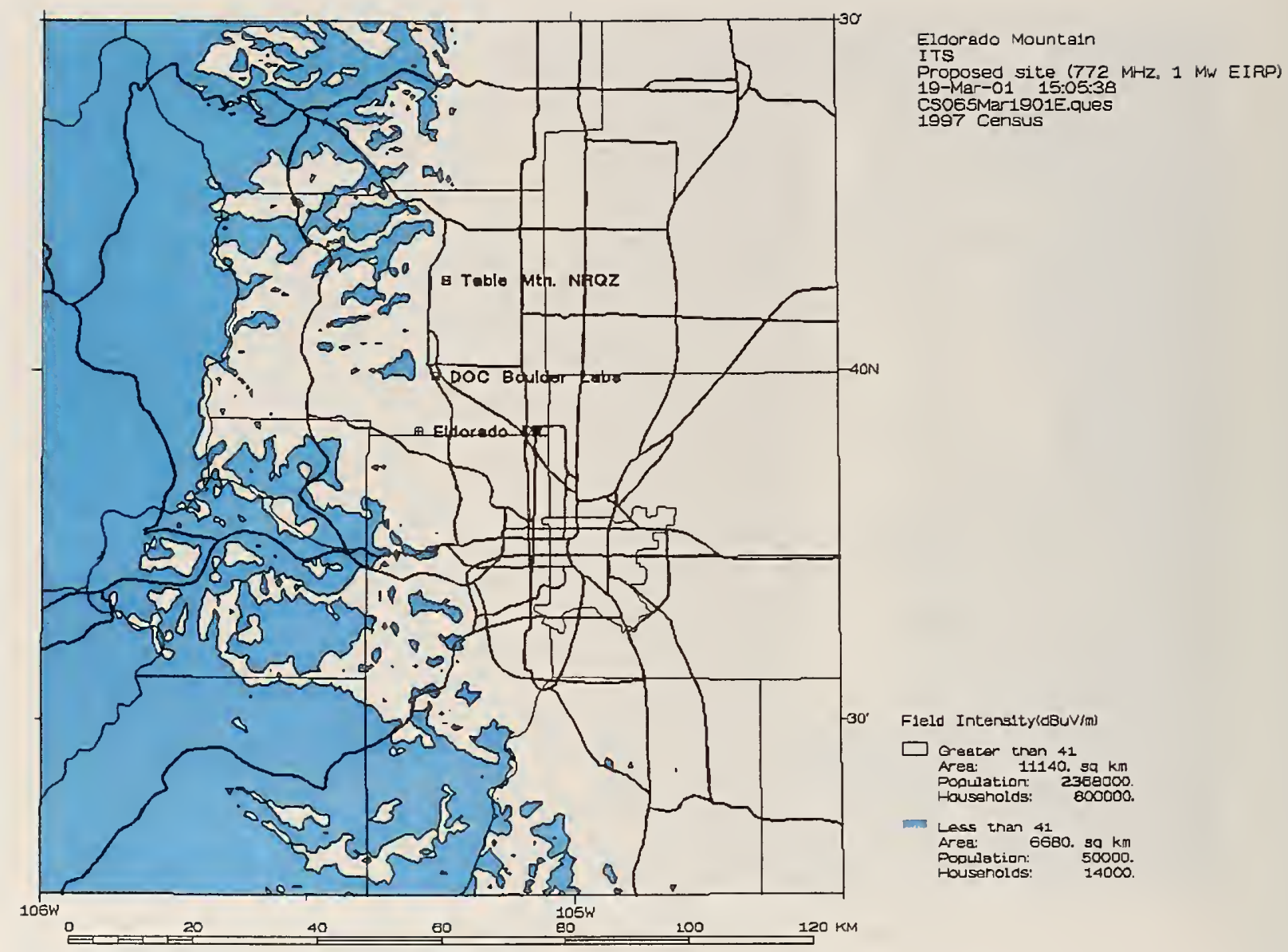

Figure 77. Area coverage plot of the $41 \mathrm{~dB} \mu \mathrm{V} / \mathrm{m}$ FCC recommendation around the Denver-Boulder area for a horizontally polarized antenna. These results are for a transmitter on Eldorado Mountain for a frequency of $772 \mathrm{MHz}, E R P=1 \mathrm{MW}$, a transmitter height of $116 \mathrm{~m}$ (379 ft), and a receiver height of $9.14 \mathrm{~m}(30 \mathrm{ft})$. 


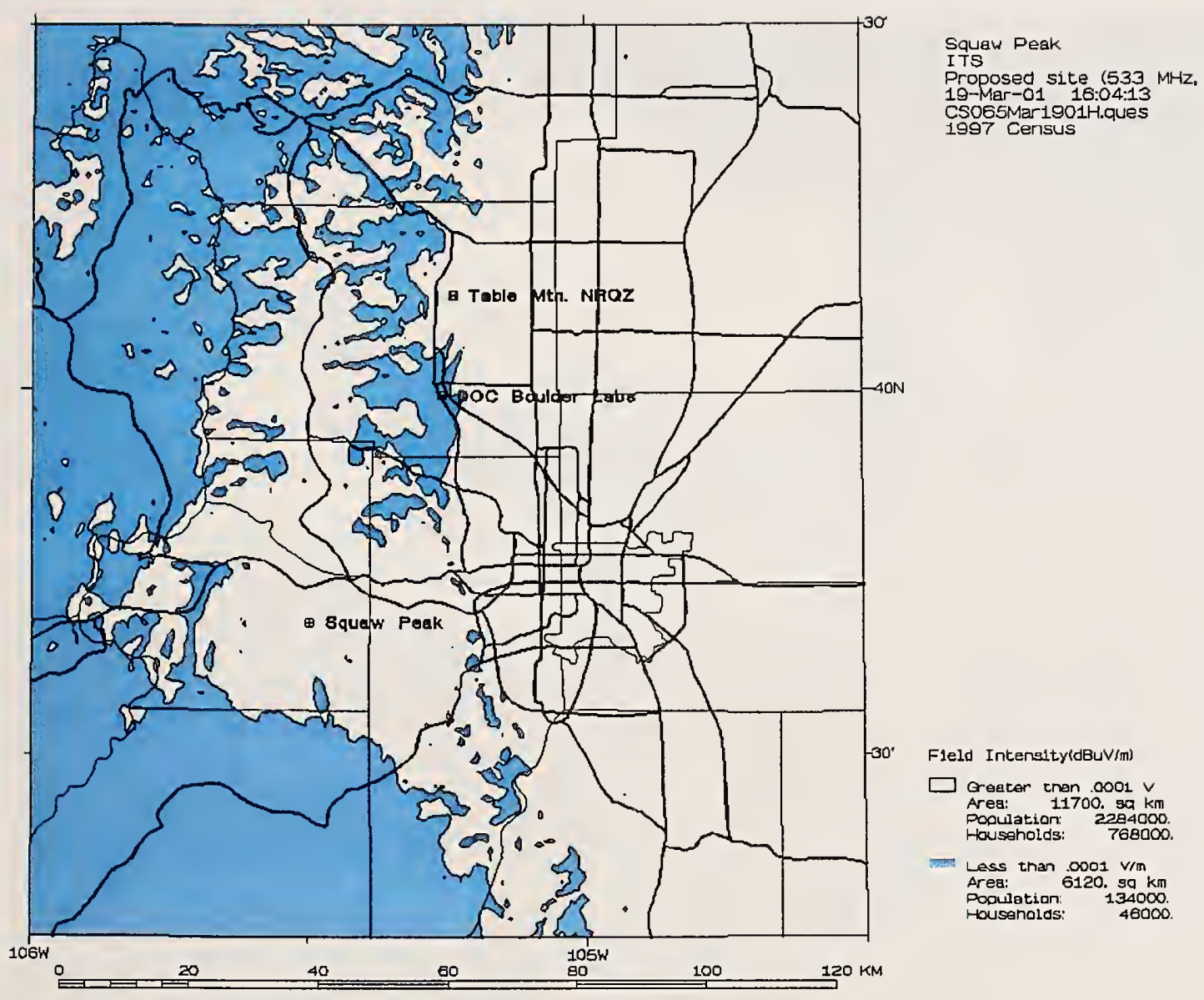

Figure 78. Area coverage plot of the $41 \mathrm{~dB} \mu \mathrm{V} / \mathrm{m}$ FCC recommendation around the Denver-Boulder area for a horizontally polarized antenna. These results are for a transmitter on Squaw Mountain for a frequency of $533 \mathrm{MHz}, \mathrm{EIRP}=1 \mathrm{MW}$, a transmitter height of $60.96 \mathrm{~m}(200 \mathrm{ft})$, and a receiver height of $9.14 \mathrm{~m}(30 \mathrm{ft})$. 


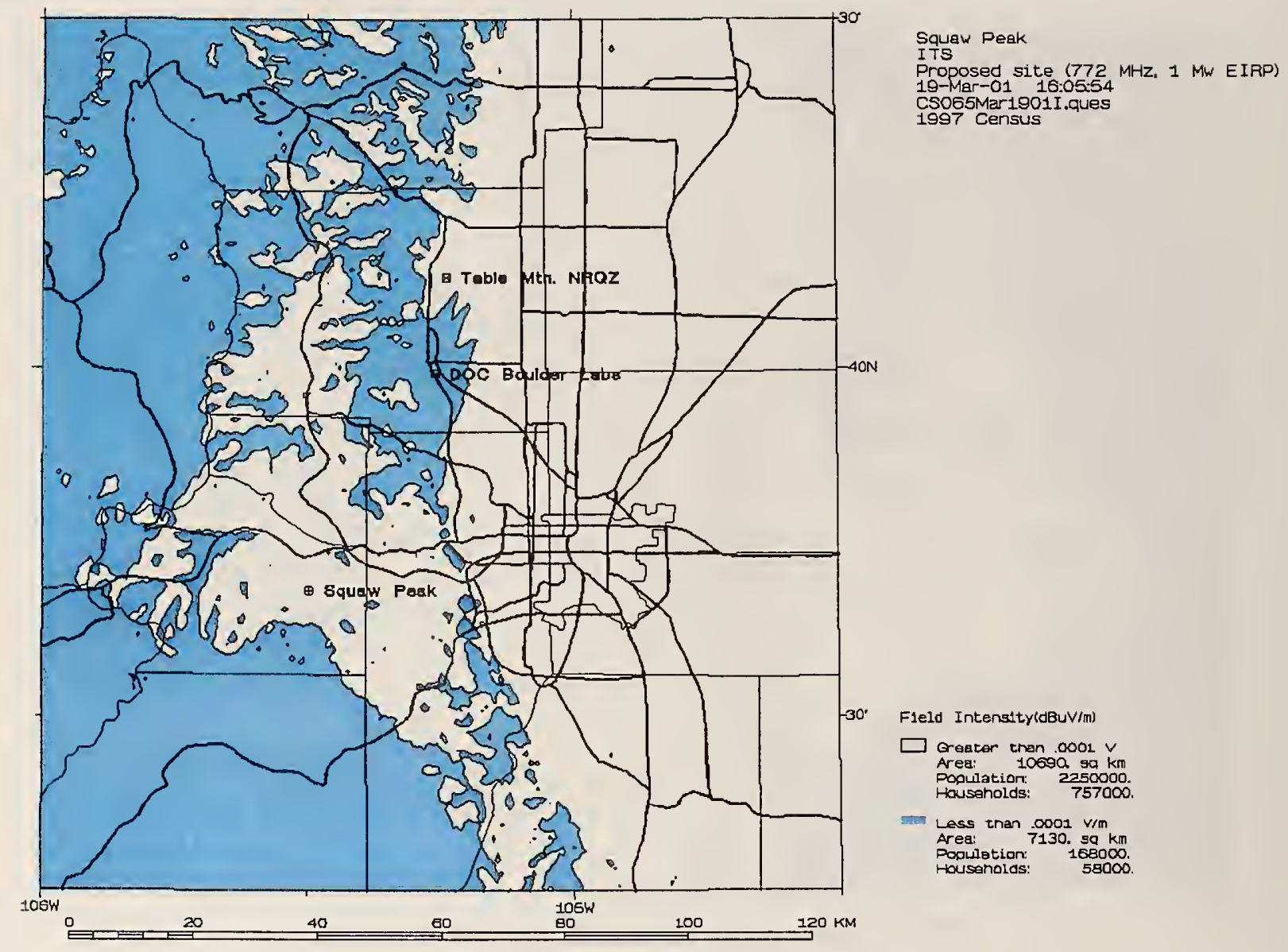

Figure 79. Area coverage plot of the $41 \mathrm{~dB} \mu \mathrm{V} / \mathrm{m}$ FCC recommendation around the Denver-Boulder area for a horizontally polarized antenna. These results are for a transmitter on Squaw Mountain for a frequency of $772 \mathrm{MHz}$, EIRP=1 MW, a transmitter height of $60.96 \mathrm{~m}(200 \mathrm{ft})$, and a receiver height of $9.14 \mathrm{~m}(30 \mathrm{ft})$. 


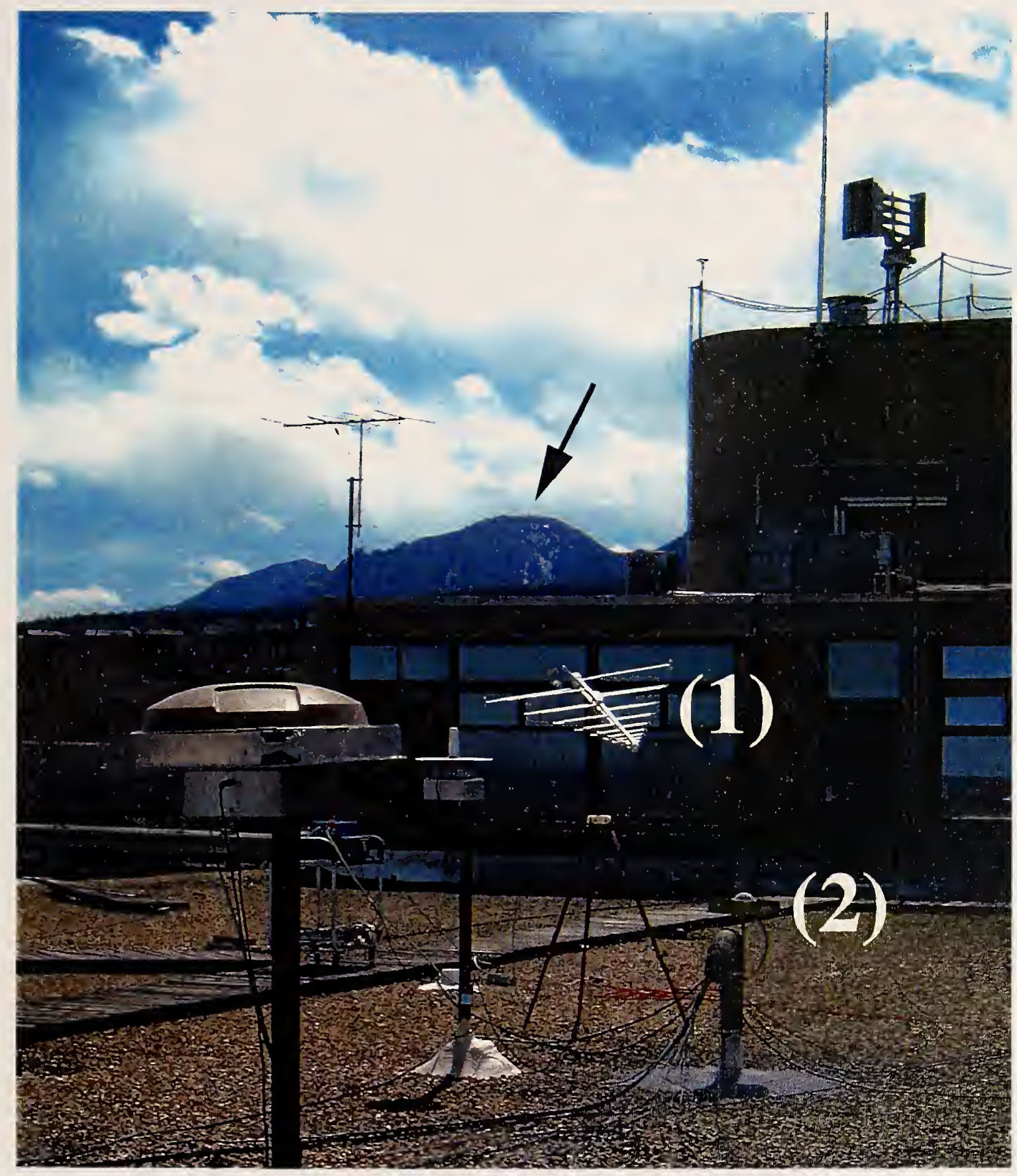

Figure 80. Arrangement of broadband, log periodic antenna (1) used to replicate field intensities predicted from DTV transmitters on Eldorado Mountain (arrow). A GPS receiver antenna (2), located on the NIST/ITS Radio Building at the DOC Laboratories, is the target of the incident field in this test. 


\section{APPENDIX A: MEASURED E-FIELD STRENGTHS OF THE 1998 AND 2001 SPECTRUM SURVEY}

In this appendix the measured data for the spectrum survey performed at both the Table Mountain NRQZ and the DOC Laboratories are presented. The data in each graph were acquired with a measurement system as described in Section 2. Figures A.1 through A.34 are the measured E-field strengths for a vertically polarized receiving antenna. These data are for the 1998 spectrum survey. Figures A.1 through A.17 are the measured E-field strengths at the Table Mountain NRQZ for the frequency range of $30 \mathrm{MHz}$ to $960 \mathrm{MHz}$. Figures A.18 through A.34 are the measured E-field strengths on the groundscreen at the DOC Laboratories for the frequency range of $30 \mathrm{MHz}$ to $960 \mathrm{MHz}$.

Figures A.35 through A.43 are the measured E-field strengths for a horizontally polarized receiving antenna. These data are for the 2001 spectrum survey. Figures A.35 through A.37 are the measured E-field strengths at the Table Mountain NRQZ, at the NIST groundscreen, and at the end of Wing 4 of Building 1 at the DOC Laboratories for the frequency range of $50 \mathrm{MHz}$ to $90 \mathrm{MHz}$. Figures A.38 through A.40 are the measured Efield strengths at the Table Mountain NRQZ, at the NIST groundscreen, and at the end of Wing 4 on Building 1 at the DOC Laboratories for the frequency range of $170 \mathrm{MHz}$ to $220 \mathrm{MHz}$. Figures A.41 through A.43 are the measured E-field strengths at the Table Mountain NRQZ, at the NIST groundscreen, and at the end of Wing 4 of Building 1 at the DOC Laboratories for the frequency range of $500 \mathrm{MHz}$ to $800 \mathrm{MHz}$.

The upper curve shows the highest level in each bin from any of the sweeps, the lower curve shows the lowest level in each bin from any of the sweeps, and the middle curve shows the average level in each bin for the entire set of sweeps. The data graphs may be interpreted as follows: the maximum curve on each graph shows the absolute envelope of received signal levels for the period of the spectrum survey. The minimum curve on each graph shows the absolute minimum level observed on each frequency for the period of the survey, and the middle curve shows the average level (in decibels) at each frequency for the period of the survey. Generally, the variation between the sets of curves in each 2001 data graph is less than for the 1998 survey results because the measurements were made over shorter intervals (a few hours at each location).

In cases in which only noise was measured, the three curves are spaced about $10 \mathrm{~dB}$ apart, and the average (middle) curve is at the measurement system's inherent noise level. If signals were sporadically present on a frequency, then the average curve may be close to the measurement system's inherent noise level, but the maximum and minimum curves will be somewhat elevated. The closer the average curve is to the maximum curve, the larger the percentage of time that the signal was present. If all three curves are elevated above the measurement system's inherent noise threshold, then the signal was present in all measurement scans. The closer the curves are together, the more constant the measured signal level. The more the curves are spread apart, the more variation occurred in the measured signal level. The average curve's proximity to the maximum or minimum curves indicates whether the signal was present in a large percentage of scans or a low percentage of scans, respectively. The absolute percentages of time that signals were present are not available in these data graphs. 


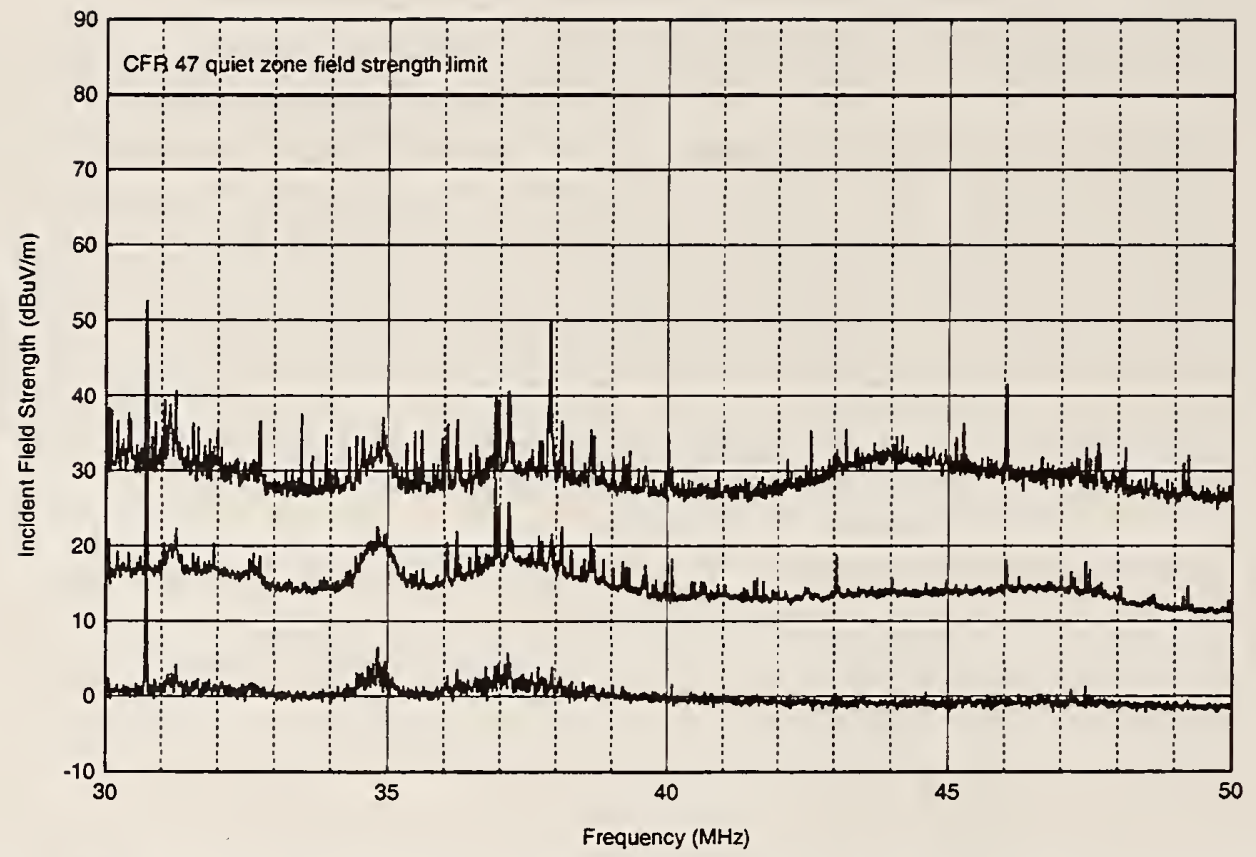

Figure A.1. Table Mountain NRQZ, 30-50 MHz, $10 \mathrm{kHz}$ IF bandwidth, 6,300 sweeps, vertical polarization. 


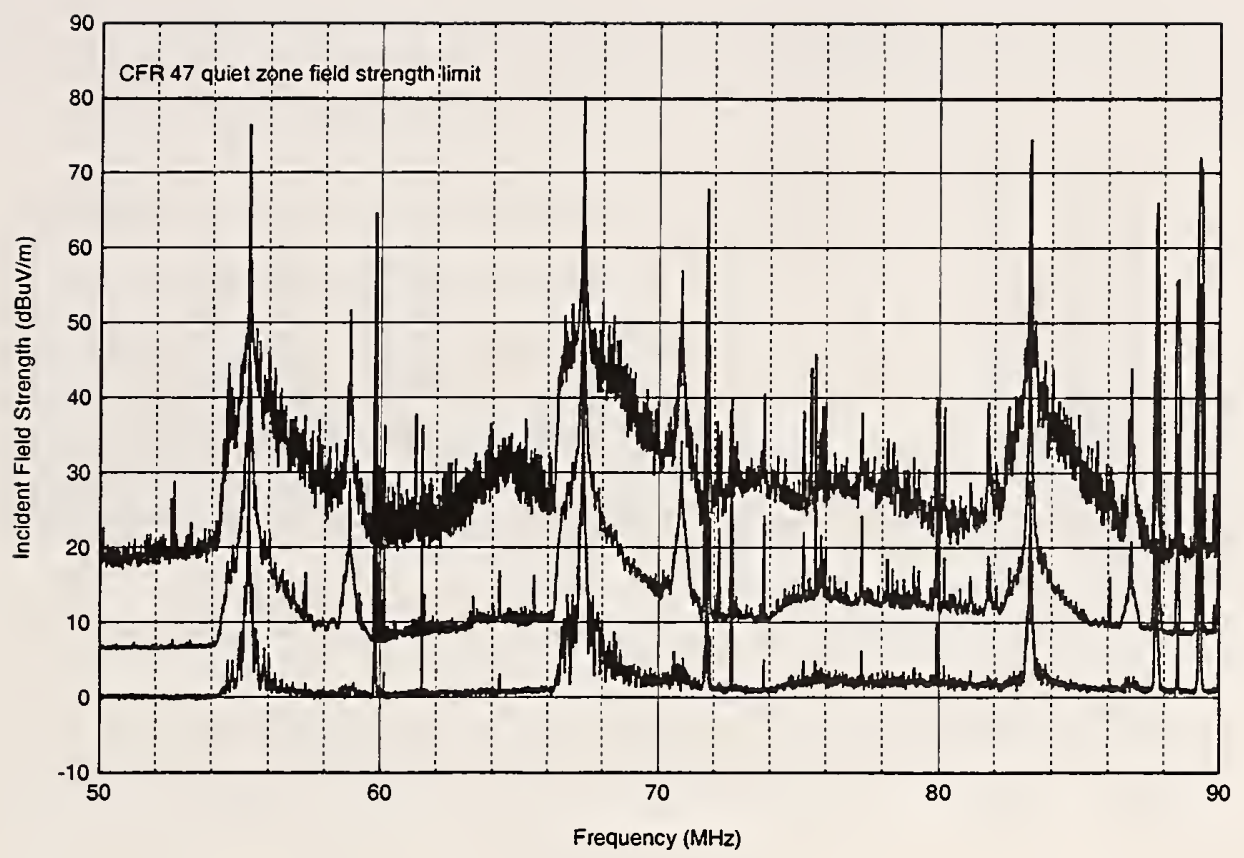

Figure A.2. Table Mountain NRQZ, $50-90 \mathrm{MHz}, 10 \mathrm{kHz}$ IF bandwidth, 1,890 sweeps, vertical polarization.

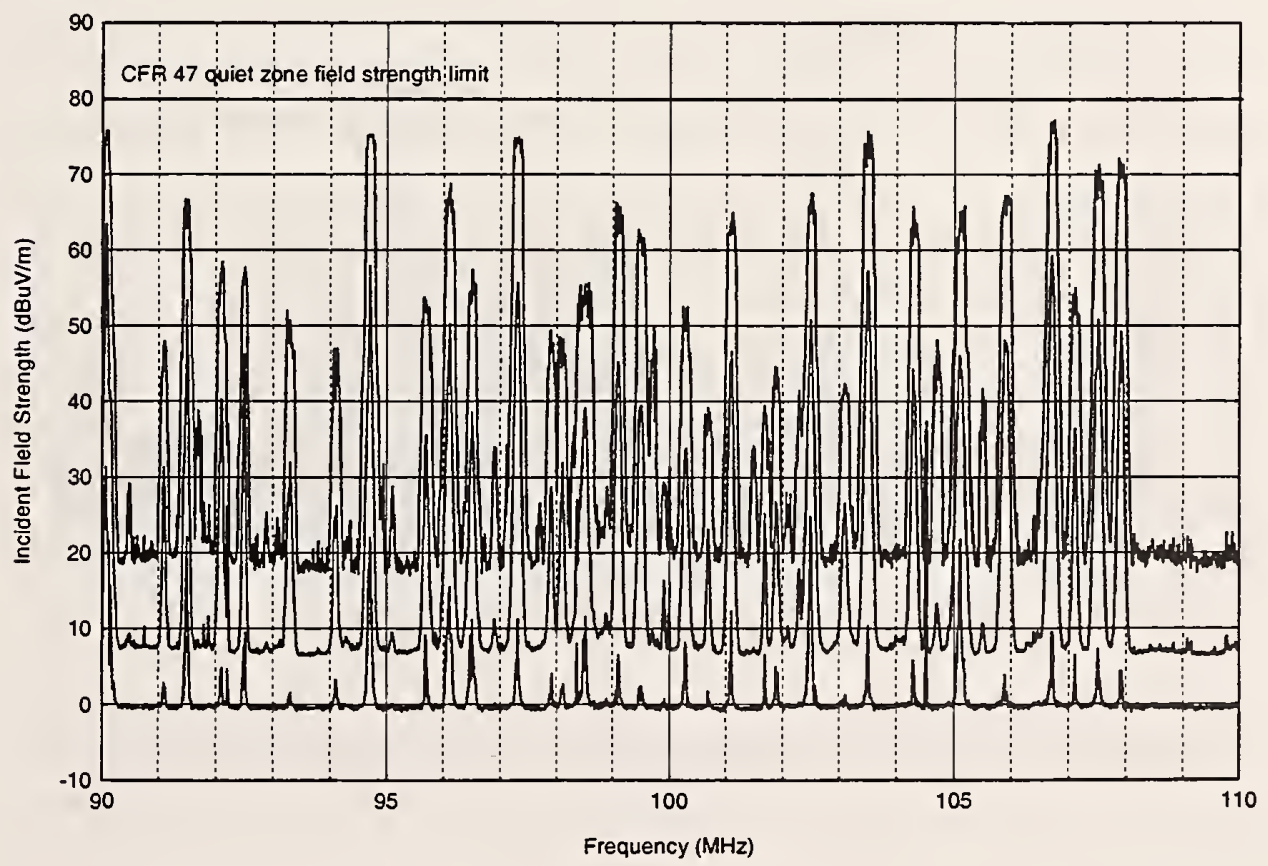

Figure A.3. Table Mountain NRQZ, $90-110 \mathrm{MHz}, 10 \mathrm{kHz}$ IF bandwidth, 1,890 sweeps, vertical polarization. 


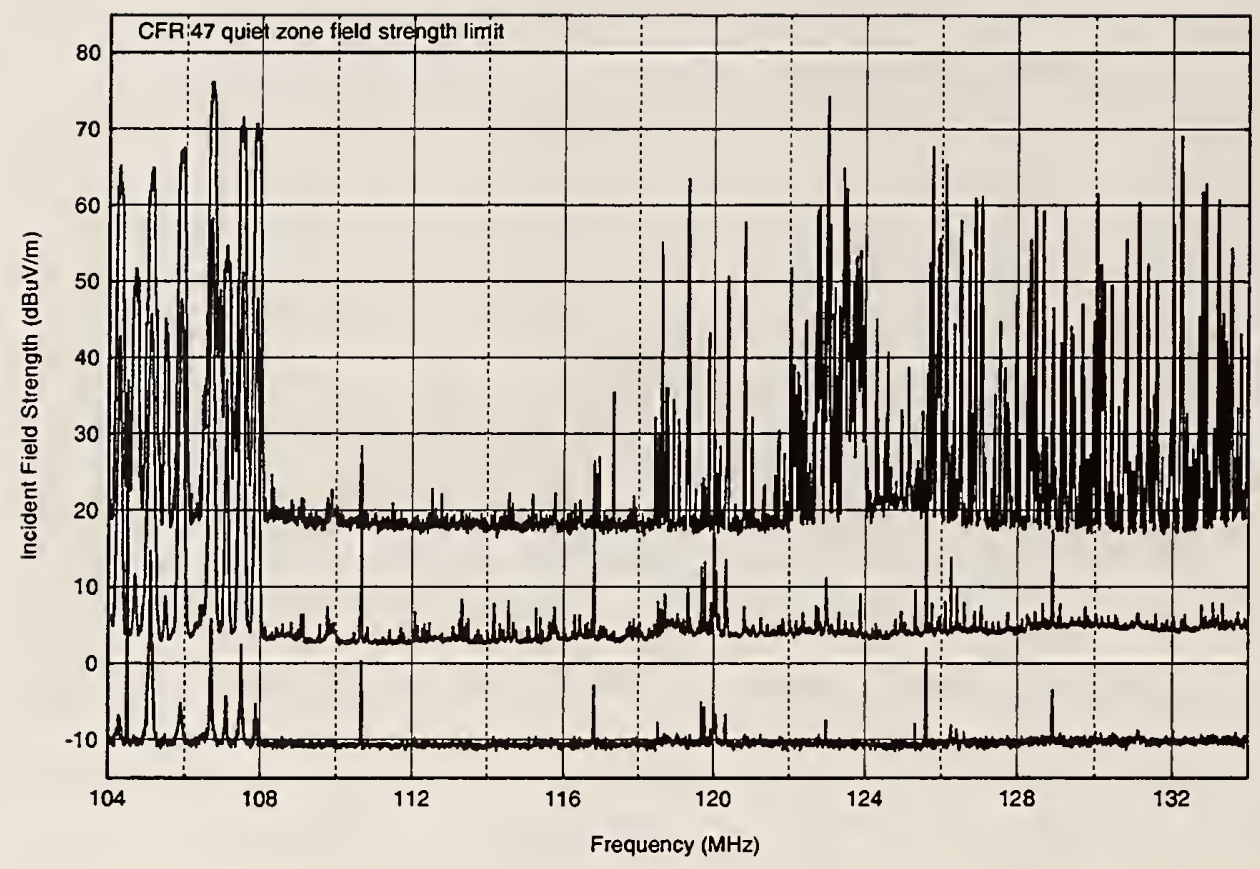

Figure A.4. Table Mountain NRQZ, 104-134 MHz, 12,400 sweeps, vertical polarization.

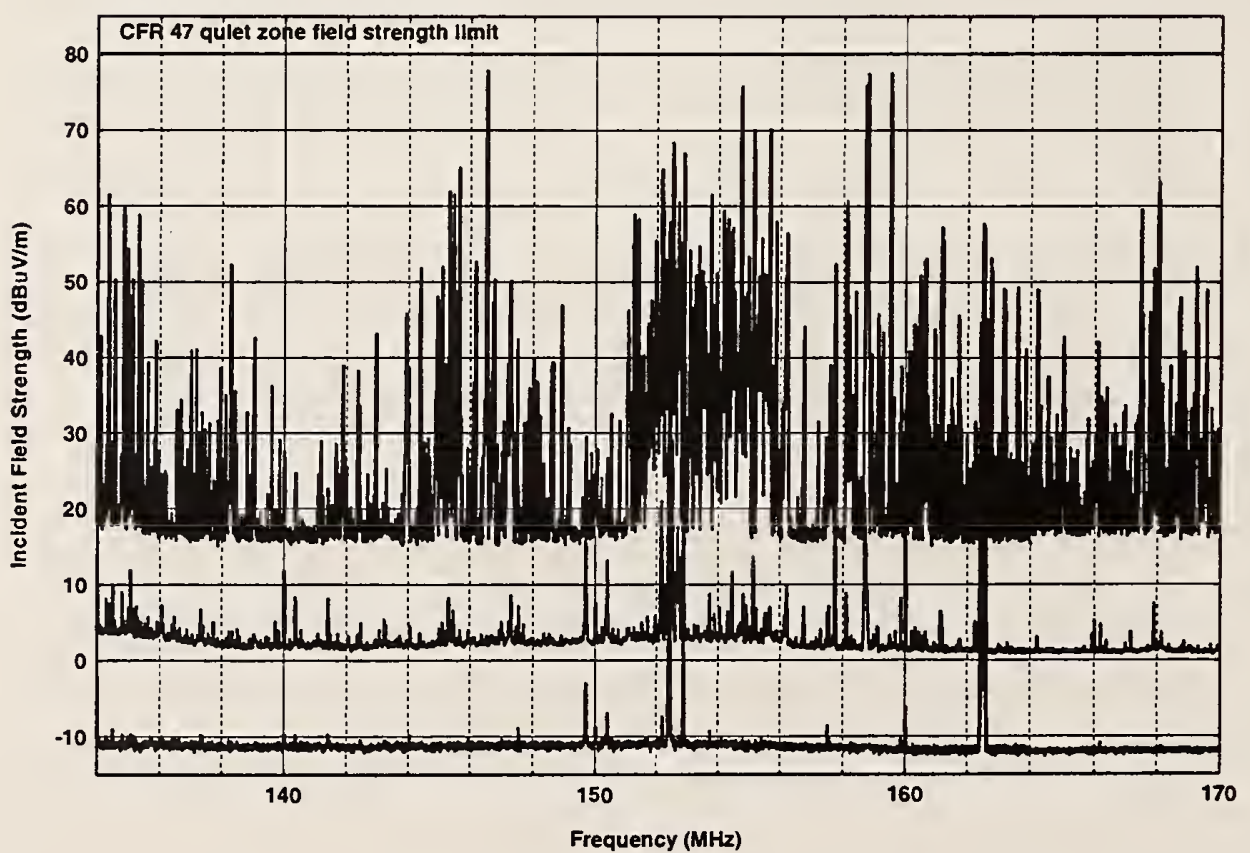

Figure A.5. Table Mountain NRQZ, 134-170 MHz, $10 \mathrm{kHz}$ IF bandwidth, 12,400 sweeps, vertical polarization. 


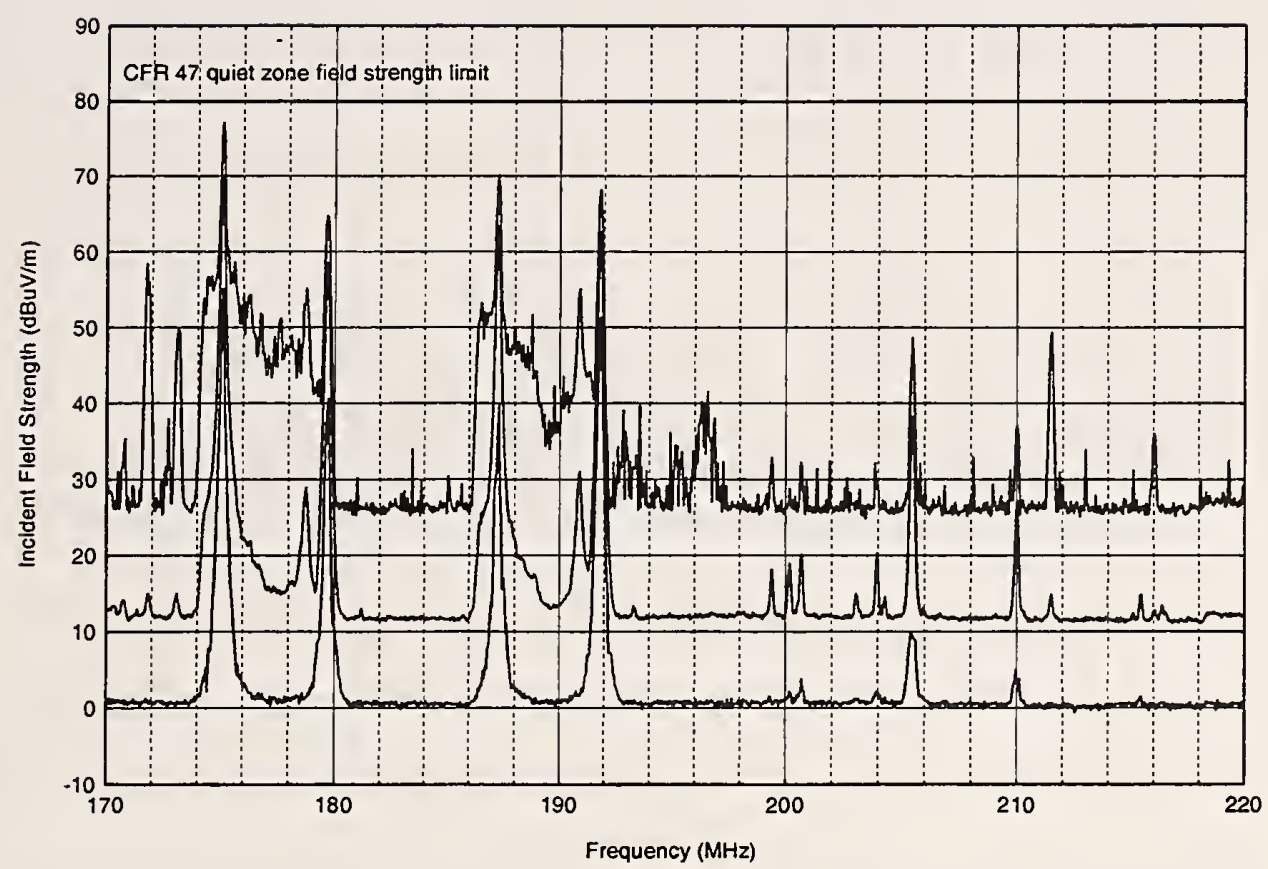

Figure A.6. Table Mountain NRQZ, 170-220 MHz, $100 \mathrm{kHz}$ IF bandwidth, 31,500 sweeps, vertical polarization.

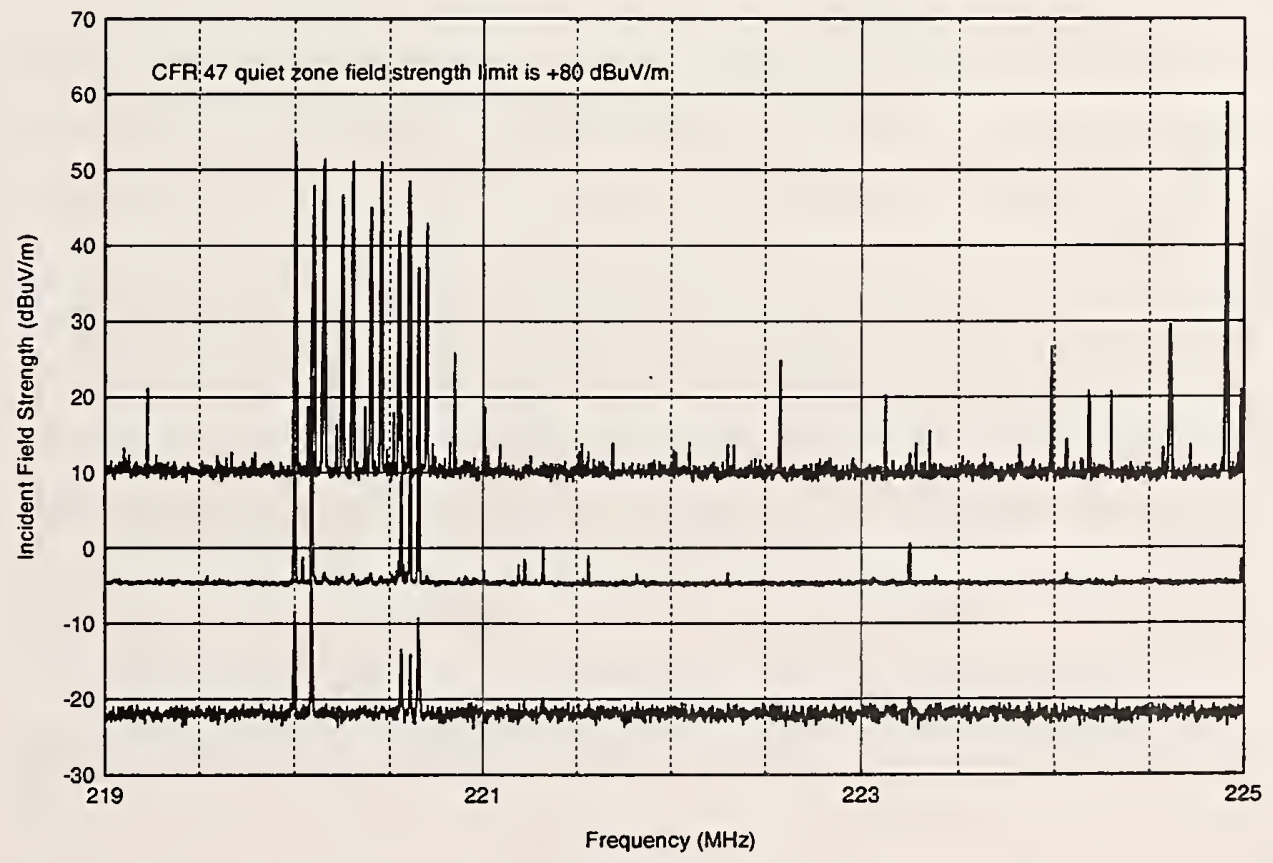

Figure A.7. Table Mountain NRQZ, 219-225 MHz, $3 \mathrm{kHz}$ IF bandwidth, 7,380 sweeps, vertical polarization. 


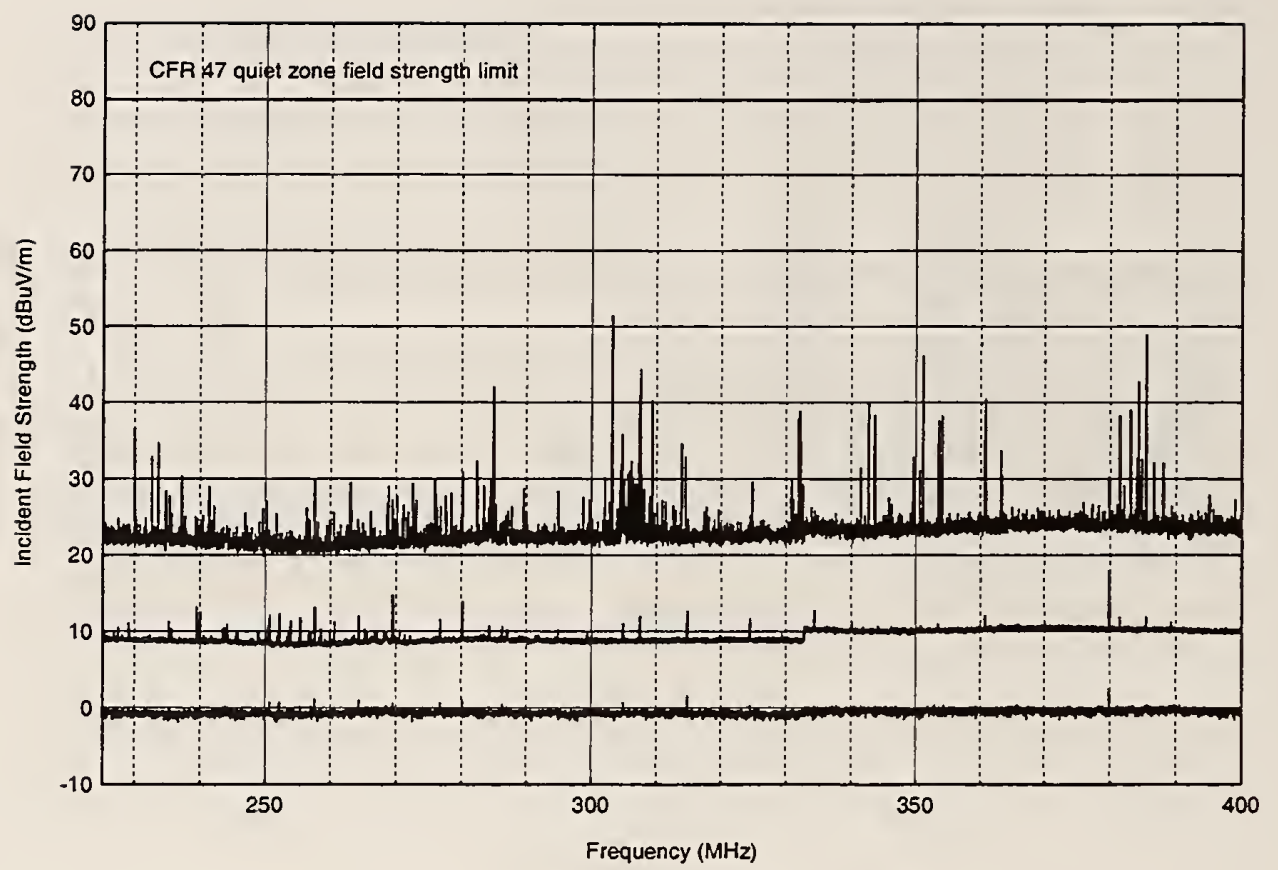

Figure A.8. Table Mountain NRQZ, 225-400 MHz, $30 \mathrm{kHz}$ IF bandwidth, 5,800 sweeps, vertical polarization.

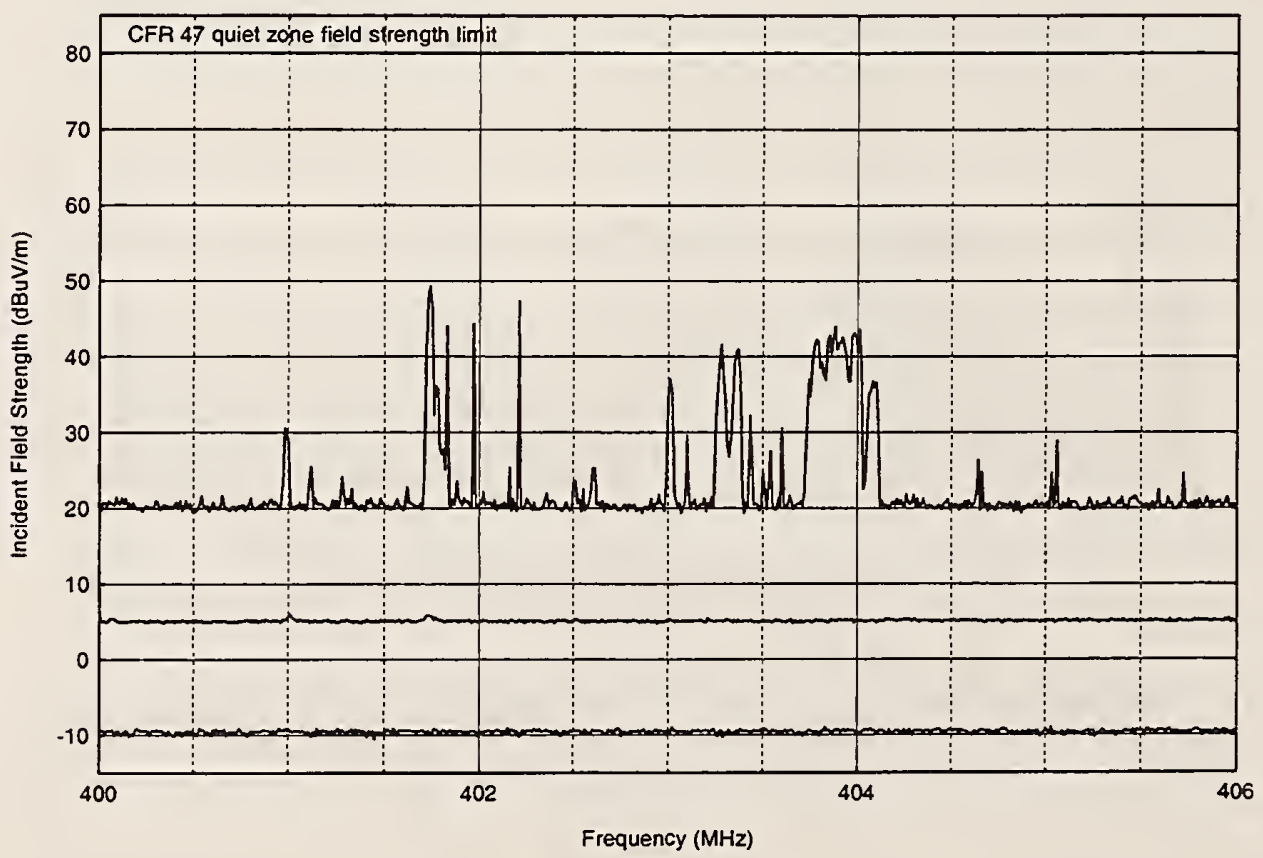

Figure A.9. Table Mountain NRQZ, 400-406 MHz, $10 \mathrm{kHz}$ IF bandwidth, 36,600 sweeps, vertical polarization. 


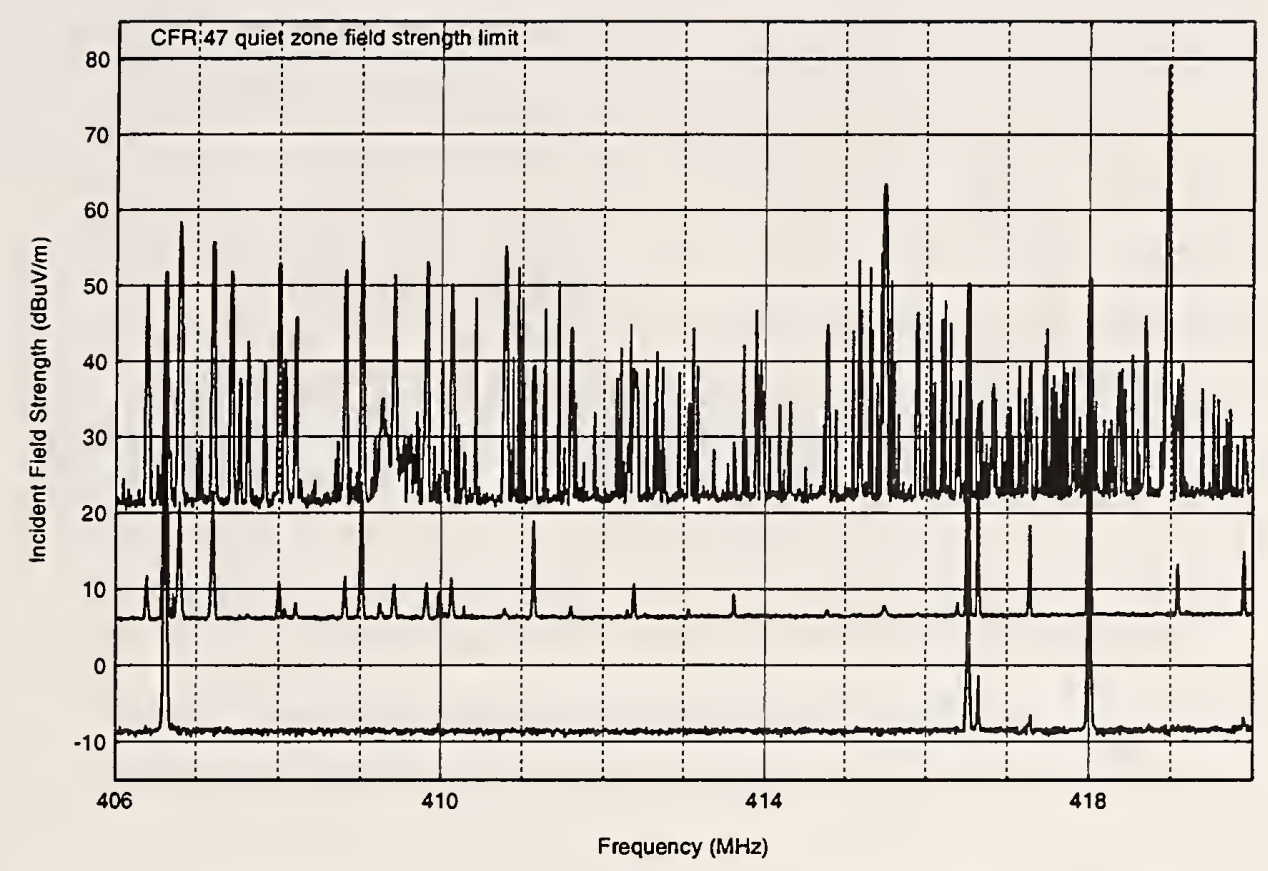

Figure A.10. Table Mountain NRQZ, 406-420 MHz, $10 \mathrm{kHz}$ IF bandwidth, 36,400 sweeps, vertical polarization.

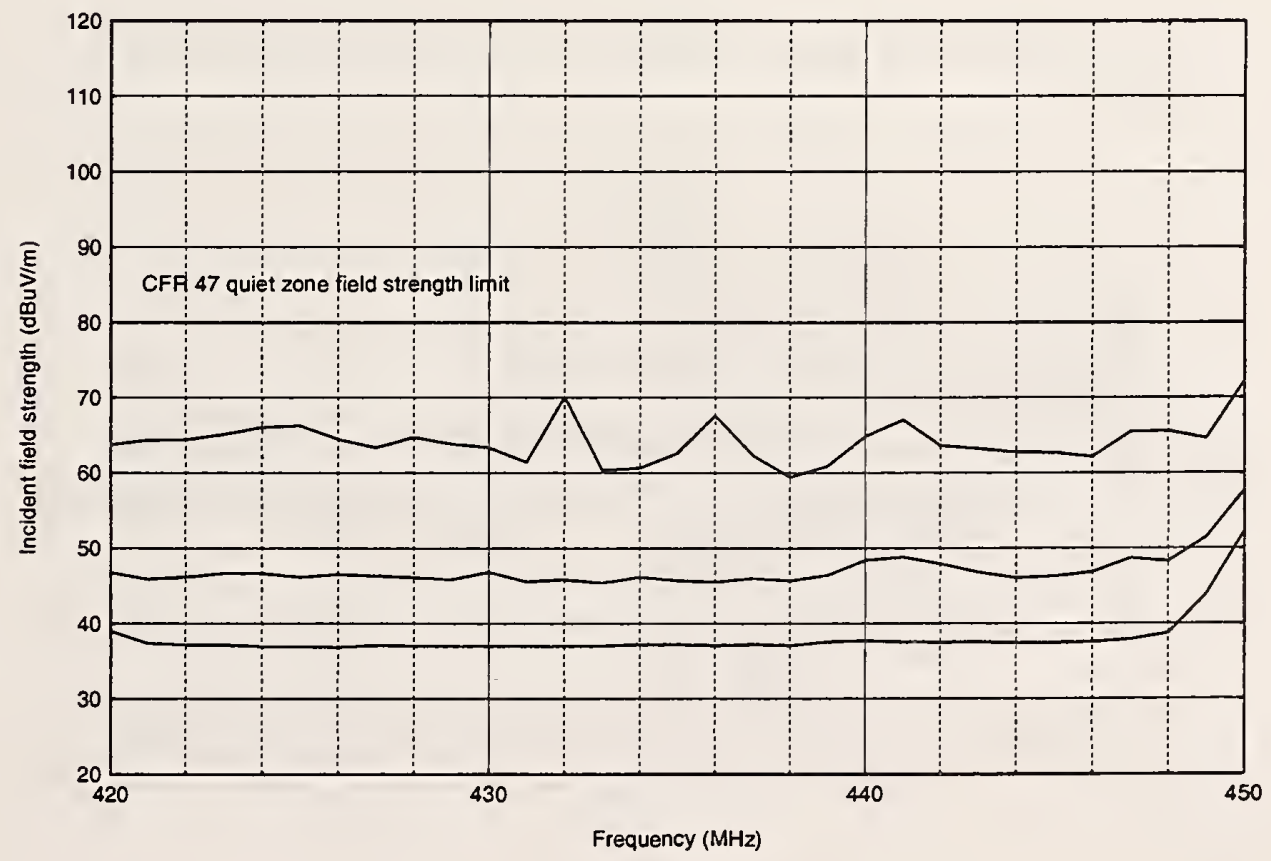

Figure A.11. Table Mountain NRQZ, 420-450 MHz, $1 \mathrm{MHz}$ IF bandwidth, 120 passes through band (stepped), vertical polarization. 


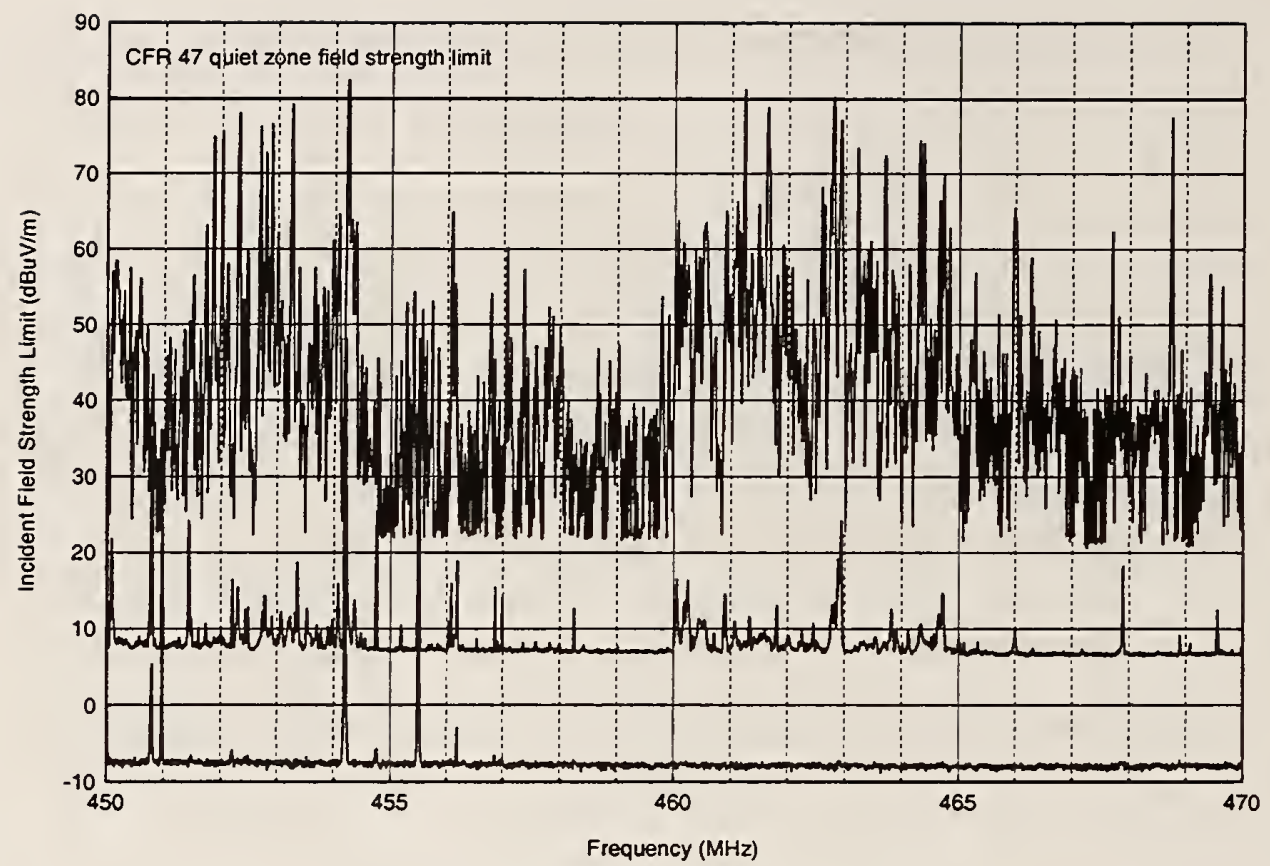

Figure A.12. Table Mountain NRQZ, 450-470 MHz, $10 \mathrm{kHz}$ IF bandwidth, 36,300 sweeps, vertical polarization.

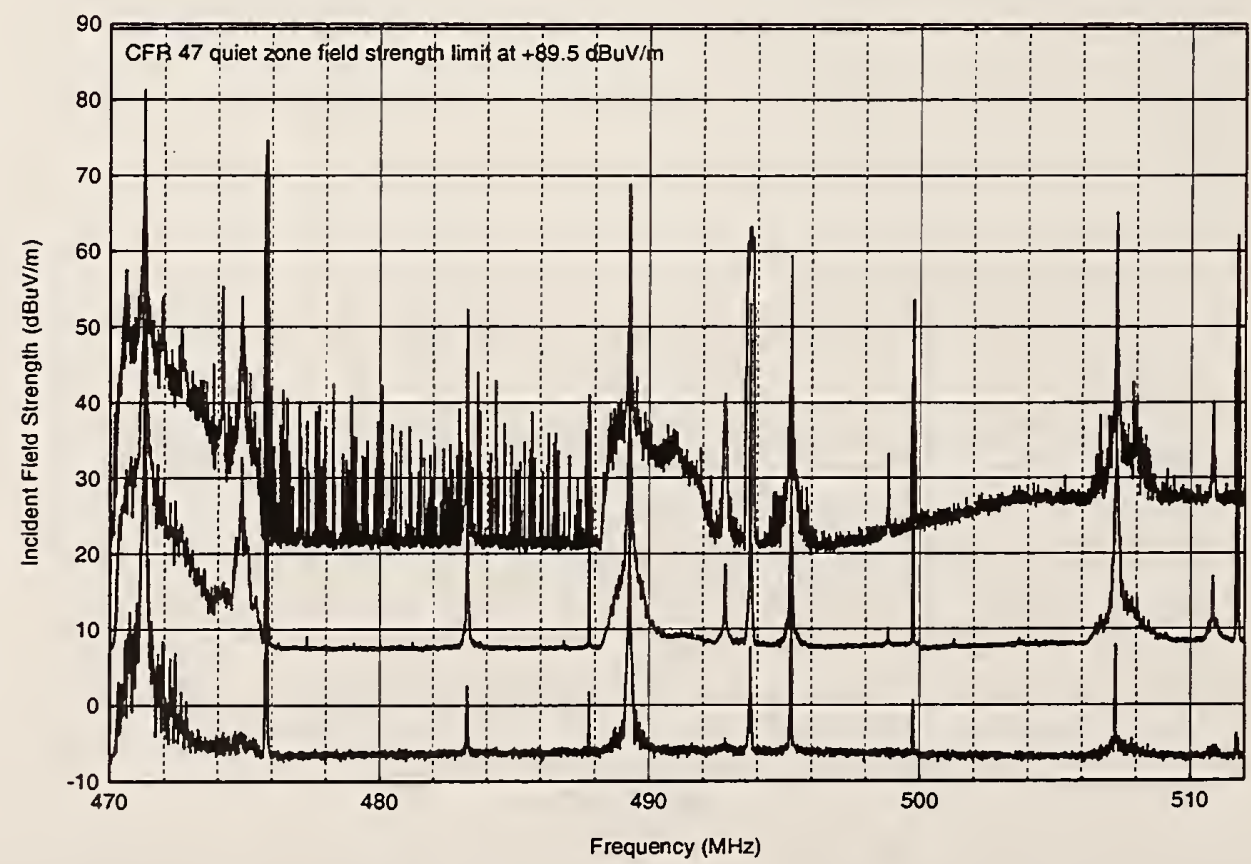

Figure A.13. Table Mountain NRQZ, 470-512 MHz, $10 \mathrm{kHz}$ IF bandwidth, 18,000 sweeps, vertical polarization. 


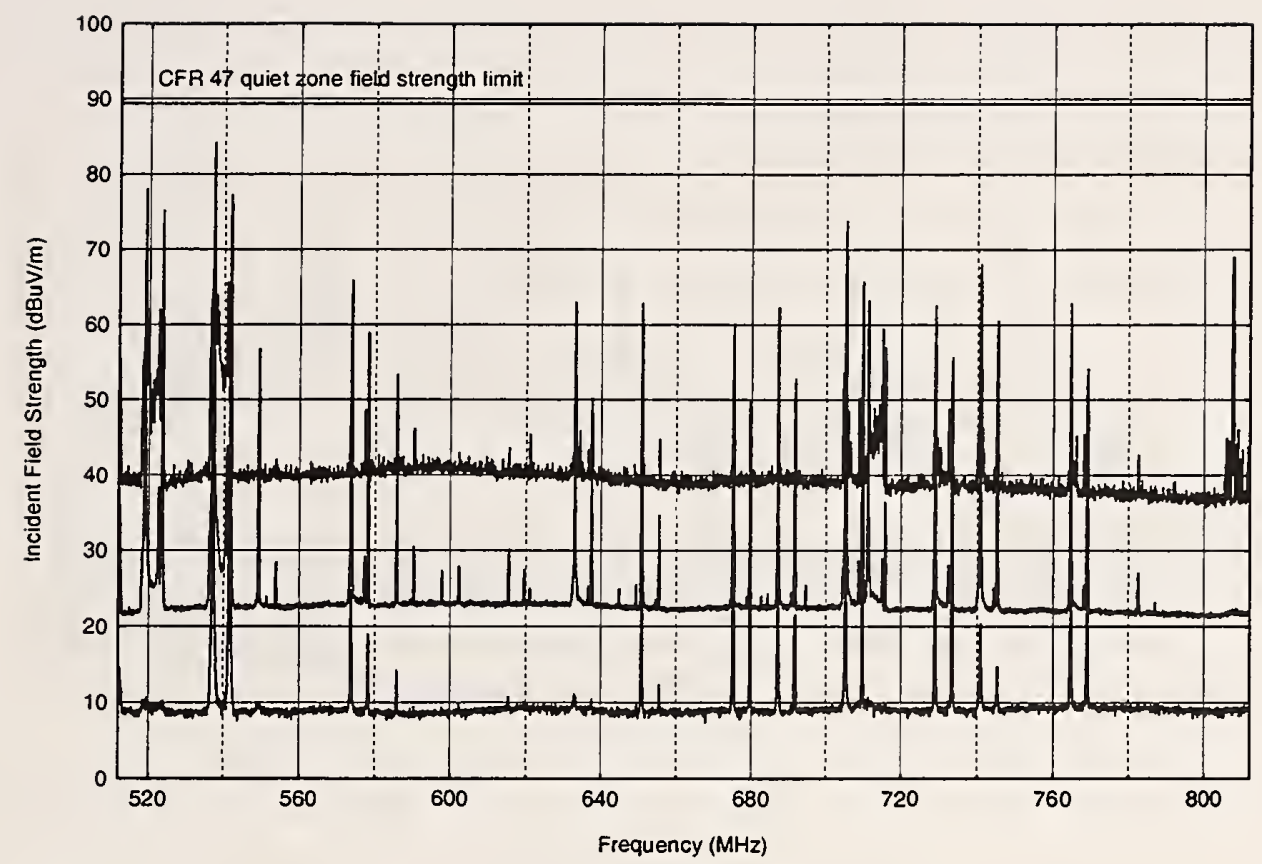

Figure A.14. Table Mountain NRQZ, 512-812 MHz, $100 \mathrm{kHz}$ IF bandwidth, 12,000 sweeps, vertical polarization.

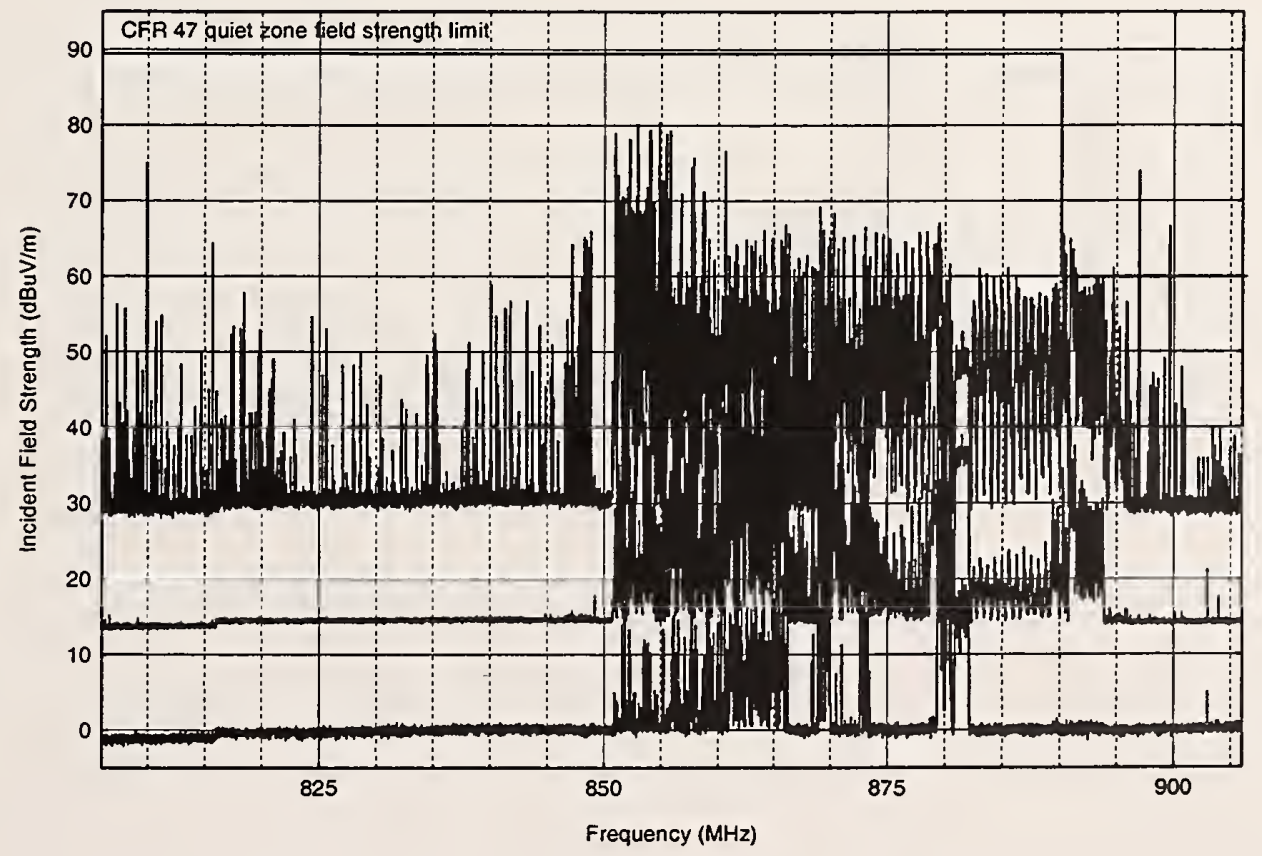

Figure A.15. Table Mountain NRQZ, 806-906 MHz, $10 \mathrm{kHz}$ IF bandwidth, 7,200 sweeps, vertical polarization. 


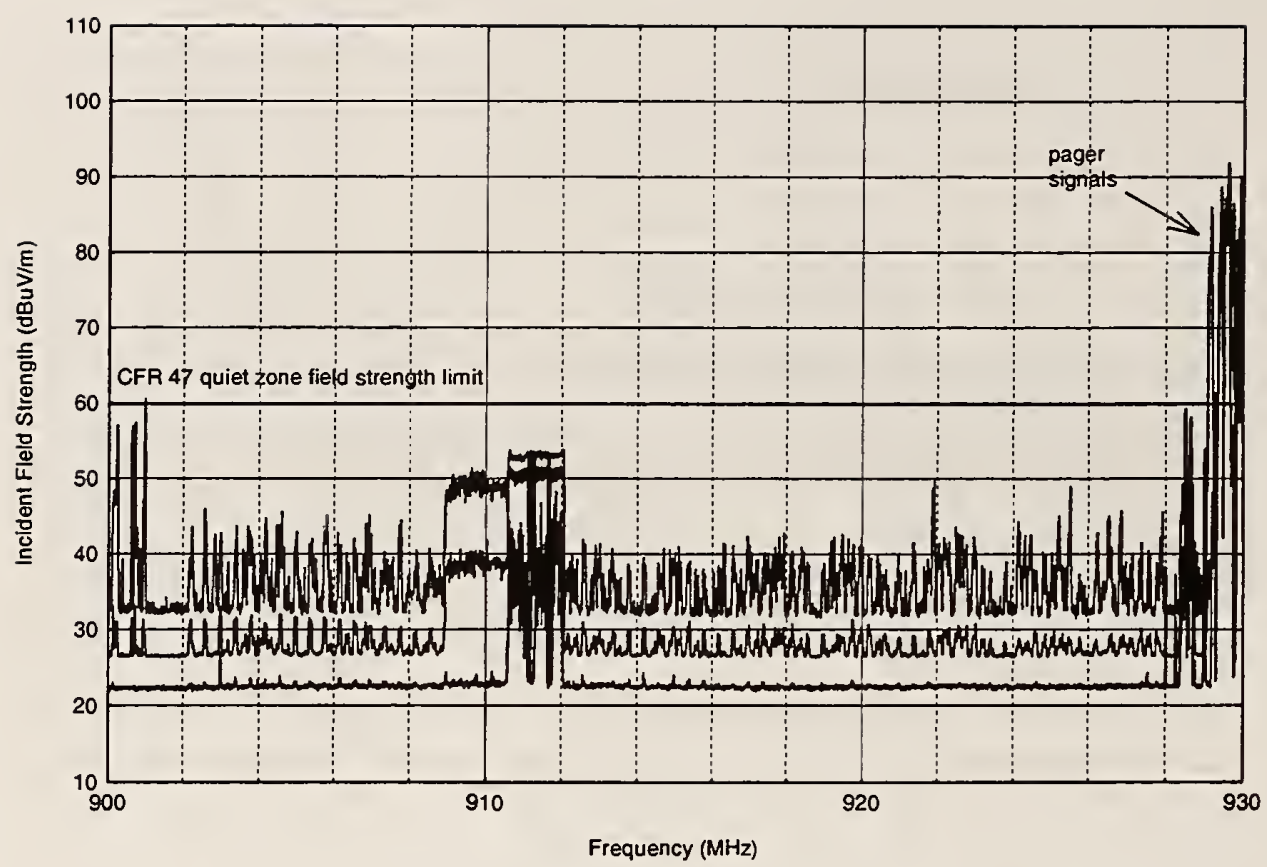

Figure A.16. Table Mountain NRQZ, $900-930 \mathrm{MHz}, 10 \mathrm{kHz}$ IF bandwidth, 120 sweeps, vertical polarization.

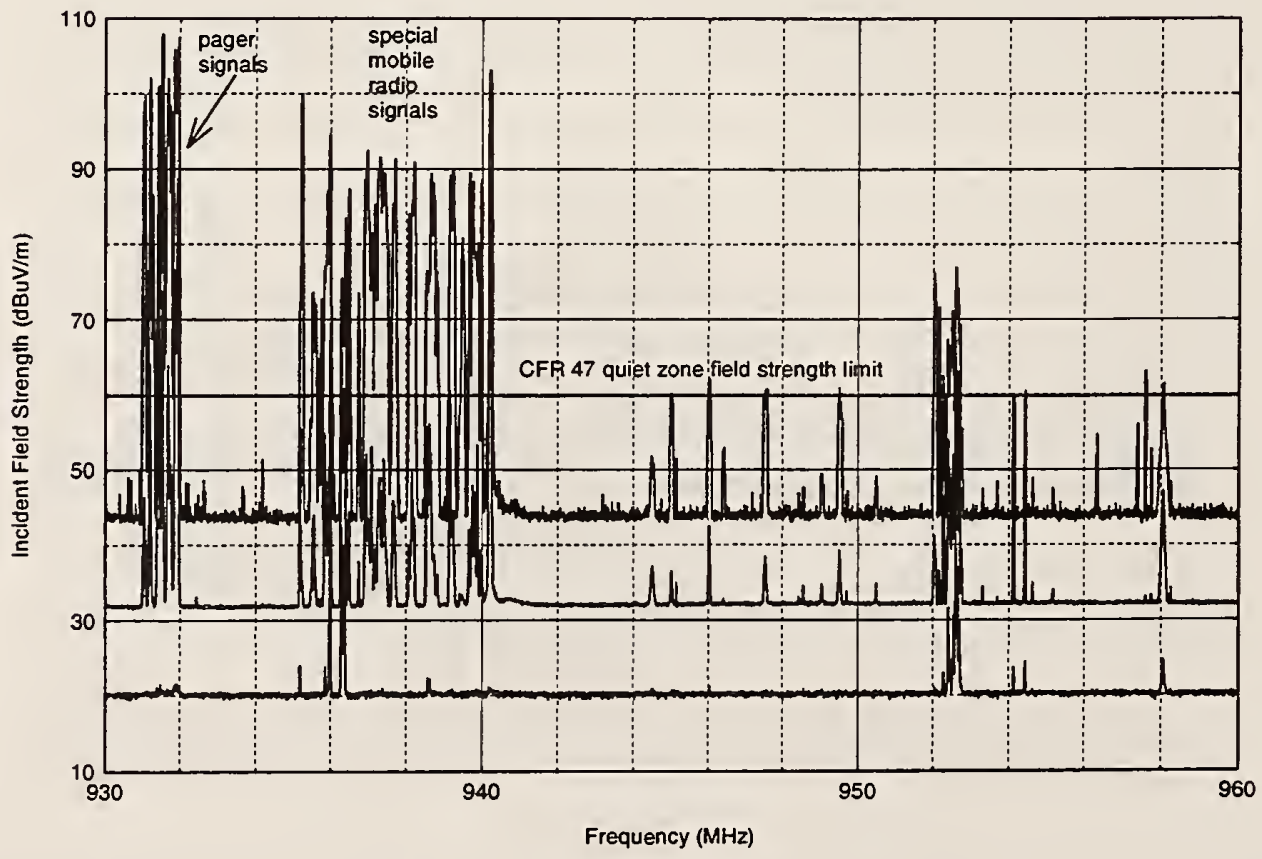

Figure A.17. Table Mountain NRQZ, $930-960 \mathrm{MHz}, 53,700$ sweeps, vertical polarization. 


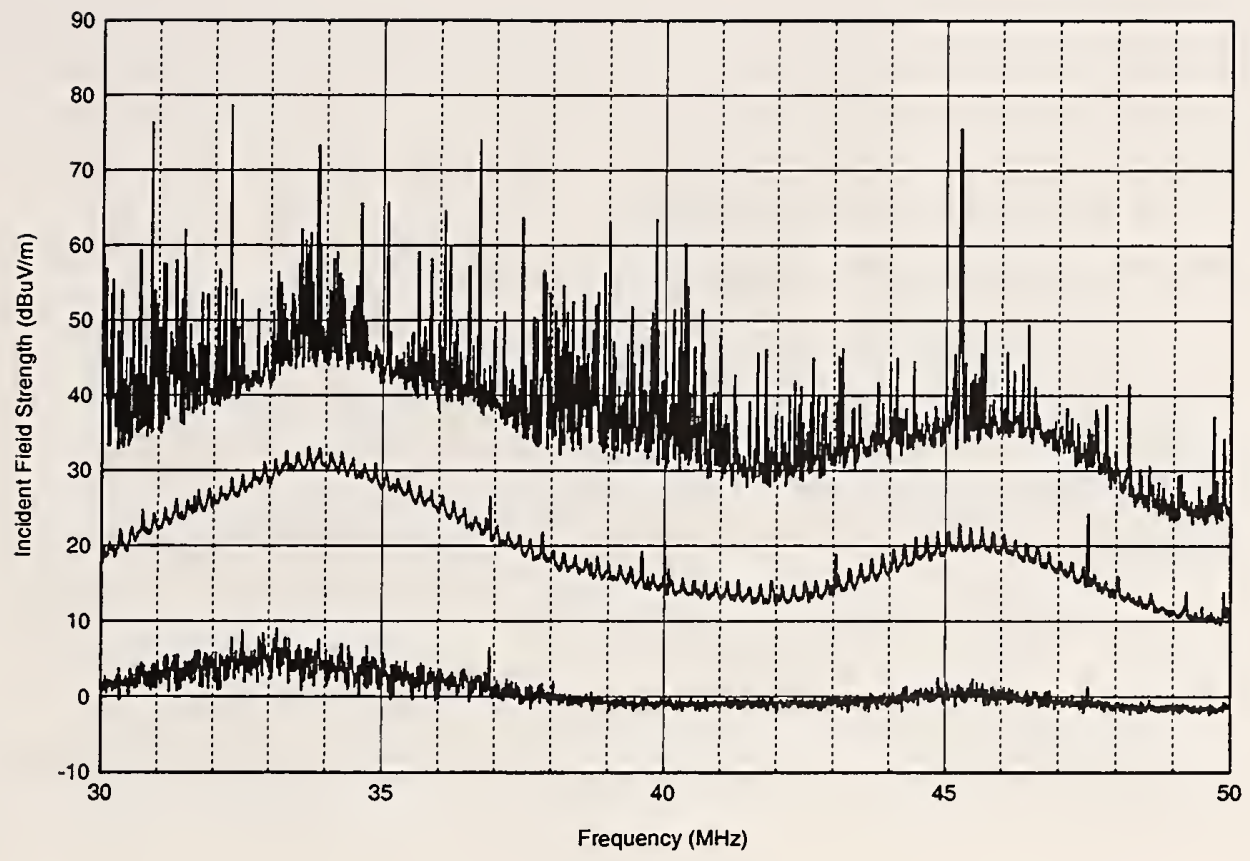

Figure A.18. NIST groundscreen, $30-50 \mathrm{MHz}, 10 \mathrm{kHz}$ IF bandwidth, 8,400 sweeps, vertical polarization.

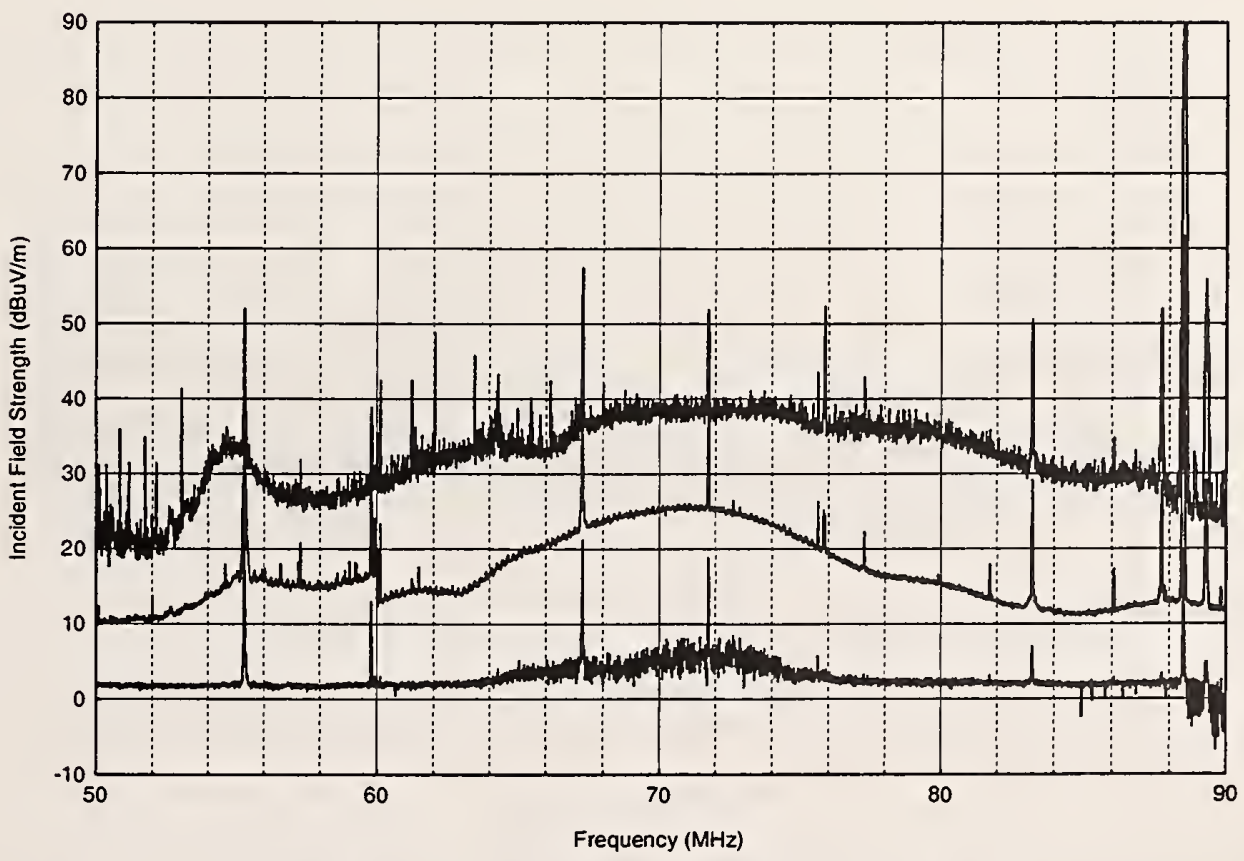

Figure A.19. NIST groundscreen, $50-90 \mathrm{MHz}, 10 \mathrm{kHz}$ IF bandwidth, 3,060 sweeps, vertical polarization. 


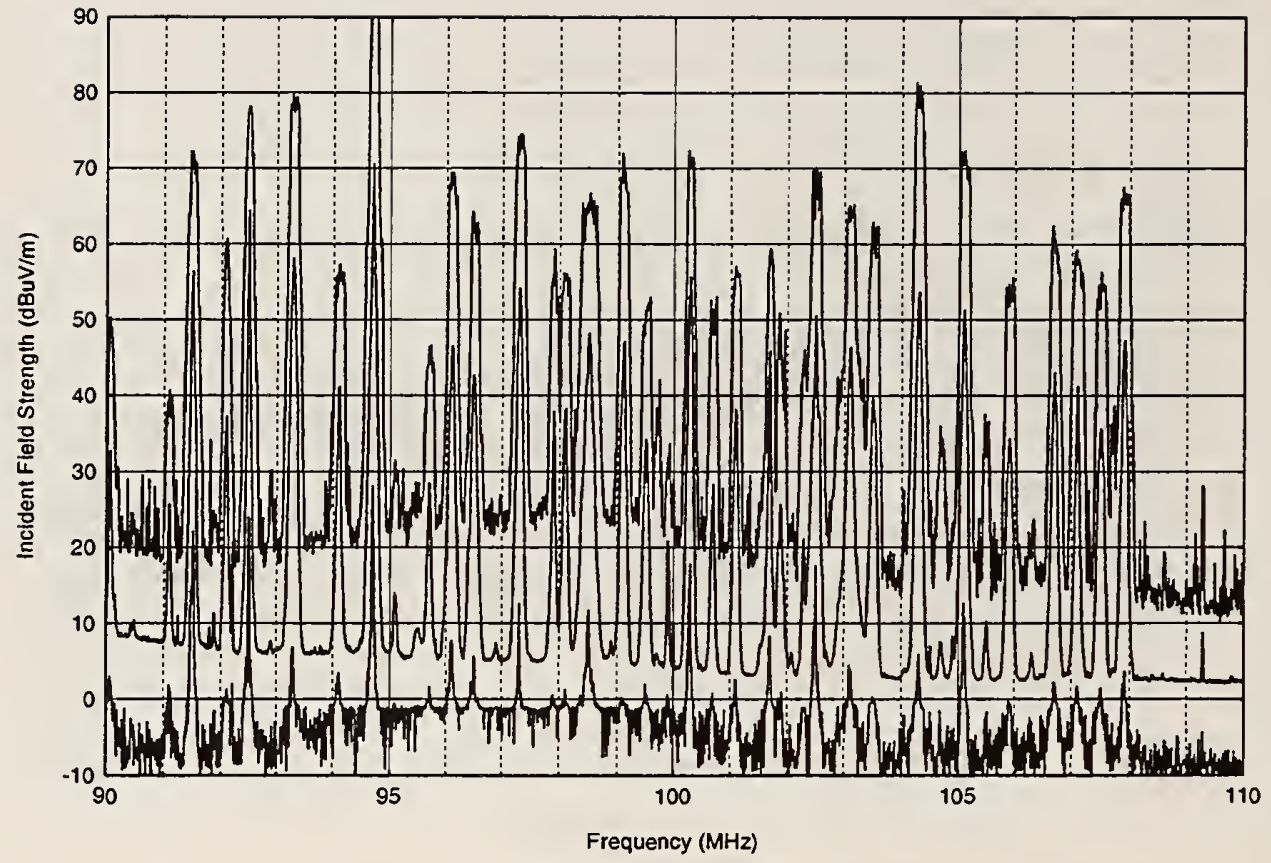

Figure A.20. NIST groundscreen, $90-110 \mathrm{MHz}, 10 \mathrm{kHz}$ IF bandwidth, 3,060 sweeps, vertical polarization.

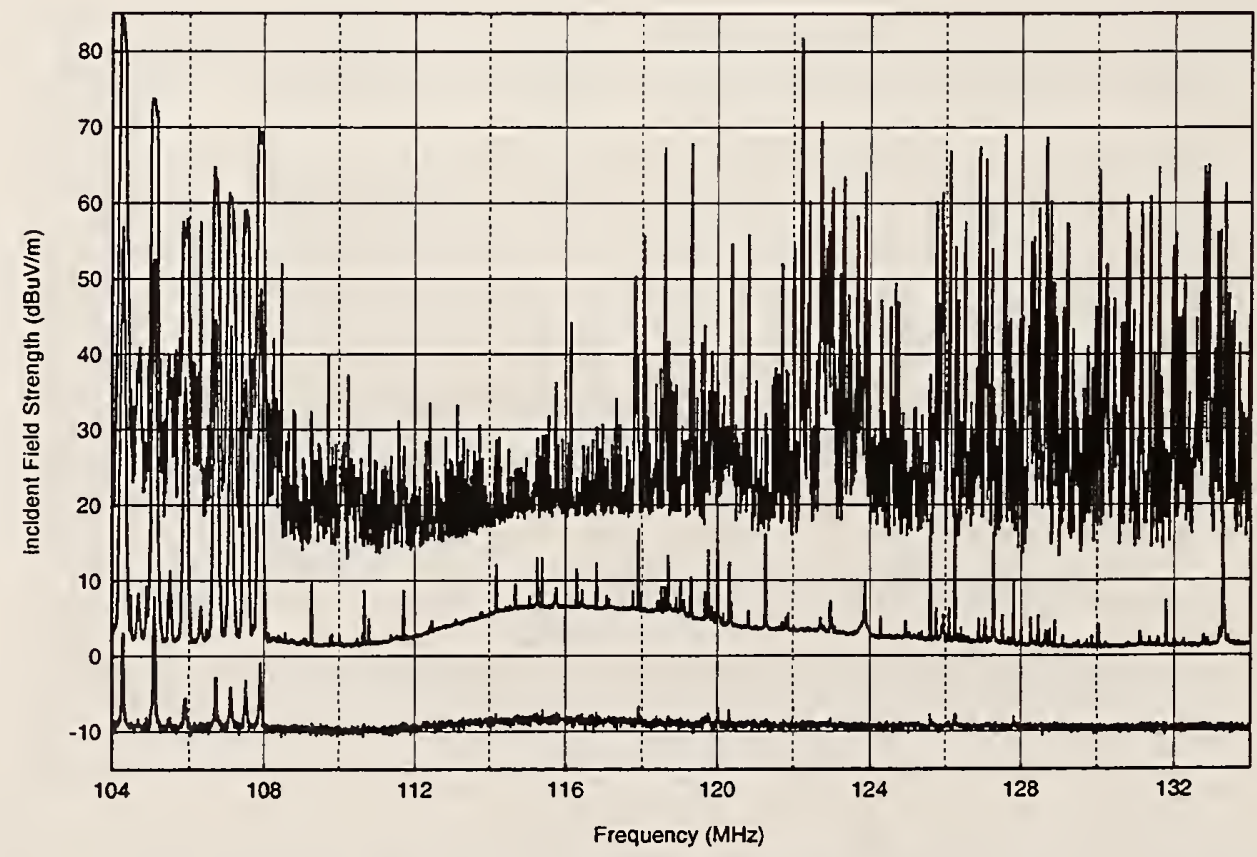

Figure A.21. NIST groundscreen, 104-134 MHz, $10 \mathrm{kHz}$ IF bandwidth, 21,600 sweeps, vertical polarization. 


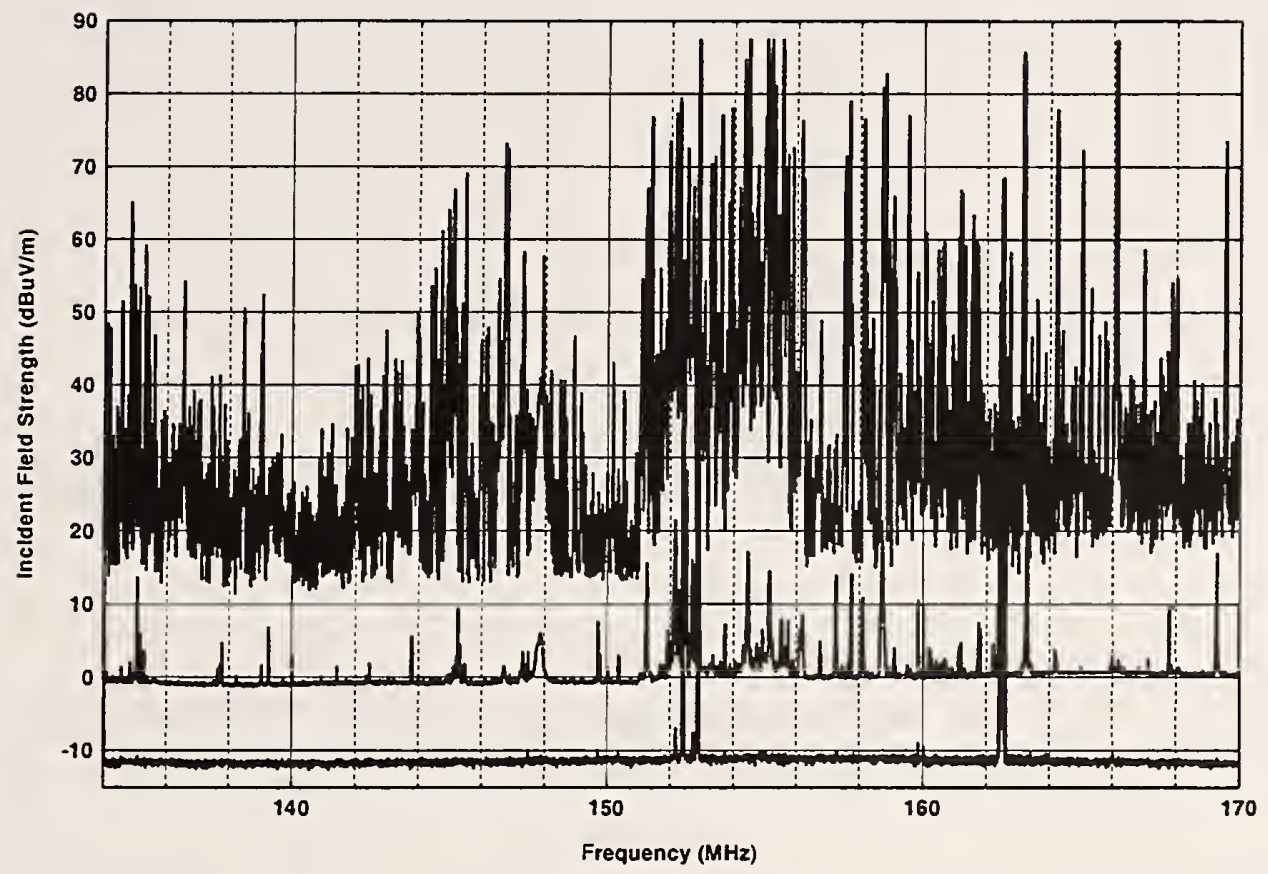

Figure A.22. NIST groundscreen, 134-170 MHz, $10 \mathrm{kHz}$ IF bandwidth, 21,600 sweeps, vertical polarization.

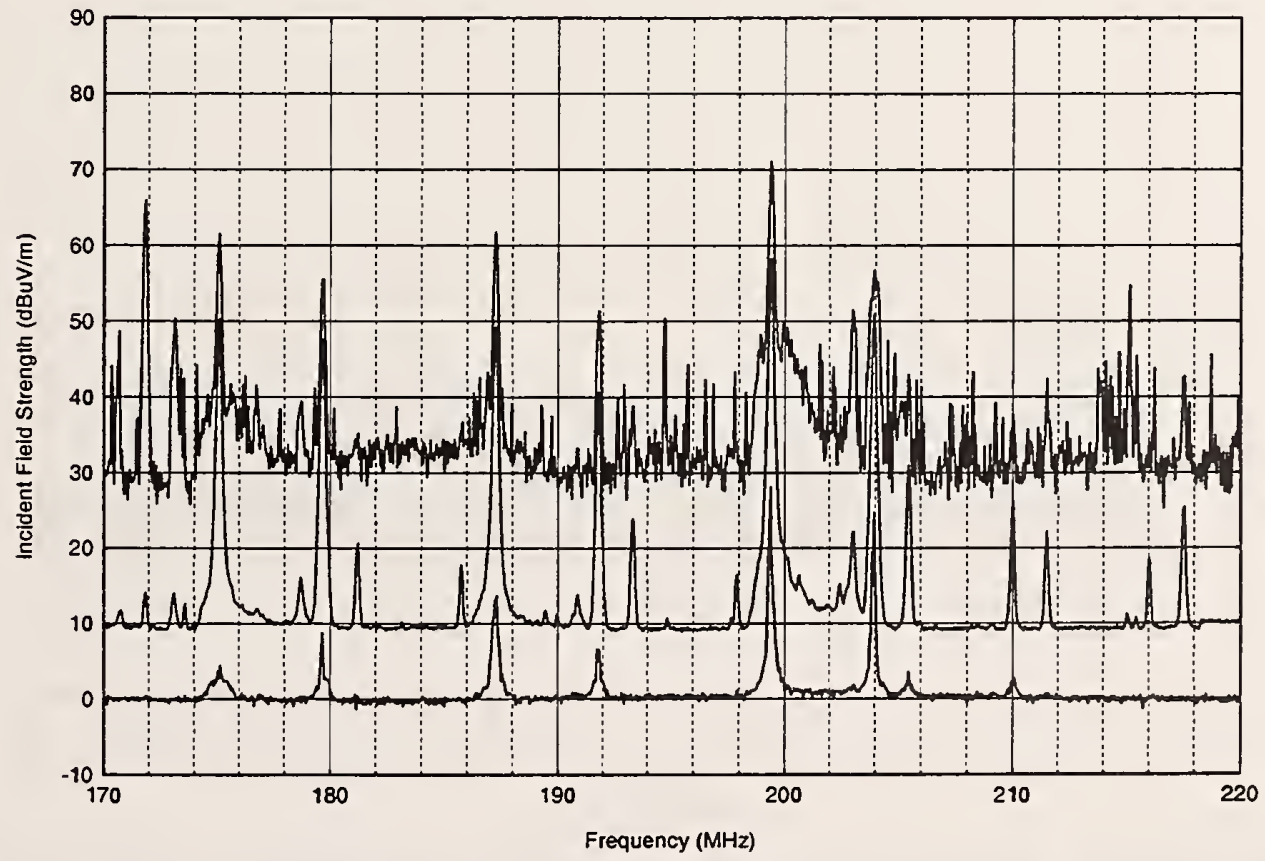

Figure A.23. NIST groundscreen, $170-220 \mathrm{MHz}, 100 \mathrm{kHz}$ IF bandwidth, 50,000 sweeps, vertical polarization. 


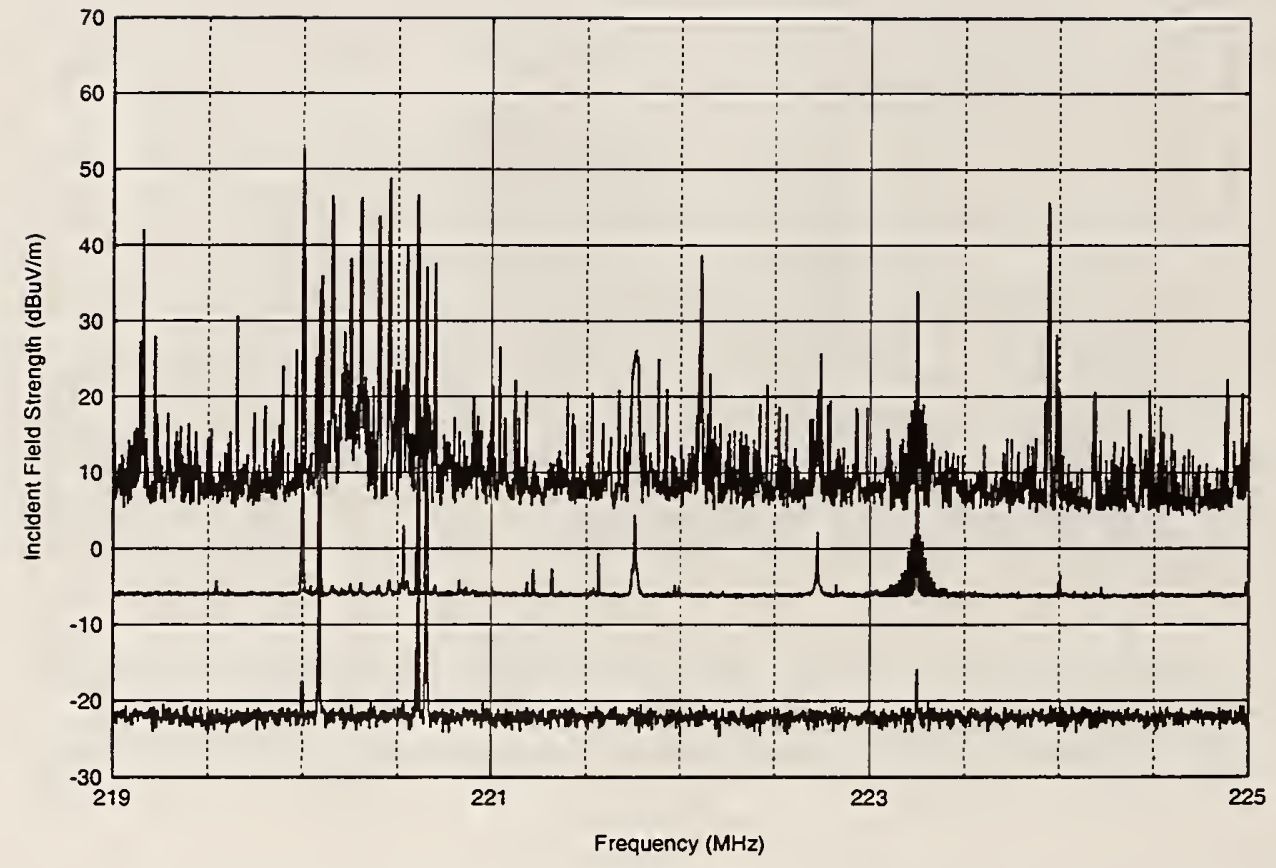

Figure A.24. NIST groundscreen, $219-225 \mathrm{MHz}, 3 \mathrm{kHz}$ IF bandwidth, 11,760 sweeps, vertical polarization.

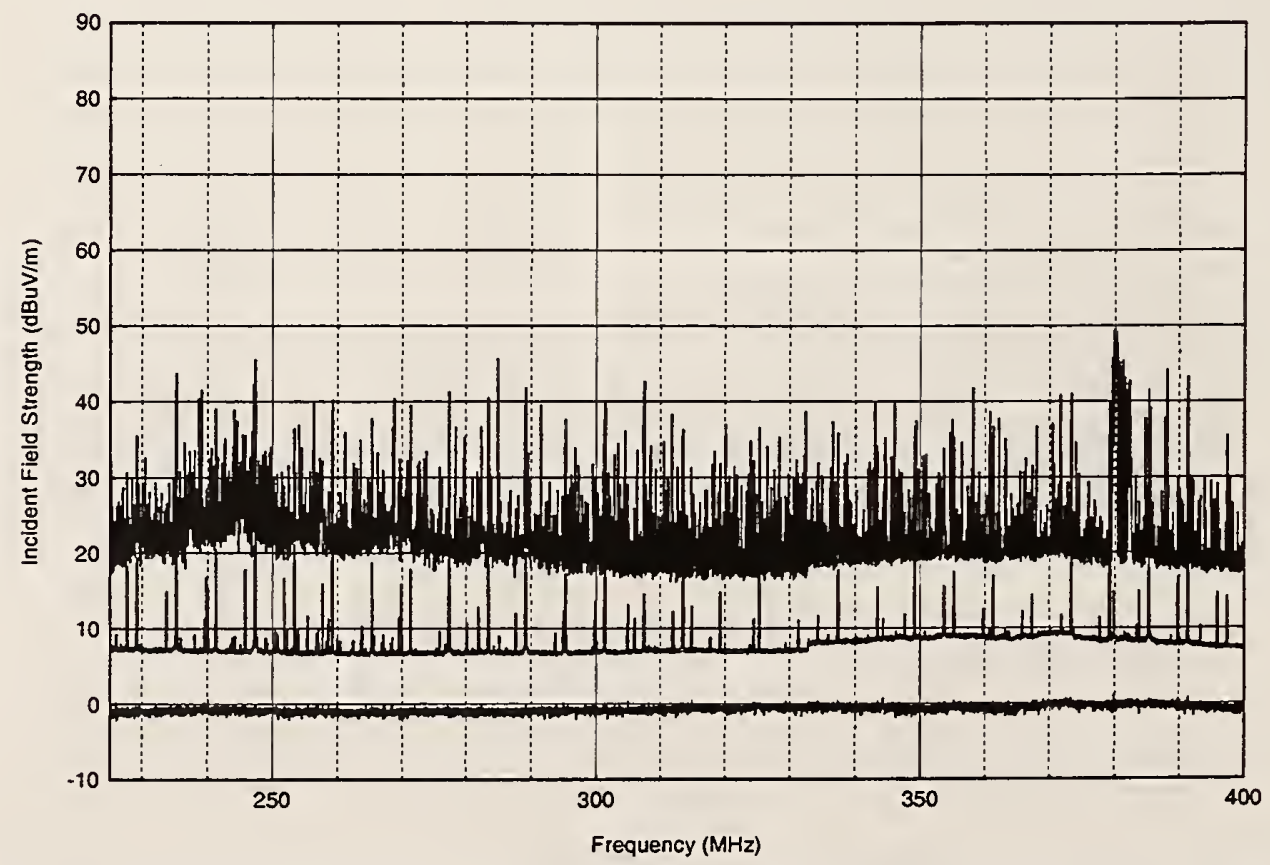

Figure A.25. NIST groundscreen, $225-400 \mathrm{MHz}, 30 \mathrm{kHz}$ IF bandwidth, 9,600 sweeps, vertical polarization. 


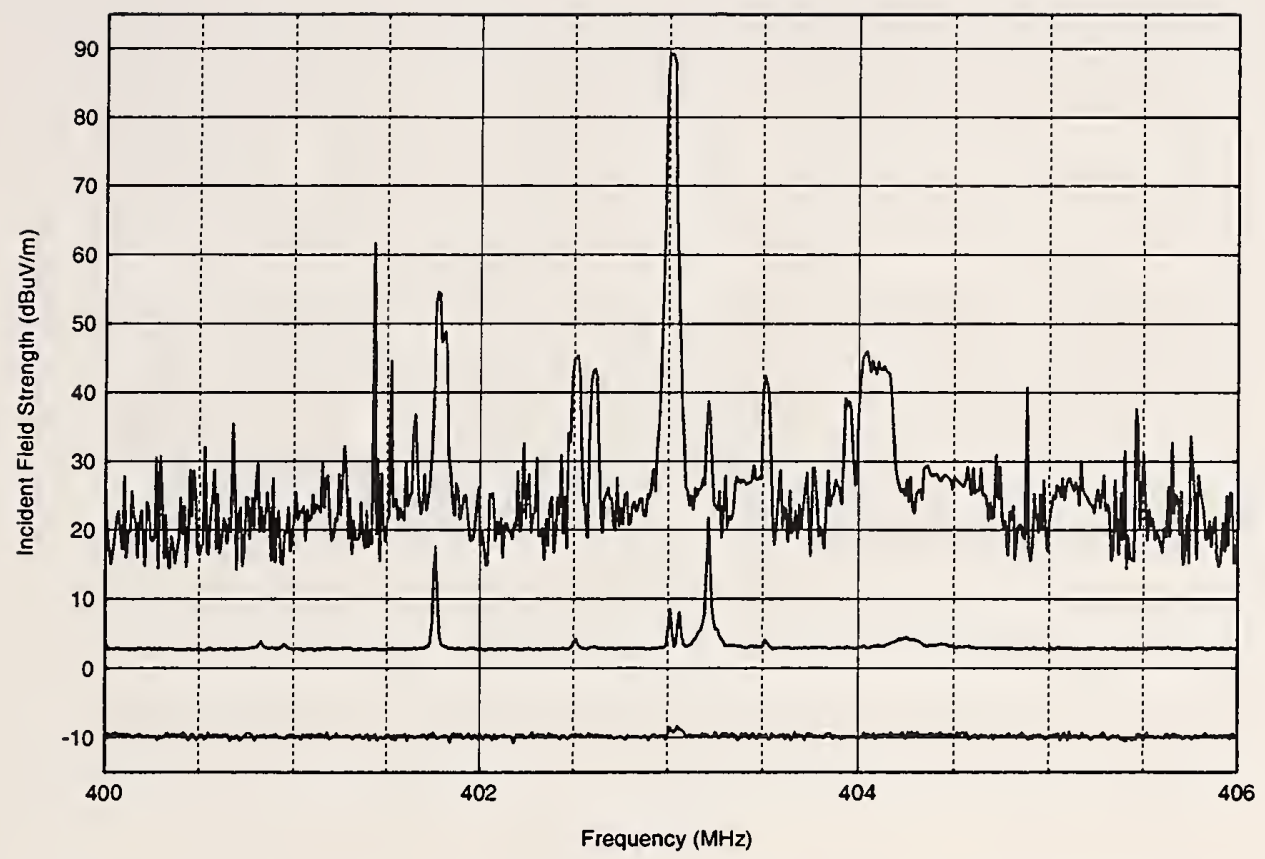

Figure A.26. NIST groundscreen, $400-406 \mathrm{MHz}, 58,800$ sweeps, vertical polarization.

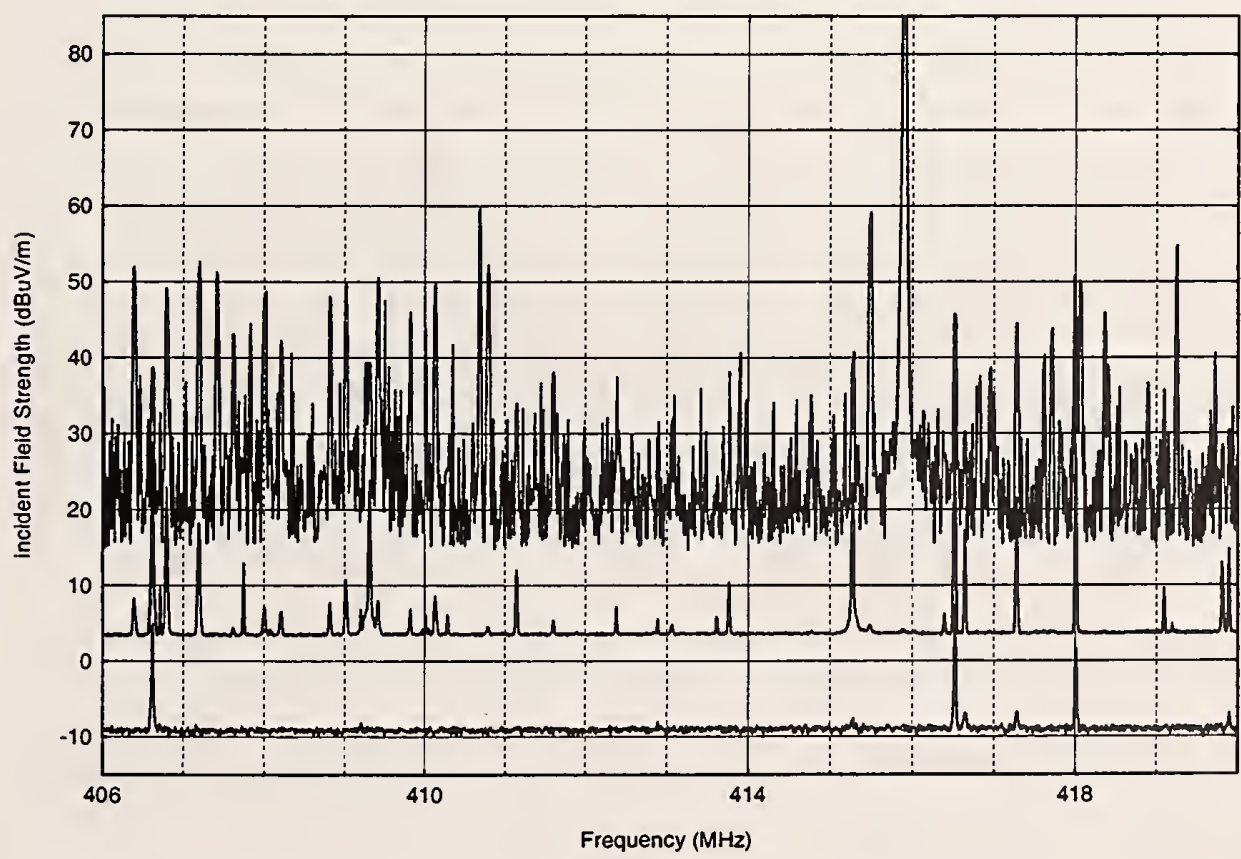

Figure A.27. NIST groundscreen, $406-420 \mathrm{MHz}, 10 \mathrm{kHz}$ IF bandwidth, 58,600 sweeps, vertical polarization. 


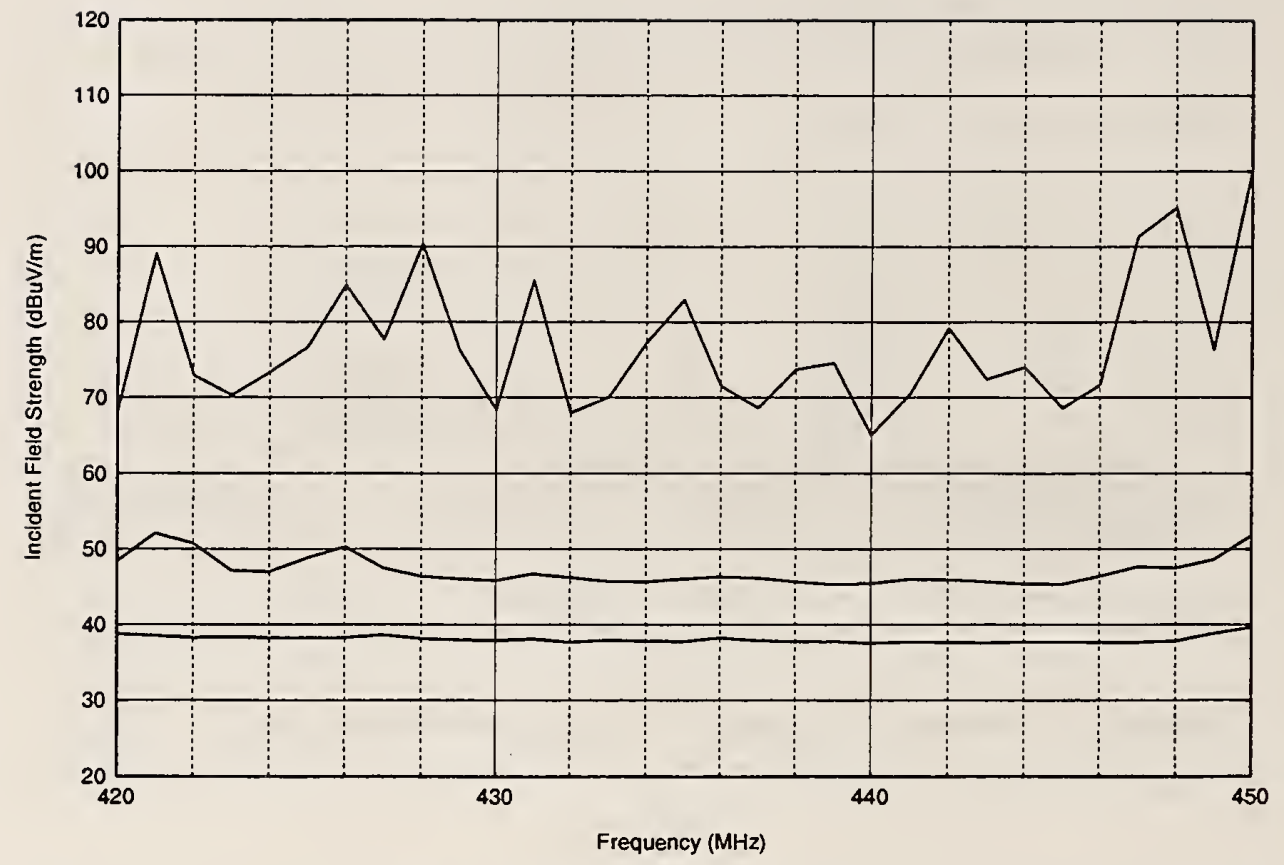

Figure A.28. NIST groundscreen, 420-450 MHz, $1 \mathrm{MHz}$ IF bandwidth, 193 stepped passes, vertical polarization.

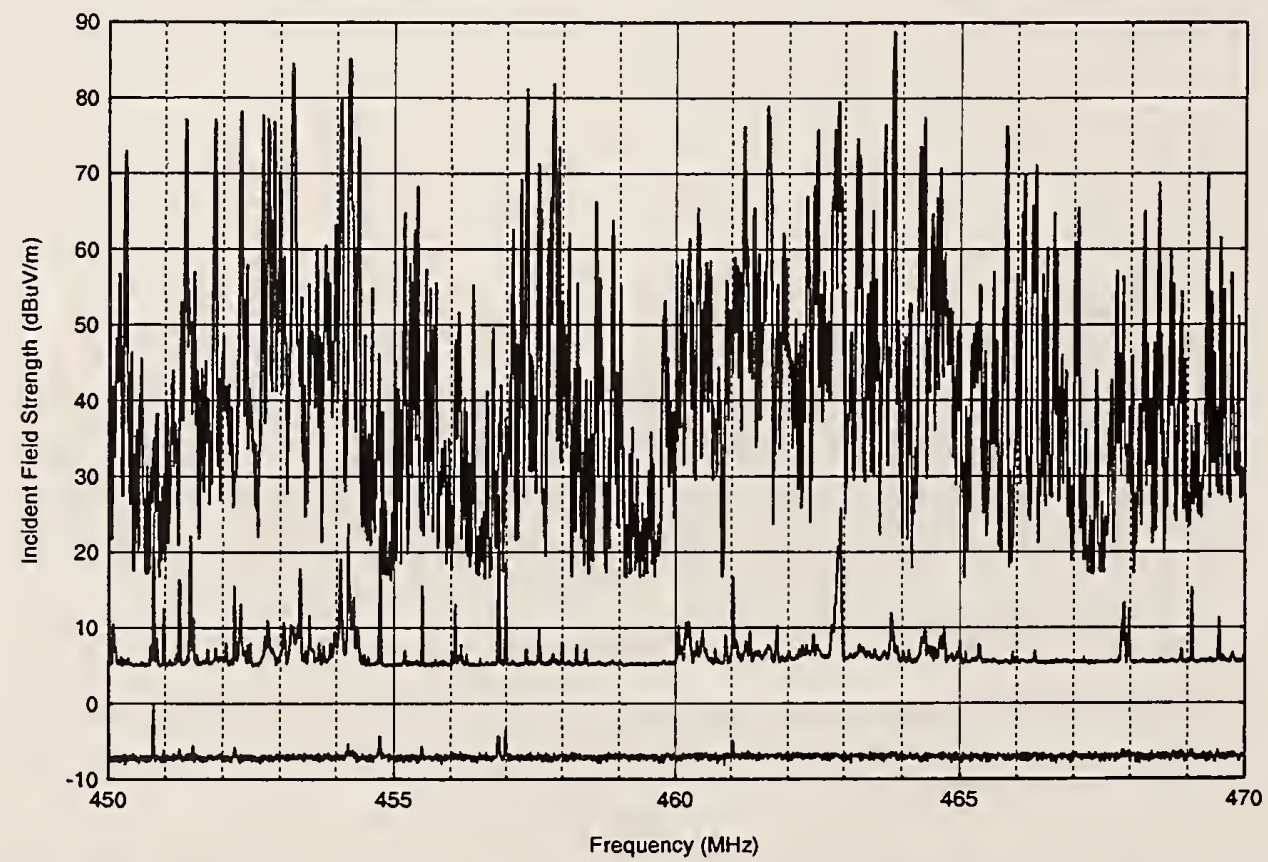

Figure A.29. NIST groundscreen, $450-470 \mathrm{MHz}, 10 \mathrm{kHz}$ IF bandwidth, 58,500 sweeps, vertical polarization. 


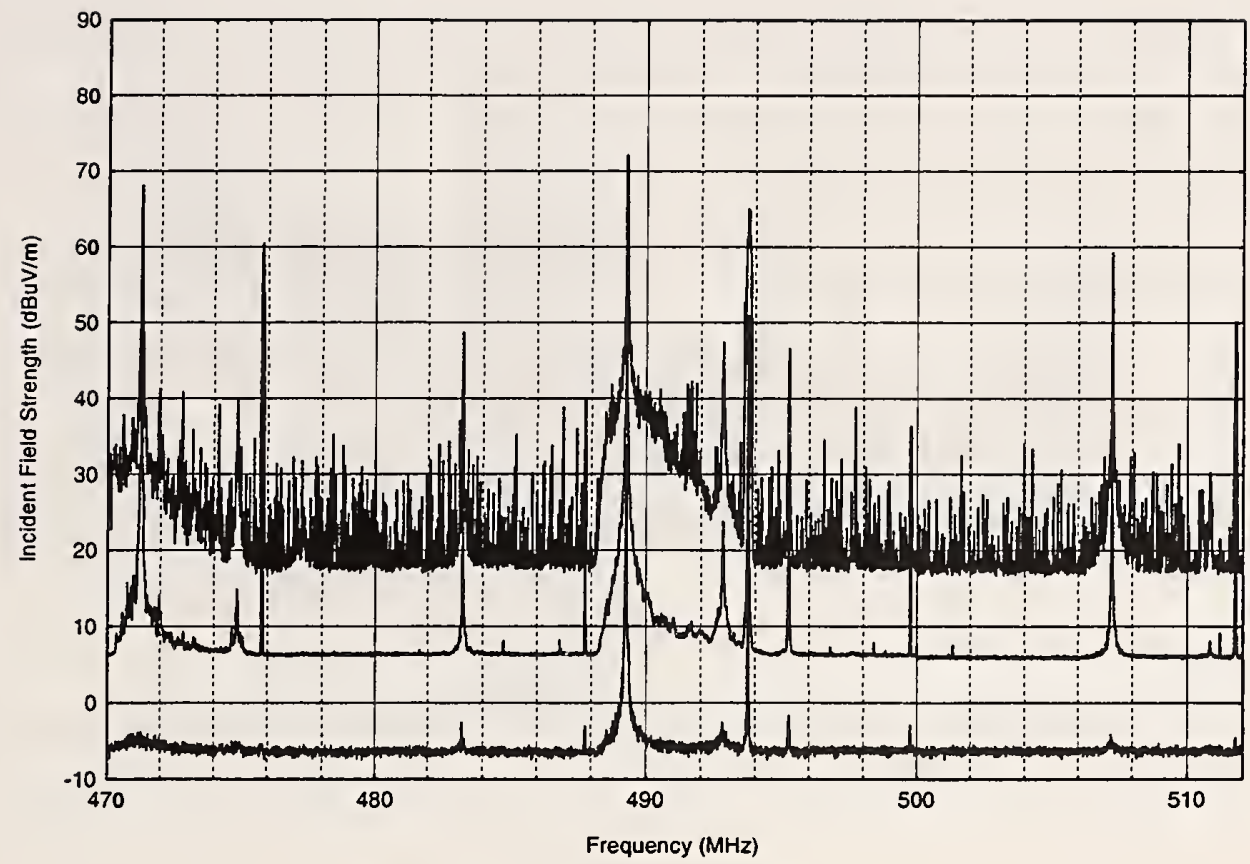

Figure A.30. NIST groundscreen, 470-512 MHz, $10 \mathrm{kHz}$ IF bandwidth, 29,000 sweeps, vertical polarization.

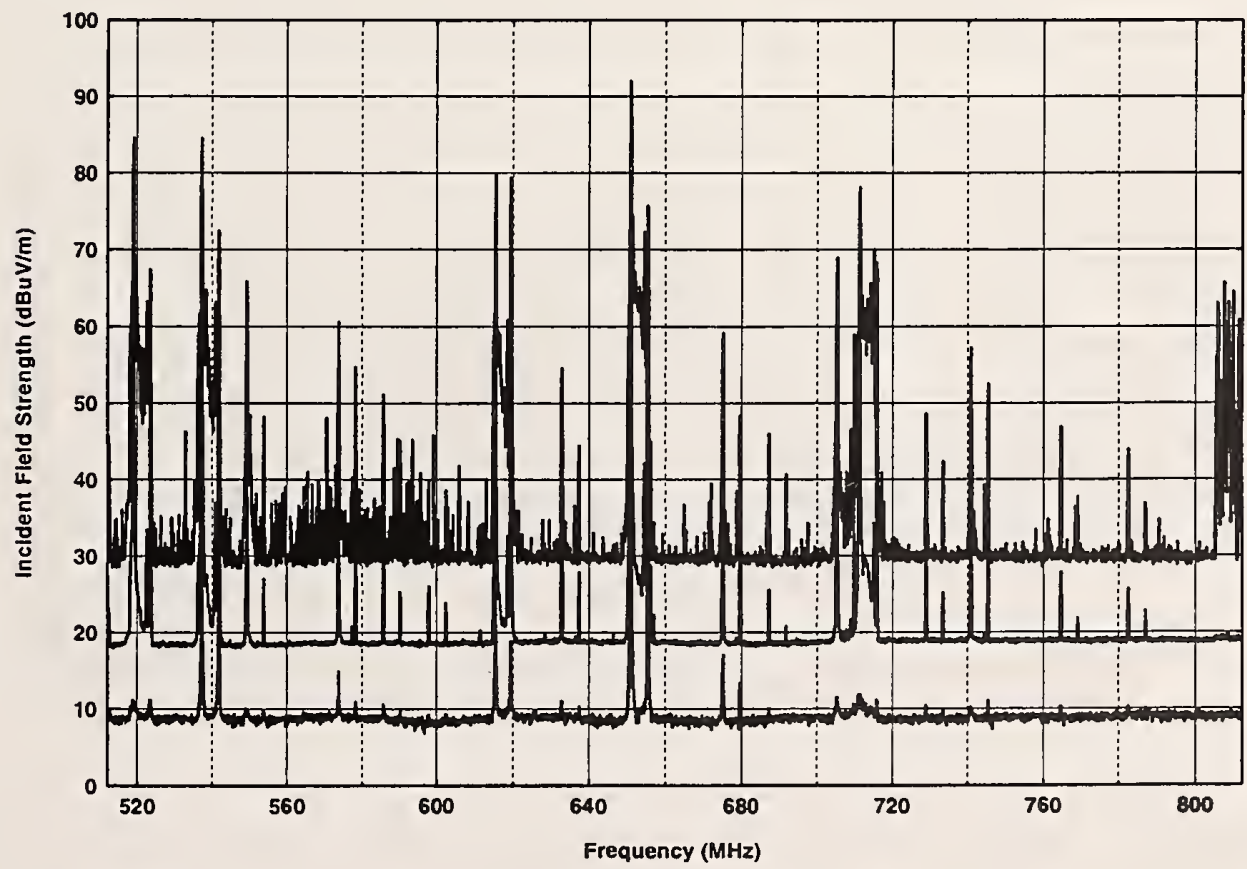

Figure A.31. NIST groundscreen, 512-812 MHz, $100 \mathrm{kHz}$ IF bandwidth, 19,200 sweeps, vertical polarization. 


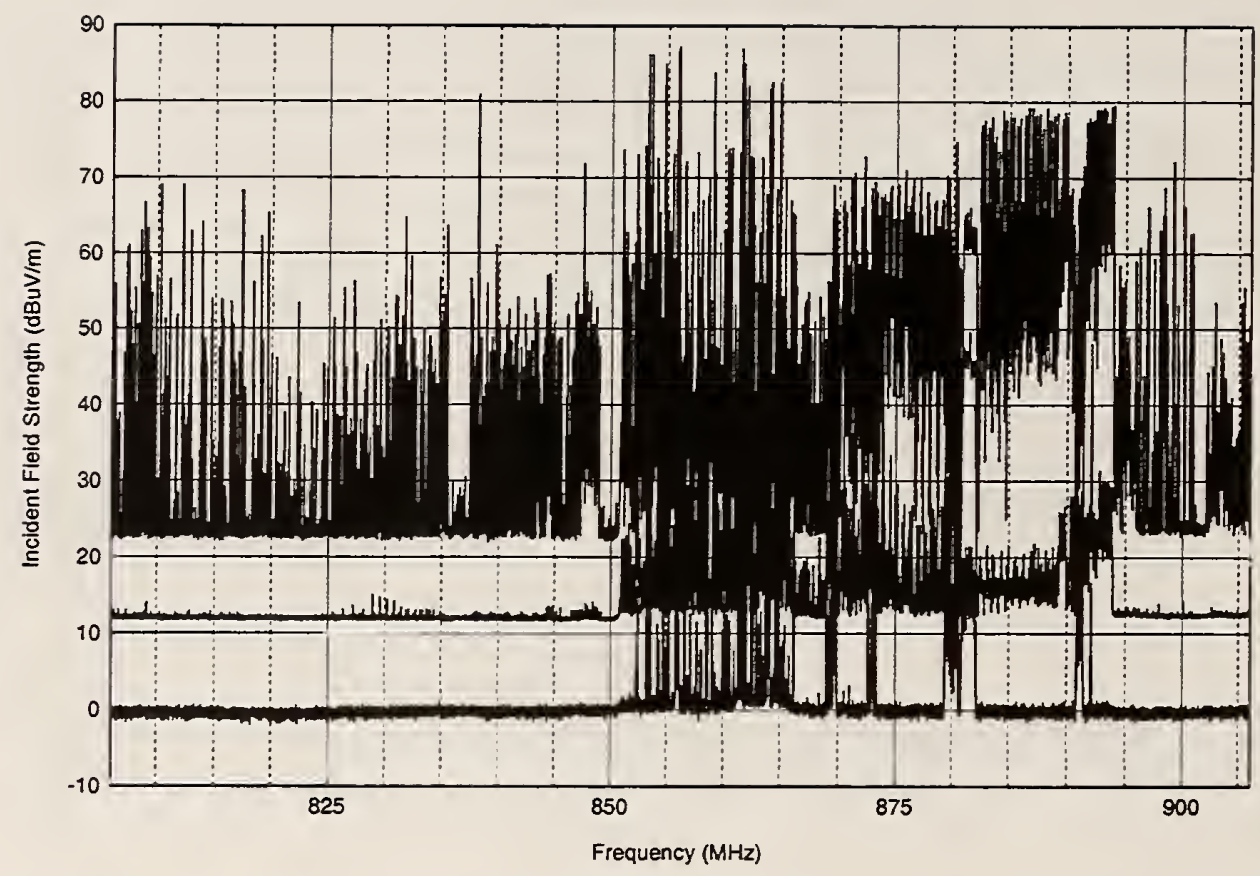

Figure A.32. NIST groundscreen, 806-906 MHz, $10 \mathrm{kHz}$ IF bandwidth, 11,760 sweeps, vertical polarization.

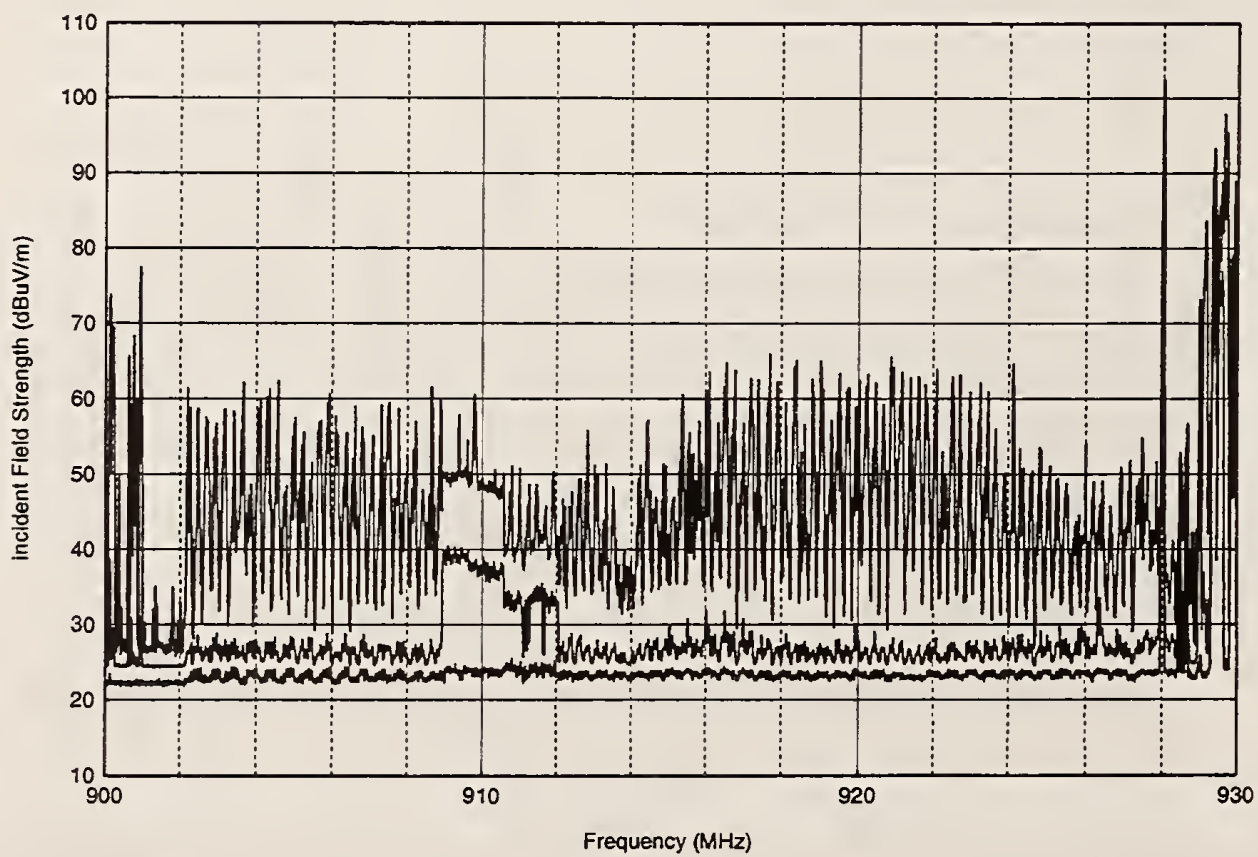

Figure A.33. NIST groundscreen, $900-930 \mathrm{MHz}, 10 \mathrm{kHz}$ IF bandwidth, 195 sweeps, vertical polarization. 


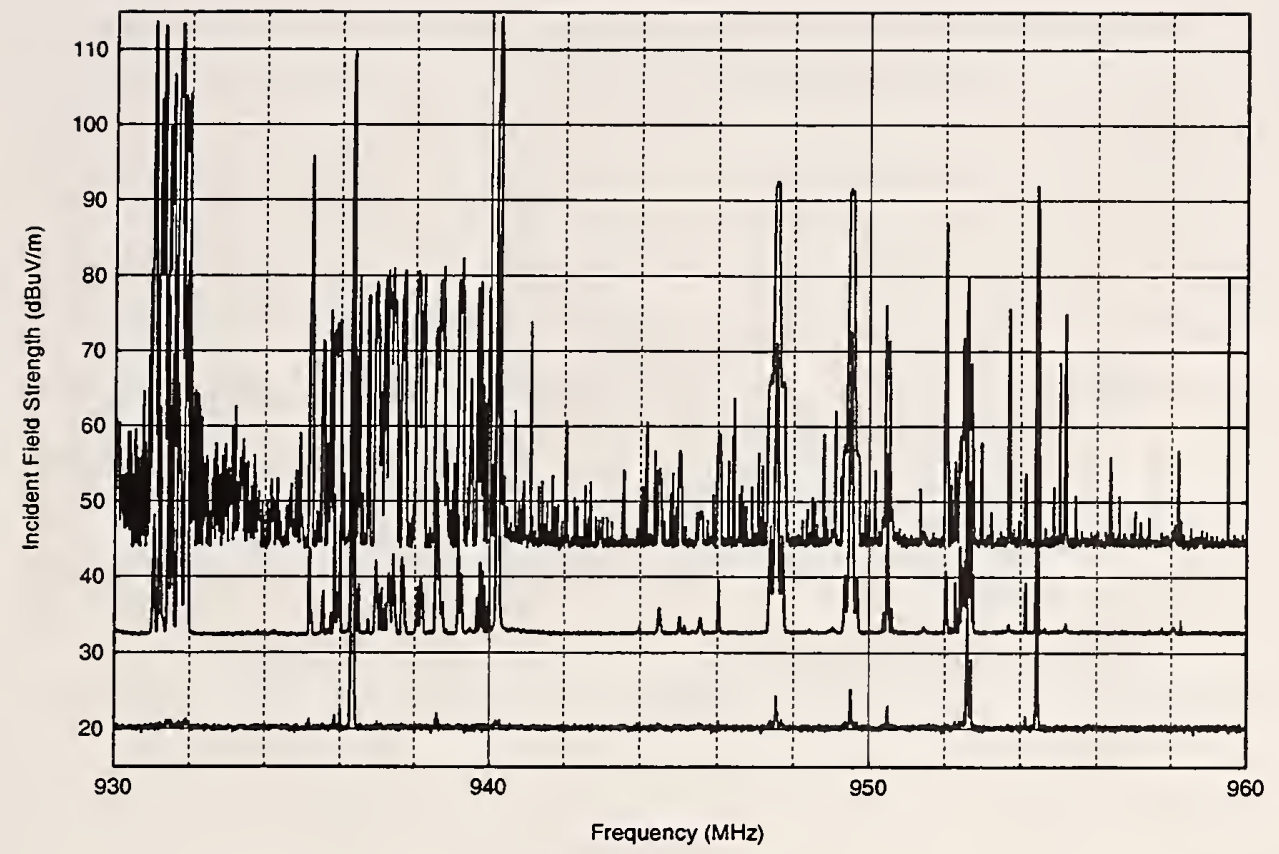

Figure A.34. NIST groundscreen, $930-960 \mathrm{MHz}, 10 \mathrm{kHz}$ IF bandwidth, 87,000 sweeps, vertical polarization.

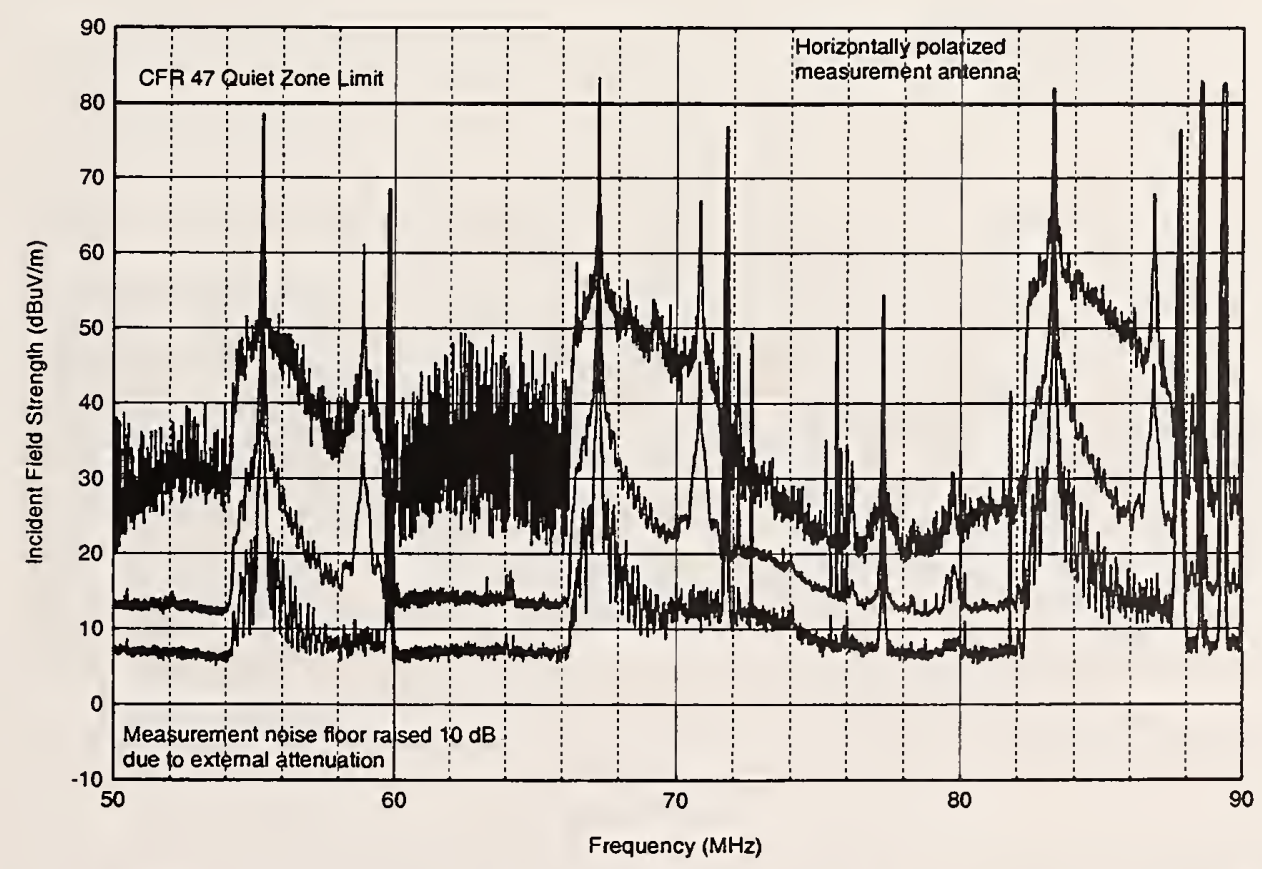

Figure A.35. Table Mountain NRQZ, $50-90 \mathrm{MHz}, 10 \mathrm{kHz}$ IF bandwidth, 2,300 sweeps, horizontal polarization. 


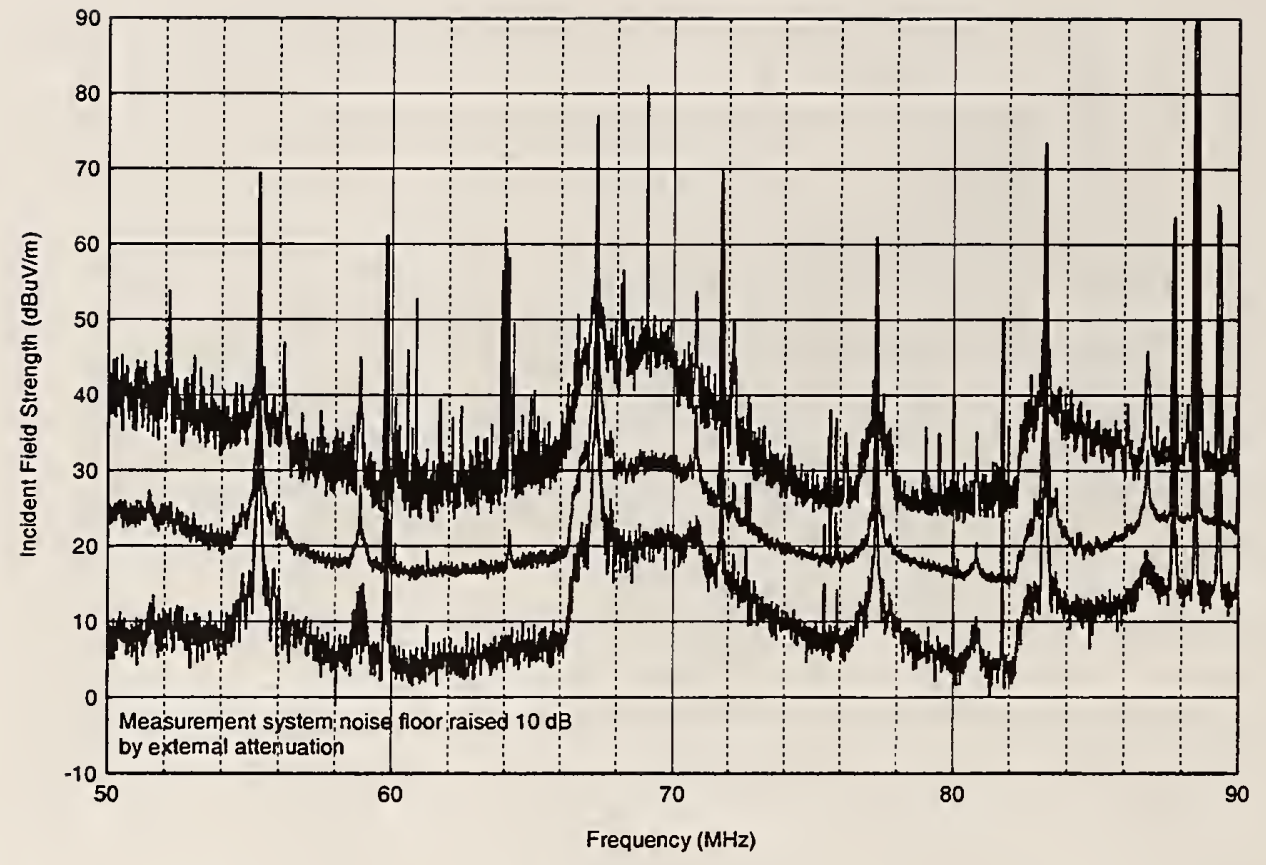

Figure A.36. NIST groundscreen, $50-90 \mathrm{MHz}, 10 \mathrm{kHz}$ IF bandwidth, 700 sweeps, horizontal polarization.

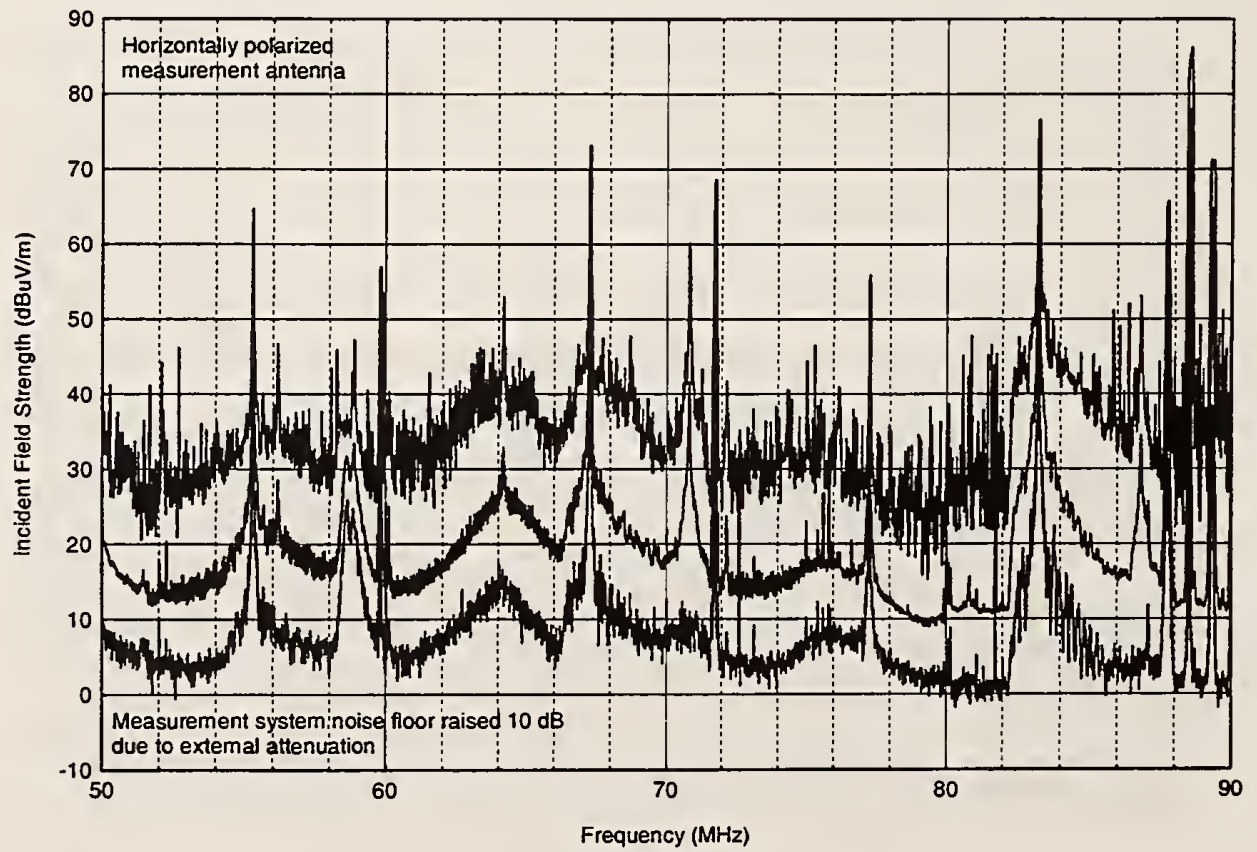

Figure A.37. Bldg. 1, Wing 4, 50-90 MHz, $10 \mathrm{kHz}$ IF bandwidth, 2,100 sweeps, horizontal polarization. 


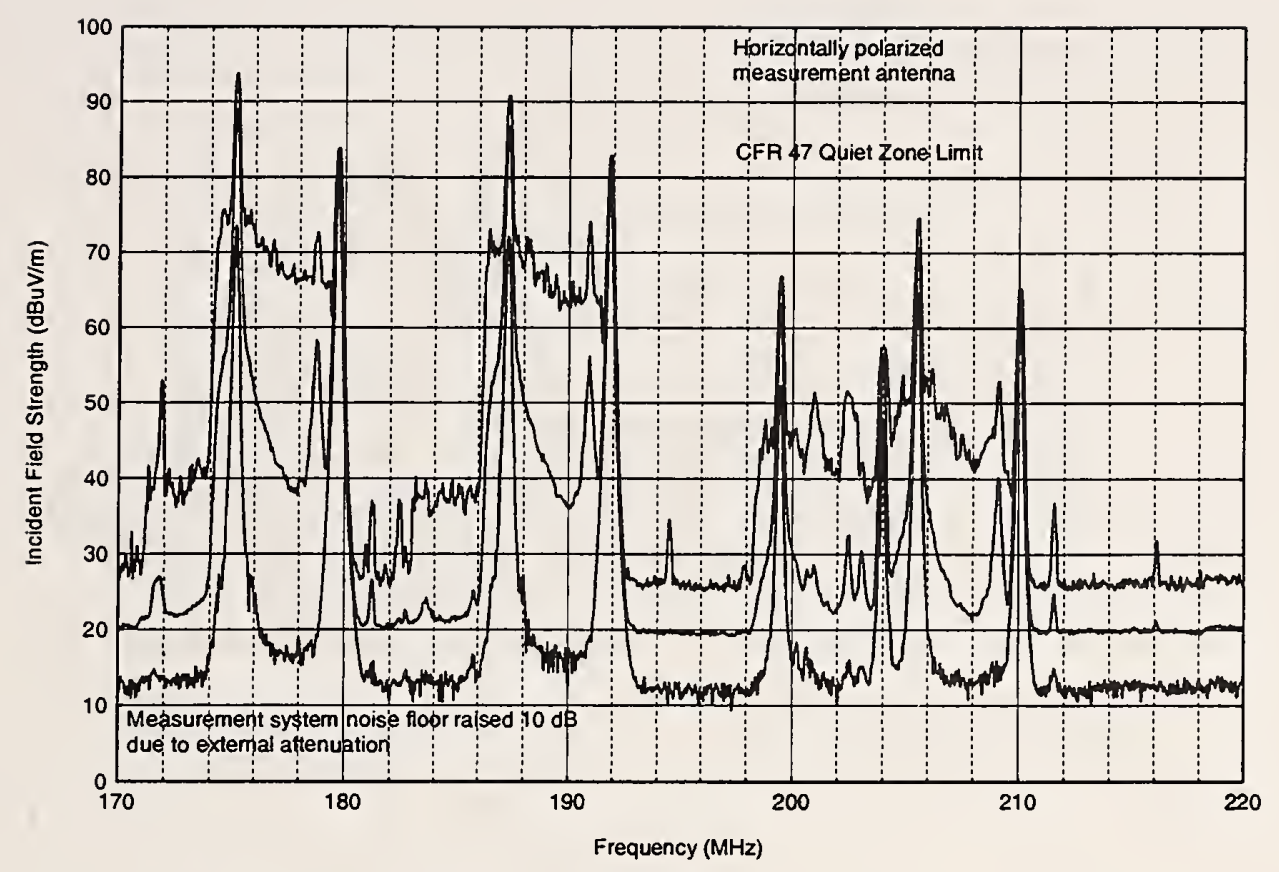

Figure A.38. Table Mountain NRQZ, 170-220 MHz, $10 \mathrm{kHz}$ IF bandwidth, 2,300 sweeps, horizontal polarization.

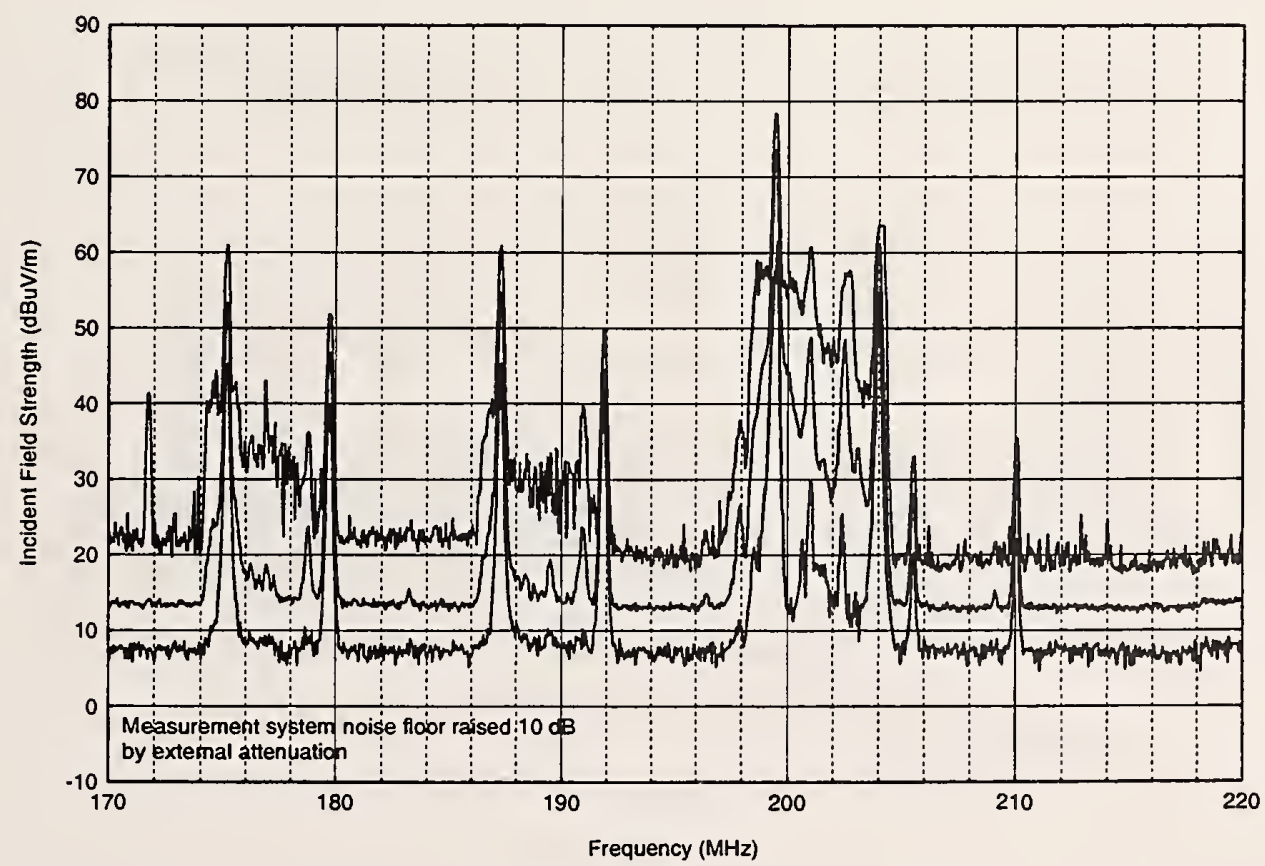

Figure A.39. NIST groundscreen, $170-220 \mathrm{MHz}, 100 \mathrm{kHz}$ IF bandwidth, 700 sweeps, horizontal polarization. 


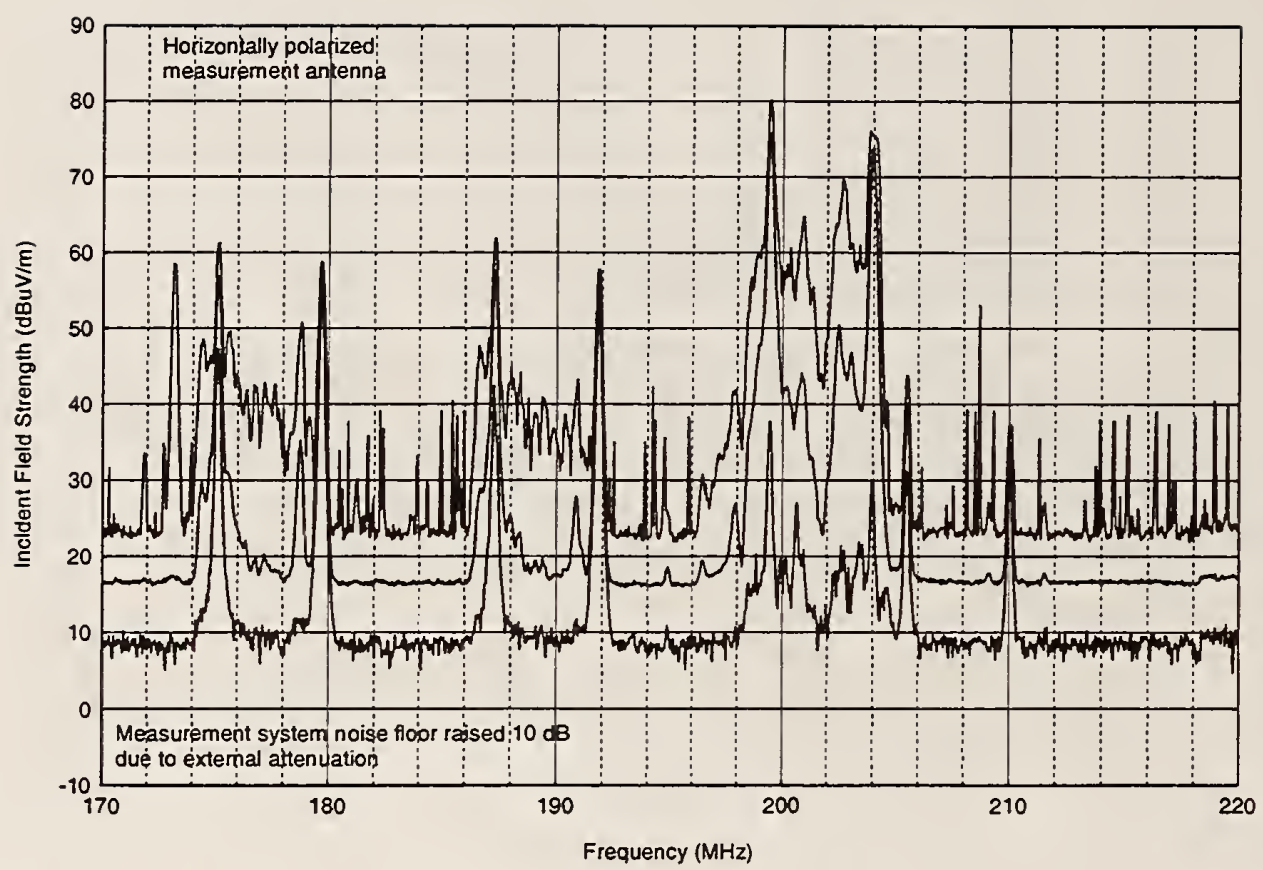

Figure A.40. Bldg. 1, Wing 4, 170-220 MHz, $100 \mathrm{kHz}$ IF bandwidth, 2,100 sweeps, horizontal polarization.

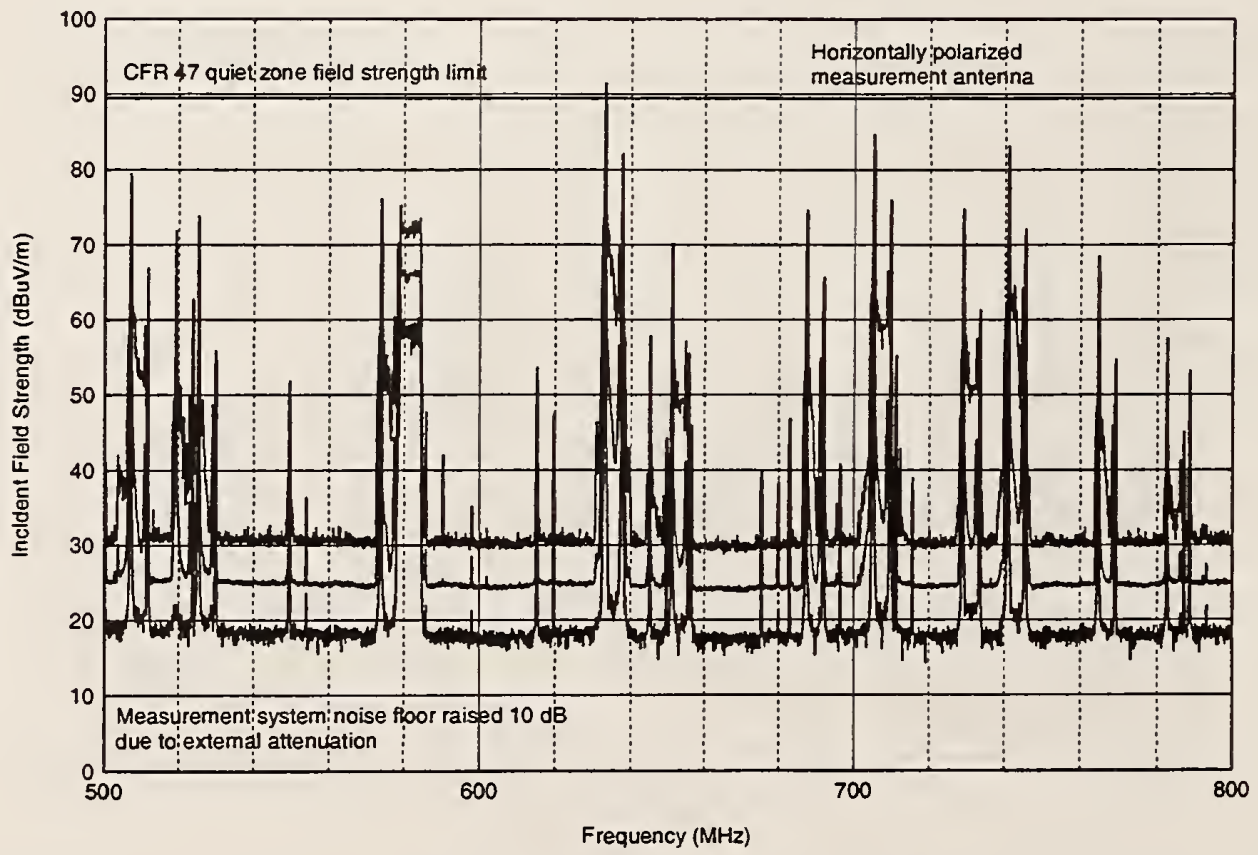

Figure A.41. Table Mountain NRQZ, $500-800 \mathrm{MHz}, 100 \mathrm{kHz}$ IF bandwidth, 2,300 sweeps, horizontal polarization. 


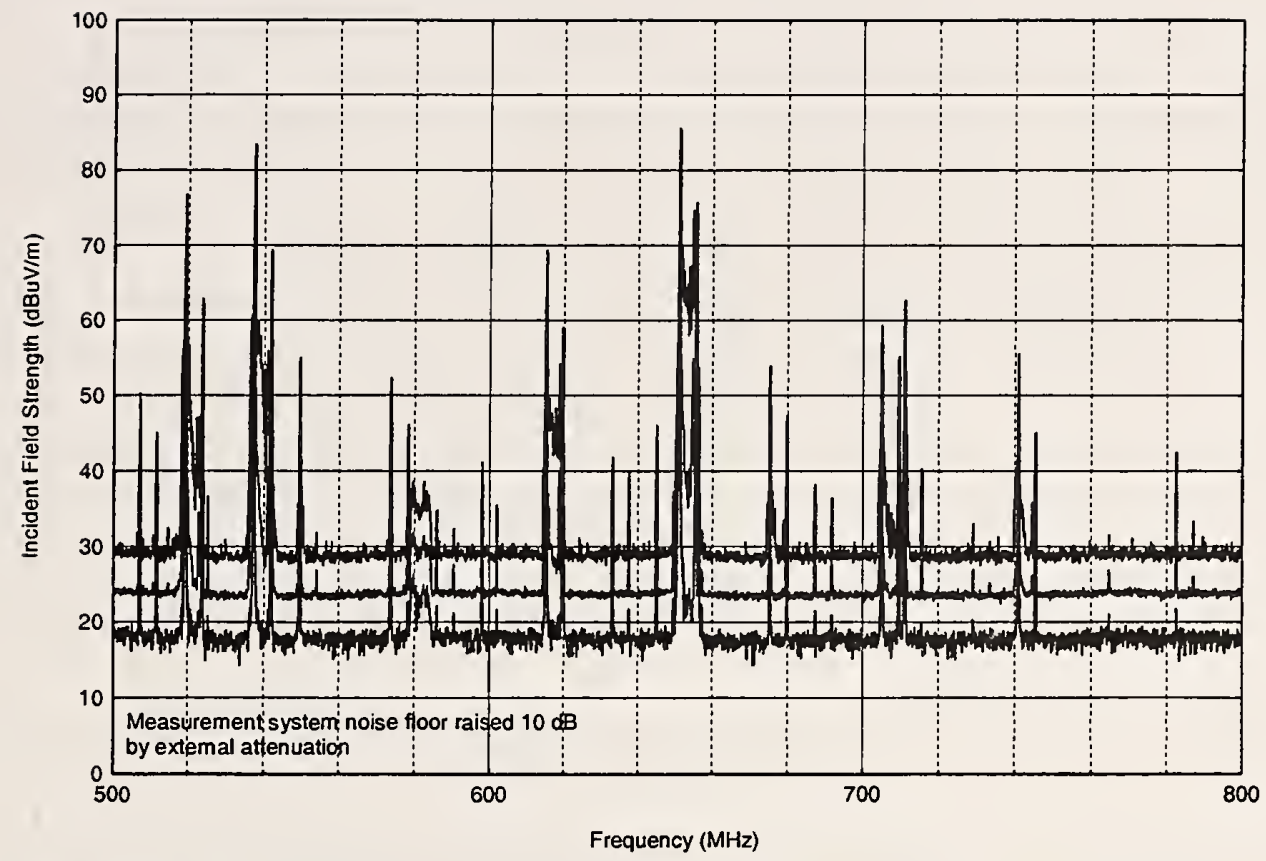

Figure A.42. NIST groundscreen, 500-800 MHz, $100 \mathrm{kHz}$ IF bandwidth, 700 sweeps, horizontal polarization.

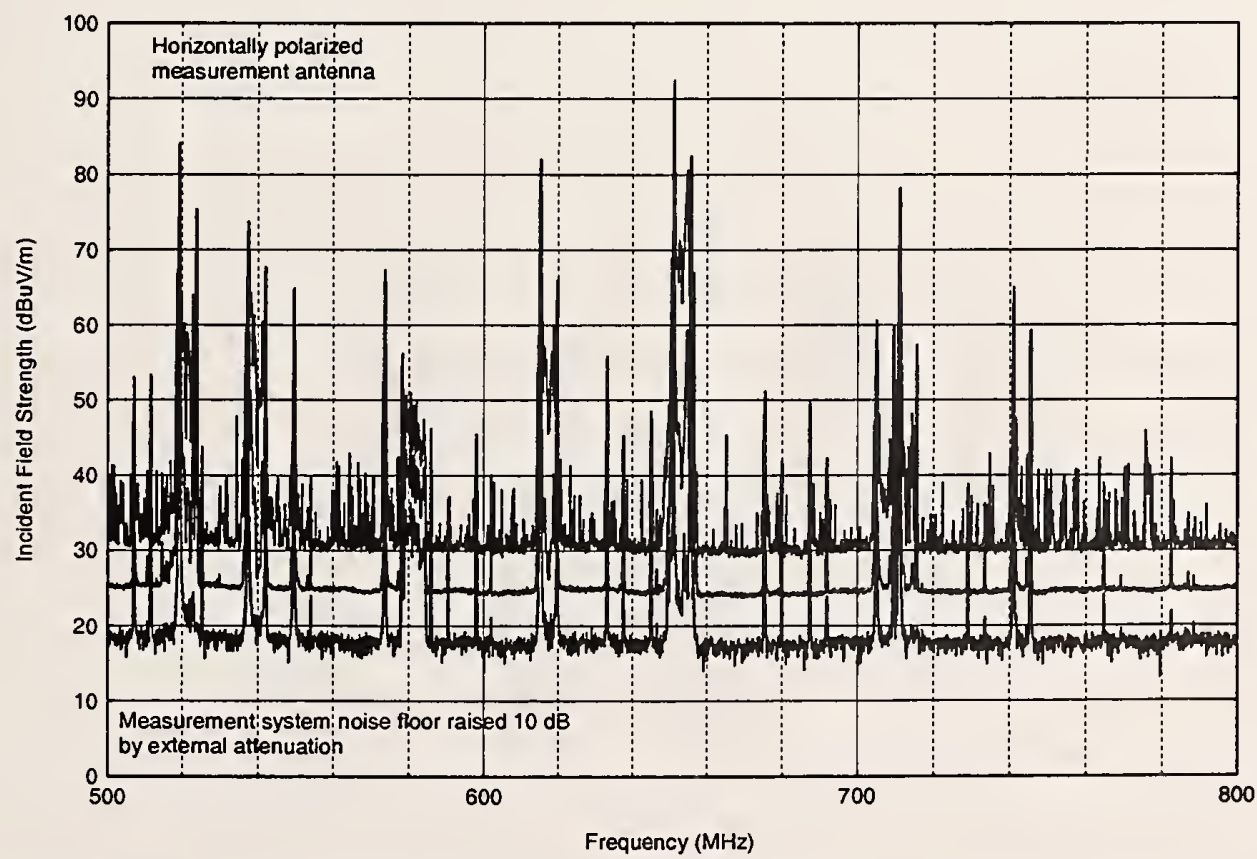

Figure A.43. Bldg. 1, Wing 4, 500-800 MHz, $100 \mathrm{kHz}$ IF bandwidth, 2,100 sweeps, horizontal polarization. 


\section{APPENDIX B: MEASURED POWER LEVELS}

In this appendix, the measured power levels are presented. These data were collected for the following parameters. The receiving antenna was mounted on the measurement vehicle. The antenna height was $2.96 \mathrm{~m}(9.68 \mathrm{ft})$ and had an antenna gain of $1.9 \mathrm{dBi}$ (1.55). At the Eldorado Mountain site, the transmitting antenna had a height of $3.66 \mathrm{~m}$ $(12.0 \mathrm{ft})$ and an antenna gain of $1.9 \mathrm{dBi}(1.55)$, while at the Squaw Mountain location, the transmitting antenna had a height of $8.20 \mathrm{~m}(26.91 \mathrm{ft})$ and an antenna gain of $6.5 \mathrm{dBi}$ (4.47). The input power at the antenna terminal was different for the two different sites and different for the two frequencies. At the Eldorado Mountain site, the input power at the antenna terminal was $20.6 \mathrm{dBm}(0.11 \mathrm{~W})$ for the $533 \mathrm{MHz}$ system and $28.6 \mathrm{dBm}$ $(0.72 \mathrm{~W})$ for the $772 \mathrm{MHz}$ system. At the Squaw Mountain site, the input power at the antenna terminal was $28.6 \mathrm{dBm}(0.72 \mathrm{~W})$ for the $533 \mathrm{MHz}$ system and $37.0 \mathrm{dBm}(5.0 \mathrm{~W})$ for the $772 \mathrm{MHz}$ system.

\section{B.1 Measured Data for a Transmitter on Eldorado Mountain at $533 \mathrm{MHz}$.}

At this location and frequency, the transmitter power level was $20.6 \mathrm{dBm}(0.11 \mathrm{~W})$ with an antenna height of $3.66 \mathrm{~m}(12.0 \mathrm{ft})$ and a gain of $1.9 \mathrm{dBi}(1.55)$. The height of the receiving antenna was $2.95 \mathrm{~m}(9.68 \mathrm{ft})$ with a gain of $1.9 \mathrm{dBi}(1.55)$. Figures B.1 through B. 10 present the measured power levels for various locations around the Boulder area.

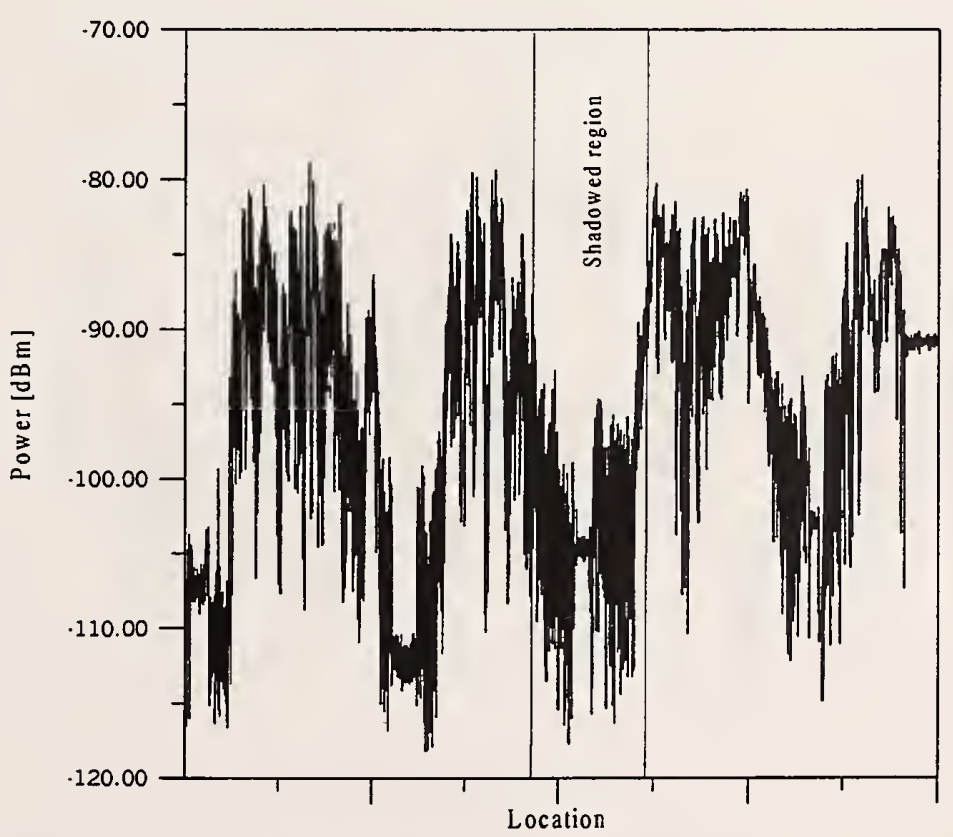

Figure B.1. Measured power levels for different locations at the DOC Laboratories for $533 \mathrm{MHz}$ from a transmitter on Eldorado Mountain. The results correspond to different locations as the measurement vehicle was driven along various roads on the Laboratory property. 


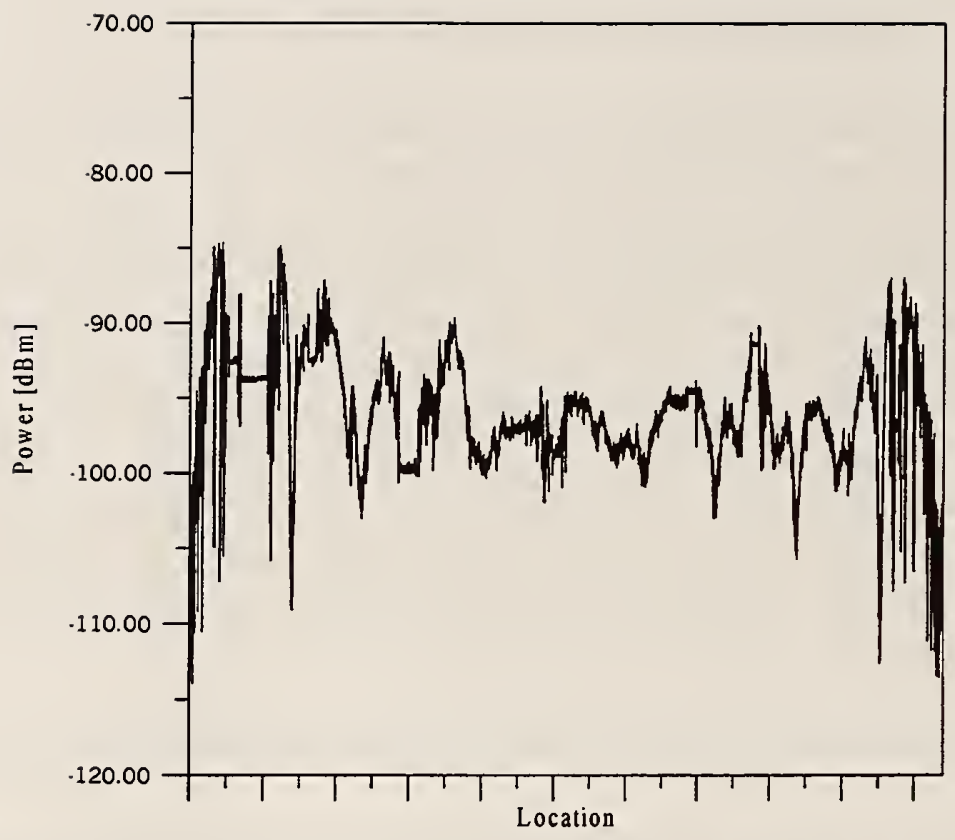

Figure B.2. Measured power levels at various locations on the Table Mountain NRQZ for $533 \mathrm{MHz}$ from a transmitter on Eldorado Mountain. The results correspond to different locations as the measurement vehicle was driven along the north-south road and the eastwest road on the NRQZ.

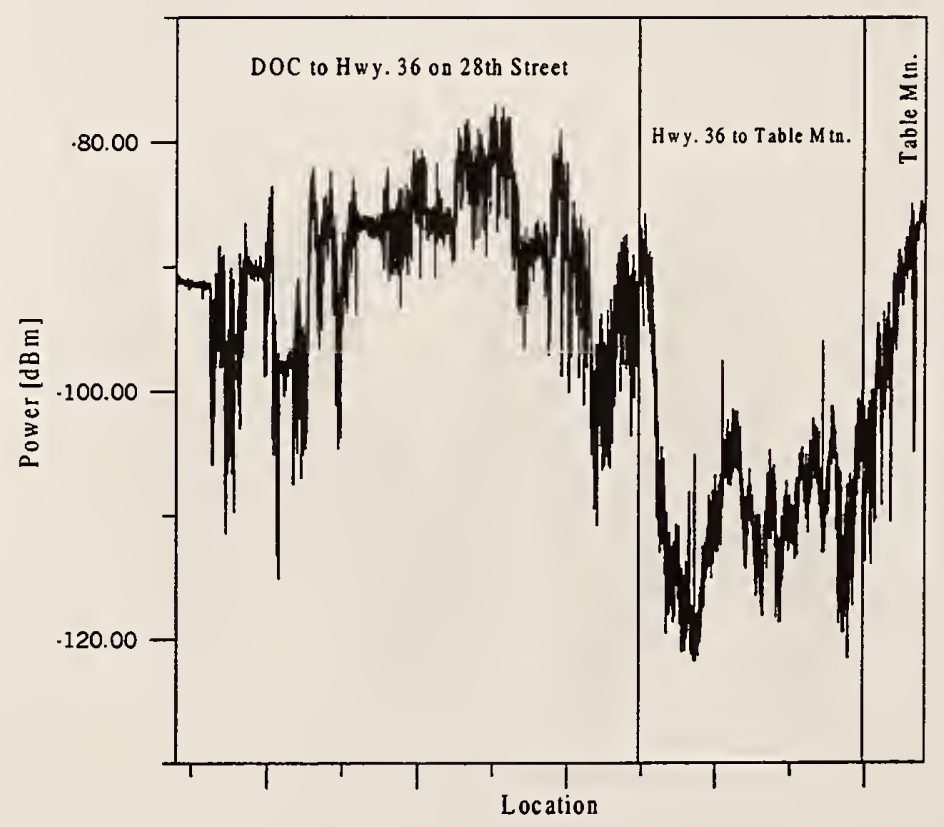

Figure B.3. Measured power levels on the $28^{\text {th }}$ Street route for $533 \mathrm{MHz}$ from a transmitter on Eldorado Mountain. These data were taken on $28^{\text {th }}$ Street and on Highway 36 (from the DOC Laboratories to the Table Mountain NRQZ). 


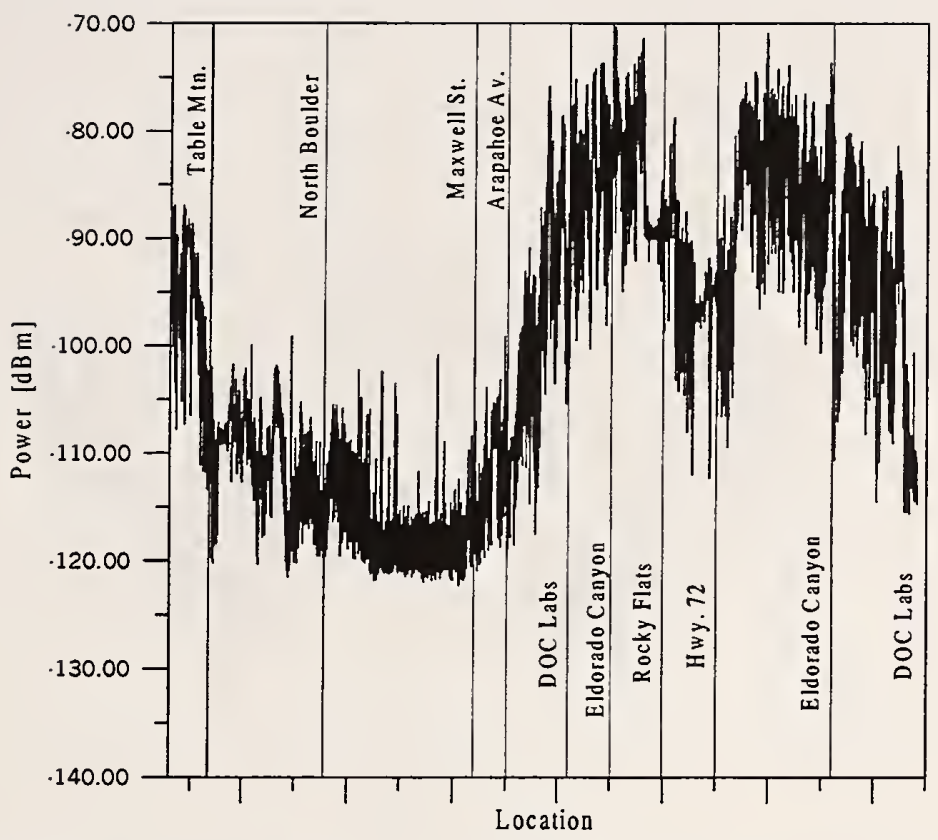

Figure B.4. Measured power levels on the Broadway loop for $533 \mathrm{MHz}$ from a transmitter on Eldorado Mountain. These measured data were taken on Highway 36 and Highway 93, starting at the Table Mountain NRQZ going to Highway 72, and returning to the DOC Laboratories.

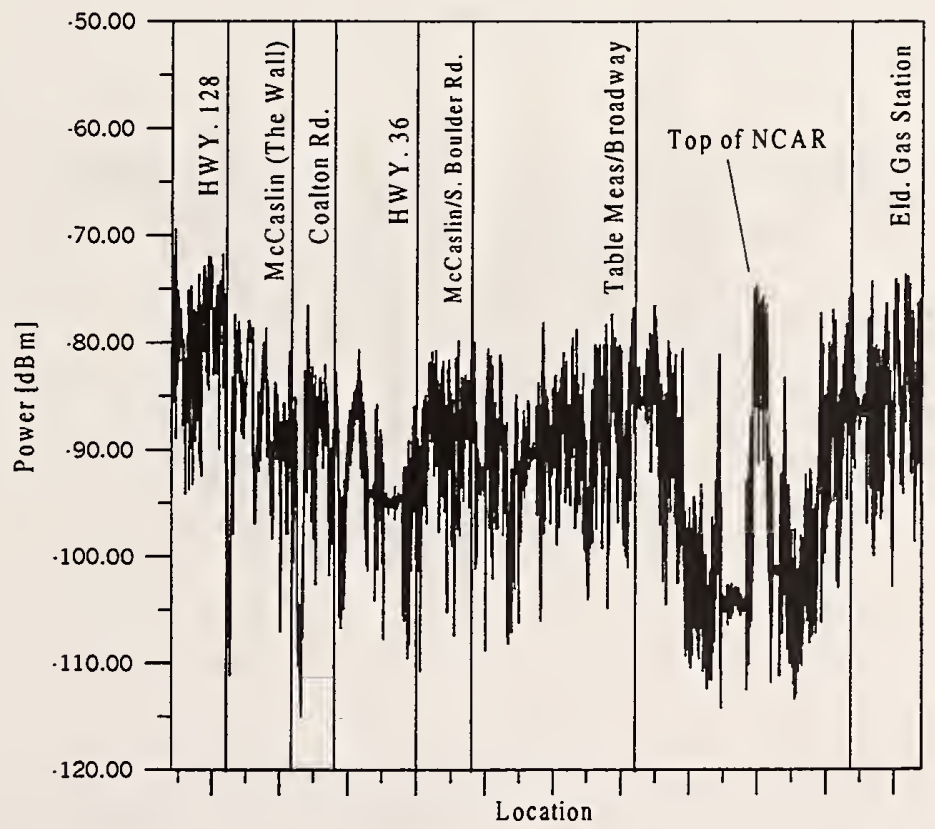

Figure B.5. Measured power levels on the McCaslin loop for $533 \mathrm{MHz}$ from a transmitter on Eldorado Mountain. These data were taken on various roads starting at a gas station at Eldorado Canyon and returning to the starting point. 


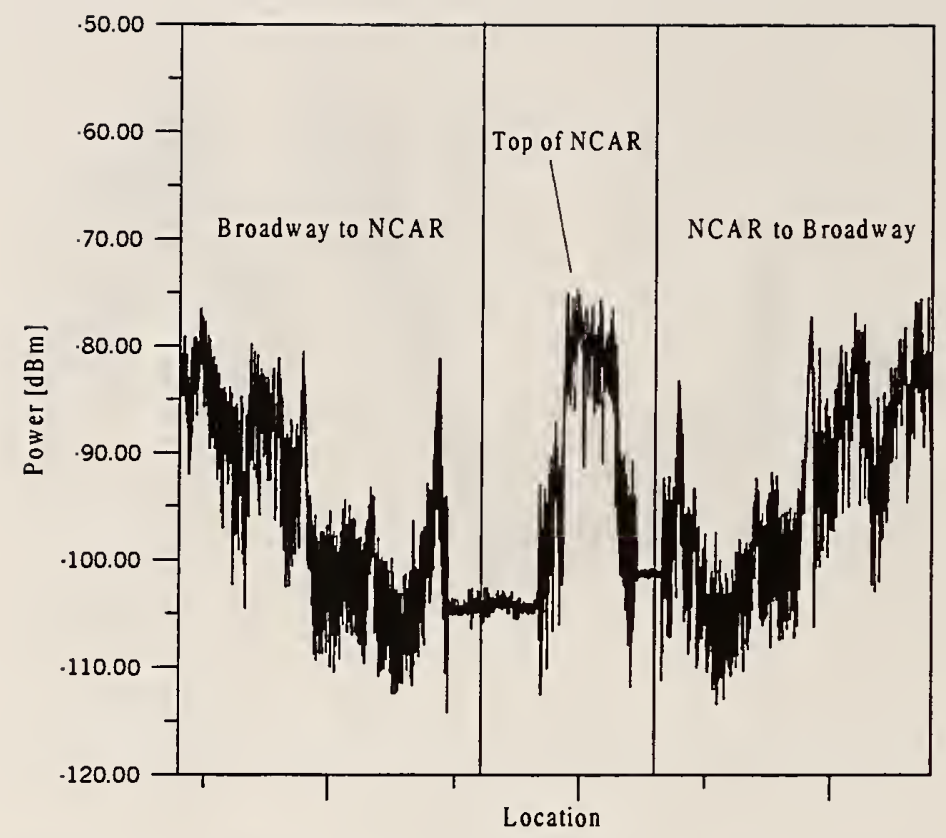

Figure B.6. Measured power levels at the NCAR facility at the top of Table Mesa for 533 $\mathrm{MHz}$ from a transmitter on Eldorado Mountain. These data were taken from the intersection of Broadway and Table Mesa, to the top of Table Mesa to NCAR, and returning to the Broadway-Table Mesa intersection.

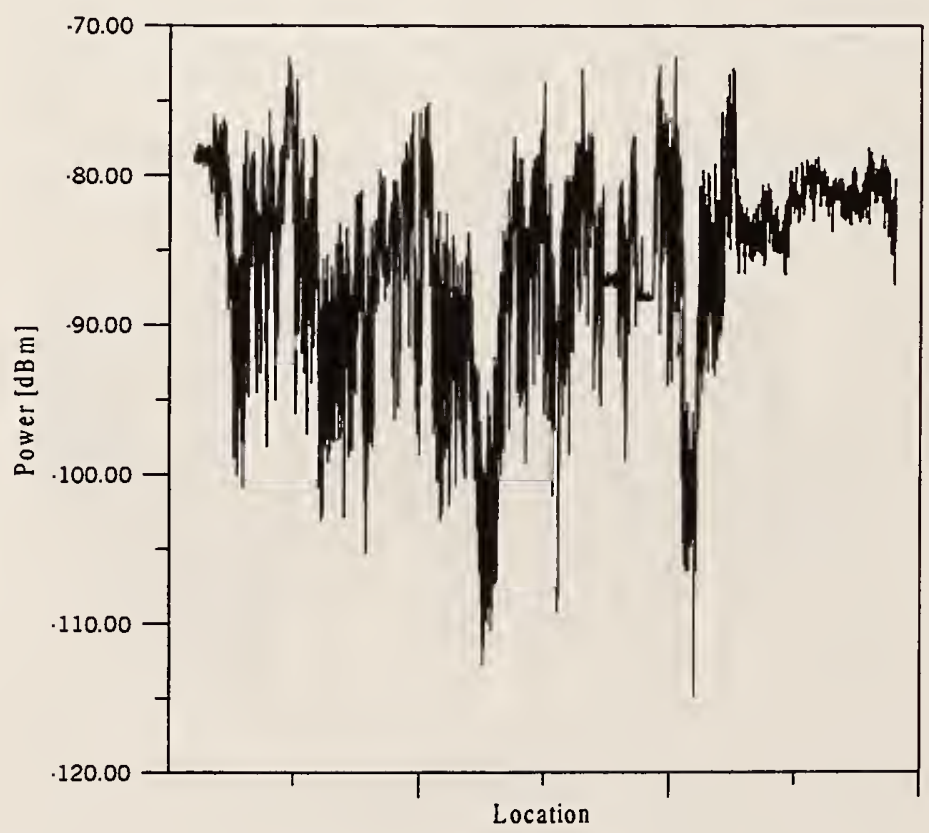

Figure B.7. Measured power levels on the Greenbriar loop for $533 \mathrm{MHz}$ from a transmitter on Eldorado Mountain. This loop consisted of Greenbriar Blvd., Lehigh Street, Table Mesa Drive, and Gillaspie Drive. 


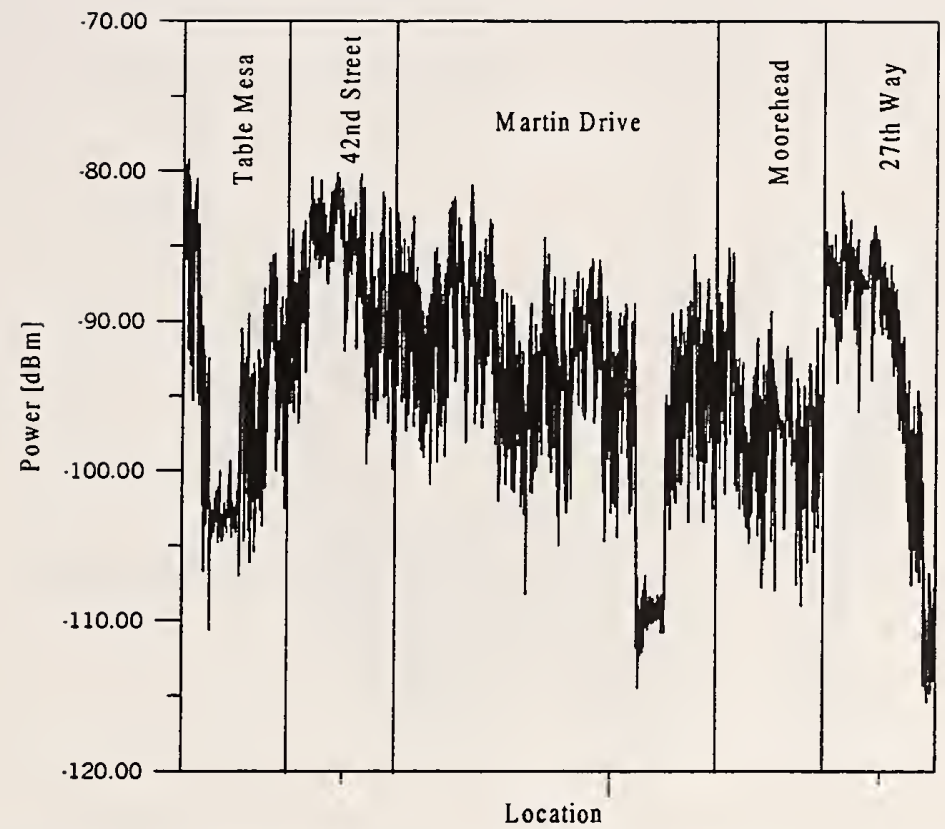

Figure B.8. Measured power levels in the Martin Acres neighborhood for $533 \mathrm{MHz}$ from a transmitter on Eldorado Mountain.

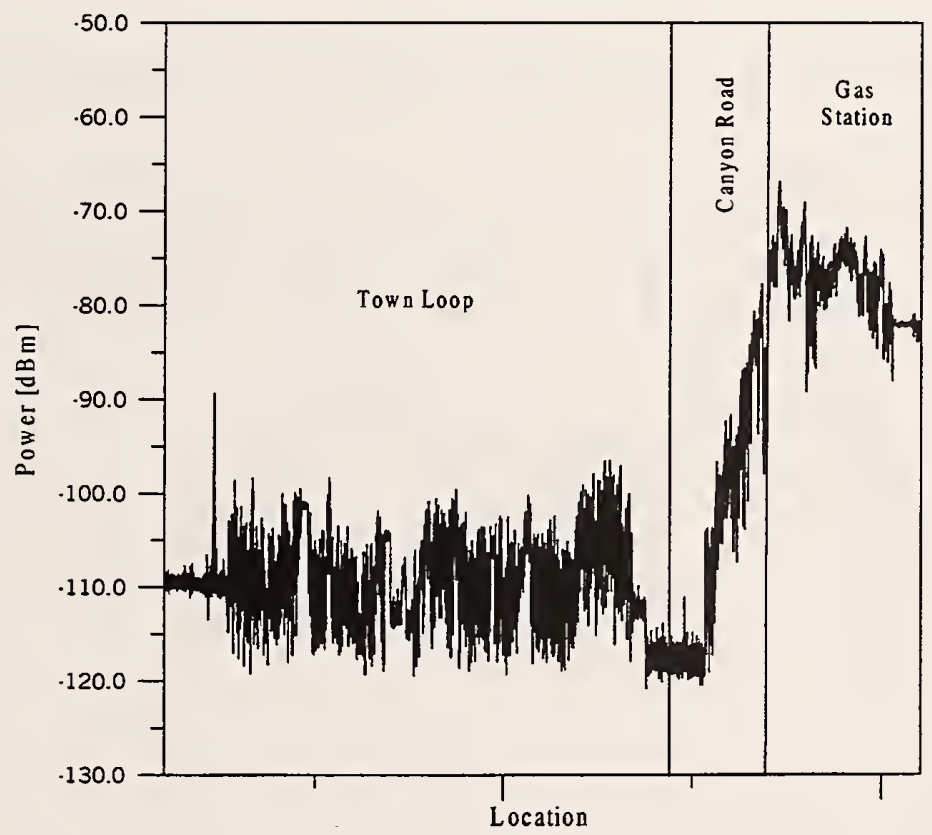

Figure B.9. Measured power levels in Eldorado Canyon for $533 \mathrm{MHz}$ from a transmitter on Eldorado Mountain. 


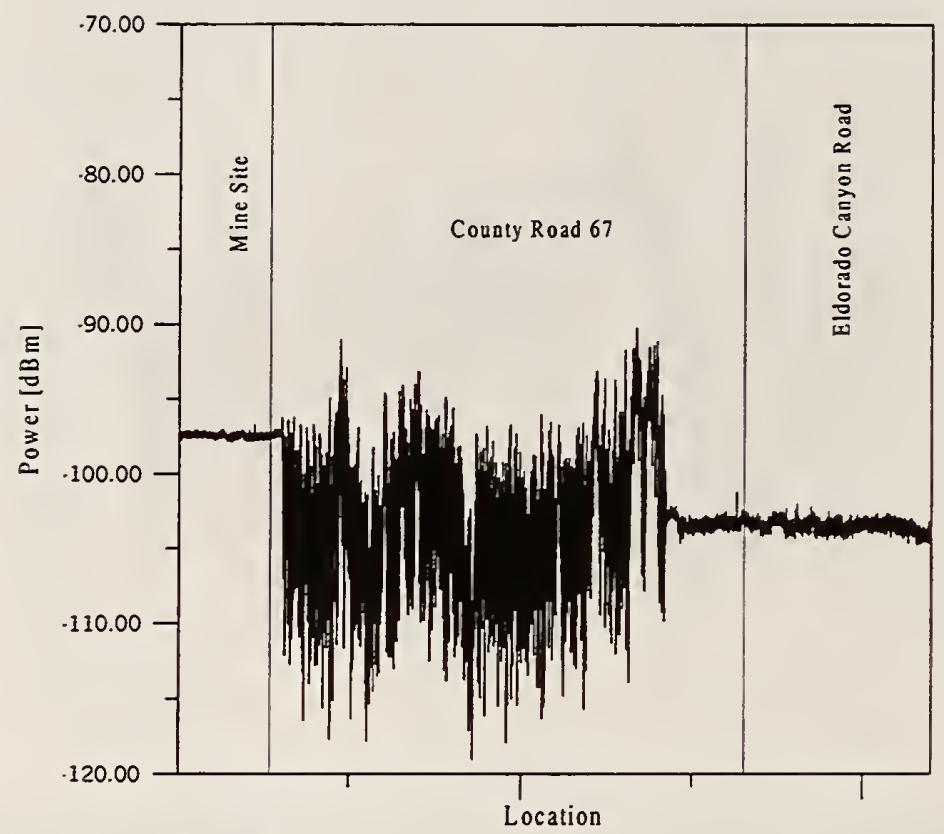

Figure B.10. Measured power levels on County Road 67 for $533 \mathrm{MHz}$ from a transmitter on Eldorado Mountain.

\section{B.2 Measured Data for a Transmitter on Eldorado Mountain at $772 \mathrm{MHz}$.}

At this location and frequency, the transmitter power level was $28.6 \mathrm{dBm}(0.72 \mathrm{~W})$ with an antenna height of $3.66 \mathrm{~m}(12.0 \mathrm{ft})$ and a gain of $1.9 \mathrm{dBi}(1.55)$. The height of the receiving antenna was $2.95 \mathrm{~m}(9.68 \mathrm{ft})$ with a gain of $1.9 \mathrm{dBi}(1.55)$. Figures B.11 through B.20 present the measured power levels for various locations around the Boulder area. 


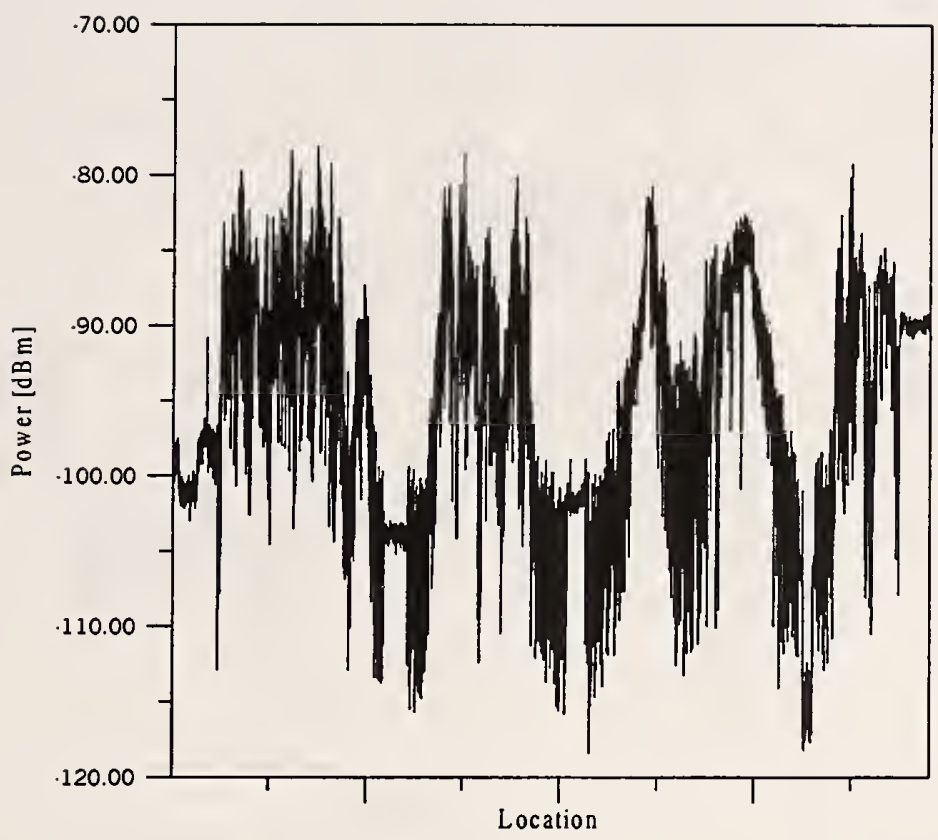

Figure B.11. Measured power levels for various locations at the DOC Laboratories for $772 \mathrm{MHz}$ from a transmitter on Eldorado Mountain. The results correspond to different locations as the measurement vehicle was driven along various roads on the Laboratory property.

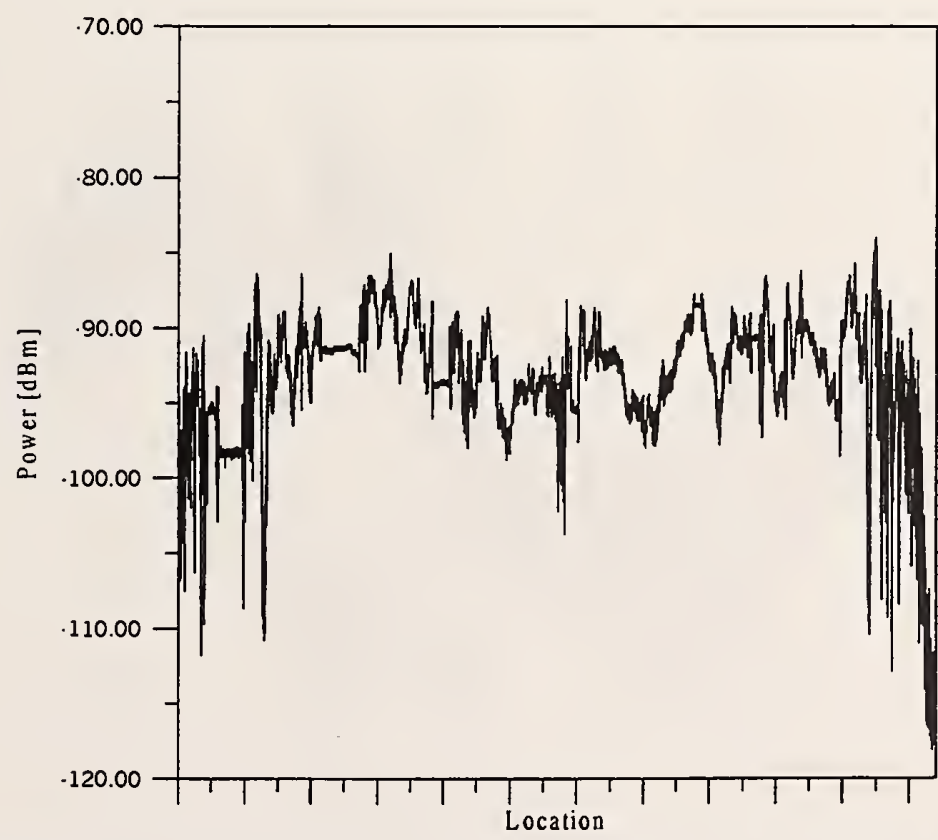

Figure B.12. Measured power levels at various locations on the Table Mountain NRQZ for $772 \mathrm{MHz}$ from a transmitter on Eldorado Mountain. The results correspond to different locations as the measurement vehicle was driven along the north-south road and the east-west road on the NRQZ. 


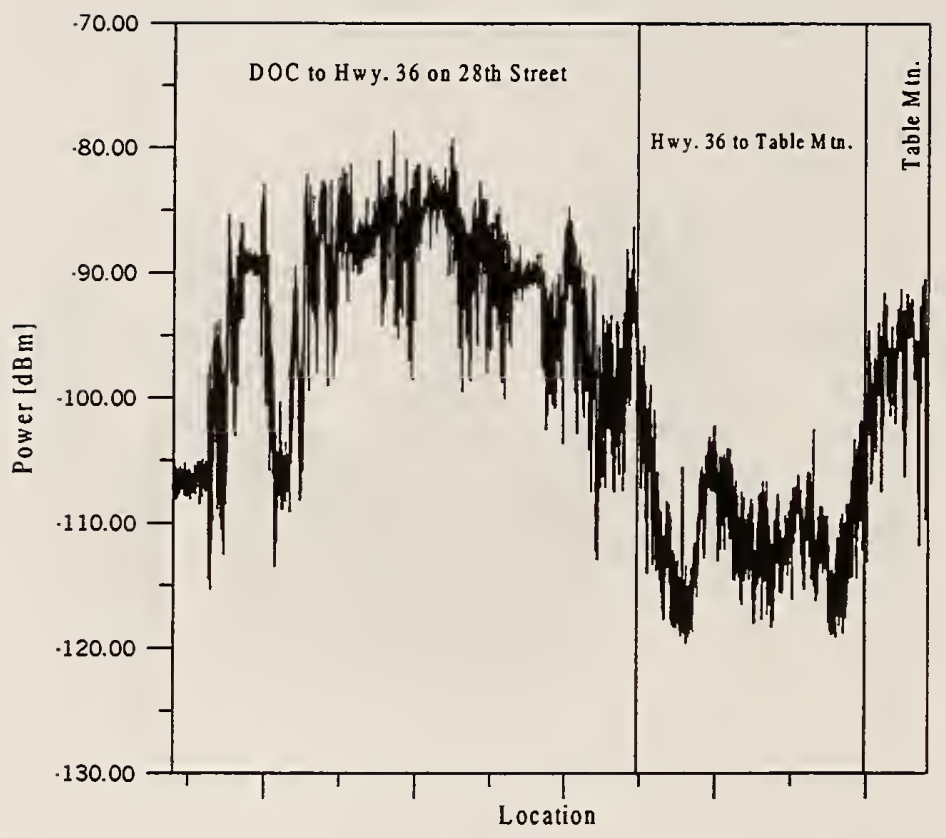

Figure B.13. Measured power levels on the $28^{\text {th }}$ Street route for $772 \mathrm{MHz}$ from a transmitter on Eldorado Mountain. These data were taken on $28^{\text {th }}$ Street to Highway 36 (from the DOC Laboratories to the Table Mountain NRQZ).

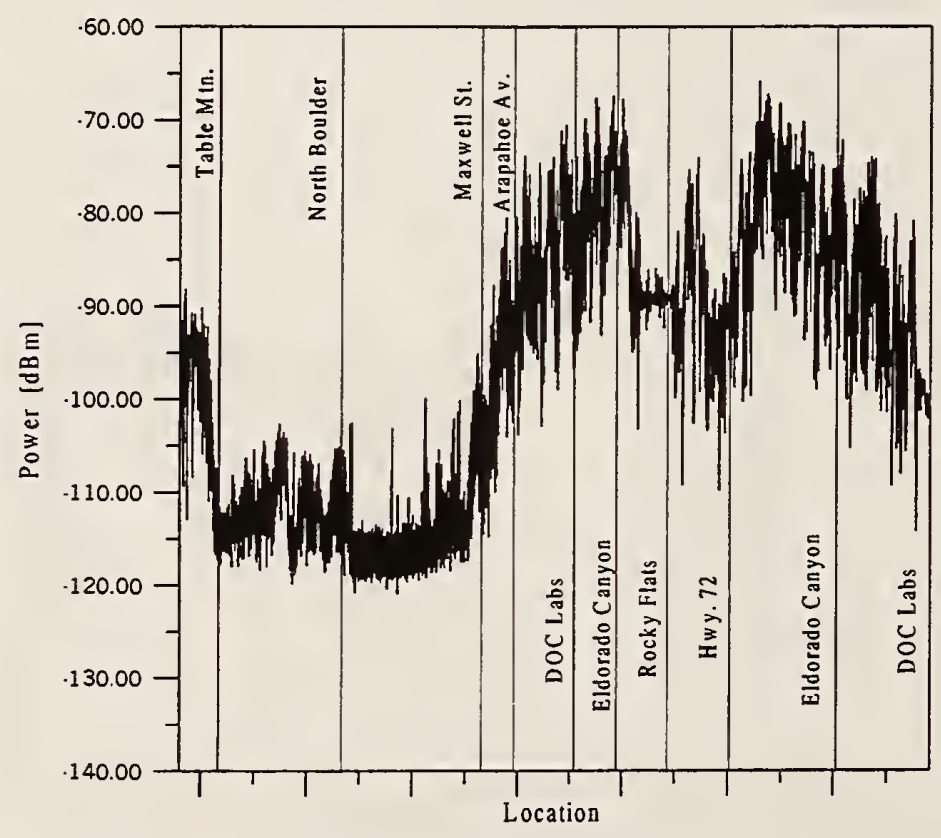

Figure B.14 Measured power levels on the Broadway loop for $772 \mathrm{MHz}$ from a transmitter on Eldorado Mountain. These measured data were taken on Highway 36 and Highway 93, starting at the Table Mountain NRQZ going to Highway 72, and returning to the DOC Laboratories. 


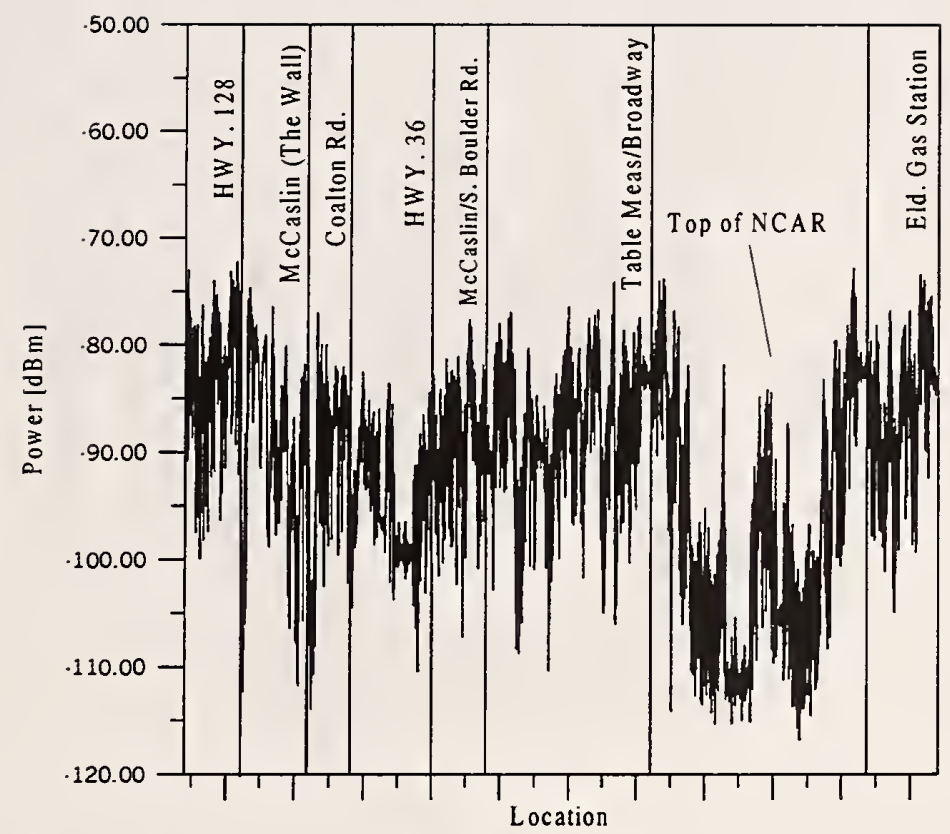

Figure B.15. Measured power levels on the McCaslin loop for $772 \mathrm{MHz}$ from a transmitter on Eldorado Mountain. These data were taken on various roads starting at a gas station at Eldorado Canyon and returning to the starting point.

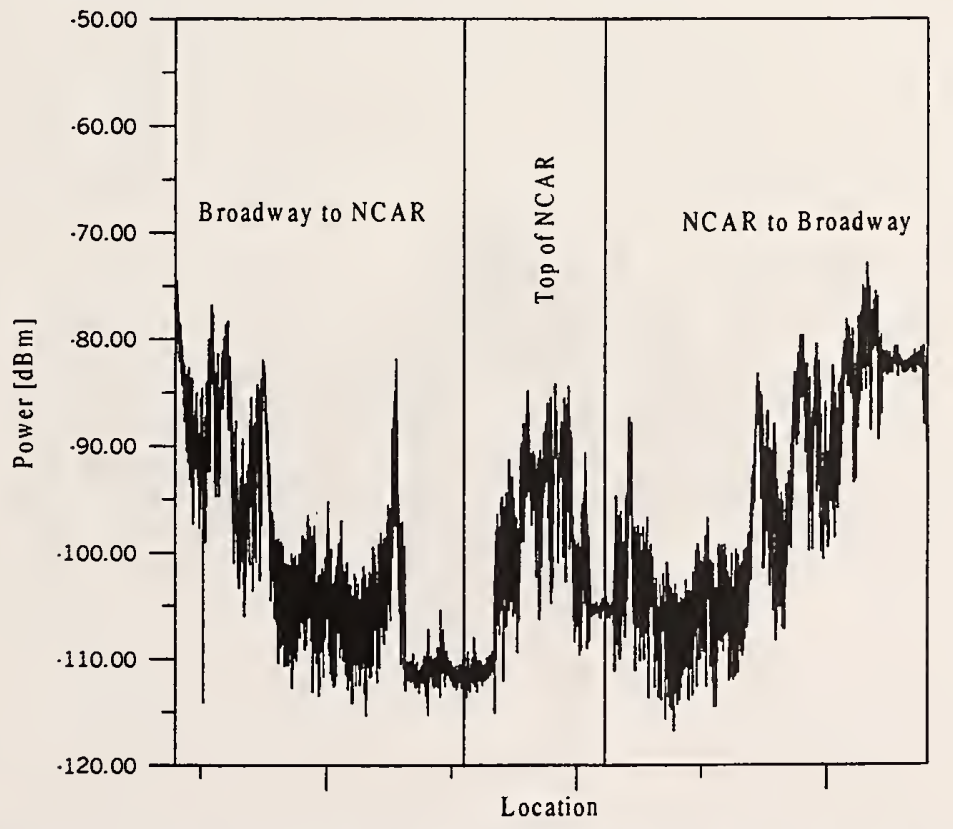

Figure B.16. Measured power levels at the NCAR facility at the top of Table Mesa for $772 \mathrm{MHz}$ from a transmitter on Eldorado Mountain. These data were taken from the intersection of Broadway and Table Mesa, to the top of Table Mesa to NCAR, and returning to the Broadway-Table Mesa intersection. 


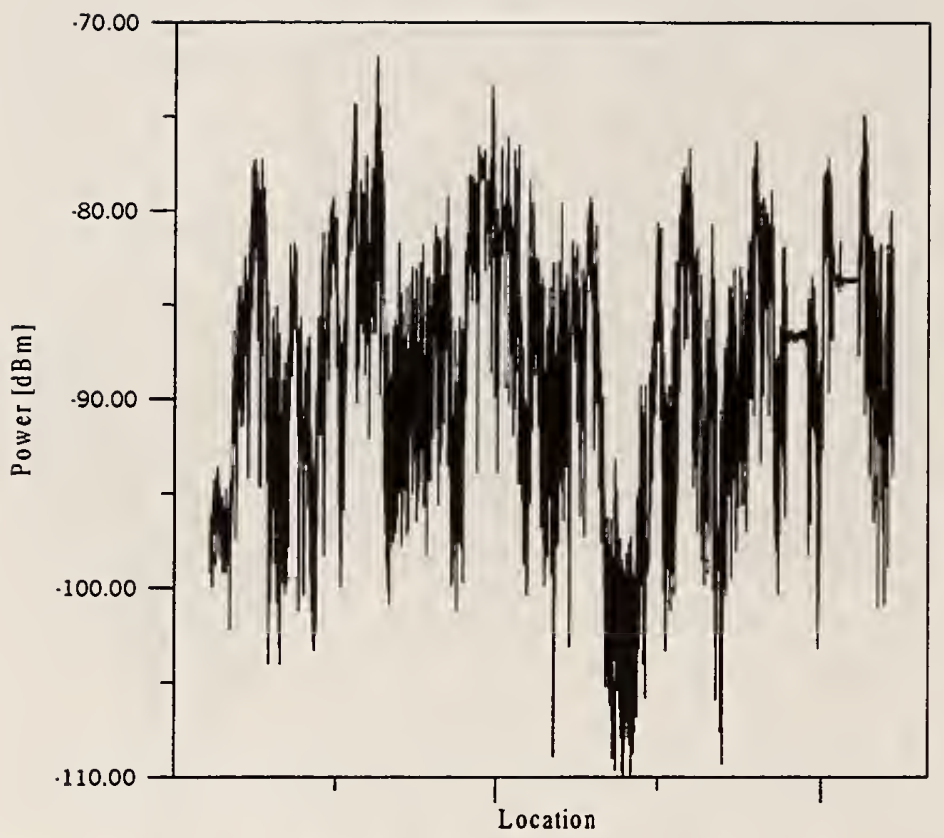

Figure B.17. Measured power levels on the Greenbriar loop for $772 \mathrm{MHz}$ from a transmitter on Eldorado Mountain. This loop consisted of Greenbriar Blvd., Lehigh Street, Table Mesa Drive, and Gillaspie Drive.

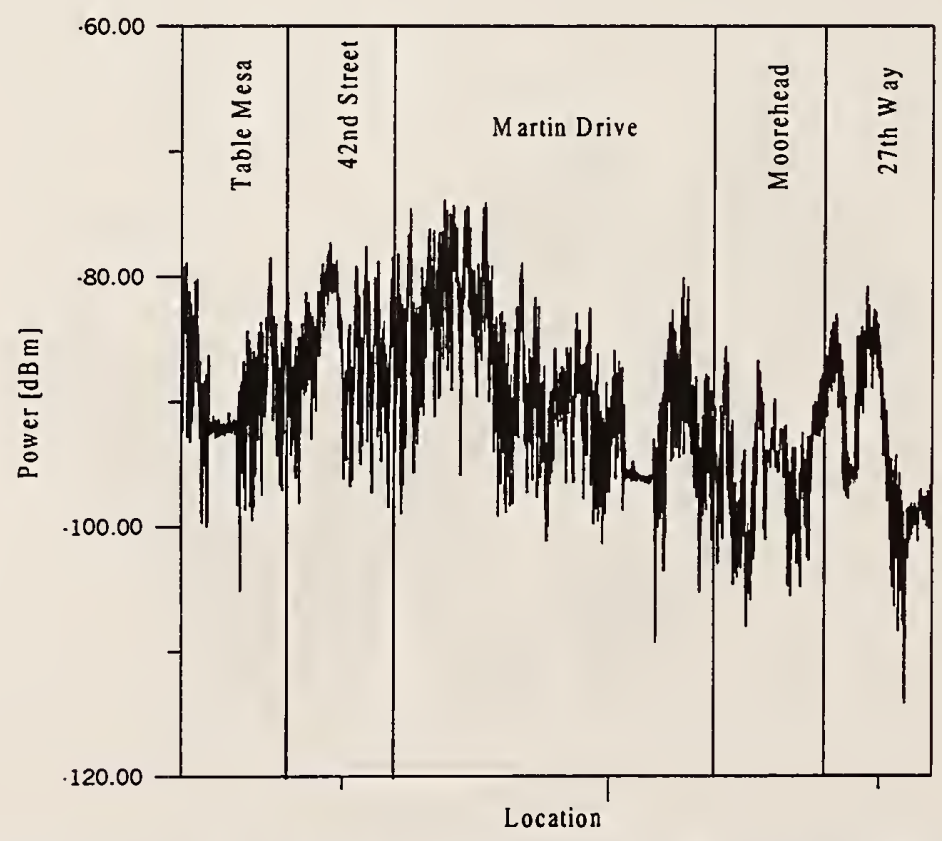

Figure B.18. Measured power levels in the Martin Acres neighborhood for $772 \mathrm{MHz}$ from a transmitter on Eldorado Mountain. 


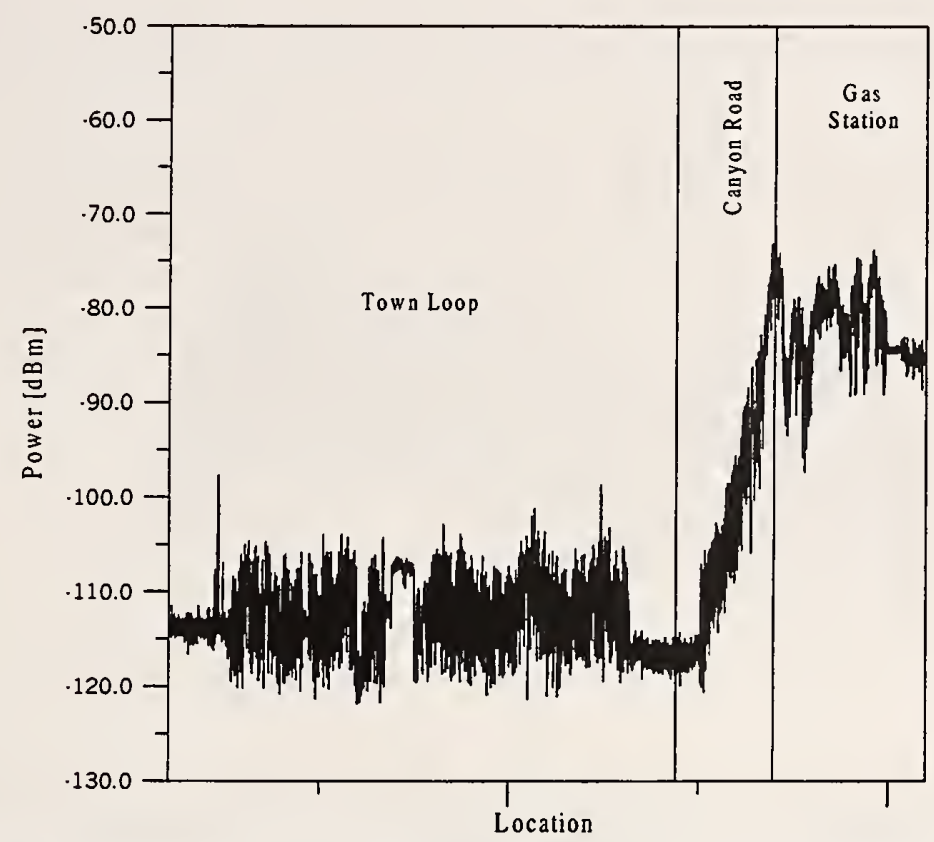

Figure B.19. Measured power levels in Eldorado Canyon for $772 \mathrm{MHz}$ from a transmitter on Eldorado Mountain.

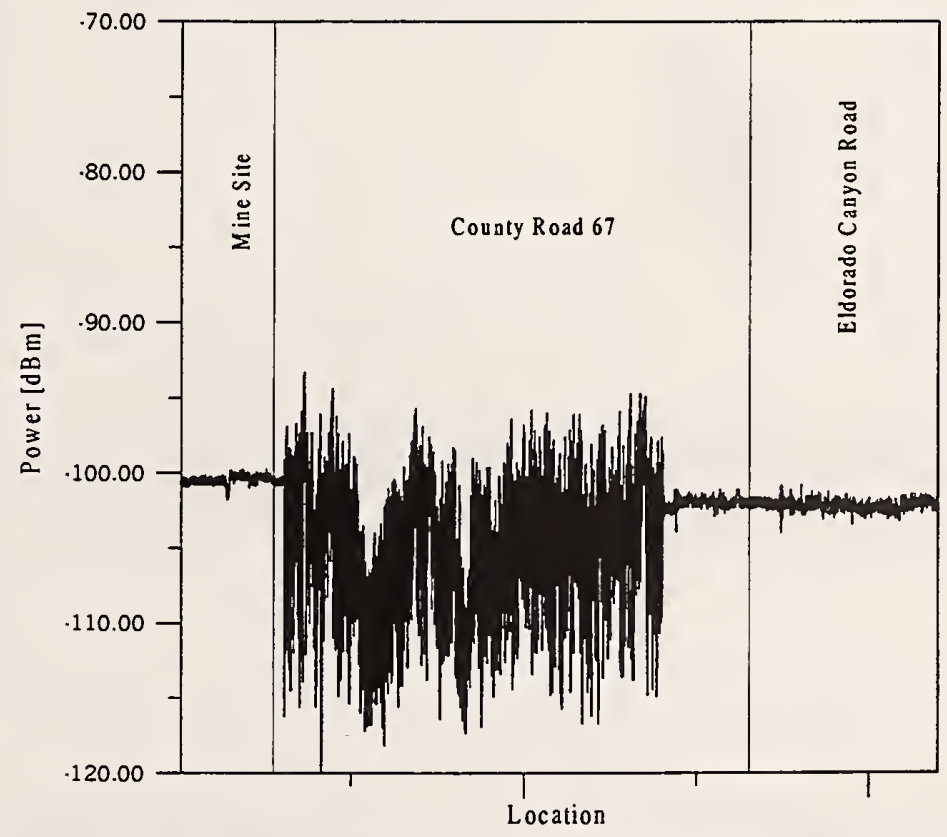

Figure B.20. Measured power levels on County Road 67 for $772 \mathrm{MHz}$ from a transmitter on Eldorado Mountain. 


\section{B.3 Measured Data for a Transmitter on Squaw Mountain at $533 \mathrm{MHz}$.}

At this location and frequency, the transmitter power level was $28.6 \mathrm{dBm}(0.72 \mathrm{~W})$ with

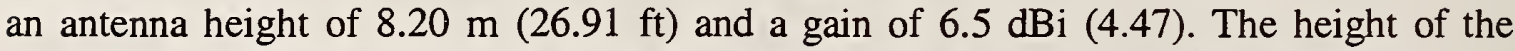
receiving antenna was $2.95 \mathrm{~m}(9.68 \mathrm{ft})$ with a gain of $1.9 \mathrm{dBi}(1.55)$. Figures $\mathrm{B} .21$ through B.27 present the measured power levels for various locations around the Boulder area.

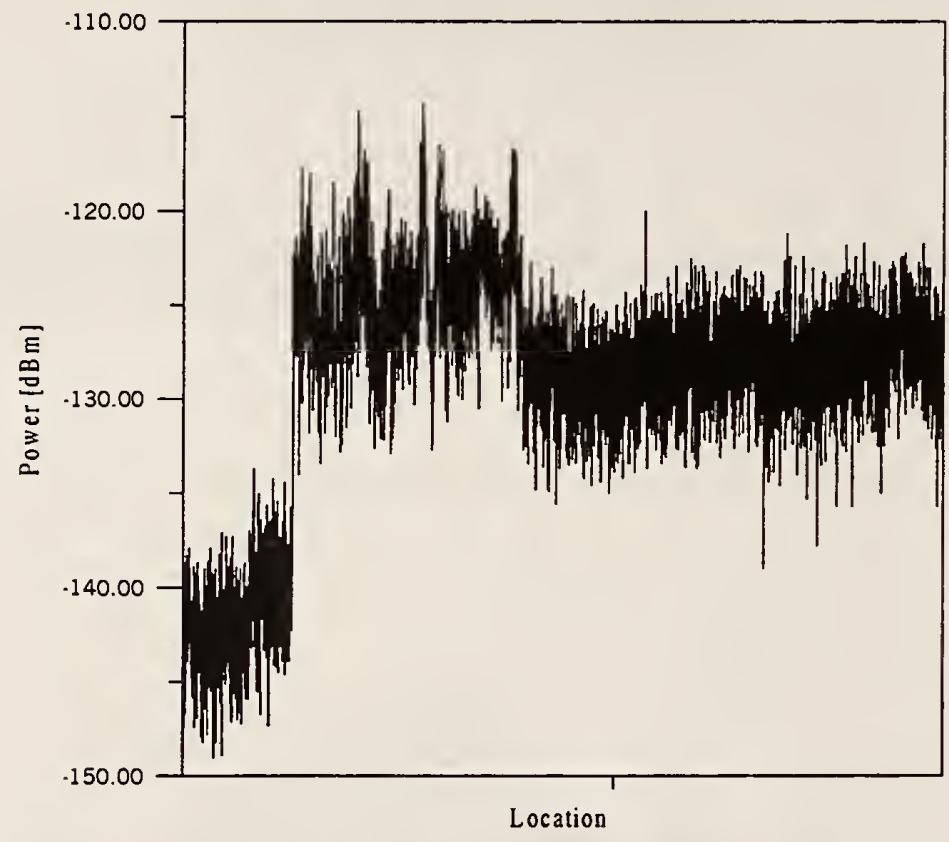

Figure B.21. Measured power levels for various locations at the DOC Laboratories for $533 \mathrm{MHz}$ from a transmitter on Squaw Mountain. The results correspond to different locations as the measurement vehicle was driven along various roads on the Laboratory property. 


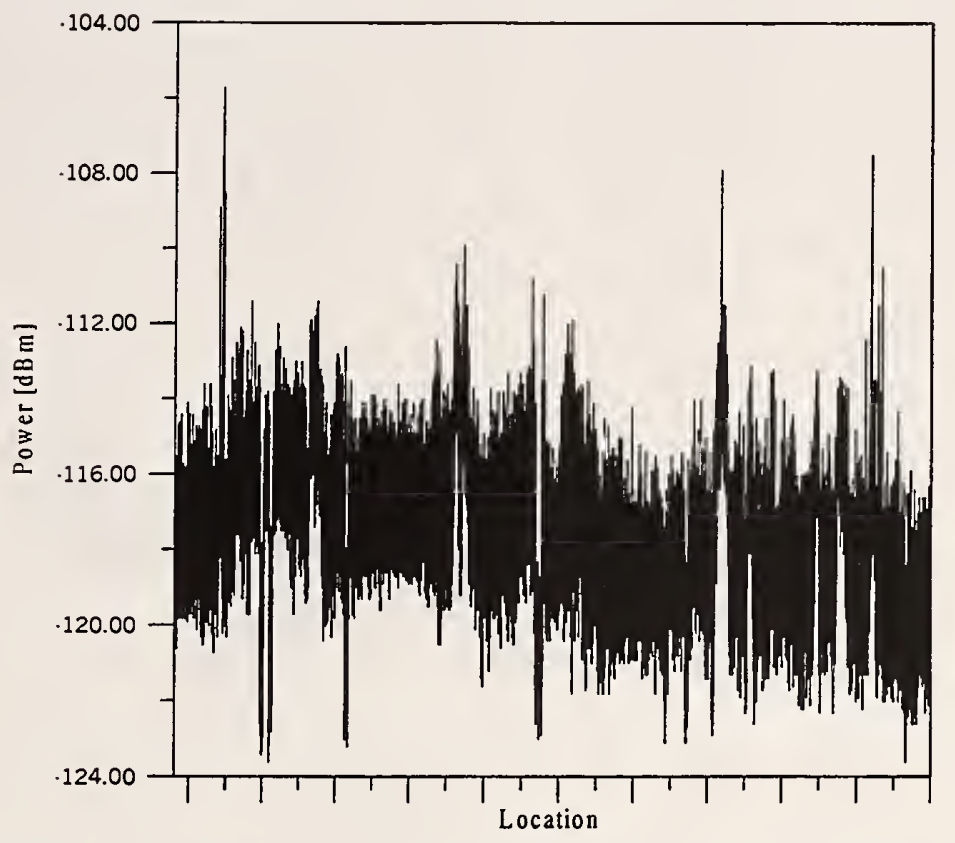

Figure B.22. Measured power levels at different locations on the Table Mountain NRQZ for $533 \mathrm{MHz}$ from a transmitter on Squaw Mountain. The results correspond to different locations as the measurement vehicle was driven along the north-south road and the eastwest road on the NRQZ.

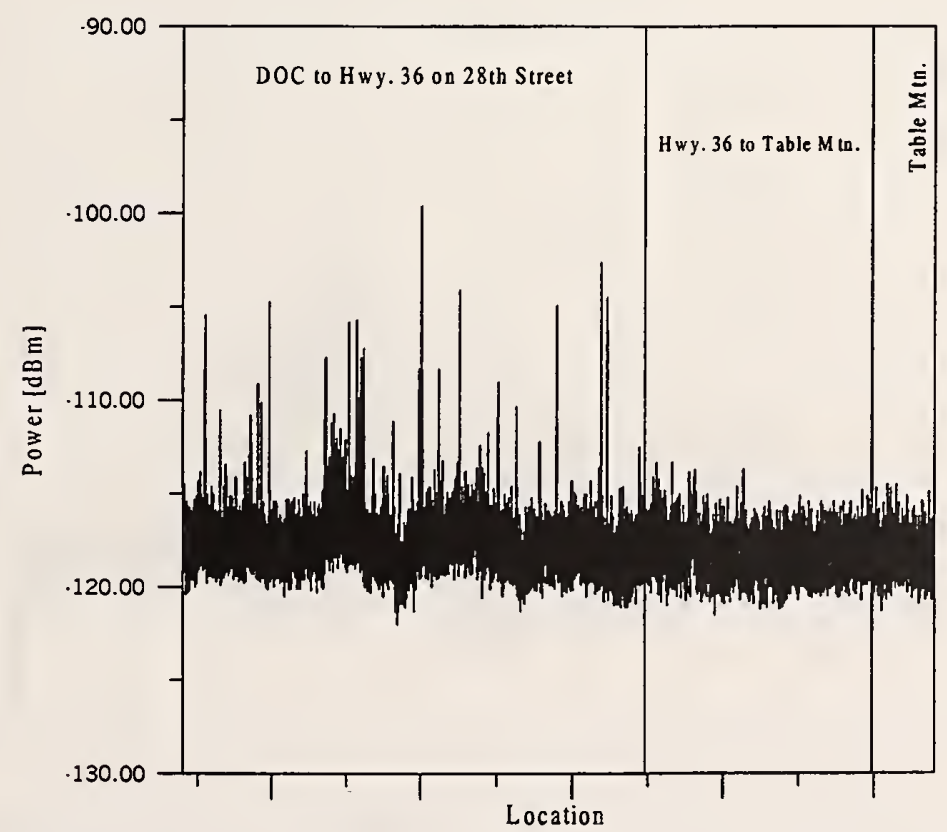

Figure B.23. Measured power levels on the $28^{\text {th }}$ Street route for $533 \mathrm{MHz}$ from a transmitter on Squaw Mountain. These data were taken on $28^{\text {th }}$ Street to Highway 36 (from the DOC Laboratories to the Table Mountain NRQZ). 


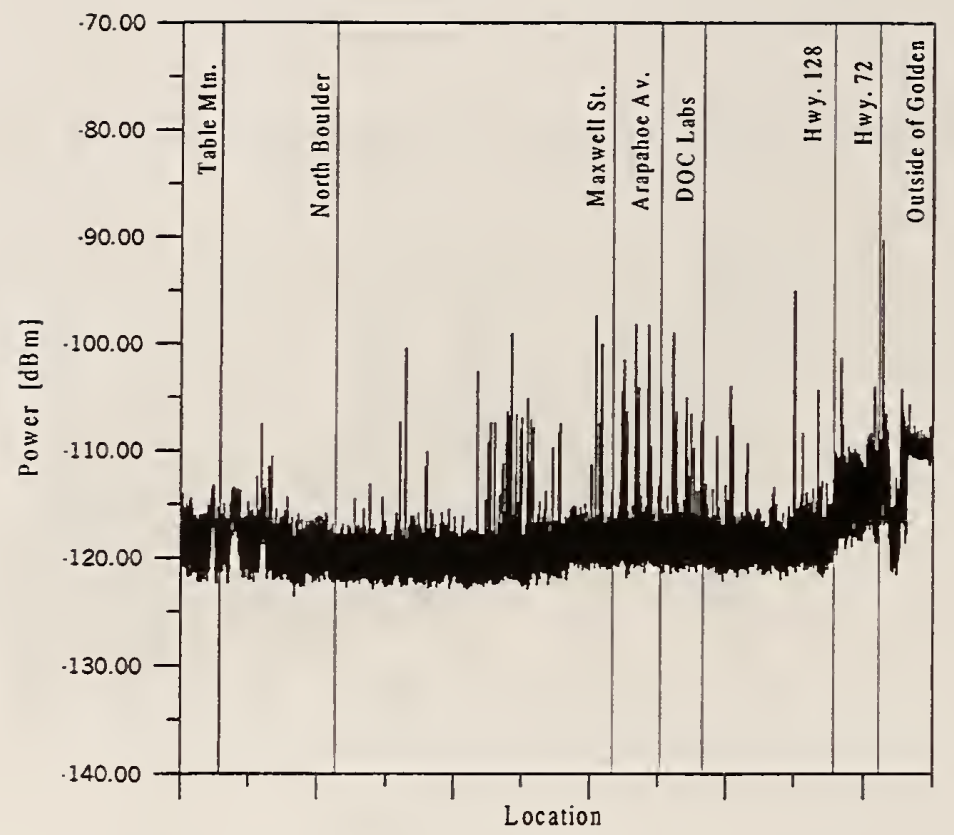

Figure B.24. Measured power levels on the Broadway loop for $533 \mathrm{MHz}$ from a transmitter on Squaw Mountain. These data were taken on Highway 36 and Highway 93, starting at the Table Mountain NRQZ, going to Highway 72, and returning to the DOC Laboratories.

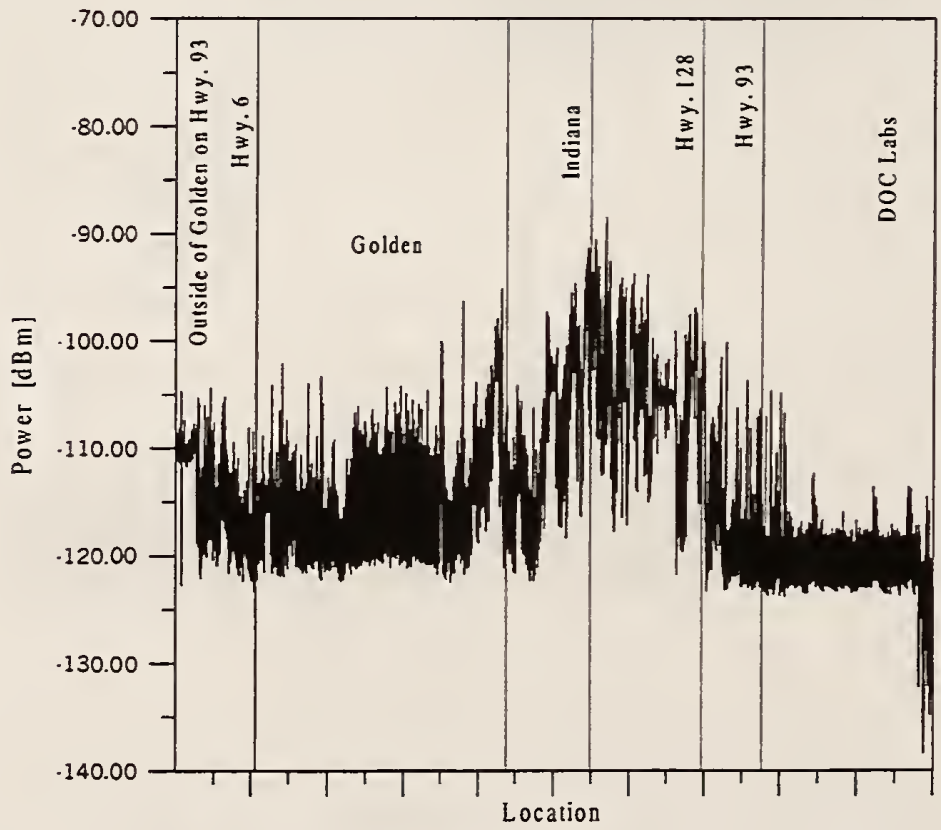

Figure B.25. Measured power levels on the Golden loop for $533 \mathrm{MHz}$ from a transmitter on Squaw Mountain. These data were taken in Golden, Colorado returning to the DOC Laboratories via Indiana Ave. 


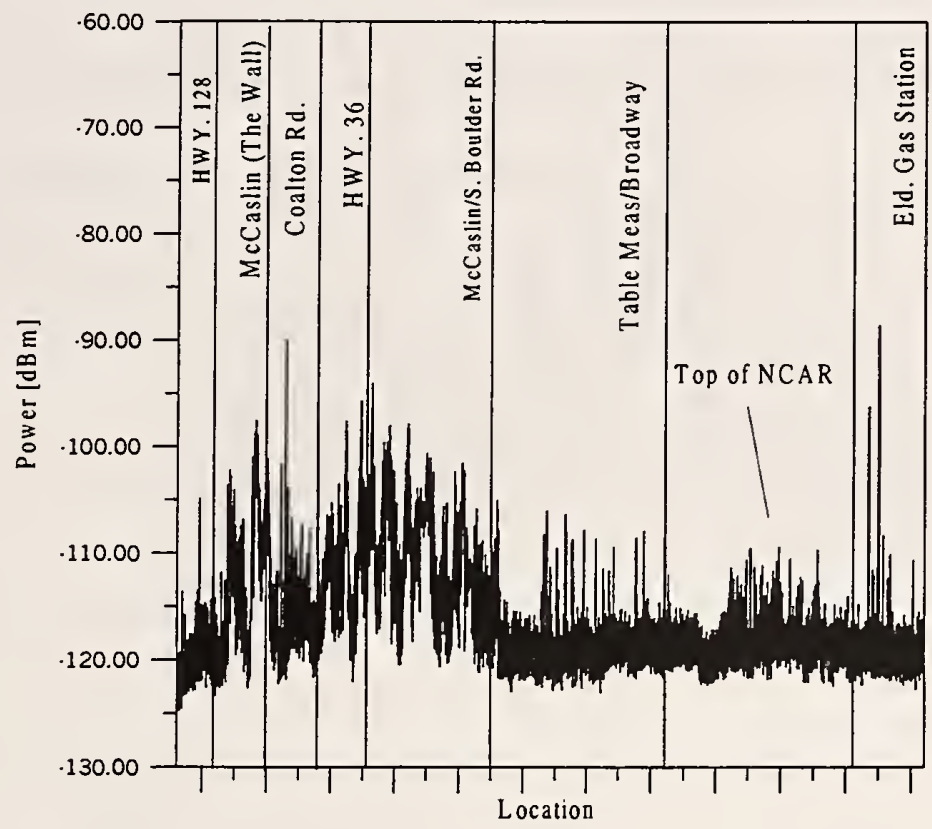

Figure B.26. Measured power levels on the McCaslin loop for $533 \mathrm{MHz}$ from a transmitter on Squaw Mountain. These data were taken on various roads starting at a gas station at Eldorado Canyon and returning to the starting point.

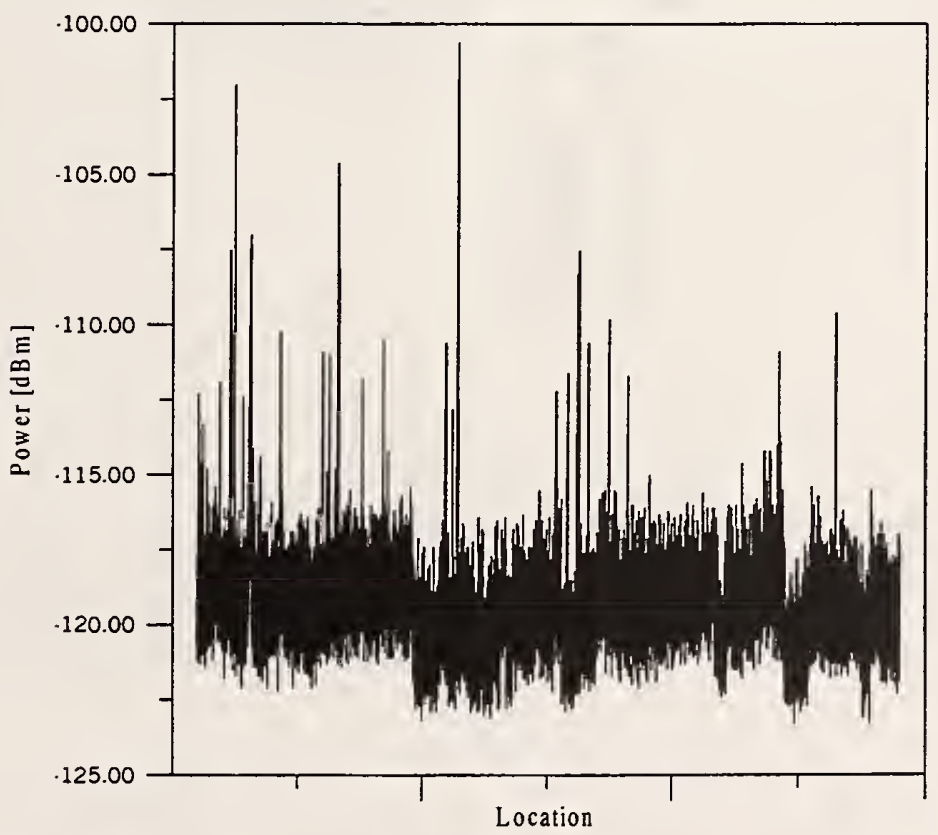

Figure B.27. Measured power levels on the Greenbriar loop for $533 \mathrm{MHz}$ from a transmitter on Squaw Mountain. This loop consisted of Greenbriar Blvd., Lehigh Street, Table Mesa Drive, and Gillaspie Drive. 


\section{B.4 Measured Data for a Transmitter on Squaw Mountain at $772 \mathrm{MHz}$.}

At this location and frequency, the transmitter power level was $37.0 \mathrm{dBm}(5.0 \mathrm{~W})$ with an antenna height of $8.20 \mathrm{~m}(26.91 \mathrm{ft})$ and a gain of $6.5 \mathrm{dBi}(4.47)$. The height of the receiving antenna was $2.95 \mathrm{~m}(9.68 \mathrm{ft})$ with a gain of $1.9 \mathrm{dBi}(1.55)$. Figures B.28 through B.34 present the measured power levels for various locations around the Boulder area.

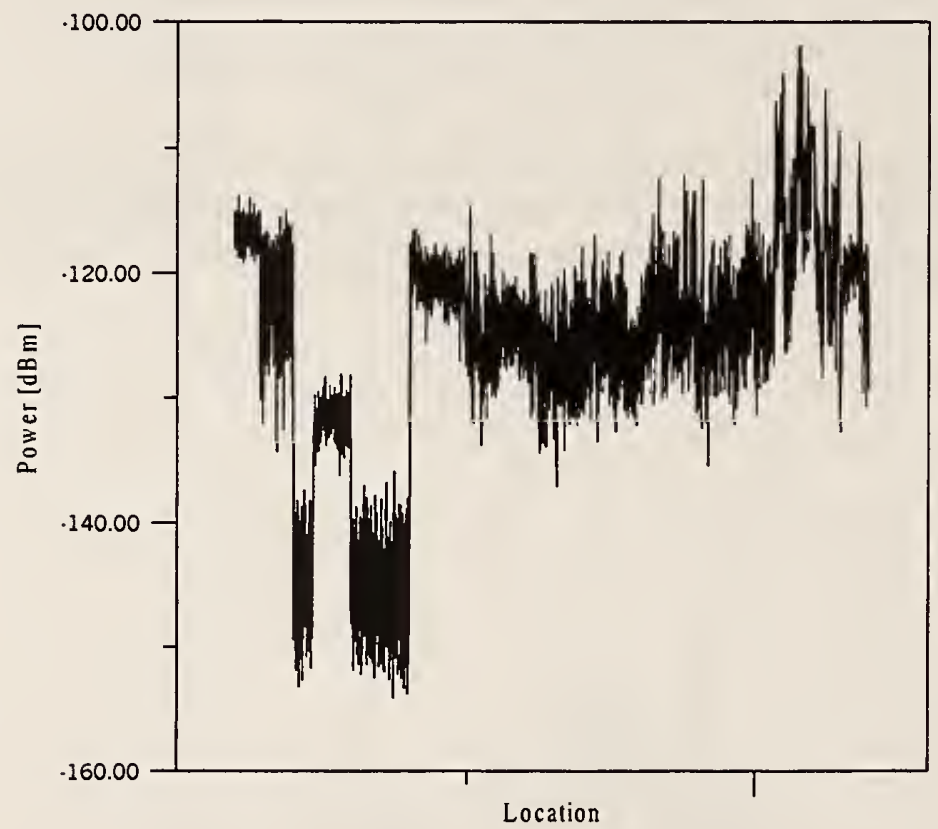

Figure B.28. Measured power levels for various locations at the DOC Laboratories for $772 \mathrm{MHz}$ from a transmitter on Squaw Mountain. The results correspond to different locations as the measurement vehicle was driven along various roads on the Laboratory property. 


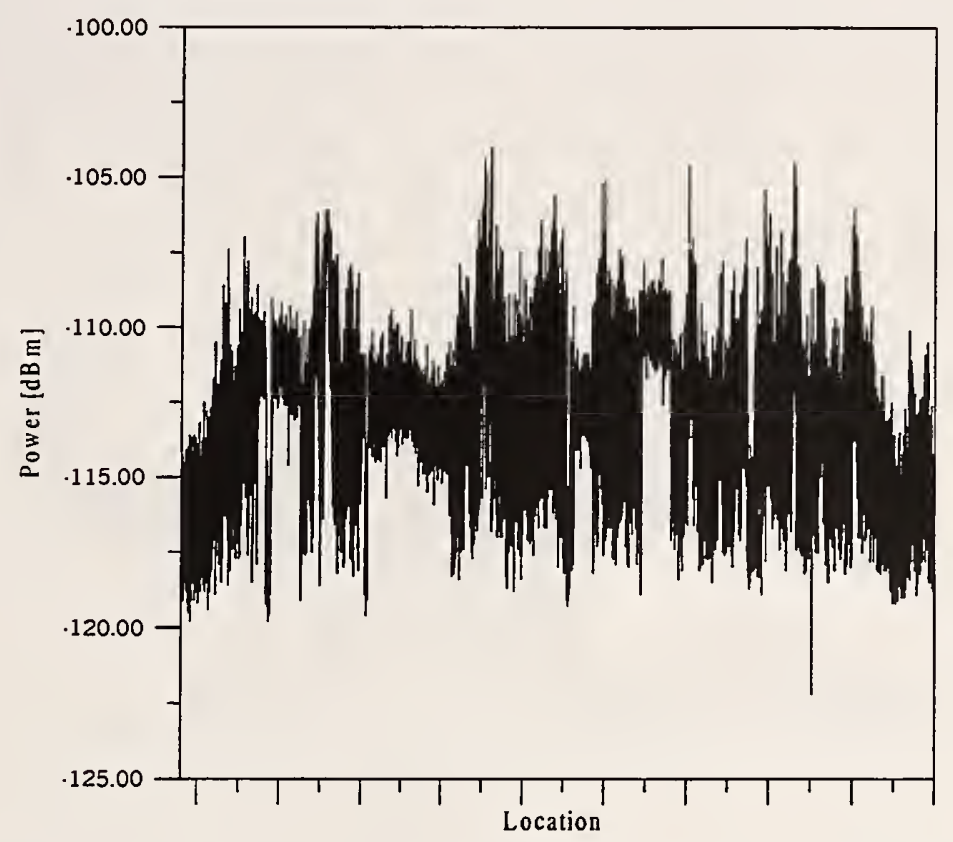

Figure B.29. Measured power levels at various locations on the Table Mountain NRQZ for $772 \mathrm{MHz}$ from a transmitter on Squaw Mountain. The results correspond to different locations as the measurement vehicle was driven around the north-south road and the east-west road on the NRQZ.

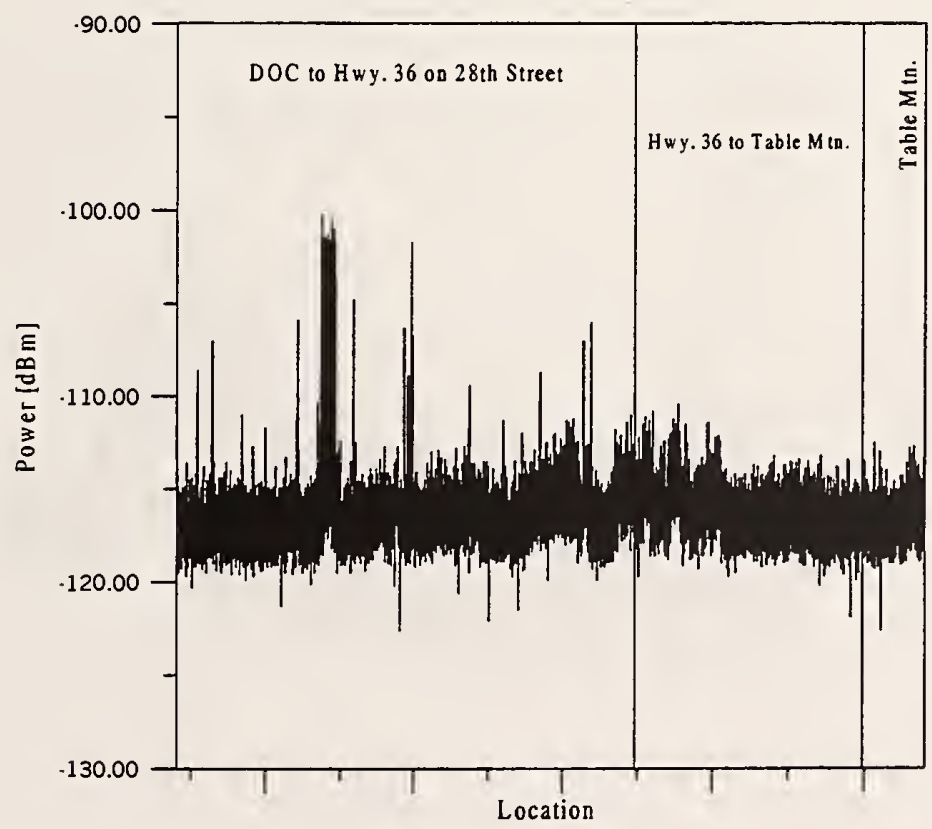

Figure B.30. Measured power levels on the $28^{\text {th }}$ Street route for $772 \mathrm{MHz}$ from a transmitter on Squaw Mountain. These data were taken on $28^{\text {th }}$ Street to Highway 36 (from the DOC Laboratories to the Table Mountain NRQZ). 


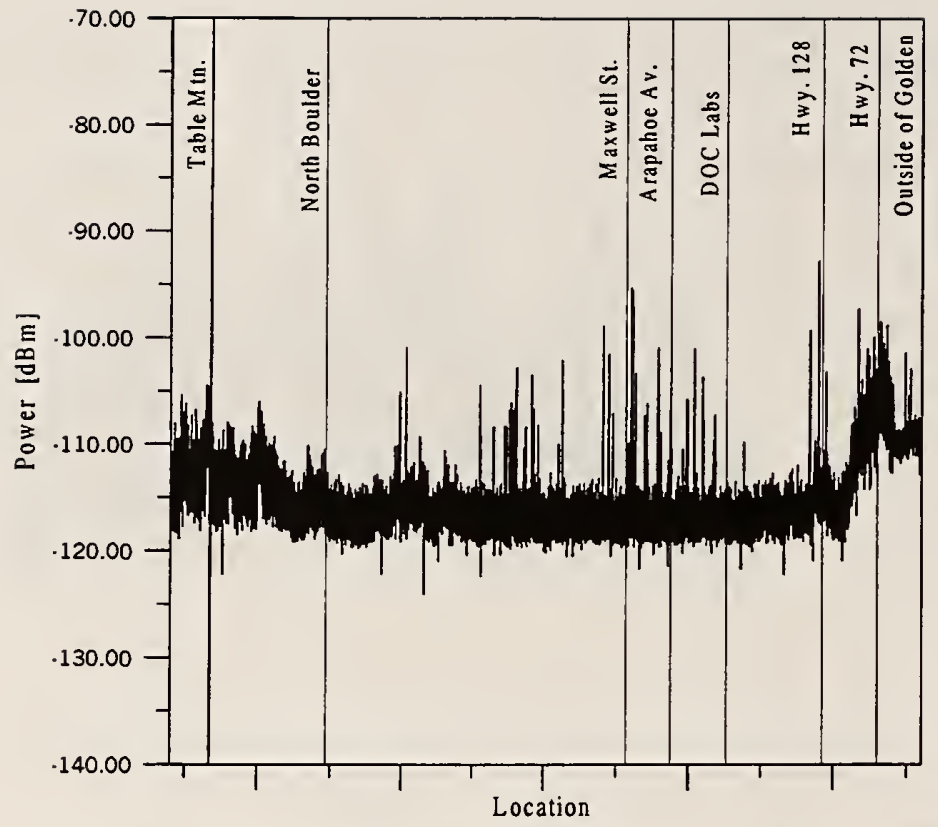

Figure B.31. Measured power levels on the Broadway loop for $772 \mathrm{MHz}$ from a transmitter on Squaw Mountain. These data were taken on Highway 36 and Highway 93, starting at the Table Mountain NRQZ, going to Highway 72, and returning to the DOC Laboratories.

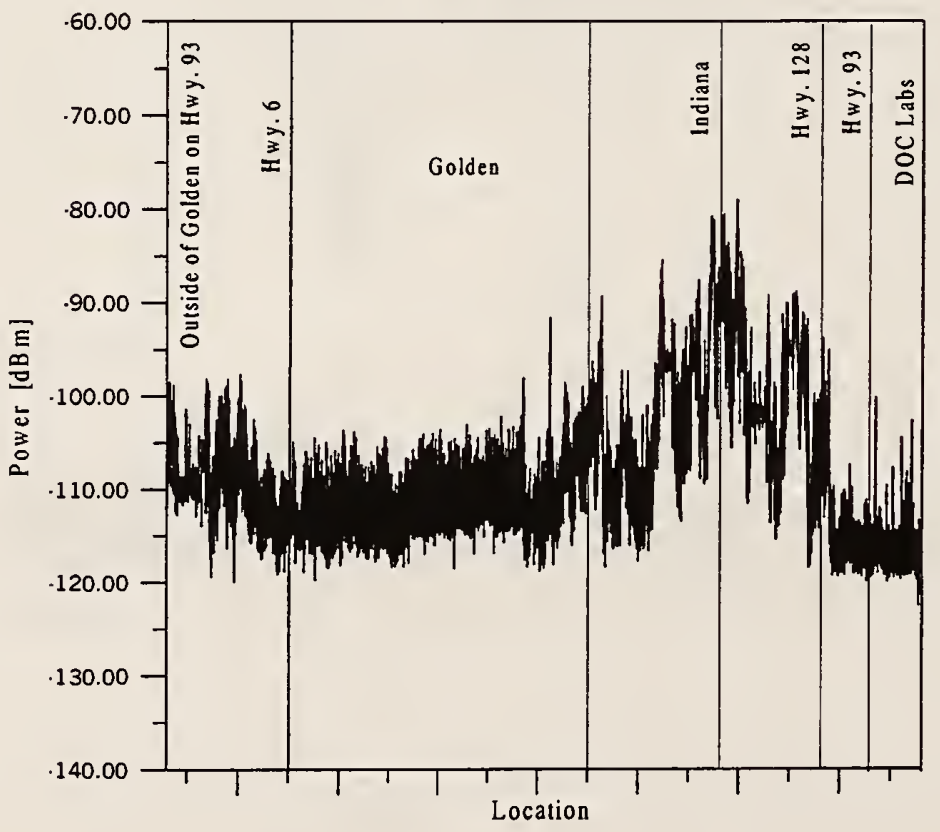

Figure B.32. Measured power levels on the Golden loop for $772 \mathrm{MHz}$ from a transmitter on Squaw Mountain. These measured data were taken in Golden, Colorado returning to the DOC Laboratories via Indiana Ave. 


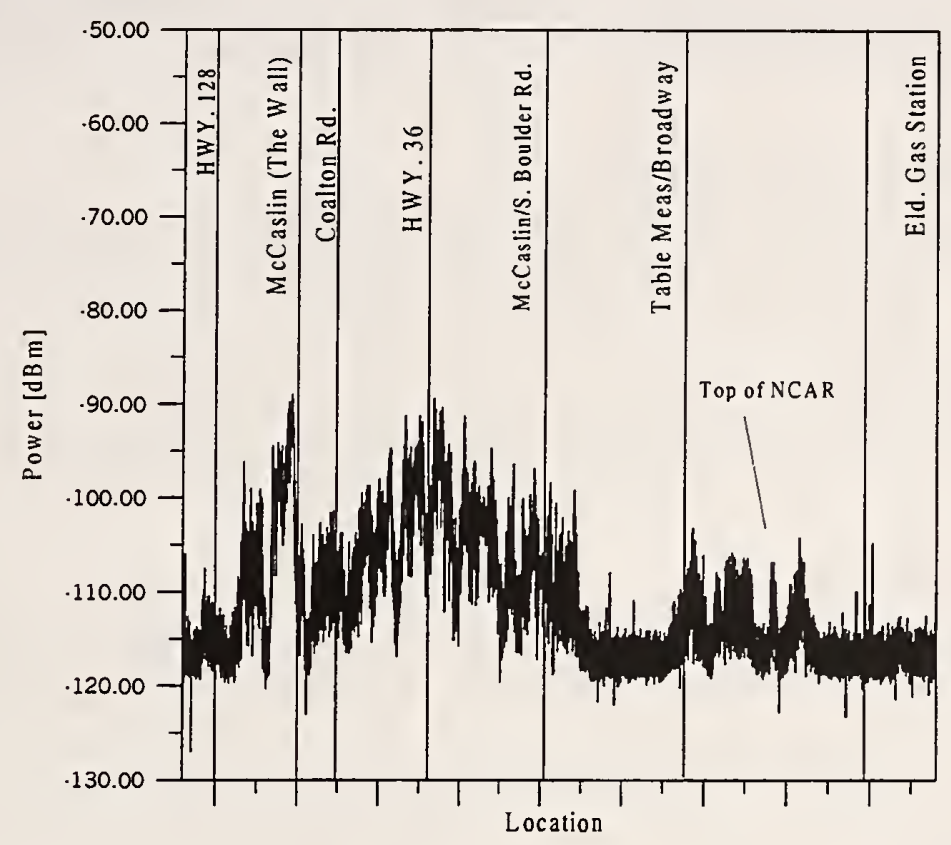

Figure B.33. Measured power levels on the McCaslin loop for $772 \mathrm{MHz}$ from a transmitter on Squaw Mountain. These data were taken on various roads starting at a gas station at Eldorado Canyon and returning to the starting point.

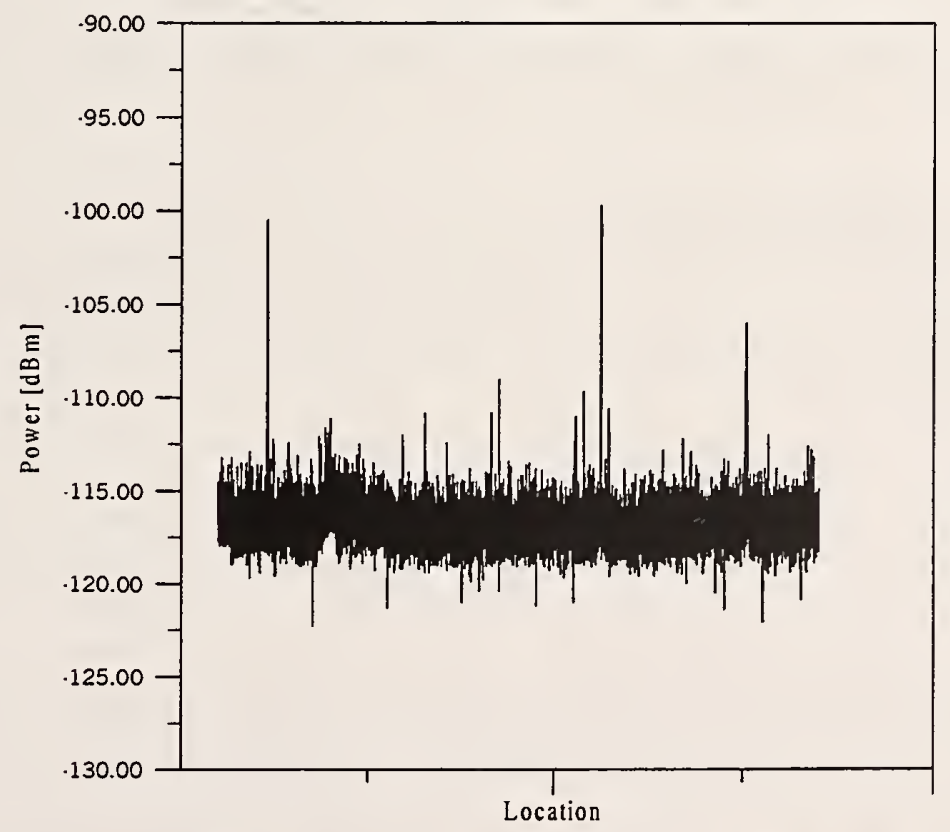

Figure B.34. Measured power levels on the Greenbriar loop for $772 \mathrm{MHz}$ from a transmitter on Squaw Mountain. This loop consisted of Greenbriar Blvd., Lehigh Street, Table Mesa Drive, and Gillaspie Drive. 


\section{NTIA FORMAL PUBLICATION SERIES}

\section{NTIA CONTRACTOR REPORT}

Information generated under an NTIA contract or grant and considered an important contribution to existing knowledge.

\section{NTIA HANDBOOK}

Information pertaining to technical procedures, reference and data guides, and formal user's manuals that are expected to be pertinent for a long time.

\section{NTIA MONOGRAPH}

A scholarly, professionally oriented publication dealing with state-of-the-art research or an authoritative treatment of a broad area. A monograph is expected to have a long lifespan.

\section{NTIA REPORT}

Important contributions to existing knowledge but of less breadth than a monograph, such as results of completed projects and major activities, specific major accomplishments, or NTIA-coordinated activities.

\section{NTIA RESTRICTED REPORT}

Contributions that fit the NTIA Report classification but that are limited in distribution because of national security classification or Departmental constraints. This material receives full review and quality control equivalent to the open-literature report series.

\section{NTIA SPECIAL PUBLICATION}

Information derived from or of value to NTIA activities such as conference proceedings, bibliographies, selected speeches, course and instructional materials, and directories.

\section{SPONSOR-ISSUED REPORTS}

NTIA authors occasionally produce reports issued under an other-agency sponsor's cover. These reports generally embody the criteria of the NTIA Report series.

For information about NTIA publications, contact the ITS Technical Publications Office at 325 Broadway, Boulder, CO, 80305 Tel. (303) 497-3572 or e-mail luebs@its.bldrdoc.gov.

This report is for sale by the National Technical Information Service, 5285 Port Royal Road, Springfield, VA 22161, Tel. (800) 553-6847. 
Journal of Research of the National Institute of Standards and Technology-Reports NIST research and development in those disciplines of the physical and engineering sciences in which the Institute is active. These include physics, chemistry, engineering, mathematics, and computer sciences. Papers cover a broad range of subjects, with major emphasis on measurement methodology and the basic technology underlying standardization. Also included from time to time are survey articles on topics closely related to the Institute's technical and scientific programs. Issued six times a year.

\section{Nonperiodicals}

Monographs-Major contributions to the technical literature on various subjects related to the Institute's scientific and technical activities.

Handbooks-Recommended codes of engineering and industrial practice (including safety codes) developed in cooperation with interested industries, professional organizations, and regulatory bodies.

Special Publications-Include proceedings of conferences sponsored by NIST, NIST annual reports, and other special publications appropriate to this grouping such as wall charts, pocket cards, and bibliographies.

National Standard Reference Data Series-Provides quantitative data on the physical and chemical properties of materials, compiled from the world's literature and critically evaluated. Developed under a worldwide program coordinated by NIST under the authority of the National Standard Data Act (Public Law 90-396). NOTE: The Journal of Physical and Chemical Reference Data (JPCRD) is published bimonthly for NIST by the American Chemical Society (ACS) and the American Institute of Physics (AIP). Subscriptions, reprints, and supplements are available from ACS, 1155 Sixteenth St., NW, Washington, DC 20056.

Building Science Series-Disseminates technical information developed at the Institute on building materials, components, systems, and whole structures. The series presents research results, test methods, and performance criteria related to the structural and environmental functions and the durability and safety characteristics of building elements and systems.

Technical Notes - Studies or reports which are complete in themselves but restrictive in their treatment of a subject. Analogous to monographs but not so comprehensive in scope or definitive in treatment of the subject area. Often serve as a vehicle for final reports of work performed at NIST under the sponsorship of other government agencies.

Voluntary Product Standards-Developed under procedures published by the Department of Commerce in Part 10, Title 15, of the Code of Federal Regulations. The standards establish nationally recognized requirements for products, and provide all concerned interests with a basis for common understanding of the characteristics of the products. NIST administers this program in support of the efforts of private-sector standardizing organizations.

Order the following NIST publications-FIPS and NISTIRs-from the National Technical Information Service, Springfield, VA 22161.

Federal Information Processing Standards Publications (FIPS PUB)-Publications in this series collectively constitute the Federal Information Processing Standards Register. The Register serves as the official source of information in the Federal Government regarding standards issued by NIST pursuant to the Federal Property and Administrative Services Act of 1949 as amended, Public Law 89-306 (79 Stat. 1127), and as implemented by Executive Order 11717 (38 FR 12315, dated May 11, 1973) and Part 6 of Title 15 CFR (Code of Federal Regulations).

NIST Interagency or Internal Reports (NISTIR)-The series includes interim or final reports on work performed by NIST for outside sponsors (both government and nongovernment). In general, initial distribution is handled by the sponsor; public distribution is handled by sales through the National Technical Information Service, Springfield, VA 22161, in hard copy, electronic media, or microfiche form. NISTIR's may also report results of NIST projects of transitory or limited interest, including those that will be published subsequently in more comprehensive form. 


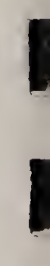

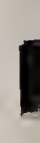

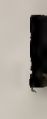

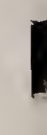



